\title{
Perceptions and Practices of Inclusion in Malaysian Integrated Preschools
}

\author{
By \\ Sailajah Nair Sukumaran
}

A thesis submitted to the Victoria University of Wellington in fulfillment of the requirements for the degree of Doctor of Philosophy in Education

Victoria University of Wellington 2013 



\begin{abstract}
This study examines perceptions and practices of inclusion of children with special educational needs (SEN) in Malaysian integrated preschool programmes. Integrated programmes in Malaysia refer to educational settings in which units of special education classrooms are set up within existing regular school compounds. I aim to determine the state of inclusion in Malaysian integrated preschool programmes; educators' and parents' perceptions of and support for inclusion; and factors influencing the implementation of inclusive practices in these settings.
\end{abstract}

Situated within a pragmatic research paradigm, my study adopted a two-phased sequential mixed-methods research design. The first phase involved regular and special classroom teachers' self-reports of inclusion in their school, through a survey by questionnaire. In the second phase, data gathering was carried out in three case-study preschools, which, based on questionnaire findings, were preschools that demonstrated differing levels of inclusion (i.e., high, moderate, and low). Information sources in each site involved interviews with the school principal, regular and special classroom preschool teachers, and parents of preschoolers with and without SEN, as well as observations of daily events and examination of relevant documents in the preschool settings. The perspective proposed by the bioecological systems theory (Bronfenbrenner, 1995, 2005; Bronfenbrenner \& Ceci, 1994; Bronfenbrenner \& Morris, 1998), which strongly advocate that human development involves a combination of interactions between proximal processes, personal characteristics, context, and time, served as a useful conceptual framework for examining and elaborating on inclusion in this study.

Questionnaire and case study findings presented substantial evidence that integrated preschool programmes in Malaysia were neither practising nor promoting inclusion. Whilst there were some efforts towards partial inclusion of children with SEN, educators' and parents' views, as well as findings across my case study sites showed that preschools generally engage these children in socially integrated activities, otherwise segregating them totally to activities confined to 
their own classrooms. Furthermore, educators lamented that there was lack of information and guidance training from the Ministry of Education in relation to inclusion and SEN. Parents on the other hand were barely involved in decisions about the nature of their children's preschool's inclusion. These issues were exacerbated by the absence of a clearly delineated policy governing inclusion.

Nevertheless, the study found that the ways in which inclusion (or non-inclusion) practices were implemented in each case study site was reflective of the individual school's philosophy towards inclusive education. The principals' role, the regular and special classroom teachers' shared perspectives on inclusion, parental involvement, and the preschool's physical and instructional environment gave each preschool an individual "inclusive-identity". Accordingly, this information provided empirical evidence to support the usefulness of the bioecological systems perspective, especially in understanding how interacting factors within and beyond the school setting can influence how inclusion is perceived and practiced. Thus important implications for policy and practice are identified in this thesis, including the need to develop mandates in support of inclusion; in particular the reexamination of initial and in-service teacher education programmes, opportunities for teacher trainees' practical experience in teaching children with SEN, encouraging collaboration between regular and special classroom teachers, support for principals to develop their leadership concerning inclusion, educating parents and the wider community on inclusion and SEN. 


\section{Acknowledgement}

First of all I thank you God for giving me the strength to survive this challenging journey.

I am greatly indebted to The Ministry of Education, Malaysia, for granting me the Federal Training Scholarship, which made it possible for me to pursue my $\mathrm{PhD}$ study. I would also like to thank Victoria University of Wellington Scholarship Office for awarding me the Victoria PhD Submission Scholarship.

I wish to express deepest gratitude and appreciation to my research supervisors, Dr Judith Loveridge and Associate Professor Vanessa Green. Their expert guidance, stimulating discussions, and critical feedback have assisted me greatly in this study. I wish to specially thank Dr Judith Loveridge for her kind words of encouragement that kept me going throughout my study.

My heartfelt thanks go to all my research participants whose openness and willingness to share their views, knowledge and experiences provided the much needed valuable information to complete this study successfully.

I wish to also gratefully acknowledge the staff at the VUW Student Learning Services, Dr Deborah Laurs and Kristen Reid for reading my work, sharing ideas and providing intellectual insights. A special thank you also goes to Dennis Dawson who kindly assisted me with my quantitative data. To Robyn Kenealy, many thanks for your proof reading and editing expertise.

I would also like to thank Dr Haniz Ibrahim, the former director of the Research and Development Division, Department of Special Education (Malaysia) for sharing his knowledge and expertise about special education and inclusion within the Malaysian education system. 
Special appreciation also goes to Dr Carolyn Tait for her very kind and helpful gestures, especially when my study stress was exacerbated with accommodation stress. To Sheila Law and Alix Klein at the Postgraduate office, I thank you for always being available to help out in many different ways.

I would like to thank my wonderful friends who were pillars of support throughout my PhD journey. To my late-night work buddies Rasela Tufue-Dolgoy, Assunta Carolina Antonysamy, Truphena Oduol, and the late Jocelyn Hill, I thank you for the many discussions that helped me make sense of the issues I struggled with. To my dear friend Juvena Jalal and family, thank you so much for the many ways you have made me and my family feel so much at home in New Zealand.

Lastly, but most importantly, I owe the deepest gratitude to my dear family, Shanthi, Ashok, Shekhar, Subash and Reva for your unwavering support throughout my study and being there for Acha and Amma. To Atha and Mama, thank you for your prayers and blessings. Gowrie Chechi and Pushpa Kamalajothi thank you heaps for your help with all the little daily on-goings back home, which gave me the peace of mind to work less-stressfully on this thesis. 


\section{This thesis is dedicated with deepest appreciation to:}

My beloved parents, Sukumaran and Lalitha, for believing that one day I would make this journey;

My best friend and husband, Sooria, for being the best teammate in my life and supportive of all my personal and professional efforts; ‘

My dearest son, Vishaanth Sooria, for touching my life with love, joy and warmth; and

all individuals with special needs, for you have inspired me in many different ways. 


\section{Table of Contents}

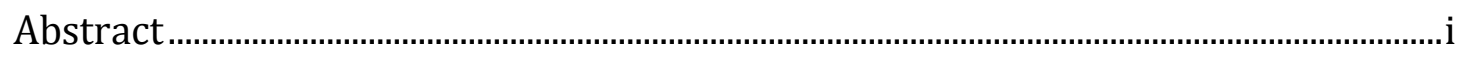

Acknowledgement ............................................................................................................

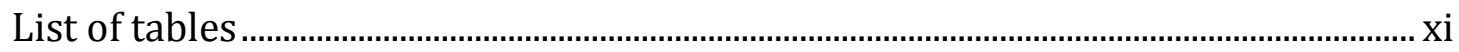

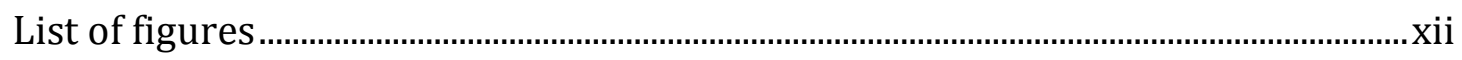

CHAPTER 1 -Introduction- ............................................................................ 1

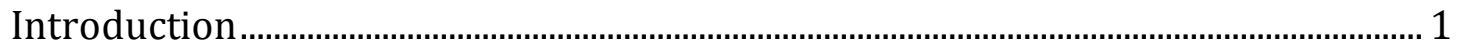

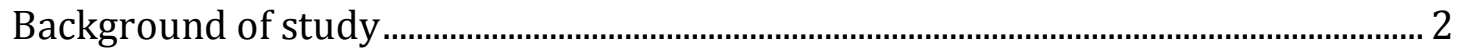

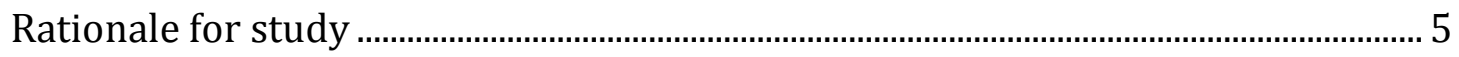

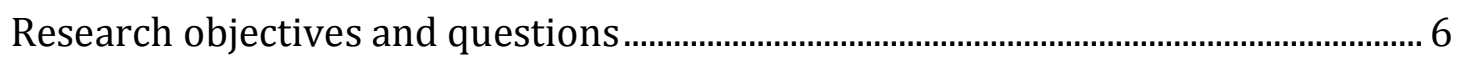



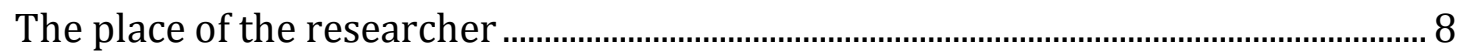

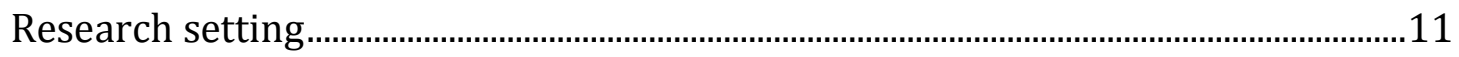

Definition of key terms ............................................................................................

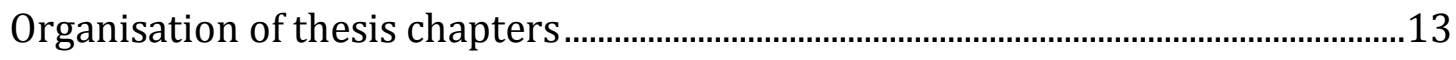

CHAPTER 2 -An Overview of Special Education, Integrated Programmes and Inclusion in Malaysia- ............................................................................... 15

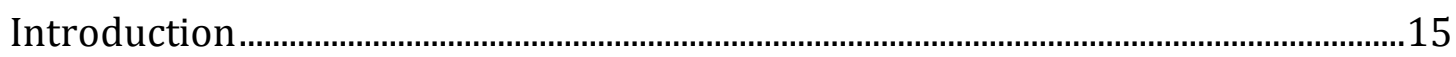

Introducing Malaysia: The research context.............................................................. 15

Current education structure and organisation ...........................................................17

The development of policy and legislation for special education and preschool education in Malaysia..................................................................................................18

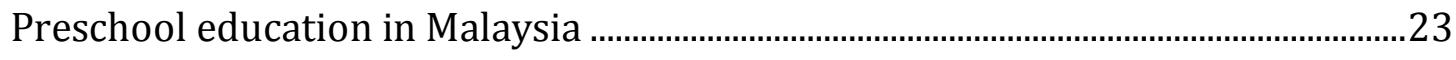

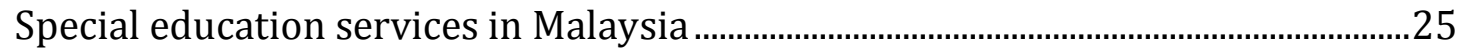

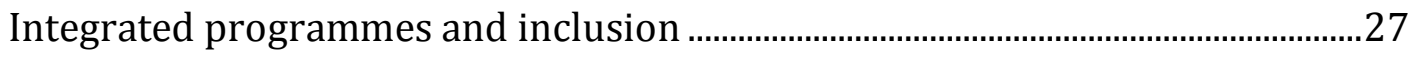

Integrated preschool programme characteristics.......................................................33

Educators and parents: key players in the education of children with SEN............35

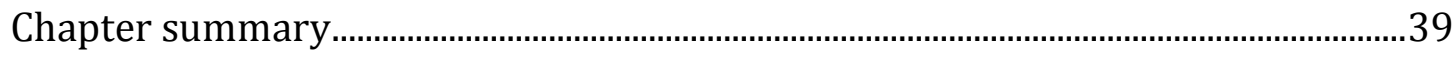


CHAPTER 3 -Literature Review- Inclusion: The Nature, Extent and Perceptions of it....................................................................................41

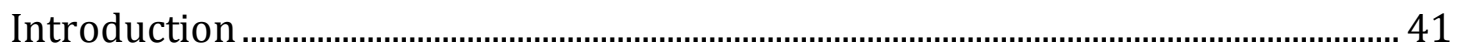

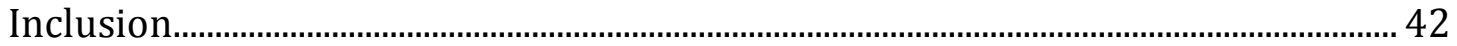

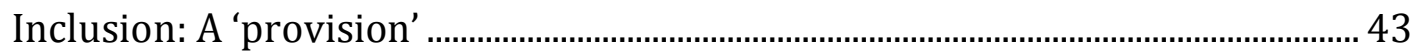

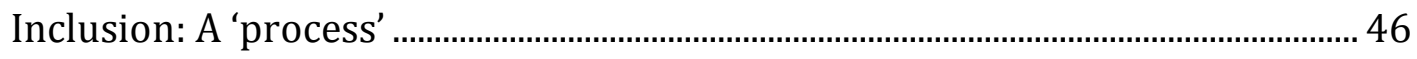

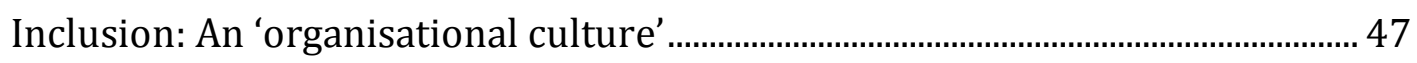



Perceptions of inclusion.............................................................................................. 57

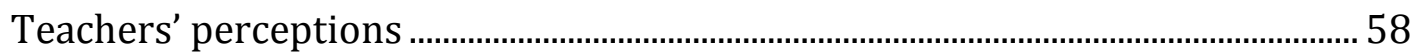

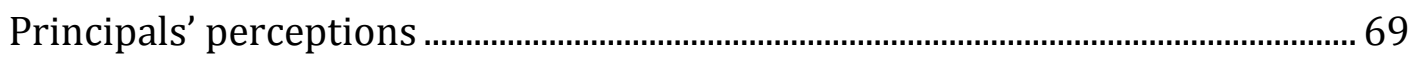

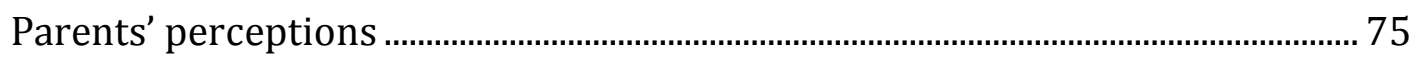

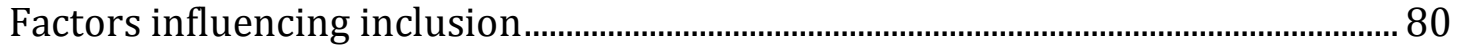



CHAPTER 4 -Theoretical Framework- ..........................................................87

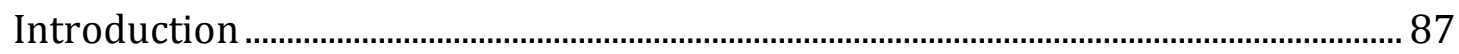

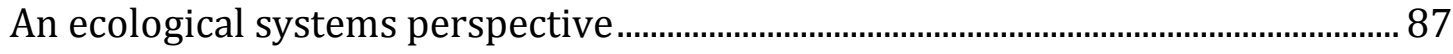

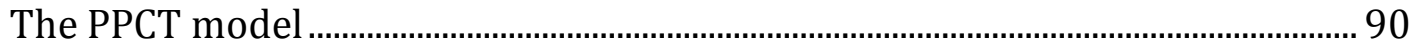

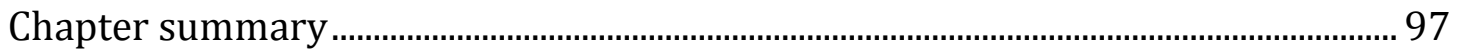

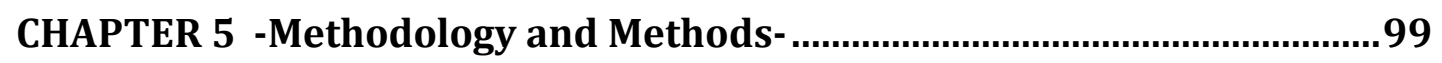

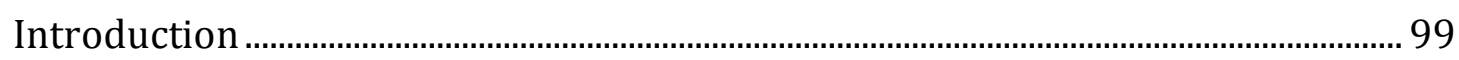

Method, methodology and research process ……............................................................. 99

The research paradigm.................................................................................................101

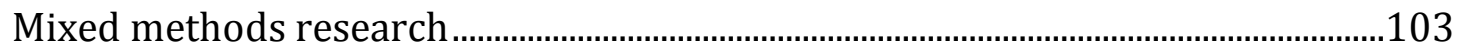

Rationale for choice of mixed methods research .......................................................105

Quantitative phase: Survey ……………………….....................................................106

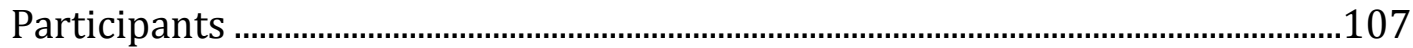

Instrument development..........................................................................................107

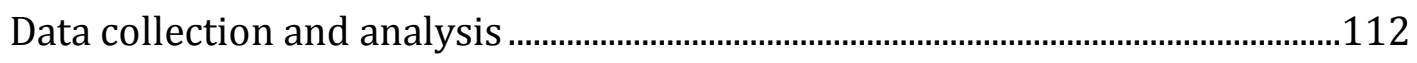

Qualitative phase: Case Study ......................................................................................114 
Multiple site case studies

Selection of site, participants, and events

Data gathering

Individual interviews: teachers, principal, and parents.

Observations

Document examination

Data management and analysis

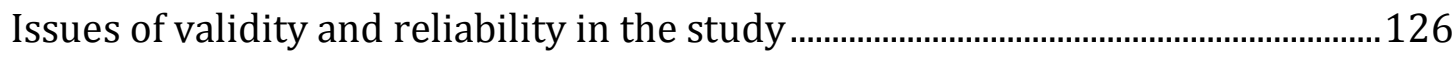

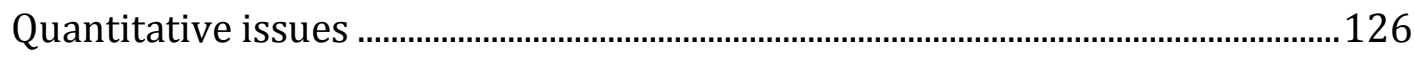

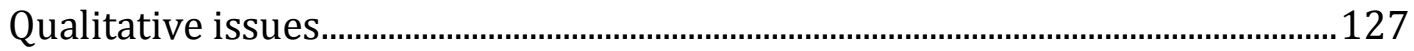

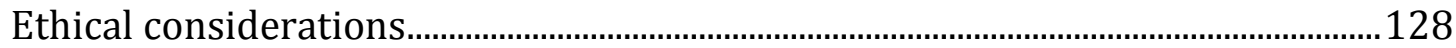

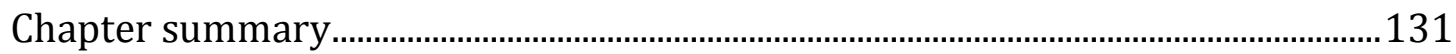

CHAPTER 6 -Quantitative Data: Questionnaire Findings-........................ 133

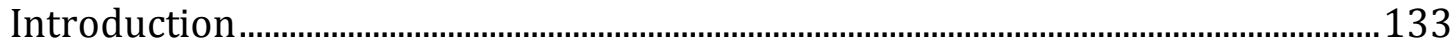

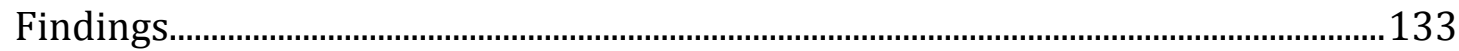

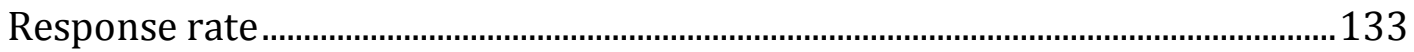

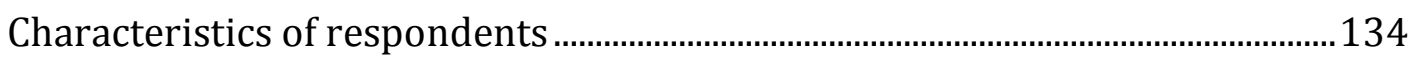

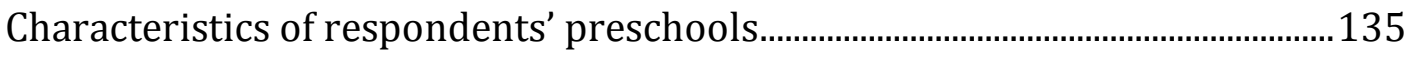

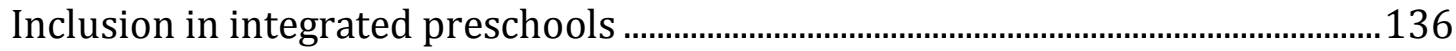

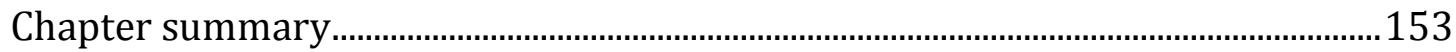

CHAPTER 7 -Qualitative Data: Case Study Findings- ............................... 155

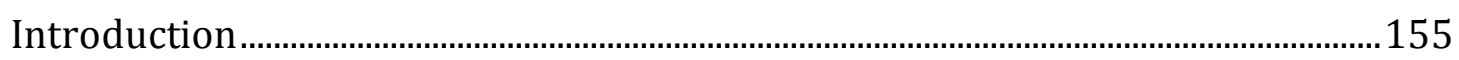

General description of case study sites and procedures ...............................................156

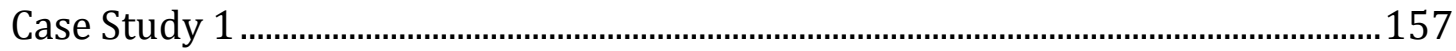

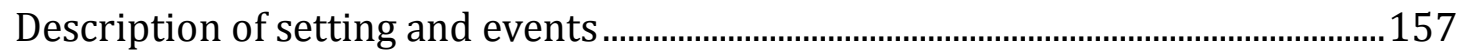

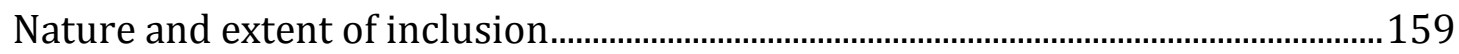

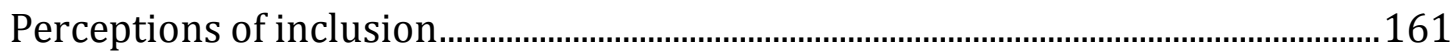

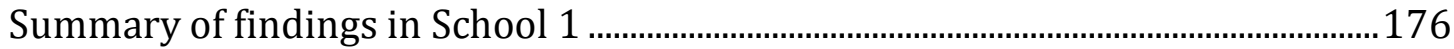

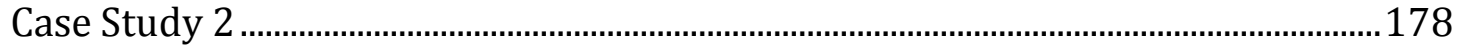

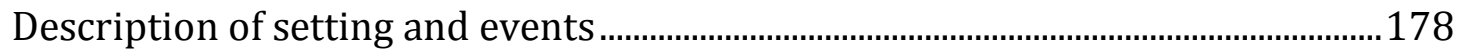


Nature and extent of inclusion

Perceptions of inclusion



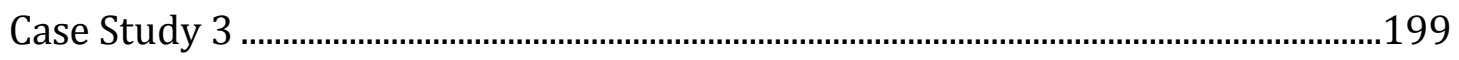

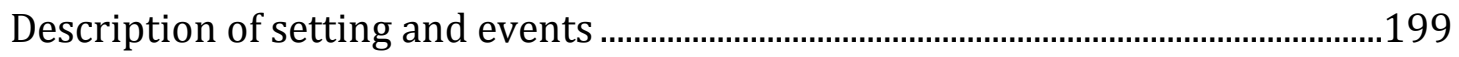



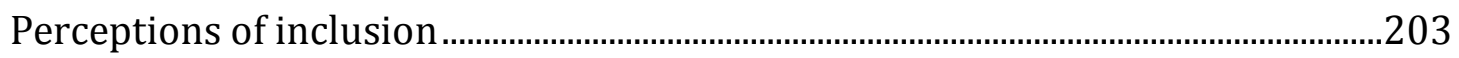

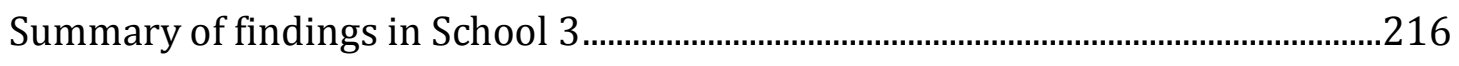

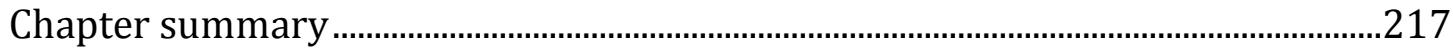

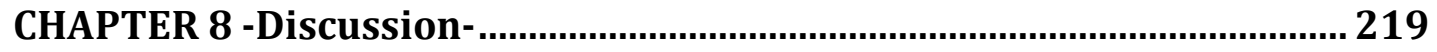

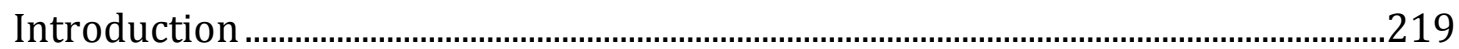

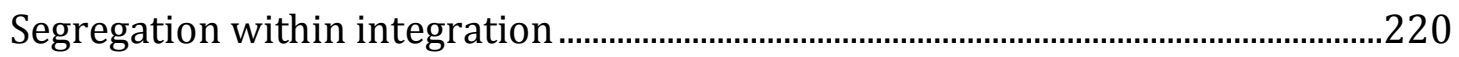

General lack of support for full inclusion...................................................................223

Unsupportive teaching and learning environment ........................................................232

Lack of collaborative efforts and commitment in relation to inclusion ..................237

Lack of information and support from the Ministry of Education............................245

Cultural beliefs and values in relation to inclusion and SEN ....................................247

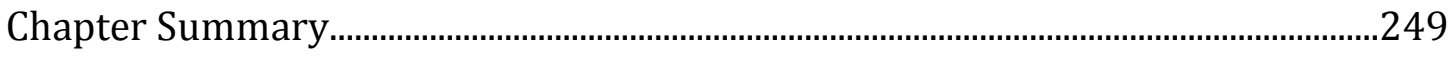

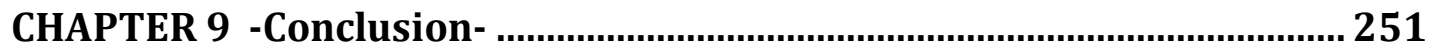



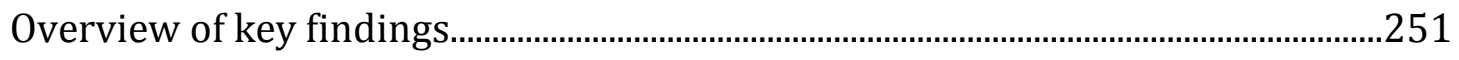

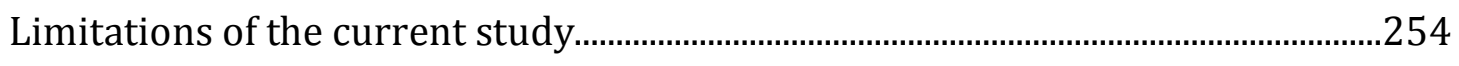

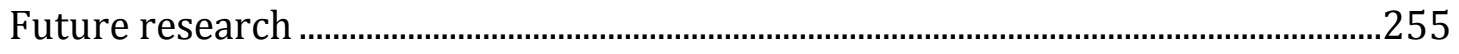

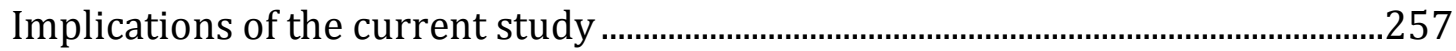



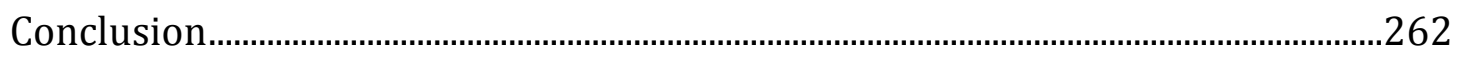

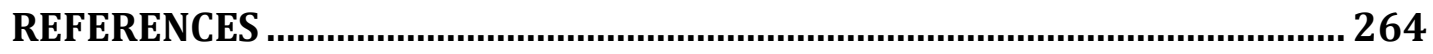


APPENDIX A: Integrated Preschool Programme Questionnaire (IPPQ).................281

APPENDIX B: Permit to carry out research ...................................................................286

APPENDIX C: Research information sheet: survey participants ..............................287

APPENDIX D: Inter-coder reliability instruction and code sheet ............................289

APPENDIX E: Research information sheet: case study participants .......................292

APPENDIX F: Letter and statement of consent: case study school principal ......294 APPENDIX G: Letter and statement of consent: case study participants - parents 296

APPENDIX H: Letter and statement of consent: case study participants -teachers 298

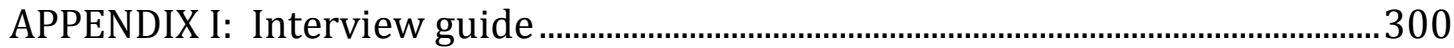

APPENDIX J: Observation guide .................................................................................. 301

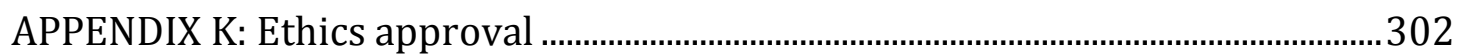

APPENDIX L: Translator's confidentiality agreement..................................................303 


\section{List of tables}

Table 1: Integrated programmes for children with visual impairment nationwide

Table 2: $\quad$ Integrated programmes for children with hearing impairment nationwide

Table 3: $\quad$ Integrated programmes for children with learning disabilities nationwide

Table 4: $\quad$ Case study participants

Table 5: $\quad$ Opportunities for interaction between preschoolers with and without SEN

Table 6: $\quad$ Means and standard deviation for events and processes in the preschool that facilitate inclusion based on regular and special education teachers' ratings

Table 7: Teachers' views on education of preschoolers with SEN in regular schools

Table 8: $\quad$ Teachers' views on the education of preschoolers with SEN in regular classrooms

Table 9: $\quad$ Factors influencing inclusion 


\section{List of figures}

Figure 1: Malaysia - Location

Figure 2: Proportion of preschoolers (4-6 years old) enrolled in the different types of providing agencies nationwide as of 2007

Figure 3: An integrated preschool programme in Malaysia 33

$\begin{array}{ll}\text { Figure 4: The basic elements of the research process } & 100\end{array}$

Figure 5: Participant Selection Model 104

Figure 6: Frequency of interaction between preschoolers with and without SEN

Figure 7: Proportion of preschoolers with SEN who have opportunities to interact with peers in regular classroom

Figure 8: Evidence supporting inclusion: Score distribution among preschools 


\section{CHAPTER 1}

-Introduction-

\section{Introduction}

There are a variety of placement options where children with special educational needs (SEN) may receive special education services in Malaysia, ranging from separate schools or classrooms that are meant for children with SEN only, to regular classrooms in which the predominant members are typically developing children (Haniz Ibrahim, 2007). The latter choice is more frequently referred to as inclusion (Cavallaro \& Haney, 1999). Studies have shown that there has been some agreement on the benefits of inclusion in that this practice provides children with SEN with opportunities to learn in natural, stimulating settings, with possibilities of increased acceptance and appreciation of differences by typically developing children (e.g., Ajuwon, 2008; Angelides, 2005, Katz \& Mirenda, 2002). Nevertheless, the implementation of inclusive practices, especially at the preschool level, can be challenging (Lieber et al., 2000). This is because inclusion requires coordination and collaborative consultation at all levels of the ecological system, including among families, school administrators, teachers, and policymakers (Frankel, 2004; Lieber et al., 2000). This study addresses the education of children with SEN in preschools with integrated programmes in Malaysia, in an attempt to identify some of the ways in which such collaboration may be done, or improved.

The description "schools with integrated programmes" in Malaysia largely refers to those schools in which units of special education classrooms are set up within existing regular school settings, sharing common facilities and school administration. The inclusion of children with SEN into regular classrooms in integrated programmes occurs also, but it is a non-compulsory practice in Malaysia, depending mostly on decisions made at the school level. To date, there is relatively limited research examining inclusive practices at the preschool level in this country. Existing research on inclusion in Malaysian integrated school settings has focused 
mainly on primary and secondary school contexts. Consequently, this study intends to carry out some initial research on preschool inclusion in Malaysian integrated school settings. It aims to establish the extent to which inclusion is prevalent in Malaysian integrated preschool programmes, and also seeks to examine the principals', preschool teachers' and parents' perceptions of inclusion in these settings.

\section{Background of study}

Inclusion, according to Kugelmass (2004) is explained in schools throughout the world as the placement of children with special educational needs (SEN) in regular classrooms alongside their typically developing peers. The extent to which inclusion is put into action, however, can differ between nations, and also within nations (Friend, 2011; Leyser \& Kirk, 2004), depending on the cultural, political, social and economic contexts (Leyser \& Kirk, 2011) and the interpretations of the concept of inclusion itself (Leyser \& Kirk, 2004, 2011; Odom, 2000). The prevailing debate concerning the interpretation of inclusion is often about whether or not all learners with SEN should become full-time members of a regular classroom, or whether special education provisions should still be maintained as part of a continuum of services for learners with SEN (Bergen, 2003; Hallahan \& Kauffman, 2006; Leyser \& Kirk, 2004).

In the case of Malaysia, a significant shift toward the placement of children with SEN into regular educational settings, moving them away from their traditional special schools, took place in 1981 when the Ministry of Education (MOE) adopted the 'least restrictive environment' (LRE) policy (Bosi, 2004; Haniz Ibrahim, 2007). Units of special classrooms within regular schools were established to accommodate the placements of children with SEN into regular educational settings (i.e., schools with integrated programmes). The aim of such schools is mainly to maximise the opportunities for social integration between children with and without SEN in as many school activities as possible (Ministry of Education [MOE], Malaysia, 2004). 
Emphasis on the importance of inclusive education in Malaysia came about in the mid 1990s as part of a transformation initiative for children with SEN (Jelas, Salleh, \& Ali, 2010). The landmark event in initiating this reform was Malaysia's participation in and endorsement of the Salamanca Statement and Framework of Action on Special Needs Education in 1994 (Asia Community Service, 2007), a framework by UNESCO, which has the clearest international support to date in recognizing inclusive education (Rioux, 2007). Further, inclusive education was also in line with Malaysia's aspiration of producing a "caring society" in accordance with the 2020 Vision policy, launched by the then Prime Minister, Tun Dr. Mahathir Mohamad in 1991 (Haniz Ibrahim, 1998).

The subsequent years brought about many significant changes for learners with SEN in the Malaysian education system. In 1995, the MOE established the Special Education Unit (currently known as the Special Education Division) to officially take charge of special education in government schools. In 1996, a chapter on special education was included in the Malaysian Education Act, and subsequently in 1997, following the ratification of this Act, the Education Regulation (Special Education), came into force (Lee \& Low, 2012). This Regulation drove the implementation of 1996 Education Act, ensuring special education services were made available in government schools. The regulation also specified that learners with SEN in Malaysia would be recognised for their special education needs under three different categories: visual impairment, hearing impairment and learning disabilities. More recently, the 2008 Persons with Disabilities Act (Laws of Malaysia, 2008) has stipulated that persons with disabilities shall not be excluded from the general education system on the basis of disabilities. Nevertheless, inclusion still remains a non-compulsory practice in Malaysia.

In practice, inclusion is a decision made at the school level based on guidelines by the MOE. Learners with visual impairments in integrated programmes are only included into regular classrooms from their third year of primary schooling onwards, and not during the early years of schooling (Haniz Ibrahim, 2007). Meanwhile, inclusion involving learners with hearing impairments in integrated 
programmes is carried out on a case by case basis, accommodating mostly those with residual hearing and hearing aids only. The move to include children with more profound hearing impairments is still taking time in Malaysia due to the fact that teachers who teach in regular classrooms are mostly not trained to communicate using sign language (Haniz Ibrahim, 2007).

On the other hand, inclusive practices involving children with learning disabilities or those otherwise intellectually challenged in the integrated programme depend on two criteria: that the children are (i) able to cope with regular classroom learning without much help; and (ii) do not have behavioural conditions that cause disruption to regular classroom learning. Children who fit into these criteria are included either fully, or for part of a school day, into regular classrooms (MOE, Malaysia, 2004). The assessment of whether or not children fit these criteria, and thus the decision to include children with learning disabilities in regular classrooms, depends totally on the school administration's prerogative, which is based on the advice of the special education teachers and the willingness of the regular education teachers (MOE, Malaysia, 2004).

But although primary and secondary school education for learners with SEN has been available in government schools for more than two decades now, this has not been the case for preschool education. MOE directed special educational services for preschool aged children with SEN began in 2003, with the opening of 28 special education preschools for children with hearing and vision impairments nationwide (Curriculum Development Centre [CDC], Malaysia, 2007). This undertaking was expanded in 2005 with the opening of 32 units of special classrooms in existing regular preschools nationwide (Bahagian Pendidikan Khas (BPK) [Special Education Division], 2008), and by the year, 2008, 122 such programmes were set up in the country for preschoolers with learning disabilities (BPK, 2008). However, prior to these developments, the government had been providing early intervention programmes through the Ministry of Health, and the Ministry of Women and Family Development, as well as supporting early intervention efforts of Non-Governmental Organisations (NGOs) (MOE, 2008a). 


\section{Rationale for study}

As noted in the preceding section, efforts to develop policy to aid the education of preschoolers with SEN in regular school environments have already been established through integrated programmes in Malaysia. However, detailed evidence showing the extent to which preschoolers with SEN in such programmes have opportunities for inclusion is scarce, meaning that the successes (and potential failures) of such programmes are yet to be determined.

Additionally, the attitudes with which the principal, teachers and parents view inclusion in the context of a given school, and the factors that influence inclusion in individual schools, are so far unexamined, and a matter of concern in my study. The reason for this concern is primarily because inclusion is a school-based decision in Malaysia. Although the effect of federal policies is important to prompt collective change towards embracing inclusion (Lieber et al., 2000), most international literature has shown that the fundamentals for successful implementation of inclusive practices lies within the context of a school (Ainscow, 2005, 2007). Both educators and parents have a major role in this regard - in particular, a host of studies have suggested that educators' and parents' views and personal characteristics in relation to inclusion can directly influence, or even impinge, schools' inclusive decisions (e.g., Abbott, 2006; Chhabra, Srivastava, \& Srivastava, 2010; Garrick-Duhaney \& Salend, 2000; Narumanchi \& Bhargava, 2011). Thus the leadership role and practices of the principal (Barnett \& Monda-Amaya, 1998; Conrad \& Brown, 2011), regular and special education teachers' attitudes and cooperation (Buell, Hallam, Gamel-McCormick, \& Scheer, 1999; Lifshitz, Glaubman, \& Issawi, 2004), and school partnership with parents of children with and without SEN (de Boer, Pijl, \& Minnaert, 2010; Garrick-Duhaney \& Salend, 2000) are all among the important features of successful inclusion. In other words, inclusion is, fundamentally about "those within a school developing practices that can reach out to all its learners" (Ainscow, 2005, p.112). This effect is all the more relevant in the case of Malaysian school contexts, where inclusion is a non-mandated practice. 
The Malaysian government, acknowledging that there are challenges in taking a radical approach of removing all barriers in regular schools to cater for the needs of any disadvantaged learner, has resorted to taking a progressive approach towards inclusion (Haniz Ibrahim, 1998). The largest education provision for inclusion in Malaysia is the integrated school programme (UNESCO, 2009), which locates children with SEN in units of separate classrooms established within regular schools settings (called locational integration), maximising children with SEN's opportunities for social integration, followed by academic integration, eventually leading up to inclusion.

However, as noted, there is relatively limited research examining inclusive practices at the preschool level in this country. Additionally, little is known about educators' and parents' views of inclusion and the extent to which they support the implementation of inclusion in Malaysian integrated preschool programmes. This study thus intends to add to the much needed body of empirical knowledge on inclusive education, especially in the Malaysian preschool context. As well as establishing the extent and nature of inclusion, it would seem important to gauge the extent to which educators and parents are supportive of this idea in Malaysian integrated preschool programmes, and factors that are influencing the implementation of inclusion in these settings.

\section{Research objectives and questions}

The research objectives of the current study are:

1. To determine how much inclusion is occurring in Malaysian integrated preschool programmes.

2. To explore educators' and parents' perceptions of inclusion, and their support for its implementation in Malaysian integrated preschool programmes.

3. To understand the factors that influence the extent and nature of inclusion in Malaysian integrated preschool programmes. 
In order to achieve the objectives stated earlier, the following research questions will guide the current study:

1. To what extent is inclusion practiced in Malaysian integrated preschool programmes?

2. How do the principals, preschool teachers and parents perceive the idea of inclusion and to what extent are they supportive of its implementation in Malaysian integrated preschool programmes?

3. What are the factors that may be influencing the implementation of inclusion in Malaysian integrated preschool programmes?

\section{Research design}

The study undertaken for this thesis adopted a mixed methods research design in which data collection and analysis involved both quantitative and qualitative techniques. The first phase was quantitative, and involved a short survey. The second phase involved case study research in three sites. The purpose of the survey was twofold. First, it was aimed at establishing the prevalence of inclusion in Malaysian integrated preschool programmes, subsequently answering the first research question. Because the idea of integrated schooling is still in its infancy at the preschool level in Malaysia, the survey made it possible to obtain data on a large scale and was determined to be the most suitable method to establish current information on practices of inclusion that covered the population of integrated preschool programmes in Malaysia.

The second aim of the survey was to make purposeful selection of three preschools as case study sites for the qualitative phase. It was hoped that obtaining information from settings that indicated different levels of practices (e.g., those with high/ moderate/ low) would provide a range of views and factors influencing the implementation of inclusion in each site. Data gathering in the three case study sites involved interviews, non-participatory observations, and examination of 
relevant documents. In each site, I carried out interviews with the school principal, with regular and special education preschool teachers, and with parents of children with and without SEN.

These interviews focused not only on obtaining specifics about each integrated preschool programme, but also on educators' and parents' perceptions of inclusion itself, with a particular interest in how these individuals' thinking and attitudes may be facilitating or inhibiting opportunities for shared activities between preschoolers with and without SEN. Such an approach involves careful examination of various contextual and person-related factors. Hence, I considered that the ecological and later bioecological perspectives (Bronfenbrenner, 1999, 2005; Bronfenbrenner \& Ceci, 1994; Bronfenbrenner \& Morris, 1998) the most suitable theoretical guide for this study. The combination of interactions among proximal processes, personal characteristics, context and time (the Process-Person-ContextTime model) proposed by the bioecological systems theory served as a useful conceptual tool for examining and elaborating on information pertinent to the study. In particular, the bioecological model provided the means for considering the importance of daily happenings in the preschool that foster inclusion (i.e., processes); personal characteristics (e.g., principals', teachers' and parents' attitudes, knowledge, concerns); factors operating within and beyond the preschool context (i.e., school environment; policies, cultural beliefs) and time (e.g., the development of inclusive education in Malaysia) to gain significant insights for addressing the main research questions.

\section{The place of the researcher}

All researchers bring their own values and perspectives to their research (Mertens, 2010). These values must be made explicit, as such explicitness not only allows the reader to situate the researcher in the study (Tsoi Hoshmand, 1989), but also allows disclosure of the researcher's potential biases (Bonner \& Tolhurst, 2002). Bonner and Tolhurst (2002) explain that, as a way of clarifying the researchers' role in their research, they often position themselves as either an insider or 
outsider to their research contexts. In this research I played the role of a researcher who is both an insider and outsider.

I am an insider firstly, in terms of my origin as a Malaysian. Further, having been an educator in this context, I am familiar with the knowledge and processes that are involved in the Malaysian education system. As an insider, I also have preunderstanding of my participants' cultural norms and expectations in relation to special needs education and inclusion in Malaysia.

I embarked on the current study with the experience of being an educator for different groups of learners. In Malaysia, prior to becoming a preschool teacher and later a teacher educator, I taught in an integrated programme for children with learning disabilities at secondary school. I personally believe that it is fundamental for every child with SEN to live, learn, and play in natural, stimulating settings with their typically developing peers. However, my personal experience as a special educator in a secondary school enabled me to understand the different situations and circumstances needing to be considered when inclusion decisions are made in integrated school settings. I was able to relate to how school personnel and parents perceived inclusion, what informed their thoughts, and how it impacted children's opportunities for inclusion.

In particular, there were situations in which the special education programme initiated and decided to include students with SEN into regular classrooms. However, when this occurred, it was common for parents to step in, indicating a preference for their children to remain in special classrooms. These parents often voiced concerns over issues such as academic stress for children with SEN, or the pressure of peer-acceptance in regular classrooms, which they felt caused unnecessary anxiety for their children. Conversely, I also observed situations where parents were happy for their child to be included in regular classrooms, but the regular classroom teachers in question had made it clear beforehand that devoting extra time and attention to the child with SEN would be problematic. Nevertheless, inclusion still took place, and I came to appreciate some of the regular teachers who 
were willing to walk the extra mile in catering for inclusion, despite their existing workload in meeting curriculum demands.

After my master's degree I became a regular preschool teacher, and later a teacher educator. It was during my experience as a teacher educator that the establishment of integrated preschool programmes began taking place in Malaysia. Having had experience with how inclusion issues are dealt with in a secondary school, I was keen to know how inclusion would play out at the preschool level. I was eager to discover how school personnel and parents would perceive the idea of preschool inclusion, as I believe their views and level of support is the key to inclusion initiatives. Most importantly, since integrated schooling at preschool level was a new venture, I believed it would be important to understand the factors that are impacting inclusion decisions in these settings, so that the positive factors can be enhanced and the negative issues can be addressed while this initiative is still in the early stages of its implementation.

While the advantages of being an insider researcher were helpful for in-depth understanding of my research context, too much familiarity was also particularly challenging, especially in terms of interpreting participants' perceptions and experiences. However, I endeavoured to free myself from potential bias by investigating the phenomenon of inclusion in Malaysian integrated preschool programmes by positioning myself as an outsider researcher. Firstly, I have never taught in an integrated preschool before, which is an advantage, as I regarded my participants as active informants in my knowledge seeking process. Secondly, in terms of my own understanding of the concept of 'inclusion', there is a considerable influence coming from Western knowledge and ideologies. This is mainly because my tertiary education and professional training have largely been grounded in Western epistemologies. This situation provided me with an understanding for viewing inclusion from other cultural perspectives. I also produced a range of possible interpretations of the data by reflecting on the international literature, empirical materials, and theoretical perspectives that guided my interpretation of the study. 
In addition to viewing my study from an outsider perspective, reflexivity also enabled me to overcome the bias of my position in this research. I adopted Patton's (2002) advice in this regard. That is, at every stage of the research I undertook an ongoing self-examination by questioning myself about what I know and how I know it. This way, I was attentive to and conscious of my own perspective and voice, and able to distinguish it from the voices of my participants. Further, throughout the process of the study, my research journal provided me with a record of the events that were taking place in each case study site, as well as my participants and my own perspectives about these events, which also provided a means of reflexivity, and kept me aware of the need to acknowledge and see beyond my own position. My research journal also reminded me that each of my participants had a different background and perspective from me, and that this was what I was venturing into in the first place.

\section{Research setting}

The main research setting in the current study is the integrated preschool programme under the jurisdiction of the MOE in Malaysia. The local setting of integrated preschool programmes may differ from those in the international context. To better understand this study, it is essential that the research setting is clarified at this stage:

- The Malaysian integrated preschool programme refers to an educational setting in which units of regular and special education preschool classrooms coexist within a regular primary school compound. The integrated preschool programme is usually made up of only one special classroom and not more than two regular classrooms.

- Each regular classroom is taught by a regular education teacher and the special classroom is taught by a special education teacher.

- Members of the special classroom are children with learning disabilities between the ages of four and a half and six. (Note: at the time of the current 
study, preschool aged children with sensory impairments were educated in special education preschools).

- Members of the regular classroom are typically developing children who are of four to six years of age.

- The integrated preschool programme shares the administration with the primary school. The principal of the primary school is the head of administration (Note: Primary school administrators are called headmasters in Malaysia. However, for the purpose of this study, and to maintain consistency with the broader literature, the term principal is used throughout this thesis).

\section{Definition of key terms}

To avoid confusion and misunderstanding of key terms used throughout this thesis, a concise definition of these terms is provided in the following:

\section{- Special Educational Needs (SEN)}

When referring to the literature relevant to the international context for this research, the term SEN refers to "all those children and youth whose needs arise from disabilities or learning difficulties" (UNESCO, 1994, p. 6). However, when involving the Malaysian integrated preschool programme the term SEN is used to refer specifically to preschoolers with learning disabilities. Those with learning disabilities are generally defined by the Malaysian MOE to include learners with Down syndrome, mild autism spectrum disorders, attention deficit hyperactive disorder, mild mental retardation, and other forms of specific learning disabilities, such as dyslexia (BPK, 2008). If the situation/statement in the Malaysian context is employed to refer to children with visual or hearing impairments, it will be stated as such.

\section{- Inclusion}

Inclusion in the current study refers to the physical placement of children with SEN into regular classrooms with their typically developing peers (Cook, 2001; Kugelmass, 2004). 


\section{- $\quad$ Social integration}

Guralnick (1999), in elaborating on social integration, states that one of the expectations of inclusive practices in early childhood settings is the formation of meaningful social relationships between children with and without SEN. In the current study, social integration refers to the shared participation and engagement of children with SEN and their typically developing peers in any activities that enhance peer interaction or social relationships.

\section{- $\quad$ Academic integration}

Academic integration refers to the shared participation and engagement of children with and without SEN in academically oriented activities, such as classroom lessons, or activities that involve skills and specific learning outcomes from the curriculum document incorporated into teachers' lesson planning.

\section{Organisation of thesis chapters}

This thesis is made up of eight chapters. Chapter one has introduced the background of and the rationale for the current study. It has also stated the objectives of the research and main research questions. The chapter also summarised the research design, including the theoretical perspective guiding the study, and the position of the researcher. A concise description of the research setting and definition of key terms are also stated.

Chapter two provides more detailed information on the practice of inclusion in Malaysian integrated special education programmes. An overview of special education services, preschool education and integrated schooling in Malaysia is presented also, and educators and parents' roles and perspectives in relation to the education of children with SEN are introduced.

Chapter three examines scholarship and research relevant to the concerns of this study: how inclusion is defined; how the nature and extent of inclusion is determined; research about educators' and parents' perceptions about inclusion, 
and factors that may influence the implementation of inclusion. Chapter four reintroduces, and further explains the theoretical framework that guides this study and thesis, while contextualizing its relevance to this study's data.

Chapter five recalls the research design outlined in this chapter, including the pragmatic paradigm underpinning this study, and the methods of data collection and analysis. Chapter six presents the findings of the survey organized by the three research questions I have introduced above. Chapter seven presents the findings across the three case study sites. Chapter eight discusses the results of both survey and case study findings, and critiques these in relation to existing literature. Following this, Chapter nine outlines implications and recommendations for future research, and concludes the research. 


\section{CHAPTER 2}

\section{-An Overview of Special Education, Integrated Programmes and Inclusion in Malaysia-}

\section{Introduction}

This chapter presents the context of this initial study into the nature and extent of inclusion in Malaysian integrated preschool programmes. The first section offers a brief background on Malaysia. This is followed by an explanation of the present education system in the country. Because this study concerns the education of children with SEN at the preschool level, the development of education policies and legislations that have shaped preschool and special education, as well as the types of services offered within the present education system, are presented. In particular, the concept and aims of inclusion, and of integrated schooling programmes in Malaysia, are examined. Finally, the evolution of roles and perspectives of educators and parents in relation to the education of children with SEN in the local context is discussed.

\section{Introducing Malaysia: The research context}

Malaysia is an independent country with a parliamentary constitutional monarchy and a federal government structure inherited from British colonisation. It is located in the heart of the South East Asian region. Its neighbours include Singapore, Indonesia, Thailand and Brunei. Malaysia is made up of thirteen states and three federal territories spread across two regions (Peninsular Malaysia, and East Malaysia on Borneo Island) separated by the South China Sea (see Figure 1). The country has a total area of approximately 330, 803 sq.km. Timber, petroleum and natural gas are among the range of natural resources in Malaysia, which have contributed to the country's development and industrialised economy. Traditionally however, Malaysia's main sources of income have been agriculture, mining and rubber. During the early ninetieth century under the British rule, Chinese and Indian immigrants were encouraged to migrate to Malaysia as tin miners, rubber tappers, or railway workers. This move significantly affected the 
demography of the country, transforming it from a homogeneous indigenous society to a heterogeneous one (MOE, Malaysia, 2008a).

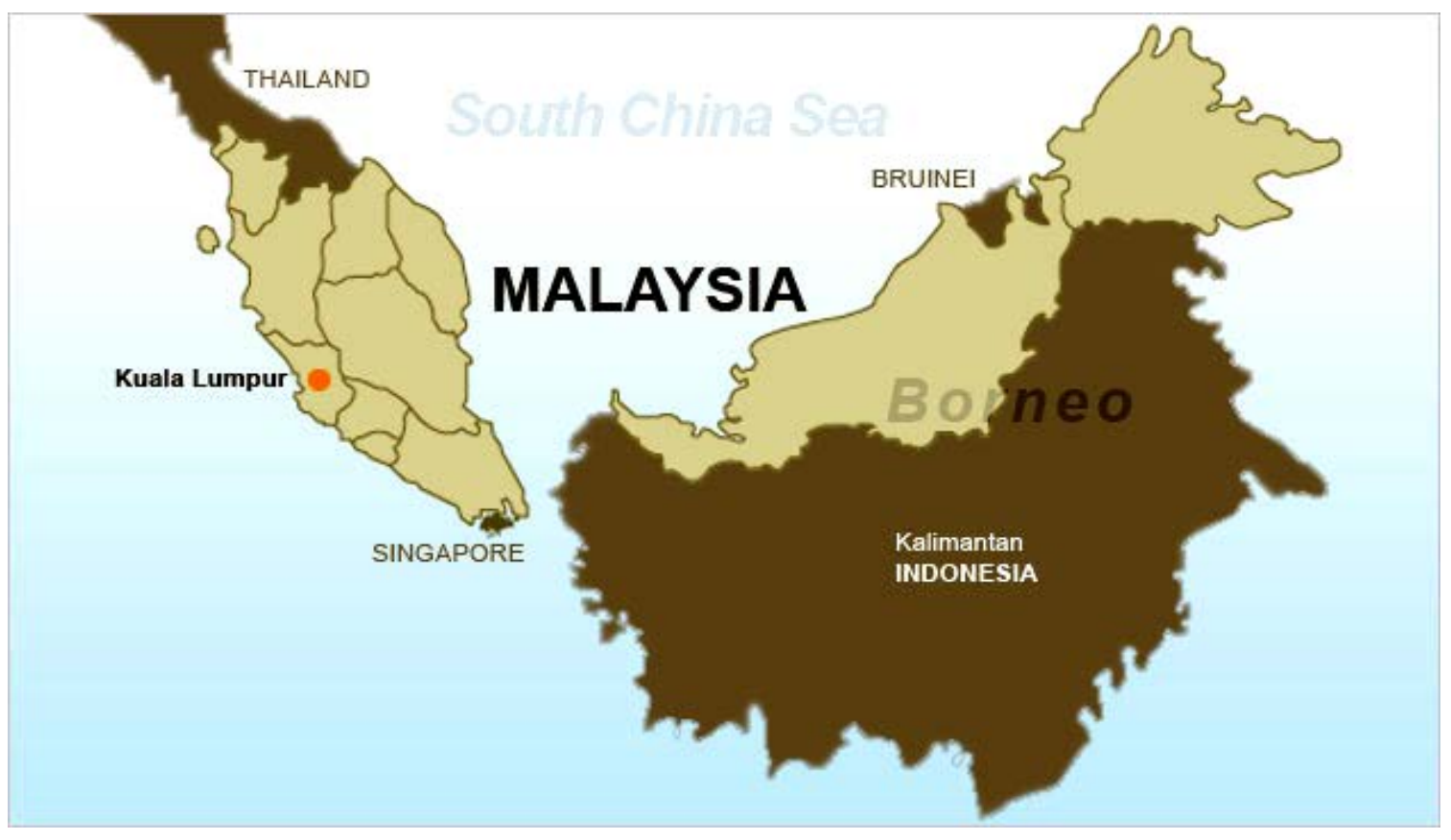

Figure 1: $\quad$ Malaysia - Location

The population of Malaysia currently stands at 28.3 million, and out of these, there are about 5, 407, 865 students and 405, 716 teachers, with an illiteracy rate of 5\% (Khader, 2012). Malaysia is also a multiethnic, multicultural, and multi-linguistic society; according to the 2009 census, the people of Malaysia are comprised of Malays, who account for around $49 \%$ of the population, Chinese (23\%), Indians (7\%), Bumiputera (Indigenous Malaysians) (11\%), and other descents and noncitizens (10\%) (United Nations, 2011). Whilst Islam is the official religion of the nation, freedom of religion is practiced, with Christianity, Buddhism, Confucianism, Taoism, Hinduism and other, tribal religions still widely practiced.

Bahasa Melayu (Malay Language), is the national language, and spoken by many. English, some Indian dialects, such as, Tamil, Malayalem, Hindi and Punjabi, and some Chinese dialects such as, Mandarin, Hokkien, Hakka and Cantonese, are among the other common languages. Malaysia's population includes those who come from diverse socio-economic circumstances and geographical location (i.e., 
urban and rural areas). As in all countries, persons with SEN constitute a small proportion of the country's population.

With such an exceptionally diverse society, the key goals of the government's policy agendas and ideologies are often centred on national unity, equity, diversity, liberty, and progress (MOE, Malaysia, 2008a). The present education policy is geared towards promoting and achieving these qualities.

\section{Current education structure and organisation}

Compulsory formal schooling in Malaysia is required from ages 6 to 17 years old (Gomez, 2004). Preschool education is not compulsory, but under the present education system, the Education Act of 1996 ensures that every child has access to it, and most Malaysian children start their preschool education between the ages of four to six. Following this, schooling is divided into four levels, namely: primary, lower secondary, upper secondary and post-secondary, of which the first three are compulsory. Mandatory primary schooling lasts for six years (i.e., year one to year six). At the end of primary education, children sit a national examination, called the Primary School Assessment Test.

Lower secondary requires three years (i.e., forms one to three), with automatic progress to two years of upper secondary (i.e., forms four to five). There are national level examinations held at the end of both lower and upper secondary schooling. Not all students progress to post-secondary level, as there are some who move on to the labour market instead (Country Report Malaysia, 2010).

Post secondary education is offered through form six (for two years: lower six and upper six), or through a two-year matriculation study, which are aimed at preparing students for university entrance. Colleges and polytechnics offer diploma level courses, after which graduates from these institutions can move on to universities, or join the labour market (MOE, Malaysia, 2008a). 
The medium of instruction in all national schools is Malay, except in national-type (or vernacular) primary schools, where Chinese or Tamil are the medium of instruction (in those cases, Malay is taught as a compulsory subject). English is the second official language in Malaysia and is a compulsory subject in all schools (Gomez, 2004).

The administration and management of educational matters in Malaysia is centralised, and is organised into four levels of command, namely federal, state, district and school. These levels are represented by the Ministry of Education (MOE), State Education Departments (SEDs), the District Education Offices (DEOs), and the schools respectively (MOE, Malaysia, 2008a). The MOE in Malaysia is the primary agency responsible for formulating policies and translating them into educational programmes, projects and activities, with guidelines for implementation (UNESCO, 2011). The implementation of education policies are carried out through fourteen SEDs at the state level that among other responsibilities, supervise educational programmes and provide feedback to the MOE. The DEOs serve as an effective link between the schools and the SEDs. Primary schools are headed by headmasters, while secondary schools are headed by principals.

In addition, other ministries and non-governmental agencies work in parallel with the MOE, helping to supplement the MOE's efforts in providing educational services and training to cater for national development and manpower needs. An overview of such efforts will be discussed with relevance to preschool education and SEN in later sections of this chapter.

\section{The development of policy and legislation for special education and preschool education in Malaysia}

As previously discussed, inclusion, according to Kugelmass (2004) is universally understood as the placement of children with SEN into regular classrooms with their typically developing peers. Nevertheless, "inclusion as we know it today has its origins in Special Education" (UNESCO, 2005, p. 9). Hence, incorporating 
inclusion requires change in the regular education system to cater for special educational needs. Because this study concerns preschool special education, discussion in this section will look at the development of policies and legislative frameworks that have shaped special education and preschool education services in the country to date.

Since gaining independence in 1957, education has always been a central part of the Malaysian government's developmental agenda. The democratisation of education was initiated in 1962, with provisions of free education for all at primary school level. This was done to encourage enrolment in primary schools, and to ensure a balance of educational opportunities between urban and rural populations. However, while the educational priority was to ensure the availability of equitable educational services for mainstream children at the primary school level, there was not much encouragement to ensure children with SEN attended school, or received proper care and services. The Education Act of 1961, which was in force at that time, officially recognised the MOE as responsible for providing guidelines defining the varying types of learners requiring special education, and the methods appropriate for the education of these learners (Country Report Malaysia, 2000), but did not place the MOE as responsible for the education itself. Hence, parents of children with SEN were not obliged to send their children for educational services or formal care if they did not wish to. Those services that were available for children with special needs were mostly offered by religious and voluntary organisations.

However, this changed during the New Economic Policy period (from the 1970s, until 1990), as government efforts were geared towards eradicating poverty and restructuring society. Providing equal educational opportunities to all was the means to restore social imbalance. Educational opportunities, particularly in rural areas, were promoted in tandem with the increase in school infrastructural facilities. A range of educational support programmes were introduced to bridge the gap between the rich and the poor. Some of these programmes included the textbook loan scheme, fully residential schools, scholarships, supplementary food 
and health programmes, and rural and day hostels (MOE, Malaysia, 2008a). It was also during this time that the educational services for children with SEN were given the importance they deserved. The 1979 Cabinet Committee Report officially acknowledged that the government should be the foremost provider of services to the country's children with SEN. Whilst encouraging voluntary organisations to continue improving the education of learners with SEN, this report recommended that the government assume responsibility of providing education to learners with SEN as well as regulating it (Haniz Ibrahim, 1998).

Since 1980 all children aged 0-6 years of age were required to go for regular health, growth and developmental assessments. Since 1986, early intervention programmes by the Ministry of Health (MOH) were also instituted (Country Report, Malaysia, 2009). There were also rehabilitative services through the Department of Social Welfare, in the form of community-based rehabilitation centres which stressed socialisation and pre-school education for children with disabilities. Most importantly, the National Social Welfare Policy in 1990 gave recognition to the fact that disability should no longer be viewed as a charitable issue in Malaysia; instead persons with disability were recognized as having a right to full participation in mainstream development (Country Report, Malaysia, 2009).

To this end, the past thirty years have seen marked improvements in the country's educational reforms (MOE, Malaysia, 2008a), with education policies being geared towards production of skilled labour for national developments, and equal educational opportunity, both in terms of access and achievement (MOE, Malaysia, 2008a). Significant changes were seen during the period of 1991-2000, also known as the National Development Policy (NDP) period in Malaysia (MOE, Malaysia, 2008a). This period was in-line with Malaysia's participation in and commitment to a series of international reforms in education, such as, The World Declaration on Education for All (EFA) in 1990, and the United Nations' Standard Rules on Equalisation of Opportunities for Person with Disabilities in 1993. Malaysia also became a state member of the Convention on the Rights of the Child in 1995 (Human Rights Commission of Malaysia, 2006). During the NDP period, the nation 
saw education legislation being strengthened and amended to provide a legal framework for implementing newly introduced education policies. The reforms brought about substantial improvements in access of early childhood care and services for children with and without SEN.

The Education Act of 1996, which is among the most pertinent policy documents for the current education system, was introduced during the NDP period. Among other initiatives, this Act (which replaced The Education Act of 1961) officially included preschool education and special education as part of the national education system (Lee \& Low, 2012). The incorporation of these areas brought about the standardisation of education regulations for both government and private service providers. In addition, the upgrading of institutions for systematic training and capacity building of staff was initiated, aiming toward providing quality care and education services to preschoolers with and without SEN (MOE, Malaysia, 2008a). Subsequently, this period saw teacher qualifications being upgraded from certificate to diploma. The absorption of preschool education into the national education system also resulted in the development of a standard preschool curriculum, which by 2003 was required by law to be followed at all public and private preschools nationwide (MOE, Malaysia, 2008a).

In responding to ongoing educational demands in the recent past, subsequent improvements have been made to education legislation, hoping to ensure no child is left out in terms of education. One example is the Education Act of 1996 (Amendment 2002), which ensures provision for compulsory education. This Act sees to it that every child nationwide from age 6, regardless of sex, residential locality, socio-economic background and disability has the right to education from 2003 onwards (Yusof, 2008). Another recent change, particularly emphasising children with SEN's right to education, is the 2008 Persons with Disability Act (Laws of Malaysia, 2008), in which it states that "Persons with disabilities shall not be excluded from the general education system on the basis of disabilities, and children with disabilities shall not be excluded from pre-school, primary, secondary 
and higher education, on equal basis with persons or children without disabilities..." (p. 23).

The importance given to preschoolers with and without SEN was also spelt out in the Education Development Master Plan for Malaysia (EDMP) (2006-2010), in which preschool education was extended to all National Schools, in the process ensuring that children with SEN had equal opportunity to obtain it. To support this objective, the EDMP also emphasised the provision of adequately trained teachers and teacher assistants as part of its action plan. The significance of preschool education in terms of access, equity and quality was also further emphasised in 2009 when the prime minister advocated for efficient and immediate action in six National Key Results Areas (NKRA) in order to bring about improvements in the country. Preschool education was specifically listed under the third NKRA, called Widening Access to Quality and Affordable Education (Prime Minister's Department, Malaysia, 2010). The aim of this thrust was (among others) to increase public and private partnership in preschool education, subsequently increasing the number of preschool educated children to $87 \%$ by the end of 2012 , from $72 \%$ in 2010 (Prime Minister's Department, Malaysia, 2010).

The discussion in this section has shown that there has been growing emphasis on the government's commitment towards education for all, particularly policies and legislation that call for the implementation of special education and preschool education in the country. In taking on their commitment to these policies, the government has been offering services of preschool special education through different entities in the country. The challenging task however, is in ensuring that these services are not just fulfilling policy provisions, but instead are offering the best services for meeting the educational needs of the children concerned. This thesis is interested in addressing the success of this task, with emphasis on understanding inclusion practices in Malaysian integrated preschool programmes that come under the jurisdiction of the MOE. To fully understand the context of the study, however, a brief background on preschool education and special education is first warranted. 


\section{Preschool education in Malaysia}

Preschool education in Malaysia comes under the broad heading of Early Childhood Care and Education (ECCE) (Ng, 2010). ECCE services in Malaysia are divided into two groups: (i) child care centres or nurseries that serve children from birth to four years old, and (ii) preschools or kindergartens that serve children from ages four to six years old. This study focuses on the latter group.

In the past, Malaysian preschool education was initiated by local communities, nongovernmental organisations (NGOs), and religious and private bodies (CDC, Malaysia, 2007; Ng, 2010). As discussed in the previous section, it was only in the 1970s and 80s that government entities began providing preschool services. The first public preschools were initiated by the Ministry of Rural and Regional Development (MRRD), and later the Federal Land Development Authority and the education wing of the police and armed forces also began providing preschool services (MOE, Malaysia, 2008a). However, since the absorption of preschool education into the national education system through the Education Act of 1996, the government has taken up the leading role in providing preschool services, placing great importance on quality care and education programming. Whilst preschools run by private providers and religious bodies are still widely available in Malaysia, the largest provider of preschool education is now the government.

Currently, there are three ministries that are responsible for preschool education in Malaysia. These are the MRRD, the Department of National Unity and Integration (DUNI), and the MOE. The MRRD is the first and largest government entity providing preschool education in the country since 1972 (MOE, Malaysia, 2008a). Preschools that come under this ministry are known as Kemas preschools. These preschools are set up based on local community request, and are primarily located in rural or suburban areas (Ng, 2010). Preschools that come under DUNI, also known as Perpaduan preschools, have been around since 1977 (MOE, Malaysia, 2008a) and are mostly set up in urban areas (Ng, 2010). Perpaduan preschools are geared towards promoting unity, nationality and harmony amongst communities of different ethnicity (MOE, Malaysia, 2008a), and ensure that the student population 
and their parents (who form the board of governance) in the preschool present a diversity of different races ( $\mathrm{Ng}, 2010)$.

Of the government providers, the MOE was the latest in setting up their preschools (Ng, 2010). Preschool provisions under the MOE began in 1992, in the form of a pilot project, with the opening of 1131 preschool classes as an annex to existing primary schools. From 2003, MOE preschools began spreading out nationwide, with an increase of 500 to 1500 classes per year, and by 2007 were already providing services to around 96,150 children nationwide ( $\mathrm{Ng}, 2010)$. Figure 2 provides a national overview of the proportion of preschool aged children enrolled in the different types of providing agencies as of 2007.

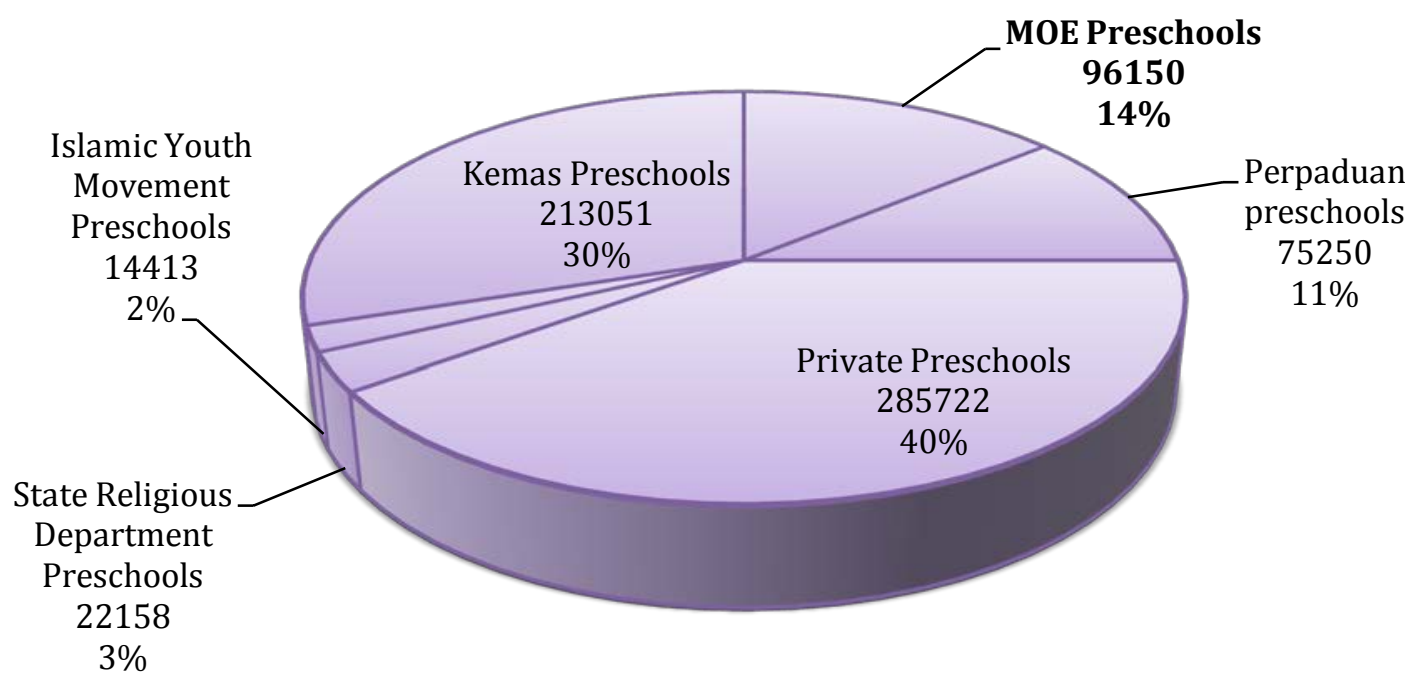

Figure 2: $\quad$ Proportion of preschoolers (4-6 years old) enrolled in the different types of providing agencies nationwide as of 2007 (CDC, Malaysia, 2007)

This study focuses on preschool special education that comes under the jurisdiction of the MOE. Interestingly however, whilst MOE preschools for typically developing children have been established since 1992, provision for preschool education for children with SEN under this ministry only came about in 2003. Prior to that, education services for preschoolers with SEN were provided by the Ministry of Women, Family and Community Development (MWFCD), along with 
supplementary services from the Ministry of Health (MOH) (notably in terms of early intervention and other health care services) (Country Report, Malaysia, 2009). The government also worked collaboratively with NGOs, and other private entities providing services of special education and care to preschool aged children.

However, the specific impetus for special education preschools under the MOE began in the year 2000, when existing special education primary schools initiated their own programmes for children with SEN between the ages of 4 to 6 . These initiatives were run without any financial allocation, and without staff trained to cater for preschoolers with SEN (CDC, Malaysia, 2007). These were the programmes the MOE took over in 2003, expressly converting them to special education preschools for children with SEN. In 2008 there were 25 such preschools in the country; 22 that served preschoolers with hearing impairments, 5 that served preschoolers with visual impairments, and 1 for preschoolers with learning disabilities (CDC, Malaysia, 2007). In addition to special education schools, the MOE currently provides special education services to preschoolers with SEN through integrated programmes.

\section{Special education services in Malaysia}

The Education Regulation (Special Education) 1997 specifies that learners with SEN in Malaysia are recognised for their needs under three different categories: those who have visual impairment, those with hearing impairment, and those with learning disabilities. Those with learning disabilities ${ }^{1}$ are generally defined by the Malaysian MOE to include learners with Down syndrome, mild autism spectrum disorders, attention deficit hyperactive disorder, or who are mildly intellectually challenged, or have other forms of specific learning disabilities, such as dyslexia (BPK, 2008).

\footnotetext{
${ }^{1}$ Children with learning disabilities in this study will be referred to as children with SEN in later chapters in order to maintain consistency with the literature on inclusive education. If a statement/situation refers to children with visual or hearing impairment in the Malaysian context, it will be stated as such (i.e., children with visual or hearing impairment).
} 
As I have discussed in previous sections, services for children with SEN in Malaysia currently come from a shared effort of the Government, non-governmental organisations (NGOs) and other private providers. Within the government, most of the ministries and government departments provide services for people with special needs and those who are physically disabled. However, there are three main ministries, namely the Ministry of Health (MOH), The Ministry of Women, Family and Community Development (MWFCD), and The MOE (MOE, Malaysia, 2008a) who provide services for preschool, primary and secondary school aged children. Their responsibilities are divided as follows:

- The MOH is responsible for screening, early detection, and the rehabilitation of children with SEN. The ministry's medical and paramedical staff are in charge of providing curative and preventive care, through a range of activities, such as antenatal and obstetric care, immunisation, nutrition and developmental assessment for children (Country Report, Malaysia, 2009). Provisions for early intervention programmes are also among their primary services for children with SEN.

- The MWFCD, through its Department of Social Welfare (DSW), is responsible for providing learning and skill-based training services for children and youths with severe physical handicaps, multiple disabilities and severe and profound mental retardation. Rehabilitative services through communitybased rehabilitation programmes are provided to children with SEN to enhance socialisation, especially for preschool aged children. The DSW also initiates job coaching programmes, independent living programmes for youths, and financial assistance to those needy persons with disabilities (Country Report, Malaysia, 2009).

- The MOE provides educational services for children who experience one type of disability (services for those with multiple disabilities are provided by the MWFCD). There are currently three different types of programme available in the formal education system through the MOE that cater for 
children with SEN, namely:

(i) Special education schools, which only children with SEN attend. Special education schools are often based on serving children with the three different types of disability mentioned above (i.e., they are visually impaired, hearing impaired or have learning disabilities). Practices of inclusion in these schools are not feasible as the total population in the schools are children with SEN.

(ii) Inclusive education programmes (total inclusion), in which children with SEN become full time automatic members of regular classrooms. However, these programmes have a higher tendency to include children who are physically disabled but have normal cognitive abilities, and are less inclined to include children with learning disabilities (Haniz Ibrahim, 2007; Lee \& Low, 2012).

(iii) Integrated programmes, in which children with SEN are educated in regular school environments but are placed in units of special education classrooms. These classrooms are coordinated under the school's special education programme. The integrated special education programme is currently the largest programme offering inclusion opportunities (partial or full inclusion) to children with SEN (UNESCO, 2009). Consequently, this thesis is particularly concerned with these programmes, and will largely be focusing on practices of inclusion in integrated programmes at the preschool level. The following section will provide more details in this regard.

\section{Integrated programmes and inclusion}

Integrated programmes in Malaysian schools began widespread initiation in primary and secondary schools in 1981, when the government adopted the least restrictive environment (LRE) policy (Bosi, 2004). The LRE policy was instrumental in the shift to remove children with SEN from their traditional, segregated learning environment, suggesting instead that they be placed in a learning environment that was as close as possible to those where typically developing children were educated (Thomas \& Webb, 1997). These actions were accompanied by parents of 
children with SEN demanding formal educational opportunities for their children in regular schools because of the logistic difficulties in catering for children with SEN in special schools (Haniz Ibrahim, 2007). Hence, instead of building special education schools to cater for the education of children with SEN, the government decided to establish independent special education classrooms in regular schools.

This move towards integrated schooling became more extensive after the government's involvement in the United Nations Declaration of the International Decade of Disabled Person (1983-1992). This declaration emphasised the importance of placing children with SEN into regular school environments, ones that offered opportunities for education equal to their typically developing peers (Ang, 1999). The primary aim of integrated programmes has since been to encourage social integration between children with and without SEN, and to maximise opportunities for children with and without SEN to engage in shared activities.

\section{The shift towards inclusion}

In 1995, substantial changes began taking place in the special education arena in Malaysia when the MOE was preparing for the introduction of inclusive education. This initiation came about as a result of Malaysia's endorsement of a declaration made in Salamanca, Spain. Delegates representing 92 governments (including Malaysia) and 25 international organisations declared support for inclusive education unanimously (UNESCO, 1994). Consequently, in Malaysia, the integrated programme, which had already embraced the concept of 'schools for all' became a suitable stepping stone for inclusion.

In 1996, for the first time in history, a chapter on special education was included in the Malaysian Education Act (Lee \& Low, 2012). Subsequently in 1997 the Education Regulations (Special Education) was in force to drive the Act's implementation, ensuring special education programmes were implemented in regular schools. Following this implementation, primary and secondary schools throughout the country were selected by the Ministry of Education as pilot project 
schools to include learners with SEN into regular classrooms (e.g., Ang, 1999; Jelas, 2000). In 1998, a total of 53 primary schools and 10 secondary schools offering educational services to students with visual impairments were categorized as inclusive schools by the government (Lee \& Low, 2012). The recent past has also seen continued research and development in relation to the implementation of inclusive education, particularly in primary and secondary school settings (e.g., Jelas, 2000; Jelas, Salleh, \& Ali, 2010; Haniz Ibrahim, 2007; Haq, 2000). Nevertheless, despite these efforts, inclusion remains a non-compulsory practice, and very much a school-based decision in Malaysia, though it is now based on, and supported by, guidelines from the MOE.

\section{Inclusion in integrated programmes}

Officially, inclusion in Malaysia instructs the placement of "SEN students into mainstream classes to be educated alongside their peers, either with or without additional support, and within the present school system" (MOE, Malaysia, 2004, p. 28). But despite the universality of this definition, in Malaysia, a distinction is made on the basis of the disability or ability of the child to function independently in regular classroom learning. Children who are able to keep up with mainstream classroom learning are included in regular classrooms fully, or for part of the school day (i.e., for selected subjects only). Those children with SEN, who are perceived as being unable to benefit from inclusion (generally due to their difficulty in coping with academic integration), are educated in special classrooms, engaging in social integration with their typically developing peers in out-of-classroom activities. At the primary and secondary school level, children with SEN are sometimes included in regular classrooms with typically developing children who are of the same or different age, depending on the level of academic integration with which they (children with SEN) can cope. 
The tables below (Tables 1, 2 and 3) show the number of integrated programmes in Malaysia for children with visual impairment, hearing impairments and learning disabilities from 2002 till 2008 at the preschool, primary and secondary school levels.

Table 1: Integrated programmes for children with visual impairment nationwide

\begin{tabular}{lllllllll}
\hline & \multicolumn{7}{c}{ Integrated programmes for children with visual impairment } \\
\cline { 2 - 8 } & Year: & 2002 & 2003 & 2004 & 2005 & 2006 & 2007 & 2008 \\
\hline Preschool level & - & - & - & - & - & - & - \\
Primary school level & 11 & 11 & 9 & 13 & 12 & 10 & 15 \\
Secondary school level & 15 & 13 & 14 & 14 & 14 & 14 & 17 \\
\hline
\end{tabular}

Source: Bahagian Pendidikan Khas (BPK), 2008

Table 2: Integrated programmes for children with hearing impairment nationwide

\begin{tabular}{lllllllll}
\hline & \multicolumn{7}{c}{ Integrated programmes for children with hearing impairment } \\
\cline { 2 - 8 } & Year: & 2002 & 2003 & 2004 & 2005 & 2006 & 2007 & 2008 \\
\hline Preschool level & - & - & - & - & - & - & - \\
Primary school level & 41 & 34 & 30 & 34 & 30 & 34 & 36 \\
Secondary school level & 39 & 39 & 37 & 43 & 42 & 39 & 33 \\
\hline
\end{tabular}

Source: Bahagian Pendidikan Khas (BPK), 2008

As indicated in Tables 1 and 2 above there are no integrated programmes at preschool level for children with hearing or visual impairments in Malaysia. During their early years of schooling, children with visual impairments generally remain segregated from regular classroom learning (MOE, Malaysia, 2008b). These children however, are provided with varying levels of inclusion opportunities once they are in the third year of primary schooling and for the next five years (Note: children with SEN have the option of being in primary schools for an extra two years). Some have opportunities for full inclusion (except during physical education 
and art lessons), while others are included for part of the school day. Nevertheless, the majority of children with visual impairments (who are cognitively able) are included into regular classrooms in secondary school education. The inclusion of children with visual impairments is perceived to be possible at this stage primarily because these children are very much able to follow verbal instructions (Haniz, Ibrahim, 2007). In addition there is also assistance from resource teachers in translating written language to Braille, and embossing diagrams, making academic integration feasible (Haniz Ibrahim, 2007).

The inclusion of children with hearing impairments in primary and secondary school integrated programmes is however, implemented on a case by case basis, accommodating mostly those with residual hearing and hearing aids only. The move to include children with more profound hearing impairments unfortunately, is still taking time in Malaysia due to the fact that teachers who teach in regular classrooms are mostly not trained to communicate using sign language.

Integrated programmes serving children with learning disabilities currently represent the largest number of integrated programmes in Malaysia, and are the only type of integrated programme available for children with SEN at the preschool level. The details are shown in Table 3. 


\begin{tabular}{|c|c|c|c|c|c|c|c|c|}
\hline & \multicolumn{8}{|c|}{ Integrated programmes for children with learning disabilities } \\
\hline & Year & 2002 & 2003 & 2004 & 2005 & 2006 & 2007 & 2008 \\
\hline \multicolumn{9}{|l|}{ Programmes: } \\
\hline Preschool & & - & - & - & 32 & 44 & 87 & 122 \\
\hline Primary school & & 404 & 473 & 532 & 588 & 656 & 767 & 882 \\
\hline Secondary school & & 160 & 187 & 225 & 281 & 320 & 348 & 319 \\
\hline \multicolumn{9}{|l|}{ Total student: } \\
\hline preschoolers & & - & - & - & 134 & 198 & 355 & 519 \\
\hline Primary school & & 7,437 & 8,496 & 10,312 & 10,721 & 13,755 & 15,501 & 17,214 \\
\hline Secondary school & & 2,786 & 3,384 & 4,450 & 5,528 & 6,861 & 8,050 & 7,826 \\
\hline \multicolumn{9}{|l|}{$\begin{array}{l}\text { Total special } \\
\text { classrooms: }\end{array}$} \\
\hline preschool & & - & - & - & 32 & 44 & 87 & 122 \\
\hline Primary school & & 1,272 & 1,221 & 1,418 & 1,714 & 2,076 & 2,778 & 2,818 \\
\hline Secondary school & & 477 & 534 & 617 & 756 & 1,006 & 1,385 & 1,225 \\
\hline \multicolumn{9}{|c|}{$\begin{array}{l}\text { Total special } \\
\text { education teachers: }\end{array}$} \\
\hline Preschool & & - & - & - & 32 & 44 & 87 & 122 \\
\hline Primary school & & 1,536 & 1,729 & 2,049 & 2,412 & 2,963 & 2,974 & 3,804 \\
\hline Secondary school & & 579 & 660 & 810 & 1,057 & 1,359 & 1,345 & 1,617 \\
\hline
\end{tabular}

Source: Bahagian Pendidikan Khas (BPK), 2008

There are no set rules governing the inclusion of children with learning disabilities into regular classrooms (MOE, Malaysia, 2008b). Inclusion decisions depend completely on the school administration's prerogative, based on the advice of the special education teacher and the support and cooperation of the regular classroom teacher (MOE, Malaysia, 2004). There are however, two generally accepted conditions: firstly, these children should be able to manage themselves without much help, and secondly, these children must not have behavioural conditions that could be disruptive to regular classroom learning (MOE, Malaysia, 2008b). Children 
who are perceived as able to cope with regular classroom learning are included fully or for selected subjects (partial inclusion), and while inclusion of these children is not compulsory, it is strongly encouraged (MOE, Malaysia, 2008b).

\section{Integrated preschool programme characteristics}

Similar to all integrated special education programmes at the primary and secondary school level, integrated preschool programmes are made up of units of special education classrooms that co-exist within regular preschool settings. However, since regular preschools in Malaysia are annexed to primary schools, all integrated preschool programmes in Malaysia are currently run in primary school compounds (see Figure 3). Integrated preschool programmes therefore, share administration and common facilities with the primary school.

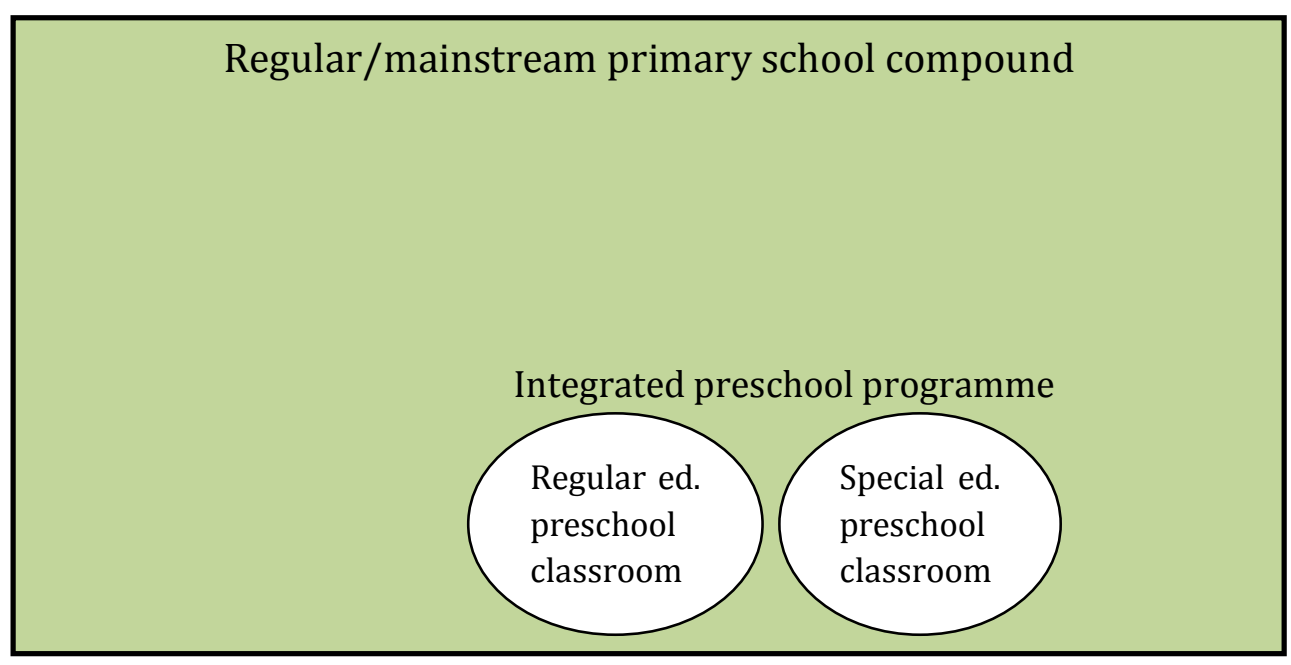

Figure 3:

An integrated preschool programme in Malaysia

The administration of all primary schools under the jurisdiction of the MOE is the responsibility of the principal ${ }^{2}$, who is in charge of providing professional as well as administrative leadership in the school (MOE, Malaysia, 2008a). The headmaster is assisted by a senior assistant and a head of student affairs. Every school also has a Parent-Teacher Association (PTA). The school management and PTA work

\footnotetext{
${ }^{2}$ As mentioned, in Malaysia, principals of primary schools are called headmasters. However, they are referred to as principals in this thesis to maintain consistency with the literature.
} 
collaboratively to ensure co-operation between the school and community is fostered.

Similar to all primary and secondary schools under the national education system, the preschools that come under the MOE are fully funded by the government. All operating expenses, such as staff salaries and capital costs are borne by the government. There is also allocation for children's meals, teaching and learning materials, and provisions for indoor and outdoor play equipment (Schools of Malaysia Directory, 2008). Research carried out by the CDC revealed that MOE preschools are the best equipped, compared to other government-run preschools, and that teachers are generally satisfied with the teaching space, the materials provided for classroom teaching and learning, and the physical facilities (such as their kitchens, play areas and storage) (CDC, Malaysia, 2007).

Teaching staff in integrated preschool programmes consist of a preschool teacher who is in charge of regular classroom teaching and management, and a special education teacher who is in charge of the special education classroom. Each classroom also has a helper/ teaching assistant who helps with the preparation of teaching aids and preschooler's meals, assists teachers with classroom activities and other daily on-goings. The teacher- student ratio in regular classrooms can vary between 1:10 (minimum) and 1:25 (maximum), whereas in special classrooms it varies from 1: 1 (minimum) and 1:10 (maximum) (CDC,Malaysia, 2007)

All preschool teachers teaching in MOE-run preschools have at least a diploma in teaching, and many have a Bachelor and a Master's degree. The training and certification of all teachers, through the Teacher Training Division (TTD) and universities, in preschools run by MOE are the responsibility of the MOE. Teacher training institutes nationwide (that are coordinated by the TTD) offer a range of courses, namely a teaching diploma (3 year course); a post graduate teaching diploma (1 year course); in-service professional training (for 14 weeks or 1 year); and degree courses (8-10 semesters, depending on candidate's initial qualification). 
Practicum and internship is a particularly significant element of all teacher training and certification (CDC, Malaysia, 2007).

Similar to all teachers who teach in regular preschools run by the MOE, course modules for the training of regular preschool classroom teachers in integrated programmes place emphasis on early childhood education theories and practices. Teachers for the special education classrooms are selected from those teachers who have a teacher qualification in special education, or who already have experience teaching children with SEN in primary or secondary schools. There are no pre-service teacher education courses available for preschool special education. However, special education preschool teachers attend in-service professional courses on preschool special education and the implementation of the preschool special education curriculum from time to time (CDC, Malaysia, 2007).

Teaching and learning activities in regular preschool classrooms is guided by the National Standard Preschool Curriculum (NSPC). The special education classroom, on the other hand, uses an alternative curriculum document. At the time the research was conducted for this thesis, teaching and learning activities for preschoolers with learning disabilities were based on the Preschool Special Education Curriculum for Children with Learning Disabilities. This document, however, is a simplified version of the core strands and skills in the NSPC, designed specifically to better suit children with learning disabilities. Both sets of documents are developed by the CDC under the jurisdiction of the MOE.

\section{Educators and parents: key players in the education of children with SEN}

The preceding sections provided a snapshot of some of the important shifts and changes that have taken place at the systems level to improve access, making way for children with SEN to learn in regular educational settings and their subsequent opportunities for inclusion. UNESCO's (2005) guidelines on inclusion however, state that the incorporation of inclusion as a guiding principle requires not only important shifts and changes at the systems level, but at a societal level as well. 
This is relevant because educators and parents carry with them the values and norms that often exist within the wider school community. Consequently, the views that they hold and the roles that they play concerning the education of children with SEN are representative of the shift and change that is present at the societal level.

In the early nineteenth century communal attitudes towards disability in Malaysia were often based on superstitious belief; disability as a form of punishment from god, or a form of bad luck (Bosi, 2004; Haniz Ibrahim, 1998). Parents of children with SEN often kept their children at home, denying them education or social engagements due to guilt or embarrassment. In addition, parents often feared that their child would be ill treated and targeted as a form of societal amusement (Haniz Ibrahim, 1998; Haq, 2000). The public's lack of empathy towards people with disability could be attributed to their lack of knowledge about disability.

However, improved attitudes towards people with disability were seen, as more voluntary organisations and social services set up by family members, religious organisations and community groups began emerging. The first institution for the blind, the St Nicholas Home, was set up by Anglican Missionaries. This initiative was then followed by The Princess Elizabeth School for the Blind in 1948. In 1954, both academic and vocational training for the hearing impaired were offered through the Federated School for the Deaf (Haniz Ibrahim, 1998).

Development in the last two decades, however, has shifted in emphasis. Particularly, there is much awareness among the community itself about the importance of not segregating children with SEN from mainstream society. For example, despite efforts to provide the most appropriate educational services, special schools in Malaysia have been under attack (Sebestian, 1992). In particular, there has been disapproval from society, not so much for the services that these schools offer, but for what they represent. That is, a segregated service that represents the isolation of children with SEN from their peers and "which almost by definition provides an 
inadequate preparation for living in an integrated adult community" (Sebestian, 1992, p. 60).

There are also views that the current education system still focuses on the medical model as central to its service delivery structure (Adnan \& Hafiz, 2010). That is, a model that focuses on the child's 'deficits', arising from their disability (Terzi, 2008), when educational placement options are decided upon. As aforementioned in the chapter, children with SEN's placements in schools are based on their disability conditions (i.e., type and severity of disability). For example, only children with single disabilities are enrolled into special education services under the MOE, while services for children with multiple disabilities are taken care of by the DSW, clearly separating children with multiple disabilities from the chance to interact with a mainstream educational setting. While the cooperative efforts between these different government entities are unquestionably intended to help children with SEN gain access to and receive the best available services according to their needs (Adnan \& Hafiz, 2010), this way of providing services has been criticised as it is seen as segregating, discriminating against, and stigmatising children with SEN.

These criticisms are reflective of the societal change in attitude toward disability outlined above. Presently, parents have spoken with assurance and optimism to continuing advancements in services for their children, and especially those that emphasise inclusion. For example, an article in the newspaper recently published a parent as stating, "as a parent, I want my child (who has autism) to be included and accepted just like anyone else..." (The Star Online, 2008, April 24). A similar article in the newspaper featured a member of the public as stating, "we should work towards the setting up of integrated special education programmes in every school with a view to full inclusion as soon as the system is ready" (The Star Online, 2008, April 23). The Malaysian community has also been displaying more awareness of the need to speak up for children with SEN. In particular, there is a demand for allowing parents of children with SEN to have more room to choose the kind of education they want for their children, calling for more liberalisation in the education system (The Star Online, 2012, January 4). 
These views from the community (especially when published in a mainstream newspaper) show that there is more acceptance towards the education of children with SEN, and more pushing for advancement in the education of children with SEN. However, this acceptance is not unanimous. Negative views and resistance towards the education of children with SEN in regular schools is still prevalent in Malaysia. For example, the very article that spoke of the importance of setting up integrated schools with a vision for full inclusion above (The Star Online, 2008, April 23), also criticised the act of a group of parents in a particular urban regular school, who wrote to the press to protest the inception of a pilot special education programme in their children's school. These parents noted that children with SEN "should be put in special schools, out of the way of other children". This conflict of views suggests that there is a crucial need to address parents' perspectives to ensure successful inclusion.

The present education system in Malaysia, however, focuses largely on educators as the key players in achieving the MOE's educational goals. With relevance to integrated schooling, teachers are seen as the main workforce for driving the shift towards inclusion practices. Simultaneously, the principals are seen as the administrative leaders with a responsibility to ensure teachers' effective commitment towards this shift. Numerous international research has also indicated that the most important aspect of inclusion involves the educators at the centre of analysis (Ajuwon, 2008; Berry, 2010; de Boer, Pijl, \& Minnaert, 2010). Praisner (2003) argued that for inclusion to be successful, the principal must first and foremost, exhibit positive attitudes and commitment to inclusion. Berry (2011) on the other hand, argues that in responding to inclusion, regular education teachers are increasingly expected to provide effective instruction for children with SEN. This means regular education teachers may need to set individual goals, adapt teaching methods and curriculum content to cater for children with SEN (Abbott, 2006; Naicker, 2008). Ajuwon (2008), also commenting from this perspective, highlighted that not only must regular education teachers be prepared to teach a diverse group of students, it is crucial for regular and special education teachers to collaborate and plan effectively so that children with SEN will in fact benefit from 
their inclusion. This situation is especially relevant to the Malaysian context, where the collaborative efforts of regular and special education teachers are seen as the essence of inclusion.

Viewing my study from the numerous international perspectives stated above, it can be argued that the nature and extent of children's inclusive opportunities in integrated preschool programmes would depend critically on educators' and parents views about inclusion. Especially critical is the fact that inclusion is a school-based decision in Malaysia. Because of this, children with SEN may be in the regular school setting but if parents and especially educators hold unsupportive views about the implementation of inclusion, they (children with SEN) may have no opportunities to benefit from this practice. Clearly then, these individual's perspectives concerning inclusion must be addressed in order to ensure successful inclusion. To date there is also not much information showing the extent to which inclusion is prevalent in Malaysian integrated preschools, making it more challenging to gauge an understanding of educators' and parents' views or support for inclusion. Therefore, a necessary step for this study was to first examine the prevalence of inclusion in these settings.

\section{Chapter summary}

This thesis is interested in practices of inclusion in Malaysian integrated preschool programmes. Fundamental information regarding the Malaysian education system necessary for grasping an understanding of integrated schooling in Malaysia and its relevance to the practice of inclusion has been provided in this chapter. The brief discussion on how people's beliefs and practices concerning the education of children with SEN have evolved in the local context provides some insights as to why this thesis has sought to understand the state of inclusion in Malaysian integrated preschools, especially through the perspectives of educators and parents. Because the idea of integrated schooling and inclusion is still a fairly new venture at the preschool level in Malaysia, it is important to first determine the prevalence of inclusion in integrated preschool programme settings, and then to explore the views and supports of educators and parents of inclusion. 
The next chapter will look at the literature on inclusion in international and Malaysian contexts. It will first examine the basic constructs of inclusion, providing insights to how inclusion is interpreted in various contexts and settings. This is followed by a review of empirical research on how the state of inclusion is determined. Finally the literature relevant to educators' and parents' perceptions of inclusion is examined, and the varying factors that can influence inclusion are determined. 


\section{CHAPTER 3 \\ -Literature Review- \\ Inclusion: The Nature, Extent and Perceptions of it}

\section{Introduction}

This study examines the nature and extent of inclusion and perceptions of inclusion in Malaysian integrated preschool programmes. Whilst establishing how much, if any, inclusion is occurring in these preschools, the study also aims to examine educators' and parents' perceptions of inclusion, subsequently offering insights into the factors that may be influencing the implementation of inclusion in these programmes.

A large body of literature on inclusive schooling within international and national contexts provided a basis for this study. Since the idea of educating children with SEN in regular preschools is a new phenomenon in Malaysia, I decided early in my study that the prevalence of inclusion in these settings be established first, before examining educators' and parents' perceptions of inclusion. Therefore, the initial section of this chapter identifies the basic constructs of inclusion that offer insights for determining the nature and extent of inclusion. This section is followed by a review of empirical studies that have established the state of inclusion in the field. Next, literature relevant to perceptions of inclusion and factors influencing inclusion is examined.

However, before presenting the examination of literature relevant to the present study, it is appropriate that certain caveats are stated. Firstly, this study investigates inclusion in public integrated preschool programmes, serving children with learning disabilities and typically developing children who are between four plus and six years of age. As discussed in the previous chapter, public integrated preschool programmes in Malaysia are located in primary school compounds, sharing the same administrative and organisational structures as any other primary or secondary integrated programmes in Malaysia. Hence, the integrated 
preschool programmes can have comparable predicaments, challenges, or support concerning issues of inclusive education as the primary or secondary school integrated programmes. Therefore, in examining the present literature, it was decided that the scope of the review should not be limited to inclusion at the preschool level, and instead include relevant issues that are significant to this study regardless of whether the focus of a particular study is on preschool, primary or secondary school contexts.

I acknowledge that there is extensive research on inclusion and the involvement of educators and parent in inclusive and integrated school settings. Within that body of research, however, studies focusing explicitly on key influences on the ways in which inclusion is implemented and how people perceive it are comparatively rare (if significant). The use of, and understanding of the rarity of these studies, informs the positioning of this thesis, and allows me to locate this study within a range of previous studies, whilst also evaluating its potential contribution to existing literature. Furthermore, the exploration of related research in different contexts and settings allowed identification of the various approaches used by other researchers when exploring inclusion. Such information provided the means for informing and directing the design and analysis of this thesis.

\section{Inclusion}

In a broad sense, the concept of inclusion has been viewed as the basic right for all individuals to participate in and contribute to society regardless of their differences or disability (Bryant, Smith, \& Bryant, 2008; Mitchell, 2005; Rouse \& Florian, 1997; Winter, 2007). Within the field of education, inclusion or inclusive education has primarily focused on the education of children with SEN in regular schools, or in classrooms in the hope of increasing opportunities for shared participation and involvement among children with and without SEN on a regular basis (Rea, McLaughlin, \& Walter-Thomas, 2002; Winter, 2007).

Despite the current importance placed on inclusion in education (Mastropieri \& Scruggs, 2005; Petriwskyj, 2010), there remain numerous practical inconsistencies 
in the field (Odom, 2000; Wearmouth, Berryman, \& Glynn, 2009). The argument as to what amounts to inclusion is ongoing, with the majority of schools carrying out inclusion in their own unique way, adapting and accommodating it to the needs of their individual students and communities (Carrington, 2006; Inos \& Quigley, 1995; Refice, 2006). Part of the difficulty is due to the construct of inclusion, something continuously being shaped by social thoughts, changing policies, expert recommendations, and research (Winter, 2007).

Interpretations of inclusion have shifted in current times, ranging from being identified as a rights-based issue (UNESCO, 2005), a continuum of services (Von der Embse, Brown, \& Fortain, 2011) and strategies for accommodating SEN (Cook, Klein, \& Tessier, 2008), to those that interpret it as a process for reducing possible sources of exclusion (Booth, 1999). Taking into account the existence of a range of different interpretations, three trends in the literature are influential in developing an understanding of inclusion for informing the inquiry of my study, namely: the conceptualisation of inclusion in terms of a provision, a process, and an organisational culture. These three trends are presented in the following section, and the implications that each has on the nature and extent of inclusion are briefly discussed.

\section{Inclusion: A 'provision'}

A number of commentators in the field have interpreted inclusion in terms of provision (Von der Embse et al., 2011; Cook, 2001). Interpretations of inclusion in terms of provision provide significant information about the different types of opportunities adopted by regular schools to integrate children with SEN (Peters, 2004). The prevailing view here is often viewed as being similar to the concept of 'least restrictive environment' (LRE) (Von der Embse et al., 2011); a concept that promotes the education of children with SEN in an environment that is as close as possible to that of where typically developing children are educated (Thomas \& Webb, 1997). Ideally this 'environment' is the regular education classroom (Von der Embse et al., 2011). However, that is not always the case (Taylor, 2004). 
Researchers have described a range of service delivery models or settings that regular schools adopt to implement inclusion to the greatest possible extent (e.g., Guralnick, 2001; Heiman, 2004). The definitions and descriptions of services vary from researcher to researcher (Zigmond, 2003), and thus it is difficult to include all of them in this review. However, the general impression is that some schools have improved access, carrying out full inclusion, offering children with and without SEN maximum opportunities for shared participation and involvement in daily school experiences. Other schools however, carry out integration (Abbott, 2006), or incorporate pull-out (Vaughn, Bos, \& Schumm, 2007) or withdrawal service delivery models (Guralnick, 2001).

In full inclusion settings children with SEN are full time members of the regular classroom community (Refice, 2006). According to Refice (2006) regular classroom teachers are primarily responsible for the learning of children with and without SEN in full inclusion settings. On the other hand, in other optional service delivery models, such as integration or pull-out programmes, children with SEN are members of special education classrooms, and are included into regular classrooms on a part or full time basis. Both regular and special education teachers are in charge of students with SEN's learning (Refice, 2006).

One of the earliest models shaping the latter approach is described in the Warnock Report (1978) by the Committee of Enquiry into the Education of Handicapped Children and Young People. This report documented a detailed framework of the enquiry into the education of individuals with SEN in England at that time. Warnock (1978) detailed the three main forms of integration, locational, social and functional integration in regular educational settings:

(i) Locational integration is when special units or classes are set up in regular schools, or when special and regular schools share the same site;

(ii) Social integration is when children from the regular and special education classrooms or units share social places. They eat, play and consort with each other, or share organised outdoor activities together; 
(iii) Functional integration (the fullest form of integration) takes place when the locational and social association of children leads to shared participation of children with and without SEN in educational programmes. They are educated together, sharing the same set of goals and activities.

According to Warnock (1978), functional integration, which is the closest form of association between children with and without SEN, enables children with SEN to be included, part-time or full-time into regular classrooms in the school. Whilst the overall views in Warnock's framework have been used as the basis for offering positive social and educational opportunities for children with SEN in regular educational settings (House of Commons Education and Skills Committee, 2006), the framework has had its own share of critiques in recent years. According to Baldock, Fitzgerald and Kay (2009) critiques of the Warnock framework, including one by Warnock (2005) herself are focused primarily on the basis that this framework is no longer relevant to convene the needs of children with SEN in the present time. As they write, among "key factors under debate are the impact of inclusion on special schools closures, changed concepts of SEN now increasingly focused on social aspects of disability, and the impact of increased numbers of children with SEN in mainstream schools" (Baldock et al., 2009, p. 63).

However, Warnock's model above is certainly relevant to the enquiry of this thesis. More specifically, in Malaysia, integration is seen as the first step towards inclusion. Although educated in regular schools, children with SEN are placed in separate special education classrooms (MOE, Malaysia 2004). Only if the child with SEN can function independently without much help, and does not have behavioural conditions that cause disruptions to mainstream learning will they be included part or full time into regular classrooms. Otherwise, inclusion is limited to social integration of children with and without SEN in daily activities outside the regular classroom setting. 
In short, interpretations of inclusion as a provision generally refer to the placement of children with SEN to educational purposes. The discussion in this section clearly indicates that different types of service delivery models or placement options adopted by the school can have significant influences on the nature and extent of inclusion that takes place. On another note however, some researchers argue viewing inclusion in terms of where children with SEN receive their education is too limiting a definition (Maher, 2007; Tutt, 2007), since it only provides one small dimension of inclusiveness (Friend, 2005). Pijl (2007) argues that although physical integration of children with SEN in regular school environments can be an "important first step" (p. 2), the focus is simply to ensure that children with SEN are "just being there" (p. 2). Also commenting from the same perspective, Von der Embse and colleagues (2011) argue that interpreting inclusion from a provision or placement perspective gets at only one way to measure inclusion, which is limited in the information it can provide; the information is quantitative, examining the duration that a child with SEN spends in regular educational settings (e.g., part time/ full time).

\section{Inclusion: A 'process'}

Apart from (or as well as) regarding inclusion as provision, some researchers look at inclusion as a process (Booth, 1999; de Boer, Pijil, \& Minnaert, 2010; Wilde \& Avramidis, 2011). Berry (2006), for example, argues that access to physical space in regular schools alone does not guarantee that calls for educational inclusion are answered. Rather "what is going on" in that space is what makes the difference (Zigmond, 2003, p. 198).

This way of conceptualising inclusion takes on a broader perspective than the provision approach, in that the emphasis is placed on how instructional strategies and ongoing initiatives in the school are aimed towards reducing the barriers to inclusion. Describing it as two linked processes - inclusion and exclusion, Booth's (1999) interpretation of inclusion provides a clear idea of this concept. Booth describes inclusion as a process for "increasing the participation of learners in and reducing their exclusion from the curricula, cultures, and communities" of 
mainstream schools (p. 164). According to Booth this way of looking at inclusion places emphasis on the reality of exclusionary pressures in education, and the need to identify and counter them if the participation of learners with SEN is to be increased in regular educational settings. More importantly, however, this way of looking at inclusion recognises that a child with SEN can physically be in a regular school, but may have no opportunities for inclusion if they are excluded from curriculum, peers, and other ordinary experiences that allow full or fair access to the everyday happenings of the school. In short, as Booth argues, researchers and policy makers need to pay equal attention to finding ways to reduce situations of exclusion that arise even when children with SEN are able to be present in regular schools to enhance inclusion.

The core principle in regarding inclusion as a process has "the needs of the children at heart", ensuring that the physical and social environment, instructional strategies, and support systems are accommodating to the needs of all children, with and without SEN (Swain \& Cook, 2001, p. 185). Value is placed on implementing conditions that foster meaningful inclusion, and most importantly inclusion of good quality. Thus critical to this study is the idea that inclusion is not just about ensuring the physical presence of children with SEN in regular school settings. Children with SEN, even in regular school settings, may have no opportunities for inclusion if teachers do not initiate practices that facilitate it, particularly fostering meaningful participation among children with and without SEN in academically or at least socially integrated activities.

\section{Inclusion: An 'organisational culture'}

As well as regarding inclusion as a provision or a process, other commentators in the field have taken up the term inclusion and applied it in direct relation to a culture of acceptance (Carrington, 2006; Gilles \& Carrington, 2004). Gilles and Carrington (2004) for example, synthesise alternative perspectives on inclusion and conclude that inclusion is about "listening to the voices in a school community ... Above all, it is about a philosophy of acceptance where all people are valued and treated with respect" (p. 117). 
Exemplifying this approach, Reid (2005) argues that "if the culture and climate are not inclusion-friendly then the outcome, irrespective of policies or indeed practices, may not be successful" (p. 100). In addition, Whyte (2005) points to the relationship between culture and beliefs, asserting that the "school culture is one of the most complex concepts in education because at its core is the deeper level of shared basic assumptions and beliefs that operate unconsciously as the accepted way things are done" (p. 120). Consequently, interpretations of inclusion that focus on organisational culture are often made based on the underlying belief system that directs the inclusive decisions in the school. Friend's (2005) definition of inclusion puts this idea in clear terms; “....inclusion is a belief system shared by every member of a school as a learning community - teachers, administrators, other staff members, students, and parents - about the responsibility of educating all students so that they reach their potential" (p. 20).

Kearney (2009), however, argues that there are two levels in which inclusive cultures can exist within the context of the school, "some of which can be observed (for example language, rituals, symbols, and customs) and some of which are not visible and deeply embedded within organisations (e.g., values, norms and beliefs, and taken for granted assumptions)" (p. 45). The latter category, unlike knowledge or skills (which are more inclined to be impersonal), includes people's emotions, attitudes, opinions, prejudices and judgements and thus, can have significant effects on their behaviour and actions about inclusion (Lefrancois, 1997).

In short, interpretation of inclusion from this perspective (organisational culture) has a fundamentally different approach from the earlier two conceptualisations (i.e., provision and process). It refers not only to the actions or processes taking place in the immediate school setting (micro level) but takes on a new dimension in addition, looking at broader or macro level discourses that may be shaping the actions and processes that are taking place in the school. The central focus in this concept is the ethos or social climate of the school. On an interpersonal level, interpretations of inclusion from this perspective suggest that teachers' practices of 
inclusion may be affected not by their own efforts (Berry, 2011), but also by the school's philosophical perspective concerning inclusion (Gilles \& Carrington, 2004). Unless there is a whole-school approach to foster inclusion, "involving teachers, heads, students and parents" (Abbott, 2006, p. 631) inclusive practices may be a continuous challenge for the teachers. For example, if parents of typically developing children have negative attitudes towards disability or inclusion, it may affect the decisions that school principals and teachers make about inclusive practices in the school.

In summation, this section has discussed three prominent interpretations of inclusion in the literature that addresses it (provision, processes and organisational culture). Frameworks from each of these perspectives can be useful in providing an overarching basis for examining the nature and extent of inclusion. In particular, this thesis is invested in examining whether the current situation of educating children with SEN in Malaysian integrated preschool programmes is limited to just provision (i.e., children with SEN gaining access to regular educational environments as a basic condition for inclusion) or whether it has progressed further, supported by relevant processes that shape quality learning environments, and a philosophy of inclusion in the school.

\section{Nature and extent of inclusion}

As I have discussed in previous sections, the main aim of this study is to explore educators' and parents' perceptions of inclusion in the context of Malaysian integrated preschool programmes, as well as factors that may be contributing towards their thinking and practices in relation to inclusion. However, in order to begin this exploration, it is essential to first establish the current state of inclusion in these settings, as a basis upon which to build further understanding of issues, supports or challenges concerning inclusion. This section examines the information drawn from current literature on the different ways in which researchers have established the prevalence of inclusion in various contexts and settings, subsequently informing and directing a suitable approach to be used in this study. 
A study by Wills and Jackson (2001) investigated the nature and extent of inclusion in Australia. These researchers believed that information on the nation's state of inclusion was imperative to understanding where Australia stood in terms of promoting an inclusive society. It aimed to identify areas needing further attention, and to locate the areas that programme funders and developers should be encouraged to attend to more rigorously to encourage inclusive education. These researchers assigned ratings (in the form of 'grades') to each school in their Report Card on Inclusive Education in Australia, the tallying of which were based on the Education for All themes (particularly in relation to the Jomtien Conventions and Salamanca Statements) and other critical attributes of inclusive education attained from previous study. Among the 10 items that were included in the report card were physical inclusion, social inclusion, curricular inclusion, physical access, and participation. Items were to be rated based on criteria set out under different grades ranging from ' $A$ ' to ' $F$ '. The criteria for the grades are defined and represented with scores. For example, A is the criteria for highest quality and the corresponding score is 5. Raters included parents of children with SEN, teachers, principals, education officials and academics from different states in Australia. The study's findings indicated that while the 'grades' given for physical inclusion, social inclusion and curricular inclusion of children with SEN varied from school to school, all over the country they were generally at low levels.

Similar to the study by Wills and Jackson (2001) that used rating scale descriptors to understand the extent of inclusion in Australian schools, the Education Review Office (ERO) in New Zealand used a set of performance indicators to evaluate the extent of inclusion involving children with high SEN in primary and secondary schools in this country (ERO, 2010). The indicators, which were developed based on three dimensions: presence, participation and engagement, and achievement were used primarily for guiding the review officers' judgments about the extent of inclusive practices in the schools. Information was gathered to identify how well schools included students with high needs; the existing issues and challenges in enrolling and supporting the inclusion of these students; and if any exemplars of 
good practices existed with regard to including students with high needs. The core information for the study was gathered through quantitative and qualitative approaches, using interviews, documentary evidence, and questionnaires. Findings were reported from three groups of schools: schools with mostly inclusive practices, schools with some inclusive practices, and schools with few inclusive practices. The types of challenges and good practices in implementing inclusion were then reported based on the different groups of schools. In terms of this thesis, this way of reporting the extent of inclusion proved rather useful and relevant. Particularly, it suggests that initial identification of preschools that are more or less inclusive is a good way of selecting suitable centres for detailed examination of a diversity of challenges.

Two studies in Malaysia - one carried out by Ayob, See, and Selamat (2008), and the other by Muhammad and Wan Mahmud (2010) - that explored the implementation and effectiveness of inclusion reported contradictory results. Ayob, See, and Selamat (2008) employed quantitative and qualitative methods through questionnaires, interviews, and observations to examine the implementation and effectiveness of inclusive education in integrated primary and secondary schools. The school principals, regular teachers, special education teachers, and parents of children with learning disabilities were all included as study participants. Data collection in the quantitative phase involved the posting of 1,982 questionnaires to all 560 integrated primary and secondary integrated schools listed under the Special Education Division. The questionnaires in this study were set accordingly to suit the different roles of the participants, but generally they were aimed at gaining an overall view of the quality of education in integrated settings, including the level of social integration and inclusion that was taking place from all individuals involved. In addition, the questionnaire aimed to determine educators' and parents' perspectives about the education of children with SEN in regular school settings. Qualitative data collection was also carried out in 49 randomly selected schools, and took place concurrently with the quantitative phase. In-depth data was obtained through structured interviews with special education teachers, field notes and observational checklists to examine, among other things, how the daily on- 
goings of the schools, and the environmental adaptations and teaching and learning activities supported the education of children with learning disabilities in integrated settings. Overall findings showed that only four (8.2\%) schools carried out inclusion. The majority (91.8\%) of schools practiced only locational integration with no evidence to support academic integration; however, social integration was reported to be taking place on an occasional basis.

On the other hand, Muhammad and Wan Mahmud (2010) used a case study approach to examine the inclusion of eight children with autism in an integrated primary school in Kuala Lumpur. The study also aimed to identify the extent of collaboration between regular and special education teachers in carrying out inclusion, and classroom practices during inclusive lessons. The selected school was part of a pilot project to fully include children with autism who had initially received support and educational services from the National Autism Society of Malaysia (NASOM). Data collection involved semi-structured interviews with the school principal, subject teachers, resource teachers (from NASOM) who assisted the children's special educational needs in regular classrooms, and the coordinator of the special education programme of the school. A comprehensive observational checklist was also used for collection of information. Observations primarily covered three aspects: the physical environment of the regular classroom, teaching and learning activities in the classroom, and social and communication features in the classroom. Findings were distinct from the one carried out by Ayob and colleagues (2008) above, showing that full inclusion was indeed taking place in the school. All eight children with autism from NASOM who were included into regular classrooms in the case study school coped well socially and academically, and were able to independently adapt themselves to regular classroom learning even when resource teachers were absent.

Nevertheless, whilst the findings from Muhammad and Wan Mahmud's (2010) study showed that full inclusion was taking place, it represented data that was obtained from one primary school in Malaysia only. On the other hand, the earlier study by Ayob and colleagues (2008) covered data that was obtained from primary 
and secondary integrated schools nationwide. In addition, qualitative methods were employed to verify information gained from the quantitative phase in this study. Therefore, the approach taken in Ayob and colleague's (2008) study clearly provided more extensive evidence compared to the latter study for supporting wide-spread information about the existing situation of inclusion in the country.

A number of researchers and organizations have also developed Program Quality Indicators (PQI) to identify most promising practices in educational services for children with SEN (Cushing, Carter, Clark, Wallis, \& Kennedy, 2009; Eichinger, Meyer, \& D’Aquanni, 1996; New York State Education Department [NYSED], 2001). Cushing and colleagues (2009), for example, developed the Program Quality Measurement Tool (PQMT) to enable administrators and educators to evaluate the services provided to students with severe disabilities against best practice indicators in school districts in Tennessee. It was designed to reflect the recommended practices for students with SEN according to "the Individuals with Disabilities Education Improvement Act (e.g., promoting access to general education curriculum, participation in statewide assessments)" (p. 197). Although the instrument scoring was straightforward and the result for the PMQT showed interobserver agreement of acceptable levels, test-retest reliability, internal consistency, congruent and discriminative validity for the PMQT, the items in this tool were too complex to be adapted to the Malaysian context.

Another PQI - The Autism Program Quality Indicators (APQI) - authored by Crimmins, Durand, Theurer-Kaufman and Everett for the New York State Autism Network (NYSED, 2001) better fits the requirements of the Malaysian context. The APQI is a self-review tool concerning quality improvement for programmes serving children with autism spectrum disorders, and identifies inclusion as one of the 14 areas that are most important for educating children with autism. Under the APQI, there are four items that come under the inclusion heading, all of which are straightforward and well suited the initial aim of this study: to establish the prevalence of inclusion. The rating scales are designed specifically to identify the amount of evidence supporting a particular indicator (item), ranging from 0 (no 
evidence) to 3 (clearly evident), enabling the scores for each item to be added based on the evidence available, making it possible to easily identify centres that obtain the highest or lowest score.

The APQI has no previous research application in academic literature. However, it has served as a means of guiding quality improvement for schools and programmes serving children with autism between the ages of three and 21 in New York State, which suggest that it has been perceived as a useful tool in the field. In addition, since the APQI is intended as a tool for schools or programmes to self-evaluate their educational services "as a whole rather than an evaluation of services provided to any specific child" (p. 7), the tool makes it possible for individual schools to selfreport the extent to which there is evidence supporting inclusion in their setting.

Furthermore, the items and scale dimensions in the APQI underwent significant development processes before being finalised, and the extensive processes they underwent in being constructed (as well as the contexts, in which it is being implemented) suggest that this APQI is a potentially reliable tool. The criteria were initially developed based on information gathered from multiple sources including "federal and State law and regulations, scientific evidence, and professional experience" (p. 8). A preliminary draft of the APQI was also field tested with the New York Autism Network regional advisory groups. The working draft of the APQI derived from the compilation of information gathered from advisory groups, and subsequent interim drafts were shared for comments with national experts in the field and staff from Vocational and Educational Services for Individuals with Disabilities before it was finalised.

Another tool that has been recognised in the literature as a useful resource for reviewing and building on inclusive schooling is the Index for Inclusion (Booth \& Ainscow, 2002; Booth, Ainscow, Black-Hawkins, Vaughan, \& Shaw, 2000; Booth, Ainscow, \& Kingston, 2006). The initial Index for Inclusion (Booth et al., 2000) was developed in the United Kingdom. It is a compilation of events and situations that is designed to guide schools in reviewing and developing inclusive schooling on three 
dimensions: school culture, policy and practice (Booth et al., 2000). Indicators in each dimension of the Index "represent statements of aspiration against which existing arrangements can be compared in order to set priorities for development" (Booth et al., 2000, p. 11). The use of the Index in inclusive schooling is well documented (Carrington \& Holm, 2005; Carrington \& Robinson, 2004; Deppeler \& Harvey, 2004; Hick, 2005). Carrington and Holm (2005) used the Index as a guide in their study of inclusive schooling in an Australian secondary school. Participatory Action Research methods were employed in which the Index was used as a tool to engage students in conversations about issues pertaining to inclusion and exclusion, aiming towards an action for change. Focus group interviews were also carried out with the school principal, and parent and teacher representatives to find out their views on the students' presentations of issues, as well as ideas for recommended actions. The school culture and processes that supported it indicated that the school was developing well towards an inclusive view of student diversity.

More recent versions of this index have also been developed. Booth, Ainscow, and Kingston (2006) developed a similar version of the earlier Index as a substantial resource for supporting and building on next steps for inclusion in early years schooling and childcare. The Index includes various aspects to be assessed from the (pre)school's/centre's point of view, encouraging thoughtful reflections about how 'inclusive' the setting is, and how to work on promoting successful inclusion. Among the aspects to be assessed by schools include the extent to which barriers to play, learning and participation are identified and addressed; whether diversity is recognised and supported; and if discrimination is minimised while emphasis is placed on positive behaviour and inclusive values. According to Maher (2007) several other elements in the version of Index published in 2002 (by Booth and Ainscow) are very similar to parts of the criteria used for school inspection in the UK. These elements include students' schooling experiences; opportunities for effective learning, students' access to all aspects of the curriculum, and whether everyone feels happy at school. 
The use of the Index in research permits different groups of people to participate (e.g., teachers, students, parents/carers, staff). Hence, it makes a useful contribution by providing opportunities for every member involved with the school to have their say about inclusion and the processes that support it. It potentially offers substantial understanding of the wider contextual issues that may be affecting practices of inclusion in the school. However, the Index for Inclusion is primarily aimed towards facilitating change in the school culture, policy and teaching practice, reflected through action research cycles described in the Index (Carrington \& Holm, 2005; Carrington \& Robinson, 2004). The collection and reporting of data "informs cycles of review, development and data collection" (Carrington \& Holm, 2005, p. 4). Therefore, at this stage, the use of the index as a research tool was not wholly pertinent to the study this thesis undertakes, but would be very relevant for future research once more is known about the inclusive situation in the preschools assessed here.

Collectively, the review in this section indicates that the information on the nature and extent of inclusion is important for building upon further understanding of other issues pertinent to inclusive education. Two studies that addressed this information and its relevant issues within Malaysia were located and examined in this section. However, both studies were carried out in primary and secondary schools, respectively. There is not much information to be found in the area of preschool education in Malaysia. Nevertheless, the different studies reviewed here suggest that a number of different approaches can be used to examine the amount of inclusion taking place in the preschools. To gain a broader perspective of inclusion, surveys seemed to be a commonly used method by researchers. However, interviews and observations in selected settings appeared to be pivotal for establishing exhaustive details to support the state of inclusion specific to the purposes of a study. Since little is known about the amount of inclusion taking place in Malaysian integrated preschool programmes or educators' and parents' perceptions of it, a good first step for determining the prevalence of inclusion in my study may therefore be a survey. In addition to this step (and as suggested in the literature reviewed), follow up observations in the preschools and interviews with 
educators and parents may provide essential information relevant to the nature and extent of inclusion in these settings.

\section{Perceptions of inclusion}

Hinkson and Kieth (2000) describe perceptions as "an individual's current appraisal of an object, or program, as experienced in the immediate situation" (p. 180). According to Robbins, Millett, Cacioppe and Waters-Marsh (1998) perceptions can be influenced by factors that reside in the perceiver, in the object that is being perceived, or in the setting or circumstances in which the perception is made. Robbins and colleagues (1998) argue that people's attitudes, motives, interests, past experiences and expectations are the most relevant personal characteristics that influence their perceptions.

The literature in education provides strong support for the fact that a wide range of perspectives and personal characteristics have been consistently linked to educators' and parents' perceptions of inclusion, such as their attitudes, opinions, support, thoughts and feelings (e.g., Abbott, 2006; Chhabra, Srivastava, \& Srivastava, 2010; Garrick-Duhaney \& Salend, 2000; Narumanchi \& Bhargava, 2011). Such characteristics have also been identified to influence and impinge on a school's decision to implement inclusion (Friend, 2005; Odom et al., 2004; Vaughn, Bos, \& Schumm, 2007). In reviewing the literature relevant to educators' and parents' perceptions of inclusion, studies that addressed one or more of the above characteristics are presented in the following. 


\section{Teachers' perceptions}

As more children with SEN are being included in regular school environments, there has been increased interest in the perceptions of teachers who work in inclusive settings. Research has been carried out in most parts of the world on the underlying assumption that teachers' beliefs, attitudes, views, acceptance, and concerns may contribute significantly towards facilitating or impeding the implementation of inclusive education (Avramidis \& Norwich, 2002; Horne \& Timmons, 2009).

To gain a wide-spread idea of how large numbers of teachers view the concept of inclusion, Chhabra, Srivastava and Srivastava (2010) surveyed 200 senior and community junior secondary mainstream school teachers in five districts in Botswana, determining their attitudes and concerns towards inclusion. A threepart questionnaire, consisting of demographic details, the Attitudes towards Inclusive Education Scale (ATIES) developed by Wilczenski (1992), and the Concerns Inclusive Education Scale (CIES) developed by Sharma and Desai (2002) was used. The findings showed that participants generally held fairly negative attitudes towards inclusion. However, these negative attitudes were limited to learners who had hearing difficulty and those who were not well versed with Braille. Teachers also had reservations about including those who required individualised or modified programmes, and those students who displayed behavioural difficulties. More favourable attitudes however, were displayed towards learners with language disorders rather than those with physical disabilities.

Similar to the study by Chhabra and colleagues above, other studies have also suggested that the types or severity of disability affect teachers' perceptions of inclusion. Obeng (2007) surveyed a sample of 400 primary and junior secondary school teachers in Ghana to examine their views about teaching children with SEN in regular classrooms. Findings showed that teachers "had great love for all their students" (p. 101), however, they were not happy to have children with SEN, especially those with hyperactive behaviour in their classroom. Also within the 
Ghanaian context, Agbenyega (2007) examined teachers' attitudes and concerns toward inclusion. One hundred primary school teachers from five inclusive and five non-inclusive schools completed the 20 item Attitudes Toward Inclusion in Africa Scale (ATIAS). This study was combined with a qualitative phase, where teachers who agreed were later called for an interview to obtain a comprehensive understanding of their perceptions about inclusion and other issues associated with it. The researcher stated that the "qualitative findings provided a rich description of teachers' perceptions and attitudes toward inclusion" (p. 51). Teachers were able to talk about their concerns, their level of expertise and the types of support services available with regard to inclusion in their schools during the interviews. Findings in this study confirmed Obeng's (2007) report that children's conditions of SEN affected teachers' views about inclusion, revealing that teachers preferred that students with SEN, particularly those with sensory impairments, be educated in special schools.

In addition, survey findings in Agbenyega's study above also demonstrated that teachers from both inclusive and non-inclusive schools demonstrated high levels of concerns and negative attitudes toward multiple issues concerning inclusion, including insufficiency of resources and materials, improper infrastructure in the school, and teachers' lack of competencies to support students with SEN in inclusive classrooms. It is however particularly worth noting here that although findings in both these Ghanaian studies (Obeng's and Agbenyega's) demonstrated similarities in terms of the overall negative attitudes that teachers held toward inclusion, the interviews carried out in Agbenyega's study yielded specific details that provided clear understandings of why teachers held such attitudes and therefore further validated the information obtained from the survey. Interview findings revealed that the teachers in this study believed that the inclusion of students' with SEN into regular classrooms limited teachers' teaching endeavours, delayed teachers' attempts to complete the syllabus, and affected the academic performance of typically developing students. Additionally, these teachers perceived themselves as lacking the needed knowledge and skills to teach children with SEN and feared that this inadequacy would contribute towards a reduction in 
the overall academic achievement of their classrooms. The information gained from this study (Agbenyega's) indicates that the use of both questionnaires and interviews offers in-depth understanding of teachers' perceptions of inclusion, subsequently suggesting that the use of these methods as data gathering instruments was a necessary consideration for the study undertaken by this thesis.

Studies that examined teachers' perceptions of inclusion within the Malaysian context also appeared to reflect upon a number of issues that affect teachers' attitudes concerning inclusion in primary and secondary schools. For example Bosi (2004), in reviewing Malaysian primary school teachers' attitudes toward inclusion, emphasised that most teachers tend to hold negative attitudes toward inclusion, and do not want to include children with SEN in their classrooms, because of problems that arise from their lack of understanding of the inclusive education policy. Abdullah (2000) on the other hand, stated that the majority of secondary school teachers who were involved in her survey of teachers' attitudes believed that inclusion was a noble effort by the Ministry of Education to integrate children with SEN into the regular education system. However, these teachers reported that their reluctance to carry out inclusion was primarily due to the lack of clear guidance and guidelines by the Ministry of Education on the implementation of inclusion, as well as relevant special education courses for regular teachers, and an available specialist in areas of disabilities for teachers to be able to refer to for advice and guidance on SEN.

The different ways in which teachers perceive inclusion has also been found to be strongly associated with whether or not they have had experiences of teaching in inclusive settings and children with SEN. Kalyva, Gojkovic and Tsakiris (2007) used teachers' experience in teaching children with SEN as a basis to identify teachers' attitudes toward inclusion in their study. These researchers surveyed a sample of 72 teachers from 12 inner city primary schools in Serbia. Out of the 72 teachers who completed the My Thinking about Inclusion Questionnaire developed by Stoiber, Goettinger and Goetz (1998), 35 of them were those with prior experience in teaching children with SEN, whereas the other 37 were teachers who had never 
taught children with SEN. The participants were asked to indicate their degree of acceptance on a five point Likert scale; ranging from '1-Strongly Accept' to '5Strongly Reject'. The questionnaire was primarily aimed at assessing teachers' agreement about the entitlement of children with SEN to receive education in regular classrooms with their typically developing peers, expected outcomes of inclusion, and how inclusion influenced classroom circumstances and teaching practices. The overall findings confirmed the hypothesis of the study: that teachers in Serbia generally held slightly negative attitudes towards inclusion. However, in addition, findings also showed that teachers who had no experience teaching children with SEN had negative attitudes towards inclusion, irrespective of their years of teaching experience, compared to those who had taught children with SEN, and who typically held more positive attitudes.

Avramidis, Bayliss and Burden (2000) reported similar findings with regard to teachers' teaching experiences in inclusive settings and children with SEN. Avramidis and colleagues surveyed 81 primary and secondary school teachers' attitudes toward inclusion in one Local Educational Authority in the United Kingdom, and found that teachers with experience in implementing inclusive programmes had more positive attitudes than the rest of the survey participants, who had little or no such experience. However, Idol (2006) asserts that although teachers with experience of teaching children with SEN or teaching in inclusive classrooms may be positive about educating children with SEN in regular schools settings, teachers in general often indicate that they lack the knowledge, skills and training that they consider are needed to provide effective and appropriate education for all students in inclusive settings. Additionally, Leatherman and Niemeyer (2005) argue that it may not be teachers' previous experiences per se that determine their positive attitudes toward inclusion, but rather the nature of the experiences (i.e., positive or negative).

Also relevant to teachers' experiences, an early study in Malaysia by Mohd Daud (1992) examined teachers' views and support concerning the inclusion of four visually impaired students in a secondary school. Findings showed that senior 
regular education teachers, with more than 18 years of teaching experience, did not support inclusion in their schools. These teachers held uncompromising negative attitudes towards inclusion, arguing that they had no knowledge or training in special education and thus, were not happy to teach students with SEN. On the other hand, senior regular education teachers with some form of training in special education or inclusion were more positive about inclusion. Mohd Daud (1992) concluded that knowledge and experience must go hand in hand in ensuring positive attitudes towards inclusion and the successful implementation of this practice.

Teachers' perceptions have also been examined to reflect upon preferred inclusive placements and instructional practices for diverse learners. Heiman (2004), for example, used questionnaires to examine and compare 140 British and 116 Israeli regular education middle school teachers' perceptions, expectations and needs about inclusive processes in the United Kingdom and Israel. The questionnaires consisted of seven open ended questions concerning theoretical concepts of inclusion, the advantages and disadvantages of ideal models of inclusion, and the present state of teachers' classrooms. Findings showed that the majority of teachers from both countries indicated support for inclusion. However, their definitions of inclusive processes were reported to be pragmatic and judgemental, with positive, negative, mixed and neutral responses. Israeli teachers expressed more negative feelings about inclusive processes compared to British teachers, stating that they felt ill prepared and lacking in sufficient skills to cope with the diverse needs of children with SEN. In addition, findings also demonstrated that despite expressing their support for inclusion, teachers in both countries showed preference towards an in-and-out (partial inclusion) model and believed that this was the most appropriate approach to carrying out inclusive practices as it enabled learners with SEN to benefit from both worlds. In this model, supporters argued, learners with SEN not only received the special instruction they needed, but also had opportunities for interaction with their peers in regular settings. 


\section{Comparing regular and special education teachers' perceptions}

The review so far has revealed that much emphasis has been placed on regular education teachers' perceptions of inclusion, and that these perceptions can vary in different contexts and settings. A further review on teachers' perceptions of inclusion, however, shows that regular and special education teachers' perceptions concerning inclusion and its relevant issues often differ. A key finding in most studies focused on comparison between perceptions of inclusion held by regular and special education teachers is often that special education teachers generally hold more positive attitudes and views concerning inclusion than regular education teachers. Buell, Hallam, Gamel-McCormick and Scheer (1999) for example, compared the views of regular and special education teachers working in inclusive school settings by highlighting the results of a state-wide needs assessment in the United States. This study covered a large group of teachers in one state's Department of Education. Four percent of the state's regular education teachers and $6 \%$ of the state's special education teachers, who taught all levels; elementary, secondary, preschool and birth to 3-year-old, were involved in a survey. A total of 289 participants took part in a 25-item Likert-type scale survey with some further yes/no and open-ended questions. The survey questions primarily addressed teachers' perceptions of the types of programmatic support required for successful inclusion, teachers' confidence concerning student success in inclusive settings, and teachers' in-service needs with regard to inclusive education. Overall findings indicated that special education teachers were more confident and prepared to include students with SEN in regular classroom settings. For each of the areas that were assessed, special education teachers rated their "efficacy, ability, understanding, and resources higher than general education teachers" (p. 143).

A more recent study, also in the United States by Elhoweris and Alsheikh (2006) investigated the differences in regular and special education teachers' attitudes toward the inclusion of students with SEN in integrated settings. This study however, involved a smaller group of teachers compared to the one above, with only five regular education and five special education in-service teachers who were undergoing graduate classes in a Midwestern state university. The researcher 
employed Q-methodology in this study, "the instrumental basis of [which] is the Qsort technique" (p. 116). This is a technique that typically involves the rank ordering of a range of statements. The ten respondents who participated in this study (five regular education teachers and five special education teachers) were required to sort 39 statements about inclusion that ranged from most like my view to most unlike my view. Participants also had opportunities to comment on and give verbal explanations concerning their feelings about the statements in the Q-sorting. Findings from this study showed that overall, both groups of teachers demonstrated positive perceptions of inclusion. Further analysis of findings however, were congruent with the earlier study by Buel and colleagues (1999) in that special education teachers were more supportive towards inclusion in comparison to regular education teachers.

Also comparing attitudes of regular and special education teachers toward inclusion, Lifshitz, Glaubman and Issawi (2004) surveyed a total of 228 Israeli and Palestinian primary school teachers. One hundred and twenty five of these teachers worked in regular classes and another 103, who had background knowledge in special education, worked in integrated classrooms. The Regular Education Initiative Questionnaire by Phillips, Alread, Bruelle and Shank (1990), as adapted by Gemmel-Crosby and Hanzlik (1994), was used in this study. The questionnaire primarily aimed at discovering the willingness of teachers to include students with different severities of disability in a regular classroom, and teachers' general sense of efficacy in teaching children with SEN. After obtaining the findings of the questionnaire, an intervention programme was carried out for regular and special education teachers to see if it affected these teachers' attitudes towards inclusion. Questionnaire findings showed significant differences between regular and special education teachers' attitudes towards inclusion in relation to all degrees of disability (mild/ moderate/ severe), with special education teachers demonstrating more willingness to include children with SEN into regular classrooms. The use of an intervention programme proved more beneficial to regular education teachers because special education teachers' attitudes towards inclusion remained the same before and after the intervention, while regular education teachers showed slightly 
improved willingness to include children with SEN into their classrooms. Nonetheless, regular education teachers' overall attitudes towards including students with severe learning disabilities, and emotional disorders remained negative.

Studies examining regular and special education teachers' perceptions of inclusion in Malaysian contexts have primarily highlighted the collaborative efforts between these teachers (Ali, Mustapha, \& Jelas, 2006; Haniz Ibrahim, 1998). Such efforts between these two groups of teachers are especially critical in determining the successful implementation of inclusion in Malaysia, where children with SEN are not automatic members of a regular classroom. Instead children's inclusive opportunities are primarily dependent on teachers' decisions as to whether or not a particular child with SEN can be included based on their ability to cope with regular classroom learning (see Chapter 2). Ali et al. (2006) surveyed regular and special education teachers' perceptions of inclusion in Malaysian primary and secondary schools by using self-rated questionnaires. The data obtained were synthesised into categories of teachers' perceptions and knowledge concerning inclusive education, collaborative efforts between regular and special education teachers, and other matters relevant to the implementation of inclusive education. Findings revealed that regular and special education teachers generally had positive attitudes towards inclusion. However, both groups of teachers form perceptions of inclusion based on a number of discrete factors pertaining to the collaborative efforts between them. These included issues as to whether regular or special education teachers should take charge of inclusive lessons, or whether the presence of special education teachers in inclusive classrooms raised difficulties as to who was responsible for the student with SEN (for example, in an inclusive classroom, should special education teachers focus on assisting the student with SEN's learning, rather than contributing to generally inclusive lessons).

The findings described by Ali and colleagues appeared to be comparable to an earlier study by Jelas (2000) that investigated regular and special education teachers' perceptions of inclusion in a primary school. Among the primary aims of 
this study was to yield critical insights into the nature of professional relationships between teachers, and between teachers and parents. However, unlike the involvement of a large sample in Ali and colleagues' study, the research effort in Jelas's (2000) study involved a single case study that used interviews and observations with teachers and parents. Findings showed that all three special education teachers and their three counterparts from the mainstream had positive attitudes towards inclusion. Nonetheless, both groups of teachers maintained formal and discrete role boundaries. Special education teachers believed that regular teachers had primary responsibility towards children with SEN once these children were included into regular classrooms; but agreed that there needed to be some collaboration between regular teachers and special education teachers to ensure meaningful inclusion took place. On the other hand, regular teachers viewed the role of specialist teachers in their classroom as underestimating their competence and authority, something neither welcomed nor considered helpful. From these two studies (both Ali and colleagues, and Jelas), it seems apparent that regular and special education teachers' perceive inclusion positively; however, reluctance prevails when related factors, such as collaboration between groups of teachers, presents a challenge.

\section{Early childhood contexts}

In addition to the studies above, which examined inclusion in primary and secondary school contexts, studies examining teachers' perceptions of inclusion in early childhood settings have also been conducted. One in particular, by Smith and Smith (2000), investigated teachers' perceptions of inclusion and factors that facilitated or inhibited inclusion in a small urban school district in Nebraska. Another was carried out by Leatherman (2007), and attempted to determine teachers' perceptions of their own early childhood inclusive classrooms. These two studies were distinct from each other in terms of the approaches that were used for participant selection.

In Smith and Smith's (2000) study, a survey was first sent out to all 75 K-3 regular education teachers in the district, asking each to rate themselves as successful or 
unsuccessful with inclusion in their own classroom. Of the 47 teachers who responded, the researchers selected three teachers who rated themselves as unsuccessful, and another three teachers who rated themselves successful, for follow-up interviews. The researchers deliberately selected their participants in this manner in order to obtain a balance of perspective across the district. According to Smith and Smith (2000) this way of selecting participants "provided access to six distinct inclusion settings through the perspectives of the classroom teachers" (p. 163). This research technique highlights an idea that is crucial to the way research was conducted for this thesis: that if Smith and Smith had chosen to examine only one teacher and their classroom (a single-case design), regardless of how intensively they did so, one set of circumstances would not be able to provide the broader situation that contextualises, or perhaps explains, the fact that not all teachers felt successful with inclusion in their classroom.

The second study by Leatherman (2007) involved a narrative enquiry. The participants were eight early childhood teachers from the southeastern part of the United States. Samples were collected differently - in this study, the eight early childhood teachers were chosen based on convenience and purposeful sampling but, as with the work of Smith and Smith, open-ended interview questions were used so that teachers could share stories of their experiences teaching children with and without SEN in the same classroom.

The researchers in both studies (Smith and Smith's, and Leatherman's) analysed the content of each of the interviews for each of the cases individually, before categorising them into themes across cases. Teachers in both studies held positive attitudes and beliefs about inclusion. Findings from Smith and Smith's study showed that although three of the teachers did not feel successful with inclusion in their classroom, all six teachers believed that children with SEN benefited from inclusion when practiced in a supportive classroom environment. Although this belief was "shadowed by substantial questions, concerns, and reservations" (p. 177), none of the teachers voiced a need to do away with inclusion. Similarly, findings from Leatherman's study showed that the teachers surveyed found 
inclusive classrooms the best place for educating children with SEN, as well as a valuable opportunity for teachers themselves to learn and grow. However, teachers also expressed needs and complications; their feelings about the importance of having additional training and support from administrators, the need to be involved in decisions about inclusive classrooms, and the fact that positive experiences were crucial for successful inclusion to take place.

Both studies, Smith and Smith's (2000), and Leatherman's (2007) provided examples of methods that have seemed to offer in-depth understanding of teachers perceptions of inclusion in early childhood contexts. In particular, the participant selection approach used in Smith and Smith's study was especially relevant (and realistic) in addressing the state of inclusion in Malaysian integrated pre-schools, a research context in which little previous study exists. These researchers obtained wide-spread examples of self-described states of inclusion in preschools, by approaching teachers first, and by selecting a range of participants reporting differing levels of inclusion so that further in-depth investigations could be carried out. Recognising the relevance of their approach, in writing this thesis, I decided to adopt similar research methods.

As the review in this section indicates, there has been extensive, internationally diverse research into identifying teachers' perceptions of inclusion, and the range of different factors that affect it, suggesting that much academic emphasis has been placed on these individuals' perspectives, and underscoring the points that researchers have made in regard to the power of perception and attitude in influencing an inclusive classroom. Mahat (2008) for example, argues that teachers' attitudes toward inclusion "can create positive (or negative) expectations and behaviours which increase (or limit) the successful inclusion of students with a disability in educational environments" (p. 82). Yet, teachers seem to react to inclusion in a number of different ways, with some researchers describing teachers' perceptions of inclusion as complex (Smith, 2000), ranging from being favourable to non-favourable, mixed, and in some cases favourable subject to supportive 
conditions in school settings (Ali et al., 2006; Cook, 2001; Leatherman \& Niemeyer, 2005).

Yet despite the extensive emphasis on teachers' perceptions of inclusion and its relevant issues, such research within the Malaysian context is scarce. The few existing studies within this context seem to be focusing primarily on inclusion in primary and secondary school settings, and little has been done to identify teachers' perceptions of inclusion in preschool settings. The lack of such information identifies a gap in the literature that needs to be examined - a gap that this thesis addresses.

\section{Principals' perceptions}

Researchers have strongly indicated that the school principal's perceptions of inclusion are crucial to ensuring the successful implementation of the practice (Barnett \& Monda-Amaya, 1998; Praisner, 2003; Riehl, 2000). The development of inclusive practices within the school organisation does not simply occur when technical changes and processes in the school are undertaken in response to policy (Riehl, 2000; Salisbury \& McGregor, 2005). Instead, Riehl (2000) argues that to ensure lasting change in an education system that embraces inclusion, there must be improved understandings, beliefs and values concerning diversity that are reflected through the reformation of the school's structures, cultures, and routine practices. In this regard, the principal's perception of inclusion is seen as critical.

As the school's instructional head, the views that principals hold about inclusion can significantly influence the much needed administrative efforts to support inclusive practices among students, staff and parents (Salisbury \& McGregor, 2005). This situation is especially relevant in Malaysia, where inclusion is not a mandatory practice, and the decisions to include children with SEN into regular classrooms is primarily made at the school level. In particular, Nanus (1992) argues that the principal's acceptance and support for inclusion will directly influence a range of issues; "resource allocation, staffing, structures, information flows, and operating processes that determine what shall and shall not be done by the organization" (p. 
142). Such influences have the capacity to both bring about increased opportunities for students with SEN to be educated in regular educational settings, and to limit community efforts made toward that goal.

The literature has indicated a range of attitudes and views that principals hold about inclusion, reflecting the kind of support these individuals offer and the extent of their involvement in the implementation of inclusion in schools (Avissar, 2000; Villa, Thousand, Meyers, \& Nevin, 1996). Praisner (2003) for example, surveyed 408 elementary school principals in Pennsylvania. The survey generally aimed at determining principals' attitudes toward inclusion and their perceptions of placement options for children with SEN. Findings showed that the majority of the principals were uncertain, not strongly positive or negative about inclusion. Further examination of findings displayed interesting details that accounted for the particularly large number of participants that fell in the uncertain range. It was evident that most of the principals displayed acceptance toward the idea of inclusion when items in the attitudinal scale were phrased in a generic or unregulated manner. On the other hand, these participants were not supportive of inclusion for items that were specifically implying mandatory compliance rather than voluntary participation. This suggests that the majority of principals surveyed were not willing to be committed toward the implementation of inclusion in their schools.

Principals' non-committal attitudes toward inclusion were also reported in a more recent study by Conrad and Brown (2011), which examined 18 elementary school principals' perspectives on inclusion in Trinidad and Tobago. Data from a selfadministered questionnaire and focus-group interviews revealed that the principals displayed philosophical willingness to embrace inclusion, but resisted assuming responsibility for students with SEN in the regular classroom. Findings indicated that whilst the principals' generally agreed that no student should be discriminated against or deprived of education, they rejected the notion that it was their responsibility as school administrators to prepare their schools to accommodate both students with SEN and inclusive practices to support them. 
Instead, the majority of the principals in this study believed that regular schools and teachers were not ready for inclusive education, because there was still more to be done by the Ministry of Education and teacher educators so that regular and special education faculty, teacher candidates, and other stakeholders would be able to share universal pedagogical ideas, and develop suitable interventions to accommodate inclusive practices in schools. In addition, these principals felt that rather than hastily including students with SEN into regular classrooms before regular schools and teachers were ready for inclusion, students with SEN would be better off segregated into specialised settings, in order to avoid or forestall facing the risk of "peer rejection [of learners with SEN], teacher burn out, or angry parents" (p. 1026).

Principals' perceptions of inclusion and their success in promoting inclusion within their schools have also been associated with contextual factors that affect the ways in which principals conceptualise inclusion. Graham and Spandagou (2011), for example, argue that "principals do not form their perceptions in a vacuum. The process is reciprocal: context influences perceptions, perception influences attitudes and, in return, attitudes influence the context" (p. 226). These researchers examined 13 primary school principals' views on inclusive education in Australia. Findings from semi-structured interviews demonstrated that the principals' perceptions of inclusion are informed by their individualised understandings of inclusion, as well as the contextual characteristics of their own school. This study found that whilst inclusive education was significantly associated with issues concerning disability and SEN in all schools, principals from schools located in 'disadvantaged' areas conceptualised inclusive education as more than just educating children with SEN. These principals instead included a number of other factors such as "socioeconomic status, non-English speaking background, refugee status, and Aboriginality" (p. 226) that came together with learning difficulties, SEN, behavioural difficulties and disability. Thus, it was concluded that principals recognised the importance of their responsibility in establishing a school-wide understanding of inclusion relevant to the characteristics and needs of their students. However, the same principals acknowledged that contextual factors could 
influence or restrict their capacity to promote such understanding among the school community.

Some studies have used the types of inclusive placements preferred for learners with SEN in regular educational settings as a basis to reflect upon principals' attitudes toward inclusion. For example, in Praisner's (2003) study, findings indicated that the majority of principals surveyed showed preference for the placement of children with SEN in full-time regular education settings, with support. The least preferred placement on the other hand, was segregation of children with SEN to education outside regular schools. This initial information was further analysed by researchers to establish the possible relationship between principals' attitudes and placement perceptions. Findings indicated a significant positive relationship between principals' attitudes toward inclusion and their choice of inclusive placements. That is, the more positive the attitudes of principals toward inclusion, the more inclusive the placement selected. However, there were also exceptional cases where some of these principals felt that rather than a general decision about educational placements for children with SEN, a better way to make such decisions was on a case-by-case or individual basis, depending on the child's needs.

In contrast to Praisner's (2003) study, where most of the principals supported the placement of children with SEN into regular classrooms, a study in Malaysia reported on principals' rejection of the practice. The study, conducted by the Asia Community Service (2007), investigated private preschool administrators' views on inclusive preschool education. A total of 191 preschool administrators responded to a survey, and the findings indicated that, despite a large number of respondents (91.6\%) supporting the philosophy of education for all (EFA), about one third of the respondents were evidently hesitant about including children with SEN in their centres. The researchers wrote that full time inclusive placements were "definitely not popular among the respondents" (p. 37). Among the reasons identified for such rejection were the lack of teachers who were qualified to teach children with SEN in the centres, lack of co-operation from parents of typically 
developing children, and awareness of physical conditions or preschool structures not designed to cater for SEN. Only a very small number of the respondents in the study believed that children with SEN were best educated in full inclusive placements. Even respondents who favoured partial inclusion were selective about the types of activities that they considered appropriate for inclusive lessons (storytelling and art and craft being highly preferred).

Further, a total of $14.1 \%$ of the respondents supported traditional specialised settings for children with SEN, arguing that these children were better off educated in segregated placements that catered for their specific needs. Nonetheless, as took place in the study conducted by Praisner (2003) above, several respondents also felt that decisions about inclusive placement for children with SEN were best determined based on the severity of the child's disability. Such finding coincided with a study by Avissar's (2000) on principals' attitudes toward inclusion in Israel. Although the majority of principals involved in Avissar's study held generally positive attitudes toward inclusion, they believed that the severity of a child's disability should be taken into consideration when deciding on inclusion.

Avissar's study also demonstrated the importance of involving both principals' and teachers' views when examining the extent of principal's supportive efforts in implementing inclusion. Avissar used a questionnaire to examine perceptions of principals and practices of inclusion in a total of 204 Israeli elementary schools. Interviews with teachers in 30 schools and in-depth interviews with 6 principals were also conducted to confirm principals' support for inclusion. Teachers in most schools reported a supportive climate with regard to inclusion in their schools. Information obtained from teacher interviews corroborated with questionnaire findings; that the majority of principals in this study held positive views about inclusion and supported inclusion in their school. The schools were also found to be adopting a wide range of inclusion models that offered a variety of ways to include children with SEN. 
Another more recent study by Valeo (2008) also involved both principal and teacher participants in her effort to determine principals' and teachers' views on inclusive education and its support systems within Canadian metropolitan schools. This study provides a good example of a mismatch between teachers' and school principals' perceptions of the type of support required to promote inclusive practices, as the research examined the types of support principals believed they were offering as contrasted with the types of support teachers wanted to be receiving. Findings showed that principals believed that they were being supportive by taking care of the administrative aspects of integration (i.e., scheduling meetings and overseeing paperwork), yet teachers did not feel supported by their school principal. The principals saw their role, one of being available to their teachers, encouraging their teachers in what they did, and not interfering with the daily running of the integrated programmes in the school, as supportive. For the teachers however, their main concerns and frustrations about inclusion were actually issues concerning the demands of the curriculum and the lack of time to adequately meet the needs of children with SEN. However, these issues were not addressed by the principals, and so teachers tended to identify their principal as being unsupportive.

The design of both Valeo's and Avissar's studies were found to be especially useful for the research undertaken for this thesis, particularly as I seek to explore the ways in which principals perceive the idea of inclusion for Malaysian integrated preschool programmes, and the extent to which they support teachers' practices of it. Valeo's and Avissar's studies clearly imply that interpretations of teachers' views alone about administrative support may reflect a different picture to principals' attitudes toward inclusion. Thus, a good way to gain a clearer picture about how principals view the idea of inclusion, and the extent to which they are supportive of it, is to obtain information from the principals themselves. However, as Avissar's research indicates, teachers' perceptions of that support cannot be left out of the picture either. 
The review in this section has indicated that principals' perceptions of inclusion can be valuable predictors of the extent and types of efforts they are willing to initiate at the school level to support inclusion. As argued by Salisbury and McGregor (2005), principals "serve as the catalyst for key stakeholders" (p. 2). Because of a principal's role as a school administrator, their level of support and acceptance toward inclusion can determine the availability of the collaborative efforts and resources required by teachers to implement inclusion. Consequently, this affects the extent to which the teachers, and the wider school community, support a culture that thinks and acts inclusively (Barnett \& Monda-Amaya, 1998; Salisbury \& McGregor, 2005; Villa et al., 1996). Within the context of Malaysian education, however, the availability of information about principals' perceptions of inclusion or the extent to which they offer support to regular and special education teachers to carry out inclusion is limited, despite its importance. The one available study within the Malaysian context looked at private preschool administrators' views, meaning that, while it is still useful to my research, it cannot fully answer questions about public schools. Consequently, this thesis stands alone in terms of its focus; identifying Malaysian public preschool principals' perceptions of inclusion, and the extent to which these individuals are supportive of its implementation within these settings.

\section{Parents' perceptions}

Parent's perceptions of inclusion are increasingly being recognised as powerful influences in shaping the overall success and development of this practice (GarrickDuhaney \& Salend, 2000; Leyser \& Kirk, 2011). Garrick-Duhaney and Salend (2000), for example, argue that parents' views on and experiences of the impact of systemslevel factors relevant to inclusion on their child's education and development, such as administrative and organisational variables, training and commitment of principal and teachers, curricula, and availability of services, can offer valuable feedback for improving inclusive practices in schools.

Studies on parental perceptions of inclusion have reported both supportive and unsupportive views and experiences (Garrick-Duhaney \& Salend, 2000; 
Narumanchi \& Bhargava, 2011). Nind, Flewitt, and Johnston (2005) investigated the expectations that parents of children with SEN had of combined placements (i.e., special education and mainstream services) in early years settings in England. The researchers found that parents did not perceive inclusive education as offering the best of both worlds. Findings showed that although in most cases parents welcomed the normative social learning environment in inclusive placements, there was lack of faith among them that the 'special' input needed by their children could be provided by inclusive placements. Parents stated that their child's special needs were not able to be understood or supported by staff in inclusive settings. The researchers reported that the most frequently cited disadvantage in inclusive placements as indicated by the parents was the distress for their children due to the disruption of routine to attend different settings. The large class size, and the "comparatively poor ratio of staff to children" (p. 19) in such settings were other disadvantages that parents mentioned.

Another study, conducted in Aotearoa/New Zealand by Stark, Gordon-Burns, Purdue, Rarere-Briggs and Turnock (2011), also reported on negative attitudes held by parents towards inclusion and its relevant issues. However, the researchers in this study aimed to examine attitudes and understandings that parents of typically developing children had toward the attendance and inclusion of children with SEN and their families in early childhood settings (though the study included the views from both groups of parents, those of children with and without SEN). Findings showed that although some parents of typically developing children were supportive of inclusion, many were not. The negative attitudes demonstrated by parents of typically developing children made children with SEN and their families to feel "discriminated against and excluded from their local early childhood education provision" (p. 4). The researchers reported that some parents of children with SEN told of having to confront parents of typically developing children who held negative views on disability, following circumstances where those parents had openly suggested that children with SEN did not belong in regular early childhood settings. 
Not all studies on parental perceptions of inclusion have reported dominantly negative attitudes, however. In contrast to the two studies discussed above, other studies on parental perceptions have reported supportive views and experiences of inclusion, including a study by Jelas (2000), for example, which used a case study approach to examine perceptions of parents whose children were included in mainstream classrooms in a primary school in Malaysia. Findings showed that all three mothers who were interviewed were happy that their children had opportunities for inclusion, and preferred their children to remain in the mainstream classroom.

Another example, this time using a survey method, is a study conducted by Elkins, Kraayenoord and Jobling (2003) which explored the attitudes of parents of children with SEN from preschools, primary schools and secondary schools in Queensland, Australia. Findings showed that generally all the parents surveyed were either strongly or moderately supportive of inclusion. Furthermore, the parents identified several benefits of inclusion, such as, social interaction, greater independence, better understanding and tolerance by peers, stating that their children benefitted from befriending and imitating behaviours of typically developing children.

However, research has also found that when the inclusion of their own child is in question, parents' views and reactions concerning inclusive placements often do not reflect the substantial support that they express concerning the general philosophy of inclusion (El-Zein, 2009). For example, despite acknowledging the advantages of inclusive schooling, in the study by Elkins, Kraayenoord and Jobling (2003), further analysis of findings showed that 50\% of the respondents favoured special classes when asked about their own child. Whilst parents recognised special class placements as worsening and slowing down the social and emotional development for their child with SEN, most of the parents regarded their child as requiring more than what was perceived to be available in regular classrooms. The parents felt that their children needed teachers who were more patient, classroom practices that were extensively modified, and substantial additional training for teachers to support their children's special needs. These findings were mirrored in 
another study, by Leyser and Kirk (2004), conducted in the United States, which also showed that the majority of parents of children with mild, moderate or severe disabilities supported the concept of inclusion from a philosophical and legal stance, but had additional concerns over a range of issues. In comparison, however, parents of students with SEN who did not have children in an integrated setting were more supportive of inclusion than parents whose children were included.

Additionally, whilst Elkins and colleagues' (2003) and Leyser and Kirk's (2004) studies showed that parental perceptions differed when involving their own child's placement in inclusive settings, researchers from both studies recognised that such views among parents of children with SEN were largely associated with the type or severity of the disability their child had, which in some cases was perceived to preclude advantages that might arise from participation in a regular classrooms. This view is also apparent in another study by Palmer, Fuller, Arora and Nelson (2001) that examined written comments of 140 parents of students with severe disabilities in California. Findings showed that most parents who were not supportive of inclusion "cited such characteristics as medical needs, sensory impairments, lack of self-help skills, lack of language, the presence of conditions such as seizures or cerebral palsy, and the presence of multiple disabling conditions" as among the reasons why regular classrooms would not suit their children.

Similar to parents of children with SEN, parents of typically developing children also express apprehension about inclusion when involving their own child's position in inclusive settings. Narumanchi and Bhargava (2011) explored the perceptions of parents of typically developing children toward inclusive education in India. Findings showed that parents supported inclusion and reacted positively toward children with SEN. These parents agreed that an inclusive setup would benefit children with SEN over special schools, as they would be able to learn from typically developing peers, and be accepted by all. However, their positive views only extended to non-academic activities like art, music, singing and sports. When academics were involved, the majority of these parents suggested separate classes 
for children with and without SEN. These parents were concerned that the presence of children with SEN who were not able to meet the academic standards of typically developing children would affect their child's academic needs.

As the review in this section has indicated, the views and reactions that parents of children with and without SEN have concerning inclusive education and its relevant issues are varied and complex. Those parents who claim to be supportive of inclusion seem to also have doubts and concerns about their child's placement in inclusive settings. But the concerns displayed by parents of children with and without SEN seem to differ; parents of children with SEN are mostly concerned about their child's ability to cope with regular classroom learning (Elkins, Kraayenoord, \& Jobling, 2003); the possible rejection of their child due to lack of expertise in catering for SEN among regular education teachers (Leyser \& Kirk, 2011), and the fear that their child will lose out on specialised curricula and individualised instructions like those offered in special education classrooms (Garrick-Duhaney \& Salend, 2000). Parents of typically developing children, on the other hand, seem to be more concerned about the effectiveness of instructional processes for their children due to the demanding needs of children with SEN in inclusive classroom (Garrick-Duhaney \& Salend, 2000), a concern that comes through most strongly when the lesson under question is academic in nature.

However, despite the emphasis given to parental views in the implementation of inclusion in various contexts and settings worldwide, little has been done to explore such matters in the Malaysian context, again underscoring the necessity of this thesis. The availability of empirical information on parental views, concerns and support for inclusion in Malaysian preschools is scarce. This study thus intends to explore how parents of children with and without SEN perceive the idea of preschool inclusion in Malaysia, and the extent to which they are supportive of the practice. 


\section{Factors influencing inclusion}

Researchers in the field argue that in order to overcome issues associated with inclusion and its relevant processes, it is important to first recognise those factors that are fundamental in making inclusion work, or that are barriers to its implementation (Glazzard, 2011; Pivik, McComas, \& Laflamme, 2002). There are diverse reasons why schools choose to implement inclusion the way they do, all culminating in a method by which some children have opportunities for full inclusion while others remain excluded in specialised services. My review of existing studies done in previous sections has clearly demonstrated that inclusive decisions can be made on implicit criteria that are deeply entrenched in attitudes and beliefs. However, the literature also indicates that there are other factors that are just as important, and can substantially influence the successful implementation of inclusive schooling.

Pivik, McComas, and Laflamme (2002), for example, stated that successful inclusion requires school environments that ensure physical access and opportunities for maximum learning and social experiences. These researchers carried out focus group meetings to identify factors that facilitate or impede inclusion, involving students with mobility limitations and parents of children with SEN across eight different schools. Their findings showed that rigid physical structures in the school, including doors, staircases and narrow passageways limited children with SEN's accessibility around the school, and in consequence often deprived them of equal participation and involvement in educational activities. The researchers argue that such limitation was also a source of isolation from typically developing peers, the physical barriers to inclusion producing social barriers, and making it difficult for children with SEN to build friendships in inclusive settings. Also relevant to inclusive school environments, Renzaglia, Karvonen, Drasgow and Stoxen (2003) asserted that universally designed environments were essential for promoting inclusion. That is, learning environments that are "structured with the notion that a diverse group of individuals will be using it" (p. 141). 
The literature has also identified instructional planning as another aspect requiring careful attention in order to ensure the successful implementation of inclusive practices. According to Pugach and Wargner (2001), making curricular adaptations that are supportive of inclusion, and organising daily planning that can accommodate the needs of all children (including those with SEN) are pivotal for creating inclusive supportive school environments. Udvari-Solner (1996) reported that the planning processes that teachers engaged in when making decisions about curricular adaptations and instructional elements determined the extent to which classroom activities catered for the needs of diverse learners. Other researchers (e.g., Foreman, 2005; Mentis, Quinn, \& Ryba, 2005) have taken similar stances, asserting that an inclusive curriculum must be tailored to meet the needs of all the students, offering flexible instructional strategies that are supported with appropriate resources and classroom organisation. These views are consistent with a study carried out by Avramidis, Bayliss and Burden (2000) who found that large classroom enrolment, lack of flexible timetables, insufficiency of pre-organised materials, and the lack of availability of resources and support staff as significantly contributing towards teachers' lack of interest in carrying out inclusion.

The successful implementation of inclusion has also been associated with teachers' and support staff's knowledge and understanding of disability and inclusion (Buell et al., 1999; Paliokosta \& Blandford, 2010; Pivik et al., 2002). For example, in the study by Pivik and colleagues (2002), the researchers had pointed out several situations in their interview findings that reflected the ways in which school personnel's lack of knowledge in dealing with SEN could deprive those students of positive learning experiences in inclusive settings. These included students with SEN being assigned as the teacher's helper during physical education lessons instead of joining in field activities; teachers giving inappropriate alternative work when too busy to make curriculum adaptations; and the failure of staff to plan on wheel chair access when renovating the school. Both student and parent participants in this study suggested that all staff, especially teachers in inclusive settings must be provided with substantial training on disability awareness. The researchers further supported participants' views, suggesting that such training 
was pivotal in facilitating inclusion because school personnel would be better informed about SEN, and would be able to adapt and implement teaching methods, as well as learning environments that are more suited to inclusive schooling.

A more recent study by Paliokosta and Blandford (2010) has echoed the views of Pivik and colleagues (2002), arguing that teachers' knowledge and exposure to inclusion and SEN was important to informing their educational practices. According to these researchers, confusion and lack of such knowledge and information often lead educators to function under the traditional medical paradigm, which "treats impairment as a disease and difference as social deviance" (p. 184). The researchers implied that this way of viewing disability focused on the child's disability rather than their strengths, and could lead to future social exclusion. Also arguing from a similar perspective, Mentis et al., (2005) asserted that pre-service and/or in-service training for teachers are fundamental to successful inclusion because it offers expert knowledge about children with disabilities and thus improves teachers' views and actions about inclusive education.

The support and active involvement of significant individuals has also been identified as an important factor in the successful implementation of inclusive schooling (Ali et al., 2006; Lieber et al., 2000; Sandlin, 2006). At the school level, these individuals are mostly represented by the principal and teachers (Lieber et al., 2000; Valeo, 2008). As has been implied by previous sections of this chapter detailing teachers' perceptions of inclusion, teachers are capable of supporting inclusion and initiating change primarily at the classroom level (Lieber et al., 2000). Their efforts in planning and organising classroom activities and learning environments that meet the needs of all the children are crucial for successful inclusion (Leatherman \& Niemeyer, 2005; Wilde \& Avramidis, 2011).

School administrators, however, have greater responsibilities. Researchers in the field have clearly articulated that without the support and leadership efforts of school administrators, schools cannot change or progress to welcome diversity (Ali 
et al., 2006). As stated by Salisbury and McGregor (2005), principals need to take the leading role by initiating awareness, modeling inclusive behaviours, and drawing together the relevant resources and people to ensure successful inclusion takes place in the school. Conversely, Sergiovanni (2001) attests that school leaders who have no sense of purpose or value for inclusion can significantly hinder change and improvement toward inclusive schooling, as without support from school administrators, such changes hardly ever achieve support (or commitment) from other members of the school community.

Further, as indicated by my previous discussion of parents' perceptions of inclusion, parents' support for and involvement in inclusion can be as crucial as the support of teachers and school principals. Using a systems perspective, Odom and colleagues (2004) stated that parental involvement in schools' inclusive efforts is an essential home-school link for developing effective inclusive practices. A comparable view from Garrick-Duhaney and Salend (2000) reported that parental involvement concerning inclusion is closely related to teacher actions in terms of making further improvement on children's learning outcomes. A host of studies (e.g., Bennett, Deluca, \& Burns, 1997; Wong \& Cumming, 2010) have also reported that when parents share their knowledge about their child's disabilities, strengths and needs, they make valuable contributions to teachers' inclusive efforts; the teachers in turn can inform parents of their child's strengths and weakness in the classroom so parents can enhance their child's learning experiences while at home.

Parental involvement in their children's inclusive learning experiences is influenced by a number of discrete factors. Garrick-Duhaney and Salend (2000) stated that parental involvement and the extent to which parents support inclusion placements may be closely related to their perspectives and reactions toward inclusion as a philosophy or idea. Mapp (2003) on the other hand, found that a school culture that values and works aggressively to build respectful and reciprocal relationships with families is pivotal for parental support and participation in their children's learning (suggesting that parents whose children are not placed in such a school may have a less positive view of inclusion in general). For example, Bennett 
et al. (1997) explored the perspectives teachers and parents of children with SEN held concerning the relationship between parental involvement and successful inclusion. Findings showed that parents who felt that they were an important member of the school team were actively involved in and supportive of the school's inclusive efforts.

The challenges faced by families due to the lack of information and understanding about inclusion can be another factor for their lack of involvement in decisionmaking processes regarding inclusion. Hanson et al. (2001) found that family members' access to information, and their own personal abilities and comfort with advocating for themselves and their family affected their ability to be heard. These researchers reported that parents who were unfamiliar with the cultural values in schools, and those who had difficulties understanding the laws that govern the technical aspects of education were likely to be left behind in the processes of decision-making.

The literature also indicates that there are factors operating beyond the organisation of the school that can influence the ways in which inclusion is implemented. Garuba (2003), for example, states that the failure of relevant agencies in developing and implementing significant policy provisions with regard to inclusion and special education can affect the successful implementation of inclusion. Garuba (2003) gives an account of inclusive education in Nigeria, stating that despite the national education policy providing for a compulsory component of Special Education in all pre-service teacher education, some of the education providers were yet to implement this important policy provision, affecting the availability of teachers with sufficient knowledge in special education, and the ability of schools to cater for SEN. In addition, Garuba also identified a lack of intensity in terms of dissemination of information on inclusion and mobility of resources (unscientific modes) in the country, due to the high level of illiteracy. Comparatively, Chitiyo and Wheeler (2004) who examined the development of special education in Zimbabwe, found that the integration of children with SEN into regular educational settings was far too challenging. Despite the overall progress 
made in the country's education system, clearly delineated national policy on special education was sorely lacking. In addition, the lack of involvement on the part of the Ministry of Education, the scarcity of specially trained teachers, and a lack of funding were among the factors identified by the researchers as affecting the education of children with SEN in regular educational settings. The findings from these two studies imply that favourable national policies, and procedures and conditions beyond the setting of the school, must be in place in order for inclusion to be successful.

Collectively, this final section of the chapter demonstrates that there are diverse factors influencing the implementation of inclusion. In particular, these factors manifest within and beyond the organisation of the school. The factors identified in this section suggest that circumstances at various levels (cultural beliefs, government policy, school environment, and classroom practices) can interact and influence each other in a number of different ways, influencing each school in its commitment towards inclusion. Thus this study will aim to identify the factors influencing inclusion in Malaysian integrated preschool programmes.

\section{Chapter summary}

The literature that forms the context for this study enables the identification of the different ways in which inclusion has been interpreted across a broad range of schools, in a number of different countries. This literature provides significant support for the idea that inclusion requires more than children with SEN gaining access to regular educational environments. Instead, as multiple studies have demonstrated in different ways, the presence of children with SEN must be supported by meaningful participation with their typically developing peers, and by a positive culture in the school that is supportive of inclusion.

Additionally, my review of relevant literature has revealed the powerful influence of perception upon inclusion. Reviewing different methods used by researchers in determining the nature and extent of inclusion in various contexts and settings has provided considerable guidance for this thesis in selecting a suitable method for 
determining the current state of inclusion in Malaysian integrated preschool programmes. My review of the different ways researchers have attempted to determine how educators and parents perceive the idea of inclusion, and to identify the factors affecting their support (or otherwise) for inclusion, has served a similar function, subsequently providing significant insight into locating areas requiring study in a Malaysian context, and producing a sound research methodology.

Finally, in addition to information gained from my review of educators' and parents' perceptions of inclusion, other relevant factors that can influence inclusion decision were addressed. Most importantly, as my review of the literature has indicated, the practice of inclusion is influenced by a range of complex physical and social factors operating within and beyond the organisation of the school. While there are strong commonalities between schools, such factors must be examined contextually. Having this information in mind, the next chapter introduces the theoretical framework for this study, one specific to Malaysian integrated preschool programmes. 


\section{CHAPTER 4 \\ -Theoretical Framework-}

\section{Introduction}

In this chapter, the theoretical framework supporting the study undertaken by this thesis, namely the bioecological systems model (Bronfenbrenner, 1999, 2005; Bronfenbrenner \& Ceci, 1994; Bronfenbrenner \& Morris, 1998), will be presented. Bronfenbrenner's (1979) ecological and later bioecological model (Bronfenbrenner, 1999, 2005; Bronfenbrenner \& Ceci, 1994; Bronfenbrenner \& Morris, 1998) stressed the involvement of educators, parents, other significant people, and events across environments for facilitating development in young children. Accordingly my study seeks to examine how educators' and parents' perceptions and other factors surrounding Malaysian integrated preschool programmes are facilitating or inhibiting children with SEN's opportunities for inclusion. It is, however, important to note that in my study the child with SEN (i.e., the developing child) is not the centre of analysis, as it is not the child's inclusive experience that is being analysed. Instead, the events taking place in his/her immediate and distal environments that may be influencing his/her opportunities for inclusion are the focus of the study. Consequently, information pertaining to the bioecological model and its relevance to my study is presented in this chapter.

\section{An ecological systems perspective}

Bronfenbrenner's 1977 and 1979 versions of ecological systems theory emphasise the importance of context when examining human development. Ecological systems theory conceptualised the context in which development takes place as series of nested systems (microsystem, mesosystem, exosystem and macrosystem). A detailed explanation of each is presented in later sections of this chapter.

The perspectives offered by the ecological systems theory have contributed significantly to research in human development, providing researchers with invaluable conceptual tools to "understand and study the differentiated but 
integrated levels of context of human development" (Lerner, 2005, p. xiv). However, Bronfenbrenner himself identified this theory as incomplete, until and unless the developing individual was included in the given context, pointing out that it was "a mistake to assume ... that the environment does the job all by itself," independent of the developing individual (2005, p. 116). Thus, what followed was an extended and strengthened version of ecological theory, which placed significant importance on the context and the developing individual within it (Bronfenbrenner, 2005).

The conceptualisation that brings in the characteristics of the developing individual into the ecological systems theory "accounts for the label bioecological" that Bronfenbrenner attached to his new theory for human development (Lerner, 2005, p. $\mathrm{xv}$, italics in the original). Bronfenbrenner argued that investigating the interaction between the unique characteristics of the developing individual, and the integrative characteristics of the developmental context provide a richer understanding of human development than does analysis of the environment alone. This interaction was found to be a distinctive feature for my focus on preschool inclusion because such an interaction neither centres completely on the preschooler with SEN, nor on the environment in producing information about inclusive practices in the preschool. Hence, whilst the characteristics of preschoolers with SEN can be viewed as influencing and contributing to inclusion decisions in the preschool, the significant effects of other factors are equally influential (e.g., school environment, educators' and parents' support for inclusion, teachers' knowledge and skill-sets regarding inclusion). This I found to be the case in my research.

Bronfenbrenner's bioecological framework is formulated by the interactions of four interrelated components for understanding human development, namely proximal processes, personal characteristics, context, and time. Together, these four constructs constitute the Process-Person-Context-Time (PPCT) model. Lerner (2005) summarises these four constructs as: (a) the developmental process, which involves the combination of and dynamic interaction between individuals and their context, known as proximal processes; (b) the person, with their own range of 
personalised characteristics; (c) the context, conceptualised as the nested systems described by the ecological systems model (i.e., the microsystem, mesosystem, excosystem and macrosystem); and (d) the dimension of time, that signifies the multiple dimensions of temporality in human development, or changes that take place across a lifespan, bounded by time (p. xv).

A number of studies on inclusion have adopted Bronfenbrenner's systems perspectives as a framework for conceptualising and analysing various inclusive issues (e.g., Bennett et al., 1997; Odom et al., 2004; Rombo, 2007). However, the majority of these studies choose to use an earlier version of the theory (i.e., ecological systems perspective), focusing primarily on factors operating at different levels in the environment (i.e., microsystem, mesosystem, exosystem and macrosystem) that impact inclusive education. Thus information on the use of the PPCT model in inclusive education is scarce.

The PPCT model, however, suited my study far better. This study seeks to discover the principals', teachers', and parents' perceptions of and support for inclusion, while also determining the state of inclusion in the preschool programme. Such an approach requires a research design that involves the examination of personal characteristics at work in the preschool, while simultaneously ensuring that other features in the preschool programme are included in the analysis. That is, this thesis is concerned with scrutinising how all situations, events and processes in the context of inclusion in Malaysian integrated preschool programmes are played out. Accordingly, the PPCT model "permits analysis of variations in developmental processes and outcomes as a joint function of the characteristics of the environment and of the person", (Bronfenbrenner, 2005, p. 115, italics in the original). Thus, this model offered a comprehensive framework for examining and analysing specific processes and pathways in the preschools I studied that effect the ways in which inclusion is thought about and practiced. The use of this model in my study is further elaborated in the following section 


\section{The PPCT model}

As discussed, the design and analysis of this study draws upon the fundamentals of the PPCT model. The process is described as the core construct (Bronfenbrenner \& Morris, 1998) in this model. More specifically, this construct addresses proximal processes or regular activities of the developing child and their environment over an extended period of time (Bronfenbrenner, 1995). The examples provided by Bronfenbrenner to denote a continual pattern of proximal processes include childchild activities, group or solitary play, acquiring knowledge, and making plans, which are all regular activities that happen in the life of the child.

Proximal processes, however, depend on the features of the people, objects and symbols present in the micro environment where development is taking place for their content (Bronfenbrenner \& Ceci, 1994). People, objects, and symbols are the "opportunity structures" that create tendencies toward the realisation of developmental outcomes and thus profoundly shape the "form, power, content and direction" of proximal processes in the microsystem (Bronfenbrenner \& Ceci, 1994, p. 575). As I explained in my opening chapters, in the Malaysian context, preschoolers with and without SEN are placed in separate classrooms in integrated preschool programmes, and inclusion (which is optional) is initiated by regular and special education preschool teachers. Proximal processes in analysis of this context can therefore refer to the preschoolers' interactions with: i) people (e.g., interactions with typically developing peers in regular classrooms that makes the child with SEN feel included); ii) objects (e.g., structures in the preschool environment that are adapted to encourage children's inclusive experiences); and, iii) symbols (e.g., beliefs and values about inclusion, or the culture/ethos, which foster or inhibit inclusion in the school).

However, it is also important to note that the absence of such interactions (above) in the preschool can provide equally important information about the extent of exclusion, or children's missed opportunities for inclusion. In other words, in this study, proximal processes, or the regular interactions between preschoolers' with SEN and other people, objects and symbols in their preschool situations serve as 
the mechanisms for identifying situations of inclusion and/or exclusion. Most importantly, such information is fundamental for providing pertinent information about the efforts taken by teachers to initiate and support inclusive practices in their preschool.

It is also important to signal here that the "pattern of activities, roles and interpersonal relations experienced by the developing person in a given face-toface setting with particular physical and material features", is referred to by Bronfenbrenner as the microsystem (Bronfenbrenner, 2005, p. 147). Accordingly then, in this study the developing person is the child with SEN, the microsystem is the integrated preschool programme (i.e., the preschool environment), and proximal processes are the daily on-goings in the preschool environment that foster (or inhibit) inclusion.

When identifying proximal processes, however, it is important to be sensitive to the person characteristics of children with SEN, as these characteristics can reduce or enhance the power and directions of processes influencing behaviour and development (Bronfenbrenner \& Morris, 1998). For example, the developing child has the capacity to shape his or her own development through their state of emotion or dispositional tendencies (Bronfenbrenner \& Ceci, 1994). This idea was integrated by Bronfenbrenner into his explanation of a force-resource model for a person's own biopsychological characteristics (Bronfenbrenner \& Morris, 1998). That is, characteristics that have to do with one's own beliefs, perceptions, motivation, responsiveness, interest, feelings or attitude, as well as one's own resources, such as one's capabilities, disability conditions, knowledge, skills, prior experiences or birth defects.

This study, however, specifically explores the ways in which educators and parents perceive and support the idea of preschool inclusion. Such a focus involves viewing inclusion through the eyes of these significant individuals, who are responsible for the preschool education of children with and without SEN. Bronfenbrenner (1995) clearly supported the necessity of this area of research when he explained 
"significant others as environmental influences" (p. 638). Bronfenbrenner further explained that "the same force-resource model that captures the developmentally relevant characteristics of the developing child can be applied as well to the developmentally relevant features of significant others" in a child's developing environment (p. 638), and indeed, studies that examine inclusive practices in this regard have documented how characteristics of educators in the school setting correlate with children's characteristics and their opportunities for inclusion (Salisbury \& McGregor, 2005; Travers et al., 2010). Obeng (2007) for example, writes that most regular teachers are not happy to have children with behavioural problems in their classrooms because these teachers believe that they lack the knowledge and training to accommodate the needs of these children. Ashman and Elkins (2005) on the other hand, while analysing teachers' responsibilities in managing behavioural problems, argue that teachers' attitudes and tolerance are the most important contributing factors in determining the approaches taken when accommodating the needs of children with SEN and their participation in regular educational settings.

Bronfenbrenner (1995), however, stated that the 'person' characteristic in the PPCT model is best explained when it is incorporated into the 'context' (ranging from micro to macro levels), arguing that the best way to understand human development is in its ecological circumstances; that is, in the actual environment in which people live their lives. Such integration, according to Bronfenbrenner, directs increased focus toward the effects of different types of 'person-context' characteristics, and combinations of the nature and extent of proximal processes that take place within them, thus providing clearer understanding of the developmental influences and outcomes being fostered. Bronfenbrenner (2005) integrated this idea of person-context influences on human development into his explanation of the meso, exo and macrosystems.

The mesosystem is explained by Bronfenbrenner as the relationship and processes taking place between two or more settings containing the developing child. In this study, this relationship is represented by the linkage between parents and school 
personnel. Parental involvement in young children's development is an aspect of early childhood development that has been given serious importance by Bronfenbrenner, especially when involving the education of young children with SEN (Grisham-Brown, Hemmeter, \& Pretti-Frontczak, 2005; Swick \& Williams, 2006). Bennett et al. (1997), for example, note that Bronfenbrenner, in his review of early childhood programmes, concluded that the involvement of parents in strategies for early intervention produced better outcomes for children than those that do not involve parents.

Numerous studies on inclusive education have also pointed out that the relationship between school and the home is a mesosystem influence that can impact upon children's participation in inclusive settings (e.g., Bennett et al., 1997; Odom et al., 2004; Magill-Evans, Darrah, \& Adkins, 2003). Expounding on Bronfenbrenner's perspective of parental involvement, Garrick-Duhaney and Salend (2000) explain that when parents contribute their views about inclusion, they not only demonstrate their participation and interest in school decisions, but they also affect the education of their child through building better relationships with school personnel. Similarly, the relationships of parents with school personnel open up avenues for parents of both groups of children (with and without SEN) to voice satisfactions or complaints about services and practices concerning inclusive programmes (Garrick-Duhaney \& Salend, 2000; Magill-Evans et al., 2004). GarrickDuhaney and Salend (2000), however pointed out that involvement of parents is not enough - the views and reactions of parents (of children with and without SEN) concerning inclusive education and the practice of it are crucial in determining the extent to which they perform roles that are supportive of inclusive decisions made in the school. Consequently, this study seeks to explore parents' perceptions of inclusion, and the extent to which parents of children with and without SEN are supportive of the implementation of inclusive practices in Malaysian integrated preschools. One of its tools is the examination of the mesosystem.

The exosystem is another process that explains the person-context influences on development in the PPCT model. Bronfenbrenner $(1979,2005)$ explained the 
exosystem as encompassing "the linkages and processes taking place between two or more settings, at least one of which does not contain the developing person" as an active participant, but in which events that take place affect, or are affected by what happens in the setting containing the developing person (Bronfenbrenner, 1979, 2005). Odom et al. (2004) describe the exosystem very clearly in their account of preschool inclusion. According to these researchers, regulations or education policies set up by policy makers who do not personally get involved in teaching and learning activities can increasingly exert influences on inclusive decisions made in preschools. An important consideration with regard to this view in Malaysia is the fact that in public preschools, structures and inclusion guidelines are often set up beyond the preschool context, and could be impacting inclusion decisions in the preschool. In particular, policies and legislations in Malaysia ensure that children with SEN have access to regular educational settings, but leave it to schools to make inclusion decisions. Such policy proposals may influence the extent to which inclusion is practiced in Malaysian integrated preschool programmes. For example, those schools with educators and parents who hold positive views about inclusion may make decisions that favour inclusion, whereas schools with educators and parents, who are not supportive of the practice may not.

Bronfenbrenner $(1977,1995,2005)$ reiterated that the belief systems of significant others in the child's developmental context are fundamental for determining outcomes of developmental processes. This view is integrated into his idea of a macrosystem. The macrosystem, as Bronfenbrenner describes it, is the wider atmospheric conditions in which the micro-, meso-, and exosystems are embedded (1979). According to Bronfenbrenner $(1977,2005)$, the macrosystem differs in a fundamental way from the systems previously discussed, in that it refers not to the specific setting(s) affecting the life of the developing child "but to general prototype, existing in the culture or subculture that set the pattern for the structures and activities occurring at the concrete" or micro environment (Bronfenbrenner, 1977, p. 515). 
The macrosystem, also referred to as the "societal blueprints" of a given context, can exist explicitly in the form of recorded rules or regulations, but, as Bronfenbrenner points out, "most macrosystems are informal and implicit - carried, often unwittingly, in the minds of the society's members as ideology made manifest through custom and practice in everyday life" (Bronfenbrenner, 1977, p. 515). Bronfenbrenner's idea of the macrosystem suggests that the exploration of the shared beliefs of principals, regular and special education teachers, and parents of children with and without SEN are fundamental for determining the factors that facilitate or inhibit inclusive practices in preschools in general, and Malaysian integrated preschools in particular. The ideas put forth in the macrosystem in fact suggest that the belief systems of educators and parents about inclusion can be the overarching guide to the reality of the preschool's philosophy towards inclusion, and why teachers carry out inclusive practices the way they do.

The final construct in the PPCT model, is the dimension of time, which has a prominent impact on human development and was initially not considered by Bronfenbrenner in his ecological systems model. However, upon critiquing his initial model as static, Bronfenbrenner integrated the dimension of time at three successive levels; micro-, meso- and macro- (Bronfenbrenner \& Morris, 1998). Microtime "refers to continuity versus discontinuity within ongoing episodes of proximal processes" (e.g., the frequency/regularity of interaction between children with and without SEN in a school day); and mesotime "is the periodicity of these episodes across broader time intervals, such as days and weeks" (Bronfenbrenner \& Morris, 1998, p. 995).

These two constructs of time offer important considerations for identifying the extent to which inclusion is practiced in Malaysian integrated preschools. In particular, inclusion would typically involve the shared participation and involvement of children with and without SEN in socially and academically integrated activities, planned, initiated and organised by regular and special education preschool teachers. Accordingly, earlier in this section, Bronfenbrenner's idea of proximal processes posits that children's opportunities for inclusion in the 
preschool setting would be best identified by examining the types of interactions that children with SEN have with their immediate external environment (i.e., people, objects and symbols) that foster opportunities for inclusion. However, Bronfenbrenner's view of micro and meso time brings another important consideration to this analysis. Particularly, it underscores the fact that duration, as well as type, of such interactions warrant examination, in order to determine the true extent of the inclusive opportunities they offer to preschoolers.

However, identifying the extent of inclusion by considering just the duration and the types of activities that offer inclusive opportunities to children with SEN may not reflect other complexities involved in the implementation of inclusive practices in Malaysian integrated preschools. Bronfenbrenner's idea of macrotime in the PPCT model transcends this limitation. Macrotime "focuses on the changing expectations and events in the larger society, both within and across generations, as they effect and are affected by, processes and outcomes of human development over the life course" (Bronfenbrenner \& Morris, 1998, p. 995).

In other words, Bronfenbrenner implied that events and changes in a person's lifetime can alter the courses of their thinking and/or actions in either direction, "not only for individuals, but for larger segments of the populations" (Bronfenbrenner, 1995, p. 643). From this perspective, the impact of changes at the macro level become visible, for example the influence of national and international policies that place growing emphasis on equal access and participation for children with SEN in regular educational environments may impact upon people's attitudes and thinking about the education of children with SEN, and subsequently the level of support for inclusive education. Similarly, practices of inclusion or segregation in the preschool may also be attributed to significant events, experiences, or opportunities held by parents, teachers or the principal across their own life span. For example, the different roles assumed by different members in the school community during their lifetime such as, having a childhood friend with SEN, working in a disability-friendly environment, or 
exposure to special education training can affect the different ways in which they support or oppose inclusion in their preschool.

\section{Chapter summary}

The ideas put forth in the bioecological systems perspective provide a complete structure for conceptualising how interrelated factors operating at different levels of the preschool environment can be examined to identify outcomes of inclusive practices in preschools. This study holds that inclusion is not only about placement options in regular preschool settings for children with SEN; it is also about the underlying processes and organisational cultures that may be influencing the nature and extent of inclusion. The formulation of the PPCT model in the bioecological perspective, which recognises the intertwined involvement of the characteristics of the child, the situations and events in their social and physical environment, and the nature of the developmental outcomes under consideration, offers a comprehensive framework for conceptualising and examining the complexity of processes involved in achieving a whole-school approach towards inclusion.

The PPCT model thus lays the theoretical lense through which perceptions and practices of inclusion are examined in this thesis. In the analysis that follows, the developing individual/s (children with SEN) are of importance to the study by simply being in the context. The state of inclusion, perceptions of it and factors that may be influencing inclusion in Malaysian integrated preschool programmes will be examined by identifying the ways in which events, structures and individuals within preschools I have studied are working towards fostering or inhibiting children with SEN's opportunities for inclusion (i.e., processes in the microenvironment). The person-context-time constructs, which emphasise educators' and parents' characteristics, such as, their attitudes, reactions, and support concerning inclusion will also be examined, simultaneously with influences that may be coming from within and across levels of the ecological system including the ever evolving policy provisions from the MOE and other government departments, and the cultural beliefs and values specific to Malaysia that may be 
impacting inclusion decisions in integrated preschools. I believe that all these features will be able to offer a clear understanding of the extent to which inclusion is practiced and supported in the preschools under study, and in addition point out factors that may be influencing the implementation of inclusion in Malaysian integrated preschool programmes. How all of these factors are examined and analysed will be discussed in detail in the following chapter. 


\section{CHAPTER 5 \\ -Methodology and Methods-}

\section{Introduction}

This chapter describes the research approach of the study undertaken for this thesis. It will first explore relevant philosophical assumptions before explaining why a mixed method research approach was used to conduct the current study. The data collection methods and analysis procedures employed in the study will also be discussed. Finally, issues of validity, reliability and ethics will be addressed.

\section{Method, methodology and research process}

Method is defined as the techniques or procedures involved in data gathering, and analyses associated with particular research questions or hypotheses (Crotty, 1998). Methodology on the other hand is, "the strategy, plan of action, process or design lying behind the choice and use of particular methods and linking the choice and use of methods to the desired outcomes" (Crotty, 1998, p.3). In short, the methodology is what governs the choice and use of methods in a research project (Creswell \& Plano Clark, 2007).

The justification for a researcher's choice and use of methodology and method is very much influenced by the assumptions about reality that $\mathrm{s} / \mathrm{he}$ brings to the research (Creswell \& Plano Clark, 2007; Crotty, 1998). The researcher's theoretical perspectives, subsumed by a set of assumptions and epistemological stances, provide a context for the process and grounding logic of the research. These perspectives have implications for decisions made in the research process, including the choice of methods (Creswell \& Plano Clark, 2007; Mertens, 2010). Crotty (1998) illustrates how four elements, namely, epistemology, theoretical perspective, methodology, and method inform one another in the research process: 


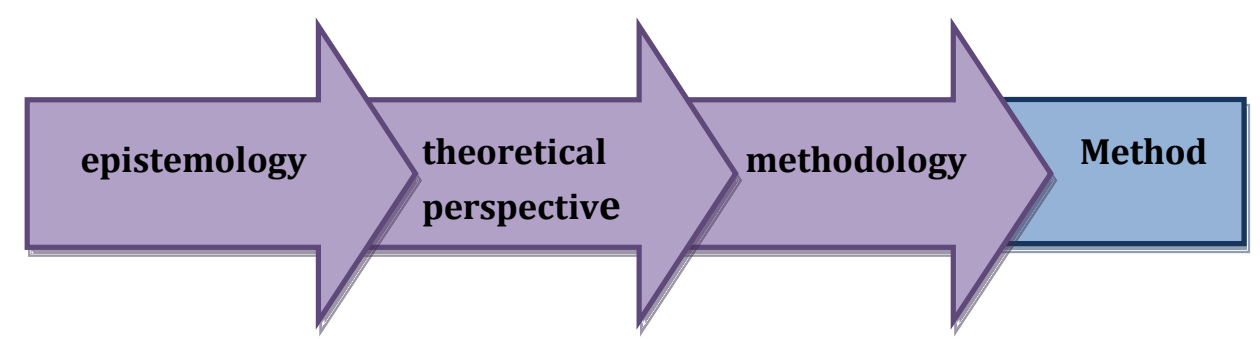

Figure 4: The basic elements of the research process (Crotty, 1998)

Because the epistemological stances used by researchers influence the procedures involved in the research, methodology is also referred to as the link between theoretical framework and methods (Creswell, Plano Clark, 2007; Mutch, 2005). Thus, methodology can be considered as the underlying theory and analysis of research procedures which determine, among other things, the "how" and "why" of techniques that are chosen for gathering evidence and every other decision made in the research process (Kandlbinder, 2003). For instance, as discussed in the previous chapter, a review of literature revealed that the ways in which people perceive inclusive education, and factors operating within and beyond the preschool environment, affect practices of inclusion. This information is supported by the bioecological theory, which emphasises the importance of both individual and environment in the development of human behaviour. Such theoretical perspectives and information were the underlying knowledge that guided the decisions I made when choosing the most suitable approach for my study.

Hence, my study adopted a mixed method research design, in which data collection and analysis involved both quantitative and qualitative techniques. The ways in which information was gathered, the importance of certain types of data over others, the analysis and presentation of findings were all among the important features in the research process, and to a large extent directed my analysis of how inclusion is perceived and practiced in the context of Malaysian integrated preschool programmes. Nevertheless, according to Burton and Bartlett (2009), the fundamental beliefs underpinning the research process and how these structure the ways in which a researcher understands the world around him/her is best considered through a discussion of research paradigms. 


\section{The research paradigm}

"A paradigm is a way of looking at the world. It is composed of certain philosophical assumptions that guide and direct thinking and actions" (Mertens, 2010, p. 7). Research in social sciences is often divided between two dominant paradigms, namely positivist or its successor postpositivist, and interpretivist (Burton \& Bartlett, 2009; Mertens, 2010). Positivists take the stance that there is a single reality and that it is the researcher's job to discover that reality (Guba \& Lincoln, 2004). Positivists claim that society can be investigated in the same objective way as the natural world, using a traditional scientific approach unaffected by the opinions and hopes of the researcher. Accordingly, in research that sits within the positivist paradigm, it is important for the researcher to "maintain an objective standpoint and keep any personal 'contamination' of the data collection process to a minimum" (Burton \& Bartlett, 2009, p. 20). For this reason positivists often favour research approaches that consist of testing hypotheses via experiments to prove initial ideas or a theory (Burton \& Bartlett, 2009; Mertens 2010). For positivists, the sample's representativeness of the whole population is also an important aspect of the research. The justification is that larger data sets offer findings with a greater significance and can be categorised and compared in numerous ways, all directed toward establishing a general truth (Burton \& Bartlett, 2009; Mertens, 2010).

However, the orientation of positivism was transformed when postpositivist psychologists responded to the dogmatic positivist view that what could be researched was limited to what was observable in a physical sense (Mertens, 2010; Tashakkori \& Teddlie, 2003). Postpositivists (whilst still holding beliefs concerning objectivity and generalisability) recognise that the values of researchers and the theory or framework used by the researchers can strongly influence what is observed. Thus the tenets of postpositivism suggest that researchers modify their claims to understandings of reality based on probability, rather than certainty (Mertens, 2010). 
Conversely, concerning the other dominant paradigm guiding research in social sciences, interpretivists or constructivists, believe that reality is socially constructed. Constructivists do not see society as having a fixed structure; rather they take the view that the social world is created by interactions of individuals through meaningful deliberate actions. This means that to a constructivist, meanings discovered by research do not represent reality. Rather, reality itself is subjective and constructed by human beings as they engage with the world that they are interpreting (Mertens, 2010). Constructivists, therefore, favour more personal, interactive modes of data collection, such as interviews and observations (Mertens, 2010); making use of individual accounts and biographies (often reliant on the reflexivity of the researcher in the research process), and producing or finding detailed description that gives a "feeling for the environment" (Burton \& Bartlett, 2009, p. 21). Accordingly, in research that sits within a constructivist paradigm, the knowledge of reality is seen as co-constructed by the researcher and the people or participants active in the research process (Denzin \& Lincoln, 2005). In particular, constructivism posits that a researcher tends to rely upon participants' views of the phenomena being studied and at the same time recognises that his/her own background shapes the interpretation.

The processes of designing the research methodology for this thesis, however, were mostly influenced by the main features of pragmatism, a research paradigm which allows a combination of methods, and the incorporation of both postpositivist and constructivist views. In the eye of pragmatists, the methods of research that are seen to be most appropriate for studying a phenomena are found based on the notion that "what works" is what is important, rather than reliance upon some abstract philosophy in search of metaphysical truths (Tashakkori \& Teddlie, 1998, p. 12). In a pragmatic approach there is no issue with asserting both, that there is a single real world (the positivist assumption) and that all individuals have their own unique interpretations of that world, each of which is "real" (the constructivist assumption). In this approach, methodology itself is placed at the centre of research design. This differs from the use of paradigms that place ontology (the nature of reality) as central (Mertens, 2010). 
In short, pragmatism emphasises that researchers should decide methods according to the purpose of the research (Patton, 2002), suggesting that a researchers' choice of methods (or combination of methods) in a research design should be made by identifying the ones that work best for answering their research questions (Johnson \& Onwuegbuzie, 2004).

As noted in the broader literature concerning inclusion (see Chapter 3), teachers, principals, and parents construct their views about inclusion from differing viewpoints. Their perceptions of inclusion can depend on a wide range of factors including their roles and responsibilities, their knowledge and experiences, their interests and perceptions of their surroundings, and other factors. Such perspectives highlighted the importance of a constructivist approach, which supports the need to include interviews with participants and observations in the preschools' natural settings as part of the process of inquiry into how inclusion is working or failing to work. On the other hand, such an approach would not suit the purpose of this study which was also aimed at determining the prevalence of inclusion in Malaysian integrated preschool programmes. Instead, the postpositivist knowledge claims - which support the use of data collection on a large scale (Burton \& Bartlett, 2009) - appeared to be a more suited approach for this purpose. Given these considerations, the pragmatic paradigm, which supports the use of both quantitative and qualitative research approaches, appeared to be most suitable for the current study. Particularly, this study fitted well within a pragmatic paradigm - the use of mixed methods to best address the research questions.

\section{Mixed methods research}

Mixed methods is explained as "research in which the investigator collects and analyses data, integrates the findings, and draws inferences using both qualitative and quantitative approaches or methods in a single study" (Tashakkori \& Creswell, 2007, p. 4). There are probably countless ways in which qualitative and quantitative techniques can be employed in a study (Johnson \& Christensen, 2008). 
Most important however, is that the researcher is familiar with the position of each of the methods, the sequence and integration of data collection, and decisions regarding analyses that are made in the study that s/he undertakes (Creswell, 2003).

The type of mixed methods research undertaken in this study was an explanatory sequential design. The explanatory sequential design is a two-phase mixed methods study in which the qualitative data helps describe or build upon initial quantitative results (Creswell \& Plano Clark, 2007). Creswell and Plano Clark (2007) offered two variants in selecting a research method that is of this design, namely the follow-up model and the participant selection model. The latter design was most appropriate to this study (See Figure 5):

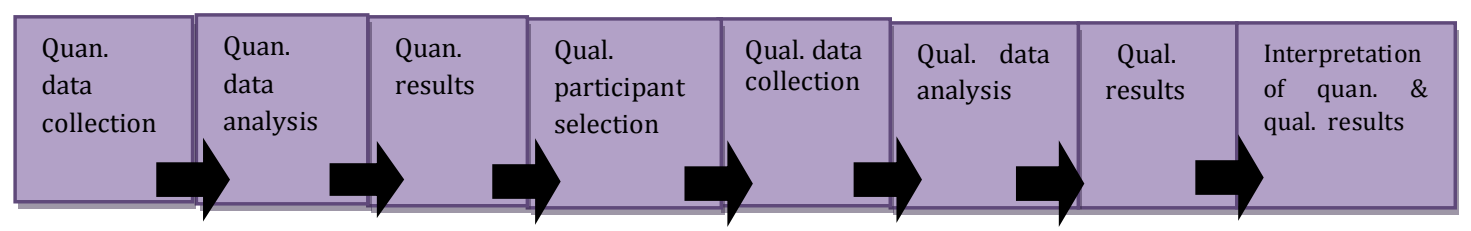

Figure 5: $\quad$ Participant Selection Model (Creswell, 2007)

As Creswell and Plano Clark explain, the participant selection model "is used when a researcher requires quantitative information to identify and purposefully choose participants for a follow-up, in-depth, qualitative study" (p. 74). Accordingly, the study presented in this thesis began with a survey to first determine the prevalence of inclusion in Malaysian integrated preschools. This step was followed by a purposive selection of three integrated preschool programmes, which were identified from the survey analyses as preschools with differing levels of inclusion (i.e., those with most, average, and least). This step was then followed by a second phase of detailed qualitative data collection and analysis in all three sites. Finally, interpretations from both phases of data were used to inform the study and answer the research questions. 
The strength of the explanatory design is that it is considered easy to implement due to the method of collecting data, which is done in two separate phases, one at a time. Furthermore, the report of collected data can be written in two parts, making it straightforward to write and providing a clear explanation and progression for readers (Creswell \& Plano Clark, 2007). Nevertheless, there were particular reasons why a mixed methods design was required for this study. These are explained in the following section.

\section{Rationale for choice of mixed methods research}

Decisions to use mixed methods are often based on the nature of the phenomena being investigated and the context in which the study is conducted (Mertens, 2010; Greene \& Caracelli, 1997). The rationale for selecting a mixed methods approach for this study was primarily based on the nature of the phenomenon I aimed to investigate (preschool inclusion), which is still new in Malaysia.

In the process of developing my research, a preliminary decision I made was to try to gain an understanding of perceptions and practices of inclusion from integrated preschool programmes that represent different levels of inclusion. I decided that equitable answers to why inclusion was practiced differently in each site, how participants made sense of preschool inclusion in each site, and what the factors that affected the practices employed in its service were, would eventually offer credible answers to address the main research problem. As stated by Patton (2002), the underlying principle in using any strategies for qualitative sample selection is selecting information rich cases. That is, "cases from which one can learn a great deal about matters of importance and [which are] therefore worthy of in-depth study" (p. 242). However, since preschool inclusion is still in its infancy in Malaysia, there was limited information available to identify and purposefully select such sites for further investigation, requiring me to gather that information myself. It was at this point - the point at which it became apparent that the use of a survey would make it possible to obtain necessary data on a large scale (Creswell, 2003) that a decision to use a combination of quantitative and qualitative approaches was made. The survey, I intended, would subsequently establish initial information on 
the prevalence of inclusion that covered the population of integrated preschools in Malaysia. Then, findings from the survey could be used as a basis for further purposeful selection of three case study sites that were representative of preschools with different levels of inclusion nationwide.

According to Johnson and Onwuengbuzie (2004), by making the most of quantitative and qualitative techniques and collecting data using different strategies, approaches, and methods within a single study, mixed methods research is likely to result in complementary strengths of both methodologies. This situation was true in the case of my research. The methodologies complimented each other; the decision to begin with a quantitative phase provided initial information that helped with the formulation of interview questions for participants to be used in the qualitative phase, as well as planning of initial observations for further examination in the case study sites. In addition, aggregated qualitative data from interviews, observations, documents, and field notes at case study sites were seen as being able to offer potential information for describing situations identified in the quantitative phase. Conversely, the use of quantitative data from the survey which covered a large population of preschool teachers were able to offer considerable possibilities for the findings of the study undertaken here to be extended beyond the specific individuals and settings in each case study site.

Hence, the use of both quantitative and qualitative data in the study undertaken for this thesis was determined to be the best method to providing strong evidence, with triangulation of data sets making for conclusions that would not have been possible through the use of either type of data alone (Creswell \& Plano Clark, 2007).

\section{Quantitative phase: Survey}

Quantitative research is dependent on the collection of information in the form of quantitative or numerical data (Johnson \& Christensen, 2008). In this study, the quantitative phase involved a survey by questionnaire. This section will discuss the participants, instruments, data collection, and analysis that were used in this phase of study. 


\section{Participants}

As discussed in the opening chapters of this thesis, a variety of preschool programmes exist in Malaysia, but the preschools chosen for this study were integrated preschools, under the jurisdiction of the Ministry of Education (see Chapter 2). Consequently, only preschool teachers who were teaching in integrated preschools were selected as survey participants.

The process of selecting participants for the survey began with obtaining the list of integrated preschools in Malaysia from the Special Education Division at the Ministry of Education. Initially, 122 integrated preschools were listed; however, the personnel at Special Education Division indicated that nine of the preschools that were listed did not run a regular preschool classroom that year. These preschools only had a special education classroom but were still 'technically' listed as an integrated preschool programme because they were located within a regular primary school compound. However, they were not appropriate cases for my study, which focuses on inclusion between preschool learners with and without SEN. Therefore, only 113 listed preschools fitted the criteria for this study.

Preschool teachers from all 113 integrated preschools, dispersed across Malaysia, were invited to participate in a survey by questionnaire. As each integrated preschool has at least one special education preschool teacher and one regular preschool teacher, a total of 226 questionnaires were sent out. I considered that the participation of both regular and special education preschool teachers was essential, since both types of teachers are equally involved in the management and administration of an integrated preschool programme.

\section{Instrument development}

The primary aim of the survey was to establish the present state of inclusive practices in Malaysian integrated preschools. Nevertheless, since regular and special classroom teachers were the respondents, an initial understanding of their views about inclusion was also included as part of the survey's aim. 
The Integrated Preschool Programme Questionnaire (IPPQ) was developed as the survey instrument for this study (see Appendix A). The IPPQ is divided into two sections consisting of 28 questions in total. Items in section one (19 questions) were drawn and adapted from information in the review of relevant literature, which was a useful source of examples of questionnaires that had already proven useful. Items in section two were adapted from "The Autism Program Quality Indicators' (APQI) authored by Crimmins, Durand, Theurer-Kaufman and Everett for the New York Autism network (New York State Education Department [NYSED], 2001).

When choosing specific items to be included, for both sections of the questionnaire I developed, careful decisions were made based on my own judgments and my supervisors' expertise. In particular, close reviews of each item were carried out to ensure that the sampling of items in the questionnaire fairly represented the wider issues being studied.

Items in section one of the developed IPPQ centered on demographic information and teachers' opinions about inclusion. Information on school environment and teachers' personal characteristics are mentioned in several international studies (e.g., Avramidis, Bayliss, \& Burden, 2000; Obeng, 2007) as being influential in shaping teachers' perceptions and practices of inclusion (see Chapter 3) and were therefore incorporated into the questionnaire.

The nine items in section two of the IPPQ were adapted from APQI, and were aimed at establishing the prevalence of inclusion in Malaysian integrated preschools. These items focus on determining the extent to which events and processes that facilitated or promoted inclusion were evident, and required participants to respond by giving a rating, based on given score descriptions adapted from items and score descriptions in the APQI. 


\section{Rationale for adapting $A P Q I$}

The APQI, which was developed to apply to schools and programmes serving children with autism (aged 3-21) in New York State (NYSED, 2001), did not completely fit the educational structure, system, and practices of Malaysian integrated preschools. Nevertheless, some of its items and score descriptions were useful (and practical) in fulfilling the aims of the quantitative phase of my study. Particularly, the APQI is described by the NYSED (2001) as a useful tool for schools and programmes to self-evaluate their educational services as a whole, rather than giving an evaluation of services provided to any specific child. This evaluation is done by rating the extent to which there is evidence supporting the fact that a particular item or practice is in place. For this reason, the APQI is also regarded as a quality improvement tool, by which programmes are able to note their relevant strengths and weakness. Accordingly, the aims and structure of the APQI were applicable to the aim of the survey I undertook to establish the extent to which inclusion was evident in Malaysian integrated preschool programmes.

\section{Adapting the APQI}

Scores in the APQI use a four-point (0 to 3) rating system, plus a 'not applicable (NA)' indicator, which does not represent a score (NYSED, 2001). These scores are described within the range of "no evidence of an indicator" that represents score " 0 " and "this quality indicator is clearly evident for all students with autism" that represents score "3" (NYSED 2001, p. 9). The score descriptions can be applied to each of the items in the APQI and finally a summary rating or score can be obtained, indicating the degree to which a particular item or practice is in place in the programme.

In developing the IPPQ for my study, the original wordings of the score descriptions in APQI that focused on programmes designed for learners with autism were modified to represent the integrated preschool programmes that survey participants were teaching in. For example, 'students with autism' were changed to 'students with special needs'. Section two of the IPPQ was specifically designed to 
obtain a total score identifying the amount of inclusion taking place in Malaysian integrated preschools. This was because a comparison of the total scores was needed to select case study sites. Therefore, the 'NA' indicator, which does not represent a score in the APQI, was omitted from the IPPQ. The 'NA' indicator did not suit the purpose of rating the level of inclusion taking place in the integrated preschools.

Items in the APQI are organised into fourteen areas and seven categories. However, only some items were relevant to the Malaysian context. These I adopted, and adapted, to specifically suit the purpose of the survey. Specifically, the IPPQ employs two areas from APQI, those which came under the headings of:

- $\quad$ inclusion, and

- $\quad$ planning the move from one setting to another

Nine items beneath these headings that were pertinent to the Malaysian integrated preschool context were selected and modified to suit (often by changes to wording). For example, 'the program' became 'the integrated preschool programme', 'general education teachers' became 'regular education preschool teacher'. The criterion considered in choosing the wording for items also considered the suitability of the items to the Malaysian context, and aimed that each responding participant, regardless of background, knowledge or experience, should clearly and easily understand each individual item. The wording and modifications were reviewed by three education academics before the questionnaire was translated into Bahasa Melayu (Malay Language).

\section{Translating and piloting the questionnaire for the study}

According to Mertens (2005), the main priority for the translation process is to ensure that the original intent of the questionnaire is preserved. Hence, in translating the final draft of the Integrated Preschool Programme Questionnaire (IPPQ) to Malay Language, no attempts were made to produce a word for word or literal translation. Instead, the translation was undertaken to make sure that items' contents and meanings were the same in both languages. Initially, I sought the help 
of two other Malaysian postgraduate students to ensure that the items' content and meaning in both English and Malay were the same. The final, translated version of the draft IPPQ was then refined by a colleague who was fluent in both languages.

The reviewed translated IPPQ was piloted with a group of individuals similar to the intended participants. The format was modified a little to allow space for participants to write their comments and the time they took. There were also instructions indicating interest in their reactions to the process of the questionnaire itself, and requesting that they note any vagueness or response options that need to be added or omitted. According to Wiersma and Jurs (2009), such clarifications from pilot groups should enable the researcher to check for ambiguity, confusion, and poorly prepared items.

Self-addressed stamped envelopes and a set of questionnaires were posted to colleagues in Malaysia, who helped to distribute the questionnaires to participants for piloting. Participants involved in the trial run of the questionnaire included both primary and preschool teachers. The reason for including primary school teachers in the pilot study was to increase the number of participants, and also to gauge the clarity of the IPPQ. Furthermore, primary school teachers, who typically have more experience than preschool teachers with integrated schooling programmes, may have had more suggestions to offer in improving the IPPQ. It was also assumed that if none of the primary school teachers in the pilot study encountered problems answering it, then any teacher would be able to respond appropriately to the questionnaire.

A total of 18 questionnaires were distributed for piloting, with seven (38.8\%) being returned. All seven respondents indicated that they had no problems in responding to any of the items and ticked "no" to the question, "Is there any item in the questionnaire you are not clear of?" Nevertheless, based on this pilot study, minor changes and revisions were made before the IPPQ was finalised (see Appendix A). Item 3 was added in section 1, Part A, requesting the type of professional qualification of the participant. Under the choice of answers for item 8, section 1, 
Part A, another box was added for participants to indicate if they had a preference to teach both groups of children instead of only regular preschool children or only children with SEN.

\section{Data collection and analysis}

Prior to sending out the IPPQ, letters of permission were obtained from the relevant authorities in Malaysia. It is a regulation in Malaysia that any foreign researcher, or Malaysian national domiciled overseas, must obtain a permit to conduct research from the Economic Planning Unit (EPU) at the Prime Minister's Department before proceeding with the research. Hence, upon gaining this permit (see Appendix B), the IPPQ were posted to Malaysian integrated preschool programmes with an attached information sheet (see Appendix C), addressed to the principals and preschool teachers of each of the 113 integrated preschool programmes nationwide. The letters detailed the purpose, significance and nature of the research, subsequently inviting regular and special education preschool teachers to participate in the survey. Each integrated preschool programme received two sets of questionnaires, coded with either B or PK followed by a four digit number; B indicating biasa (regular) and PK indicating pendidikan khas (special education). This was necessary in order to differentiate whether the responses were received from regular or special education classroom teachers. Participants were also clearly informed of this coding by a note attached to the questionnaires. The four digit number was a code enabling survey participants to enter a lucky draw, motivating teacher's participation in the survey.

Every questionnaire distributed was accompanied by a stamped envelope addressed to the researcher. In order to enhance the response rate, the preschools were contacted prior to mailing the questionnaires. Approximately five weeks after distribution of questionnaires, a total of 65 (28.8\%) questionnaires were returned. As a follow up, participants who had not responded were contacted through phone calls and where possible personal visits were made to the preschools. When follow up was done, one of the reasons given for non response was that some teachers felt they did not have enough experience to participate in the survey since they had just 
joined for duty as a preschool teacher, and it was their first posting after their graduation. Other reasons for non-response included being away on short courses or maternity leave, or for other personal reasons. Some of the teachers were willing to participate in the survey but had forgotten or misplaced the questionnaires and requested another set. The follow up resulted in a final total of 81 (35.8\%) questionnaires that were received from the survey.

\section{Analysing questionnaire data}

A preliminary analysis of the 81 questionnaires was carried out to select case study participants. Descriptive statistics in the form of individual scores, total scores, and mean score count were employed to obtain a summary description of practices of inclusion in every integrated preschool programme.

Both regular and special classroom teachers' score ratings were used to measure the level of inclusion taking place in their preschool (detailed analyses of the questionnaire are discussed in Chapter 6). Case study sites were then selected based on the mean scores of both teachers' ratings. Only questionnaires that came back in pairs, where both regular and special classroom teachers had responded were considered for case study selection. I intended that once case study sites were selected, both regular and special education teachers would be involved in the interview process, hence a non-response from either teacher was presumed as a lack of interest of the teacher in participating in the second phase.

More detailed analyses of the whole questionnaire (sections one and two) were carried out only after the whole process of data collection (quantitative and qualitative) was completed. The detailed statistical analyses of the quantitative data were carried out using Statistical Package for Social Sciences software (SPSS), Version 18. Nominal and ordinal data in sections one and two in the questionnaire were converted to descriptive and comparative statistics to obtain a general description of preschool teachers' perceptions and practices of inclusion in Malaysian integrated preschools. 
Teacher's written comments on open-ended questions in the questionnaire were analysed and incorporated into the findings. As suggested by Miles and Huberman (1994), all responses from the open-ended item were first examined so that the consistency of the contents, and codes associated with each of the responses, could be established. These codes were then categorised under themes derived from the literature and supporting theoretical perspectives.

To ensure the consistency of the coding process, an independent second coder was assigned to code the responses as well. This was done by first training the second coder (coder 2) based on an inter-coder reliability instruction and code sheet (see Appendix D). Detailed explanations for coding each theme were given, and several practices were carried out using responses from the pilot study. The researcher and the second coder compared notes and reconciled any differences that showed up before each began independently coding the open ended responses to the questionnaire. Finally, the reliability of coding was checked using percent agreement (see Chapter 6 for details).

\section{Qualitative phase: Case Study}

The qualitative phase of the research conducted for this thesis employed case study research. Case study research represents a specific tradition within the qualitative research paradigm (Creswell, 2003) and is used primarily when researchers wish to obtain an in-depth understanding of a relatively small number of individuals, problems, or situations (Patton, 1990). A case study is often set in an environmental, institutional, temporal, or other context that allows boundaries to be drawn around the case with reference to characteristics defined by individuals and groups involved, and their roles and functions in the case (Cohen, Manion, \& Morrison, 2000). The boundaries of the phenomenon are established by the researcher, determining what the case is and is not (Creswell, 2002; Johnson \& Christensen, 2008). This is then followed by researcher(s) paying meticulous attention to the activities in the bounded system, and making sense of, and optimising, their understanding of complex aspects of the studied phenomenon (Merriam, 2002; Stake, 2005). 
Accordingly, the focus of the research conducted for this thesis is the state of inclusion and educators' and parents' perceptions of it in Malaysian integrated preschool programmes. Hence, the selected event is inclusion, and subsequently the sites chosen as case studies were preschools that were implementing integrated programmes. Additionally, only teachers, principals, and parents involved in these programmes were included as participants. Their perceptions, and the events going on around them in the integrated preschool programme, were analysed in addressing the research problem.

That case study research endeavours to portray the participants' lived experience of, thoughts about, and feelings for a given situation (Cohen et al., 2000) is what made this method suitable for the current study. The use of case study methodology, which requires data collection through personal direct contact with the people, situation, and phenomenon under study (Merriam, 2002), made it possible to gain insights about inclusion in integrated preschools through the ways in which educators and parents viewed and interpreted the issue. In addition, this method of data collection also provided a comprehensive description of the people, events and situations at work in the preschool, in order to adequately address the research problem.

\section{Multiple site case studies}

Of the three types of case studies - intrinsic, instrumental, and collective case study (Stake, 1995) - the type that was most relevant and suitable to the research conducted for this thesis was the collective case study model. According to Johnson and Christensen (2008), the intrinsic case study is the classic single case design in which the researcher is interested in understanding a specific case. An instrumental case study is when the researcher's main interest is in understanding something other than the particular case. The collective case study is found to be suitable when the researcher "believes he or she can gain greater insights into a research topic by concurrently studying multiple cases in one overall research study" (Johnson \& Christensen, 2008, p. 408). This type of study is also known as the multiple-case design (Yin, 1994). While all designs can lead to successful case 
studies, when a researcher has the choice (and resources), multiple-case design is often a better option than single-case design, because it enables the researcher to study similar objects in order to identify how representative each case is within similar cases and situations (Stake, 1995). However, each individual case in a multiple case study design must be chosen carefully, and be supported by valid reasons for the contrasting or replication of features of each case (Yin, 2003).

The use of multiple site case studies was found to be suitable for this thesis due to the nature and context of the situation it addresses, especially as little is known about preschool inclusion in Malaysia. The use of three sites, which had differing levels of inclusive practices but were similar in their administrative structure, made it possible to compare and contrast the findings from each site, thus providing better understanding of the research issue.

Furthermore, the use of multiple-case study is more likely to gather evidence that is more convincing to make a generalisation of the results as compared to results obtained from a single case (Johnson \& Christensen, 2008), meaning the overall study could therefore be regarded as more rigorous. Nevertheless, the use of multiple site case study method requires extensive resources and is regarded as more time consuming than a single case design (Creswell, 2002; Merriam, 1988; Yin, 2003).

\section{Selection of site, participants, and events}

The three case study sites in this study were selected using a purposeful sampling method, which according to Merriam (1998) is the most common method used in choosing a case in qualitative investigation. The first criterion for choosing case study sites for this study was selecting three integrated preschool programmes which, based on questionnaire analyses, had the highest, lowest and median score for evidence supporting events and processes facilitating or promoting inclusion.

I intended that a comprehensive picture of inclusion in Malaysian integrated preschools would require educators' and parents' support. Hence, the school 
principal and preschool teachers who were serving in the integrated preschool programmes I approached, and parents of children enrolled in the integrated preschools at the time of research were included as case study participants.

Consequently, the second most important criterion for selecting case study sites was that educators and parents at each preschool were willing to participate and provide the relevant information to address the research questions. Hence, before confirming participation of the selected case study sites from questionnaire analyses, some formalities were followed. Since the research was conducted in government schools, an approval from the Education Planning and Research Development (EPRD) of the Ministry of Education in Malaysia was first required to gain access to schools. Then, permission to conduct research at each site was obtained by meeting the principals of each school and handing over the approval letter from the EPRD, explaining the nature of the study to the principals at each selected site, and inviting them to participate in the study.

After each principal had confirmed their willingness to participate in this study, the regular and special education preschool teachers were invited to participate. Teachers' help was sought to identify and invite parent participants. All participants were provided with an information sheet explaining the study (Appendix E), a letter inviting them to participate in the study, and a statement of consent to be signed, thus indicating that they were willing to participate in the study (Appendices F, G and H).

The initial intention was to have five participants in each of the case study sites: the principal, the regular and special education preschool teachers, and one parent from the regular and the special education preschool classroom under examination respectively. However two of the case study sites had two regular preschool classrooms each and both of the regular classroom teachers were willing to participate in the study. This increased the number of regular classroom teacher participants at each of those sites. Table 4 describes the total number of participants in the qualitative phase of research. 
Table 4: $\quad$ Case study participants

\begin{tabular}{lcccc}
\hline Case study sites: & School 1 & School 2 & School 3 & $\begin{array}{c}\text { Total } \\
\text { participants }\end{array}$ \\
\hline Principal & 1 & 1 & 1 & 3 \\
Special education preschool teachers & 1 & 1 & 1 & 3 \\
Regular education preschool teacher & 1 & 2 & 2 & 5 \\
Parent of preschooler with SEN & 1 & 1 & 1 & 3 \\
Parent of typically developing preschooler & 1 & 1 & 1 & 3 \\
Total participants & 5 & 6 & 6 & 17 \\
\hline
\end{tabular}

\section{Data gathering}

Data gathering involved visits to the case study sites in three stages. The first stage, which was scheduled for two or three visits per site, allowed the researcher to build rapport with participants, and the participants and students to get used to the researcher's presence. This was intended to help them overcome any initial inhibitions so that daily classroom activities could carry on as usual and subsequently help to facilitate data collection. Furthermore, these visits were also important for the researcher to be familiar with the routines and surroundings in each preschool before data collection commenced. The second stage site visits were to carry out observations and interviews, and to collect and examine physical documents and materials found in the study setting. In the third stage of site visits, attention was given to clarifying data with teachers and other participants concerned.

\section{Instruments for data gathering}

In a qualitative case study, the researcher plays the important role of being the primary instrument for data collection and analysis (Merriam, 1988). The researcher, as the instrument, is responsive to the context of the study by adapting their techniques to the circumstances, as well as summarising, processing, and clarifying data as the research evolves (Guba \& Lincoln, 1981). As discussed at the beginning of the chapter, the data gathering process I employed in my research was 
aligned with a pragmatic paradigm. Since case study research is defined and described from the perspective of the qualitative or naturalistic research methods (Merriam, 1988), constructivist views mostly guided the decisions I made during the case study process. That is, an interactive approach for data collection was chosen, in which priority was placed on gaining participants' views of inclusion and practices (or non-practices) of it in the preschool, but in which the researcher's account - my own account - of inclusion in each site was also seen as pivotal in gaining first-hand information, and capturing the close-up reality of inclusion in Malaysian integrated preschool programmes.

Therefore, I took an eclectic approach in terms of data collection; multiple methods and multiple sources were decided upon to help me understand the case and answer the research questions. Relating this decision to case study research, Merriam (1988) explains, "the opportunity to use multiple methods of data collection is a major strength of case study research exceeding that in other research strategies, such as experiments, surveys, or histories" (p. 69). In this study, individual interviews, observations and examinations of relevant documents were the main sources of information gathering in the qualitative phase. The use of multiple sources of data within my case studies also enabled triangulation, which according to Creswell (2003) and Merriam (1998) enhances and establishes truthfulness of the data collected.

\section{Individual interviews: teachers, principal, and parents}

In conducting the research for this study, in-depth interviews were carried out with regular and special education preschool teachers, school principals, and parents of preschoolers with and without SEN. Interviews are a foremost source of data in qualitative cases studies (Merriam, 1988) because interviews not only allow researchers to find out from the participants the things that cannot be observed, it also allows the researcher to enter into their participants' perspectives, and to find out what is in and on their participant's minds (Patton, 2002). 
The interviews in this study sought to discover participants' interpretations, and constructions of meanings about inclusive practices, their beliefs about inclusion, and to locate factors that influenced practices of inclusion in the integrated preschools they worked in relation to. The information gained from educators and parents through in-depth interviews provided significant information about each school's philosophy towards inclusion, as well as about the level of support offered by educators and parents towards inclusion, and the subsequent factors affecting the state of inclusion at each site.

During this process, individual, face-to-face, semi-structured, and open-ended interviews were used. The semi-structured form of interviewing was used because of the method's strength in ensuring cross-case comparability (Merriam, 1998; Patton, 2002). For each group of participants (teachers, principal and parents), a list of semi-structured questions served as a guide (see Appendix I). The guide consisted of main questions addressing the issues to be explored, and were helpful for ensuring that interviews were carried out systematically and comprehensively. Probing questions during the interview helped to further clarify participants' interpretations, feelings, and opinions about inclusive education and practices of it in integrated preschool programmes. Commonly used probes were "Can you explain a little more...?"

A trial run of the semi-structured interview questions was conducted through role playing sessions with colleagues in Malaysia. These sessions were recorded and replayed to listen for ways to improve questioning techniques. On site, before carrying out the interviews, conversational encounters with participants were also initiated. These conversational encounters also helped to gain some knowledge about situations within the case study setting, and to formulate questions for subsequent interviews.

Interviews were carried out with principals and teachers according to a schedule for timing drawn up in consultation with them. Following this, the advice of preschool teachers was sought in nominating parents to approach for interview. 
Regular preschool teachers nominated parents of regular classroom children, and special education preschool teachers nominated parents of children with SEN. All interviews were carried out in places that were selected by the participants. Interviews with the schools' principals and teachers were all carried out within the school compound. However, interviews with all except three parents were conducted outside the school at a location of their choice.

Malay is a language commonly used and understood by all Malaysians. Therefore, the use of Malay language seemed the most appropriate when the interviews were carried out. Furthermore, terms such as inclusion, inclusive education, special needs, and integrated could be referred to by using the terms that participants were used to. As stated by Patton (1990), "the clarity of interview questions [depends] on understanding what language participants use among themselves in talking about program activities or other aspects of the program life" (p. 310). However, when interviewing parent participants some terms needed to be explained at times when those participants were unsure of the terms used.

Another very common practice among Malaysians is the use of multiple languages in a conversation or discussion. A mixture of two languages (English and Malay) did take place at times during the interviews- except with one parent participant who preferred speaking in Tamil. In short, while I began each interview in Malay, there was no emphasis on the use of any one language in particular during interviews, as I decided that participants' views would be better represented if participants felt free and able to voice their opinions, ideas, and views in a way they felt comfortable with.

\section{$\underline{\text { Recording interview data }}$}

It is extremely important to capture the actual words, and as much additional information as possible during an interview to ensure that everything said is preserved for analysis (Merriam, 1998; Patton, 2002). Hence, with permission from the interviewees, all interviews were audio recorded. The recording of the interviews also helped in making the interview process run smoothly. This was 
because I was able to be more attentive to the needs and cues of participants, worrying less about writing down every word that was spoken.

All the interviews were then transcribed to facilitate data analysis. Transcribed interviews were presented back to participants and we checked their accuracy together. Some participants added more details to make their explanations given during interview clearer. Interview transcripts were then translated to English with the help of a translator.

\section{Observations}

As mentioned earlier in this chapter, the constructivist view guiding methodological decisions about case study research emphasises the understanding of the context or environment in order to try and understand the phenomenon under study (Denzin \& Lincoln, 2005). This is also consistent with the theoretical perspectives that guide this study as a whole, which point out that the processes at work in a preschools' environment are able to provide significant insights into how inclusion is perceived and supported in the preschool. Therefore, as part of the inquiry process detailed observations of the preschool setting were carried out.

While conducting my research, at all times, and during all visits to the preschools, I maintained the role of a non-participant observer. Observations included features within the preschool context, such as the ways in which daily preschool activities were carried out, and how artifacts, space and furniture were used and arranged in each site. It was assumed that such features could influence how inclusion is practiced and perceived by the surrounding preschool community.

As suggested by Gillham (2000), my observations consisted of three main actions: watching, listening and asking clarifying questions. During initial observations, field notes were taken. These notes contained diagrams and written description of activities and settings at each site, such as the playground, physicality of the buildings and facilities, and special equipment for children with special needs, plus questions to follow up on. Later observations involved descriptive field notes 
concentrating on how daily lessons were put into practice, and on situations and events of inclusion and/or exclusion experiences among preschool children. Notes on regular and special education teachers' planning of activities, such as their scheduling and routines, were also made. The field notes also described when, where, and under what conditions the observations were made, an essential component of rigorous fieldwork (Wiersma \& Jurs, 2005). Following site observations, short informal interviews (chats) were carried out with teachers whenever there was an opportunity. This was mainly done during their break time or after preschool hours. Field notes were made that reflected my personal account of my observations, including inference and interpretations of the observations made. An observation guide was also prepared, to ensure that all necessary observations were made (see Appendix J).

\section{Document examination}

The third source of data at each case study site involved documents and materials found within the preschool setting. According to Merriam (1988), documents of all types can furnish descriptive information and can offer further understanding, uncover meaning, and provide insights relevant to the research problem. In this study, both the National Preschool Curriculum for typically developing children and the Preschool Special Education Curriculum for children with special needs were among the formal documents examined. The curriculum was used to identify similarities in suggested skills, approaches and/or topics used in preparing daily lesson plans by both types of educator interviewed at each preschool.

Other written materials found within the study setting such as, teachers' daily teaching records, reports of activities, parent information books, Individual Education Plans of preschoolers with SEN, the school's annual plan of activities, and other materials that can provide information significant to the research were also examined. I found several such items at each site, and all were photographed or photocopied as document sources. However, specific permission was requested from the principal and preschool teachers at each site, before copies or photographs of the relevant materials were taken. 


\section{Data management and analysis}

Generally, the steps involved in data management and analysis in qualitative research are data preparation and organisation, data exploration, data analysis, and finally the display of results (Mertens, 2005; Patton, 2002). However, these are suggestive and not prescriptive steps to be followed (Patton, 2002). The analysis of qualitative data is inevitably a personal process and every researcher will have their own preferred way for interpreting and analysing the information they have gathered (Patton, 2002; Smith \& Osborn, 2008).

In conducting this study, data management was fundamental because there were multiple data sources. Developing a record for each case study site involved the sorting of data in order to locate specific data during intensive analysis. Hard copies of all qualitative data were stored in files according to each preschool, and were labelled accordingly for easy retrieval.

The definition of Miles and Huberman (1994) in qualitative data analysis "as consisting of three concurrent flow of activities" (p.10) was applied when analysing case study data for each site: (1) data reduction - where data was reduced through such means as selection, summary, and paraphrasing and decision-making about which data provided initial focus; (2) data display - where the reduced data was organised by assembling the information so that conclusions could be drawn; (3) conclusion drawing and verification - coming to a decision as to what things mean by noting regularities, patterns (differences/similarities), explanations, possible configurations, causal flows, and propositions.

Both inductive and deductive approaches were used for data analysis. In the data reduction process, content analysis was used to identify and code all case study data, field notes, and observation reports, by identifying the primary pattern in each. The coding of data was carried out manually. It began with reading and rereading, systematically working through the entire data set to code the passages. Any data with issues of interest to the study were written against with pencilled 
notes. As pointed out by Braun and Clark (2006), in manual coding, data can be coded by writing notes on the texts that is being analysed, "using highlighters or coloured pens, to indicate potential patterns, or by using 'post-it' notes to identify segments of data" (p. 89). The repeated readings at this stage helped me to get to know the qualitative data very well. It facilitated and called for a reasonable accounting of the perceptions and practices of inclusion within each case analysed. The initial questions of what was going on and how things were proceeding became progressively clearer within each case study site. Varying ideas were identified at this stage.

The next step involved assembling the information from the coded data by developing categories. Existing literature, which has revealed regularities and irregularities in the ways inclusion is perceived and practiced (see Chapter 3), informed and guided the development of categories for analysing the data that emerged in each case. Similarly, the research questions also influenced my thinking about potential categories to be found in the data. My initial interest in the nature and extent of inclusion, and in educators' and parents' perceptions of it, intensified as the data revealed the extent to which each school did or did not provide opportunities for children with SEN to interact with their typically developing peers, and shed light on what the school community thought about it. Consequently, I decided that a detailed description of each case study site was the best way of displaying the findings.

Within each case study, analysis was carried out, which resulted in an individual case description for each site (see Chapter 7), prior to cross-case analysis (Merriam, 1998). The report for each site was summarised by stating the themes that emerged from each site, subsequently enabling patterns in the data across the three case study sites to be compared and contrasted, before integrating them with my quantitative findings (see Chapter 8). 


\section{Issues of validity and reliability in the study}

The key concern for all research is ensuring the quality of the research in terms of its credibility and trustworthiness (Mertens, 2010). Because this is a mixed methods study, issues related to both the qualitative and quantitative data collection methods were taken into account in order to maintain the authenticity of the research.

\section{Quantitative issues}

Validity determines whether the study truly measures that which it was intended to measure (Mertler \& Charles, 2011). In this study, content validity of the questionnaire was determined by examining each item and relating it to the main issues to be covered in the research. For section one of the questionnaire (which centred on demographic information and teachers' opinions about inclusion), this was done by scrutinising relevant information in the surrounding literature and examining the mechanics of similar studies already carried out, and examining inclusion and its related issues.

In the case of the second part of the questionnaire (which centred on determining the prevalence of inclusion), items and scales were adapted from the APQI. The items in the APQI have already undergone field testing, and the working drafts of this tool have been shared with programme representatives, advocacy groups and other national experts in the context of its development (NYSED, 2001). This indicates that the resulting document of the APQI has been strengthened considerably by the input of many people with expertise and experience in the field of special education. Furthermore, as stated in the previous section (see instrument development) items that were included in both sections of the questionnaire used in this study were carefully reviewed, ensuring all items fairly represented the wider issue of the study, before a pilot study was carried out. The pilot study, carried out with a group similar to the study's actual participants, also helped to identify and rectify items that might be misinterpreted by participants; ensuring items in the questionnaire were specifically serving the purpose of the study. 
Reliability of research concerns the consistency of methods, conditions, and results (Wiersma \& Jurs, 2005). In order to maximise the reliability of the quantitative phase, possible sources of error were identified and measures were taken to overcome them. In this study, one possibility of error could have arisen from participants' understanding of items in the questionnaire. Although all the participants were educators, some of them might have different individual understandings of what is meant by inclusion, especially regular preschool teachers. Furthermore, the integrated programme at the preschool level is a new venture in Malaysia, and so some preschool teachers, new to their positions as integrated preschool teachers, may just be getting used to their roles and responsibilities in these preschools. Hence, clear explanation of this term was indicated on the cover letter to maximise the accuracy and reliability of participant responses.

\section{Qualitative issues}

Validity, which is also seen as a strength of qualitative research, is used to suggest whether the findings are accurate from the standpoint of the researcher, the participant, or the readers (Creswell, 2003). Issues concerning validity in qualitative research are mostly discussed in terms of the credibility and trustworthiness of the research, and relate to believability, based on coherence, insight, and the usefulness of the instruments (Eisner, 1991).

In this study, the main technique of verification entailed data and method triangulation. Different data sources of information were triangulated by examining evidence from the sources and using them to build plausible explanations about preschool inclusion in integrated preschools. Diverse evidence from interview data, observational field notes, and document verification were used to answer the research questions with the express purpose of viewing issues important to the study from more than one perspective.

Member checking was also carried out by returning interview data to participants for their comments and feedback. This was done to avoid any misinterpretation or misunderstanding of participants' words or actions. Member checking allowed the 
participants to suggest additions and deletions in order to convey their message the way they thought it should be conveyed.

Dependability was established by the use of peer debriefing. Constant meetings and discussions with supervisors, student learning support services, and fellow PhD students, who reviewed and asked questions about the study so that my explanations would resonate with people other than the researcher, enhanced the accuracy of this study as a whole.

\section{Ethical considerations}

As Merriam writes, "concerns about validity and reliability are common to all forms of research, as is the concern that the investigation be conducted in an ethical manner" (1988, p. 178). Because social science research involves gathering information from people and the activities that they (people) are involved in, questions of research ethics and the impact of the research on the people participating must be a substantial part of every researcher's methodological decisions (Oliver, 2008). The main considerations are that steps should be taken to "treat the research participants with care, sensitivity and respect for their status as human beings" (Oliver, 2008, p. 115), ensuring that they are fully informed about what is taking place relating to them as part of the research process (Oliver, 2003). Ethical approval for the study was obtained from Victoria University of Wellington through the Faculty of Education Ethics Committee (see Appendix K).

To ensure that all research participants were treated with respect, fully informed and not harmed during the research process, this study adhered to some key ethical principles. One of the most important principles of research ethics is informed consent (Kearney, 2009). Whilst providing research participants with an understanding of the research being undertaken, and any disadvantages or commitment involved, this principle ensures that the participant's entry into the research is voluntary (Bogdan \& Biklen, 2003). In this study, participants were provided with clear and open information concerning the purpose and procedures of the study through written information sheets (see Appendix C and E). 
The information sheet provided participants with comprehensive descriptions about the purpose of the study, their roles in the study, procedures for the study, and the use of data. Both mine and my supervisor's contact details were provided, so that participants had the opportunity to clarify or ask questions about the study whenever they wished. Interview participants were provided with further opportunities to discuss anything about the research, and to ask questions before their interviews. In addition to being fully informed of the processes involved, the principle of informed consent also means that participants should be under no coercion to take part in the research (Clark, 1997). In this study, the participants' choice to be involved was confirmed through voluntary consent. Every participant was provided with a letter, among other information, explaining to them they could withdraw from the study at any stage without any negative consequences, consequently assuring them that they were not placed under any form of pressure or force to take part in the study (see Appendix F, G, and H).

Maintenance of privacy and confidentiality are also among the fundamental features of research ethics (Salkind, 2009). According to Salkind (2009) the maintenance of privacy within research speaks to several concerns, but most directly to anonymity. Anonymity protects the identity of the person providing data for the research, ensuring $s /$ he is not identified in the final reporting of the research. In this study, the use of pseudonyms protected participants' identity. Because participants' work roles (i.e., principal, regular / special classroom teacher) were used when data was described and discussed, pseudonyms were used for both participants and the preschools involved, further ensuring that participants' anonymity was effectively secured.

Confidentiality, on the other hand, is upheld when anything that is learned from or about the participant is kept in confidence (Oliver, 2008, Salkind, 2009). To assure participants' confidentiality means that only the researcher will have access to the data, and that discussions with participants will not be repeated (Oliver, 2008; Wiles, Crow, Heath, \& Charles, 2006). This means that it is not possible to offer absolute confidentiality in the case of a research thesis, as data will be shared with 
supervisors, followed by examiners and other readers (Oliver, 2008). Thus the ethical issue for a thesis like this is to therefore ensure that participants are provided with an understanding of the limits to their anonymity and confidentiality while involved in the study before they provide their data (Oliver, 2008). In this study, participants were informed of these issues in the information sheet. However, steps were also taken to maintain the strictest of confidence. All soft copies of data were stored in a password protected computer and hard copies were stored in locked cabinets. Because a person other than the researcher translated the interview transcripts, the translator was required to sign a confidentiality agreement (see Appendix L), confirming her understanding to keep in confidence to all data that was translated. Additionally, the translator was not provided with the names of the participants, the preschools or its location.

Researchers also have an ethical responsibility to ensure steps are taken to minimise the risk of harm or discomfort to their research participants (the principal of non-maleficence) (Israel \& Hay, 2006). In this study, potential harms to participants were identified. Parent participants may have endured psychological harm or discomfort when recollecting experiences of their child with SEN's treatment (for example, rejection) in regular educational settings. Similarly, teachers may have felt uncomfortable recalling situations or teaching experiences that may have caused distress to them. However, steps were taken to minimise situations that caused discomfort to participants by informing them of their right not to answer any questions that they did not wish to answer, or felt uncomfortable with.

Other situations of potential harm related to specific factors impacting inclusive practices in the preschools examined. That is, the state of inclusion or segregated practices in integrated preschool programmes that were associated with the level of support, commitment or co-operation from fellow workmates, school personnel were likely to be identified and reported. The impact of these situations were minimised by informing participants of these likelihoods prior to gaining their 
consent to participate in the study, and by taking the needed measures to protect their anonymity as discussed earlier in this section.

Whilst this study did not directly involve children participants, it was primarily carried out in premises that involved young children with and without SEN. Hence, the needs of these children were also taken into account when considerations were made in relation to minimising the risk of harm or discomfort to participants. The study was carried out as unobtrusively as possible to avoid interference with the normal activities of the children in the preschool. In addition, teachers were also requested to let the researcher know if the presence of the researcher was creating discomfort for the children (through verbal or body language indications), in which case the researcher would temporarily stop the procedure. Accordingly, Salkind (2009) states, "the rights of the child supersede the rights of the investigator no matter what the age of the child" (p. 85).

\section{Chapter summary}

This chapter discussed the inquiry undertaken preceding and during the data collection stage of this study, and explains the building of a research process based on the assumption that collecting both quantitative and qualitative data best provides an understanding of the research problem. During research for this study, data collection and analytical procedures were guided by pragmatic views. Within this view, data from both quantitative and qualitative phases are seen as being able to provide a comprehensive overview of how inclusive education is practiced and perceived by educators and parents in Malaysian integrated preschools.

Besides presenting a rationale for the selection of a mixed methods study, this chapter also presented details pertaining to the selection of instruments and methods of data analysis in quantitative and qualitative phases. Finally, issues relating to validity, reliability and ethics discussed. Having described the approach undertaken in conducting research for this study, the next chapter will look the findings that emerged from its use. 


\section{CHAPTER 6 \\ -Quantitative Data: Questionnaire Findings-}

\section{Introduction}

This is a sequential mixed methods study that began with a survey. The primary aim of the survey was to determine the prevalence of inclusion in Malaysian preschools that implemented the integrated programme. The survey respondents were both regular and special classroom teachers in the preschools. Data obtained from the Integrated Preschool Programme Questionnaire (IPPQ) developed for this study (Appendix A) will be presented in this chapter.

First, general information regarding each respondent's profile and their preschool settings will be described. The presentation of the data will then be organised by addressing the following three research questions:

- To what extent is inclusion practiced in Malaysian integrated preschool programmes?

- How do the preschool teachers perceive the idea of inclusion and to what extent are they supportive of its implementation in Malaysian integrated preschool programmes?

- What are the factors that may be influencing the implementation of inclusion in Malaysian integrated preschool programmes?

\section{Findings}

\section{Response rate}

As stated in the previous chapter, integrated preschool programmes in Malaysia refer to preschools that are made up of regular and special education classrooms within a shared compound. A total of 226 questionnaires were sent out to one regular classroom teacher and one special education classroom teacher in each of the 113 such preschools in operation nationwide. There was a response rate of 
$35.8 \%(\mathrm{~N}=81)$. The analyses reported in subsequent sections are therefore based on these 81 responses.

\section{Characteristics of respondents}

\section{General characteristics}

Of the 81 teachers who responded to the survey, $48.1 \%(n=39)$ were regular classroom teachers and $51.9 \%(n=42)$ were special education classroom teachers. The respondents included 75 (92.5\%) female and six (7.4\%) male teachers.

\section{Experience teaching integrated programmes}

Respondents' experience of teaching in integrated preschool programmes ranged from one to five years. Given that the integrated preschool programme has only recently been established, the limited experience indicated by respondents was not surprising. The majority, or $33(41.8 \%)$ of teachers participating stated at least two to three years of such experience. Twenty one $(26.6 \%)$ had taught for one to two years, and another 17 (21.0\%) had four to five years of such experience.

\section{Education and training}

Twenty-one (53.8\%) of the regular classroom teachers and $19(48.7 \%)$ of the special classroom teachers had college or graduate training in preschool education. Only fifteen $(18.5 \%)$ of the total respondents $(\mathrm{N}=81)$ had obtained college or graduate training in special education. Out of them, 10 (23.8\%) were special education teachers and five (12.8\%) were regular teachers.

Findings also showed that of the 81 respondents, 32 (39.5\%) special classroom teachers and nine (11.1\%) regular classroom teachers had indicated that they had attended special education related courses during their training. Another 27 $(33.3 \%)$ responded that they did not have such training, and the rest $(n=13 ; 16.4 \%)$ did not indicate in their responses whether they had attended such courses, or had not. Interestingly, however, whilst all 42 special educators involved in the survey indicated that they had had opportunities to attend courses relevant to special 
education since qualifying as a teacher (i.e., in-service professional development), none of the regular teachers had indicated having such an opportunity with regard to special education.

\section{Teaching preference}

Twenty-nine (69\%) out of the 42 special education teachers who responded to the survey indicated that they preferred to teach only preschoolers with SEN. The rest of the special education teachers (31\%) indicated that they liked to teach both groups of preschoolers (i.e., those with SEN and typically developing preschoolers). Conversely, $35(89.7 \%)$ out of the 39 regular teachers who participated in the survey indicated preference to teach only typically developing preschoolers. Only two $(10.1 \%)$ indicated that they liked to teach both groups of preschoolers.

\section{Characteristics of respondents' preschools}

Out of the 81 responses received, 76 questionnaires came back in pairs. That is, both regular and special classroom teachers in the preschool had responded (i.e., 38 preschools altogether) and five other questionnaires came back singly (i.e., either the regular or special education classroom teacher did not respond from the particular preschool). This brought the total number of preschools involved in the study to 43 .

Of these 43 preschools, 23 (53.5\%) of them had the special education classroom located within 100 metres of the regular classroom in the school's compound. Five $(12.2 \%)$ of them had the special education classroom and the regular education classroom attached side by side. Fifteen (34.9\%) others had the special education classroom located more than 100 metres from the regular classroom within the school's compound.

Forty one (95.2\%) of the preschools reported nine or less preschoolers with SEN in the special education classroom. Out of these, twenty-seven of them (64.3\%), the majority, had four to six preschoolers with SEN in the special education classroom, 
and only two of the preschools had 10 to 12 preschoolers with SEN in the special education classroom.

\section{Inclusion in integrated preschools}

This section integrates the analyses of data from section one and two of the IPPQ, organising them under the research questions stated earlier in this chapter. Regular and special education teaches' responses were analysed according to item content and summarised as figures and tables. Descriptive analyses (frequency, percentile, mean, and standard deviation) were used to describe the state of inclusion. Teachers' written comments on open ended questions were also analysed, to explore their views on inclusion in Malaysian integrated preschool programmes. In addition, statistical tests were used to examine differences in the findings. All data were analysed using SPSS 18. The level of significance used for the various statistical tests was set at 0.05 , and all $p$ values reported here are for twotailed tests.

\section{Research Questions:}

- To what extent is inclusion practiced in Malaysian integrated preschool programmes?

In addressing this research question, a general overview of processes in the preschool that are identified with inclusion, and sources of exclusion segregated practices were examined. This was done by analysing: (a) whether the inclusion of children with SEN into regular classroom is initiated; (b) the extent to which children with SEN have opportunities to interact with their typically developing peers in the integrated preschool setting; (c) the extent to which processes facilitating practices of inclusion were evident in the preschools.

The analyses of part (a) and (b) refer to items in section one of the questionnaire. For part (c), items in section two were analysed. Responses based on rating scores and score descriptors in the questionnaire that were adapted from the APQI (NYSED, 2001) were analysed first to determine the extent to which events and processes that facilitate or promote inclusion were evident in Malaysian integrated 
preschools. Then, each respondent's score ratings of the extent to which these events and processes were available in their centre were compared to select three sites (i.e., sites with highest, average, and lowest score) for the qualitative phase of inquiry.

\section{(a) The initiation of inclusion in integrated preschool programmes}

Of the 81 teachers who participated in the survey, 79 (97.5\%) of them responded to the question asking if anyone in their preschool had initiated the idea of including preschoolers with SEN into regular preschool classrooms. A significant number responded $(55,67.9 \%)$ that this process was not applicable in their preschools. Another $20(24.7 \%)$ of them indicated that it was the special education classroom teacher who initiated this practice in their preschools, and four (4.9\%) reported parents as initiating the inclusion of preschoolers with SEN into regular classrooms.

A total of 69 (85.2\%) participants responded with information as to who had made the final decision on whether or not to include preschoolers with SEN into the regular preschool classroom. Yet again, 50 (61.7\%) out of the total participants who responded to this question indicated that this process was not applicable in their preschools. Ten (12.3\%) of them reported that it was a shared decision between the regular and special education teachers. Six others (7.4\%) indicated that it was a shared decision between the teachers and the parents. Another three $(3.7 \%)$ responses indicated that it was a shared decision between the teachers and the principal.

\section{(b) Opportunities for interaction among children with and without SEN}

The extent to which children with SEN had opportunities to interact with their typically developing peers were analysed based on (i) the types of activities that children with and without SEN engaged in; (ii) the frequency of their interaction over a given period; (iii) and the proportion of children with SEN who had opportunities to interact with peers in the regular classroom. 
(i) Types of activities

There were four types of activities listed in the questionnaire for respondents to select from. These were: activities during lessons (academic integration), structured outdoor activities, activities during recess/playground, and during assembly. Among these activities, academic integration and structured outdoor activities are those that would typically involve teachers' intentional planning and coordination to ensure there is meaningful participation of preschoolers with and without SEN in shared activities. On the other hand, opportunities for preschoolers with SEN to liaise/ interact with their typically developing peers during assembly or playground/ recess would typically take place by chance. In addition to the activities listed in the questionnaire, there was also space for respondents to list other activities they had observed, participated in or found relevant. There was no limit to the number of activities that the respondents could select or state.

As shown in Table 5 the combined information from regular and special classroom teacher respondents suggested that on the whole, shared activities among preschoolers with and without SEN were mostly those involving activities that took place by chance, without much planning or initiation on the teachers' part.

Table 5: Opportunities for interaction between preschoolers with and without SEN

\begin{tabular}{lccc}
\hline Types of activities & \multicolumn{2}{c}{ Respondents (N=81) } & \multirow{2}{*}{$\begin{array}{c}\text { Total } \\
\text { responses } \\
\text { (\%) }\end{array}$} \\
\cline { 2 - 3 } & $\begin{array}{c}\text { Regular } \\
\text { classroom } \\
\text { teacher } \\
\text { (n=39) }\end{array}$ & $\begin{array}{c}\text { Special } \\
\text { classroom } \\
\text { teacher } \\
\text { (n=42) }\end{array}$ & \\
\hline During lessons (academic integration) & 6 & 5 & $11(8.3)$ \\
Structured outdoor activities & 7 & 9 & $16(12.0)$ \\
During assembly & 30 & 33 & $63(47.4)$ \\
During recess / playground activities & 21 & 22 & $43(32.3)$ \\
\hline
\end{tabular}

Table 5 shows that there was very similar distribution of responses among regular and special classroom teacher respondents. By and large, both groups of teachers indicated that opportunities for interaction between children with and without SEN 
in Malaysian integrated preschool programmes mostly took place during assembly (47.4\%) followed by interactions at recess or on the playground (32.3\%), structured outdoor activities (12\%) and finally during lessons (8.3\%). The analyses of the types of activities that offer opportunities for preschoolers with and without SEN to interact also appeared to indicate that both groups of children interacted mostly by chance, rather than in activities that required overt planning from teachers, or those activities being intentionally coordinated by teachers. Of the 43 preschools involved in the study there were only five centres in which both regular and special classroom teachers had indicated that preschoolers with SEN had opportunities to interact with their typically developing peers during lessons. There was one other centre in which only the regular classroom teacher had indicated such opportunity among preschoolers with SEN. However, there was no response from the special classroom teacher in that centre to support this indication.

Of the total of 81 respondents $16(19.8 \%)$ of them wrote down in the open space that there were other forms of activities in their preschool offering opportunities for interaction between children with and without SEN. Their responses indicated that the shared participation of preschoolers with SEN and their typically developing peers was also taking place during field trips and on special occasions such as sports day, recognition / prize giving day, and end of year concerts. However, these activities are ones that do not take place on a daily (regular) basis in the preschool.

\section{(ii) Duration of interaction}

The analyses in this section examine the frequency and length of interactions between preschoolers with and without SEN in the integrated preschool setting. The raw data obtained from regular and special education teachers were first compared using relative frequency as shown in Figure 6. 


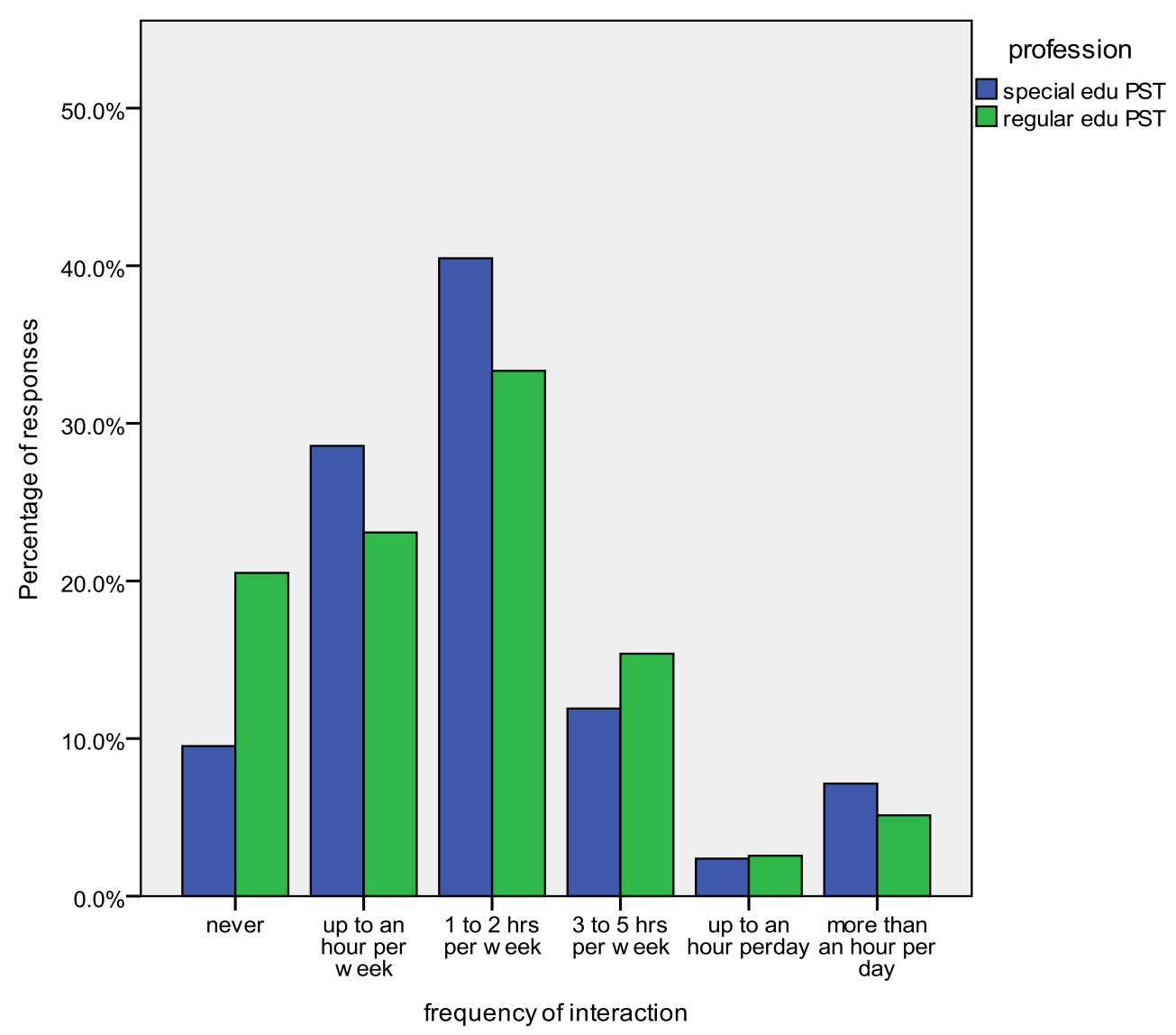

Figure 6: Frequency of interaction between preschoolers with and without SEN

As is visible in Figure 6, findings showed that the most common duration of interactions between preschoolers with SEN and their typically developing peers was one to two hours (or less) in a week. The majority of teachers (38.0\%) indicated that it happened one to two hours a week. Overall there were relatively similar distributions of views among both groups of teachers. A chi-square test found no statistically significant difference between the surveyed groups of teachers (regular and special educators) with regard to duration of interaction among preschoolers with and without SEN $\left(X^{2}=2.48, \mathrm{p}=0.78\right)$. However, Figure 6 appears to show that regular teachers were more inclined than special education teachers to hold a view that interaction among preschoolers in regular and special education classrooms never took place. An analysis of the residuals (differences between observed and expected frequencies for each category) indicated that the 
"never" category showed the largest adjusted residual $(d=-1.4)$ compared to the other categories. However, this value was not statistically significant ( $p=0.162)$.

\section{(iii) Proportion of preschoolers with SEN involved in interaction}

The proportion of preschoolers with SEN who had opportunities to interact with their peers in the regular classroom was analysed. The categorical data obtained from regular and special education teachers were first compared using relative frequency, as shown in Figure 7. The graph appears to indicate that both groups of teachers decided upon a relatively similar choice of responses. A chi square test was carried out and found that there was no statistically significant difference in the ways interaction opportunities were reported by regular and special education teacher respondents $\left(X^{2}=0.45, \mathrm{p}=0.978\right)$.

Figure 7 suggests that the proportion of preschoolers with SEN who had opportunities to interact with their typically developing peers varies across preschools. Furthermore, this figure shows that almost an equal number of respondents reported on the two extremes. That is, almost half of the respondents reported that zero to $10 \%$ of preschoolers with SEN had opportunities to interact with their peers in the regular classrooms. On the other hand, approximately half of the respondents stated that more than $80 \%$ of the preschoolers with SEN had such opportunities. Thus, opportunities for interaction between children with and without SEN in the programmes surveyed, in most instances, appeared to involve either the majority of children with SEN, or (almost) none of them. 


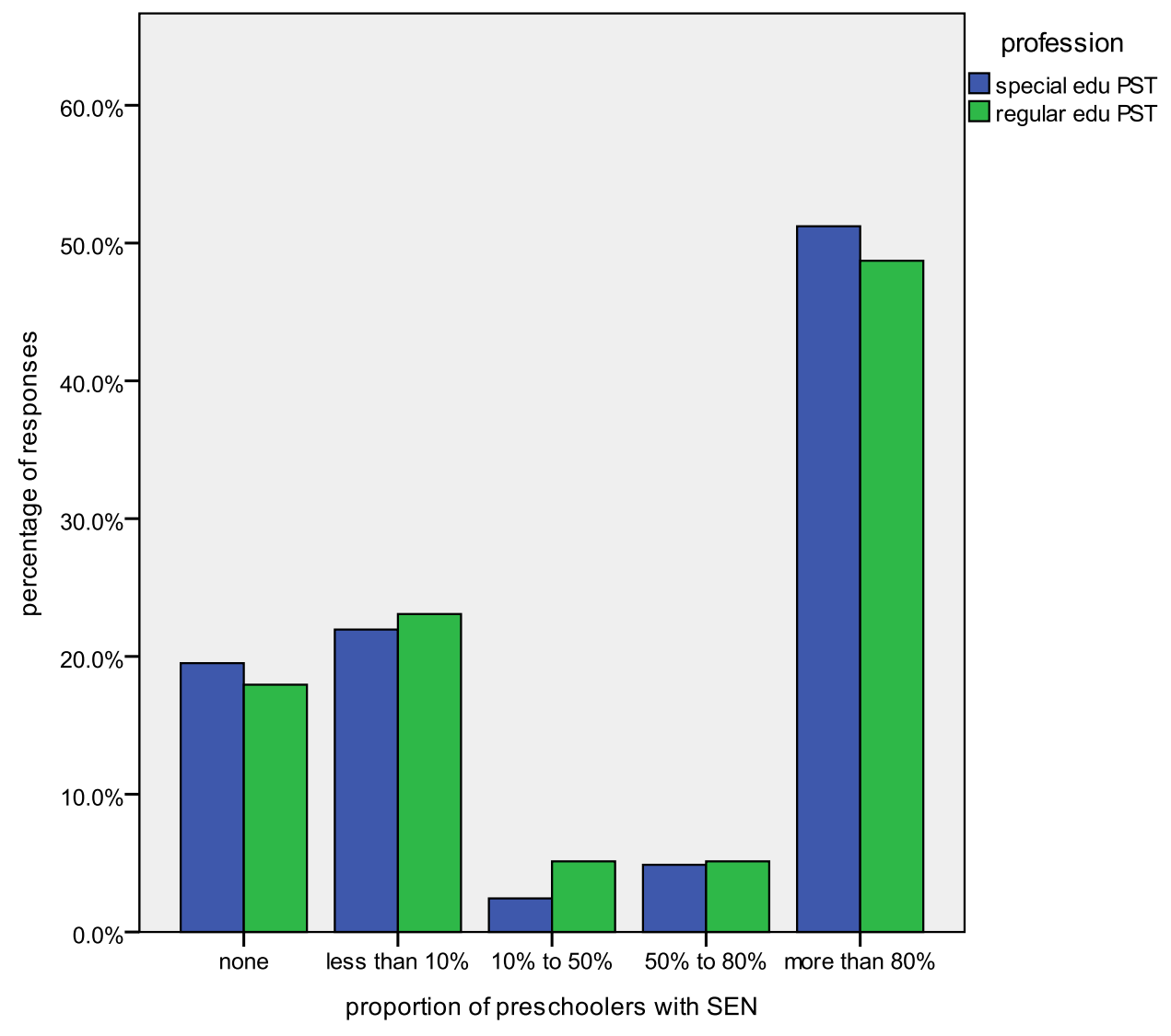

Figure 7: $\quad$ Proportion of preschoolers with SEN who have opportunities to interact with peers in regular classroom

\section{(c) Practices facilitating inclusion in the preschool}

Regular and special education teachers rated nine items (see Table 6) in section two of the IPPQ developed for this study. All nine items represent events and processes that facilitate or promote inclusion. These events and processes, largely adapted from a small section of the Autism Program Quality Indicators (APQI) (see Chapter 5), were used to allow teachers to self-evaluate the degree to which the particular item is in place in the programme. Items were rated based on score descriptions, using the adapted four point Likert scale in the APQI, which ranges from 'no evidence' $=$ score 0 , to 'clearly evident' $=$ score 3 .

The mean score rating for each indicator is shown in Table 6. Numbers were rounded to one decimal place to obtain simpler representations of computation outcomes. 
Table 6: $\quad$ Means and standard deviation for events and processes in the preschool that facilitate inclusion based on regular and special education teachers' ratings

\begin{tabular}{|c|c|c|c|c|c|}
\hline \multirow[t]{2}{*}{ Item } & \multirow[t]{2}{*}{ Events/process facilitating inclusion } & \multicolumn{2}{|c|}{$\begin{array}{l}\text { Regular c/room } \\
\text { teacher } \\
(n=39)\end{array}$} & \multicolumn{2}{|c|}{$\begin{array}{l}\text { Special c/room } \\
\text { teacher } \\
(n=42)\end{array}$} \\
\hline & & $\overline{\bar{x}}$ & (SD) & $\overline{\mathrm{x}}$ & (SD) \\
\hline 1 & $\begin{array}{l}\text { Opportunities to include children with } \\
\text { SEN into regular classrooms }\end{array}$ & 0.7 & $(0.8)$ & 0.7 & $(0.7)$ \\
\hline 2 & $\begin{array}{l}\text { Opportunities for interaction between } \\
\text { children with and without SEN in informal or } \\
\text { planned activities (e.g., playground, day trips, } \\
\text { assembly, meals etc.) }\end{array}$ & 2.3 & $(0.8)$ & 2.4 & $(0.9)$ \\
\hline 3 & $\begin{array}{l}\text { Training and ongoing support for regular } \\
\text { teacher and staff on inclusive practices }\end{array}$ & 1.0 & $(0.9)$ & 1.0 & $(0.9)$ \\
\hline 4 & $\begin{array}{l}\text { Team teaching involving regular and special } \\
\text { education classroom teachers }\end{array}$ & 0.3 & $(0.7)$ & 0.3 & $(0.7)$ \\
\hline 5 & $\begin{array}{l}\text { In their contact with typically developing } \\
\text { peers, children with SEN are provided with } \\
\text { instruction and support to maximise } \\
\text { successful interaction }\end{array}$ & 2.8 & $(0.5)$ & 2.6 & $(0.7)$ \\
\hline 6 & $\begin{array}{l}\text { Opportunities for children with SEN to } \\
\text { engage in peer coaching activities by typically } \\
\text { developing peers in regular classrooms }\end{array}$ & 0.5 & $(0.8)$ & 0.4 & $(0.8)$ \\
\hline 7 & $\begin{array}{l}\text { Least restrictive environment policy in } \\
\text { educating preschoolers with SEN }\end{array}$ & 1.6 & $(1.0)$ & 1.8 & $(0.8)$ \\
\hline 8 & $\begin{array}{l}\text { Planning integrates consideration for future } \\
\text { placements of preschoolers with SEN into } \\
\text { regular classrooms }\end{array}$ & 0.4 & $(0.8)$ & 0.3 & $(0.7)$ \\
\hline 9 & $\begin{array}{l}\text { Environmental accommodations and } \\
\text { adaptations are featured to maximise } \\
\text { inclusion }\end{array}$ & 2.2 & $(0.8)$ & 2.3 & $(0.8)$ \\
\hline
\end{tabular}

The findings in Table 6 show that regular and special education teachers appeared to have chosen relatively similar ratings for each of the nine items. Particularly important to identify the state of inclusion in the preschools is item 1 (inclusion opportunities), in which the mean of 0.7 indicates that the majority of teachers who responded to item 1 suggested that there was either no evidence or minimal 
evidence of inclusion in their preschool. This finding appeared to corroborate the generally low mean score ratings for the other items in Table 6, which represent events and processes supporting or promoting inclusion in the preschool. The teachers had highlighted three items, which were least evident in their preschools. These are represented by item 4 , with mean scores of 0.3 and 0.3 , which represent regular and special education teacher responses respectively; followed by item 8 $(\overline{\mathrm{x}}=0.4,0.3)$, and item $6(\overline{\mathrm{x}}=0.5,0.4)$. In particular, the mean scores for items 4 , 8 , and 6 indicate that the majority of teachers saw minimal or no evidence of such practices in their preschools.

Nevertheless, the information in Table 6 indicate that three types of events and processes facilitating or promoting inclusion in the preschools surveyed were more evident. These are represented by items 5 , followed by items 2 and 9 in the table. In particular, the mean scores for item $5(\overline{\mathrm{x}}=2.8,2.6)$ and item $2(\overline{\mathrm{x}}=2.3,2.4)$ demonstrate that the majority of teachers responding to these items had indicated that there were clear evidence of these practices for either some or all the preschoolers with SEN in their preschool. The mean scores for item $9(\overline{\mathrm{x}}=2.2$, 2.3) are indicative of the fact that the majority of teachers had responded that they saw some or clear evidence that their school's environmental accommodations and adaptations were structured to maximise inclusion.

Every teacher's ratings for items 1 to 9 in Table 6 were summed to obtain a total rating score. For the total of nine items each rated by 0 to 3 Likert responses, the minimum possible score value was zero (0) and the maximum possible value was 27. The total scores obtained from the regular and special education teacher respondents in each of the 43 preschools were then averaged to obtain a score that represented the extent to which events and processes that facilitated or promoted inclusion were evident in each integrated preschool programme. The scores among the 43 preschools were then compared. A higher (average) score indicates that events /processes supportive to inclusion were more evident in that particular preschool. (Note: single response preschools used only one teacher's score). Figure 
8 shows the frequency of score distribution across the 43 Malaysian integrated preschool programmes nationwide that participated in the survey.

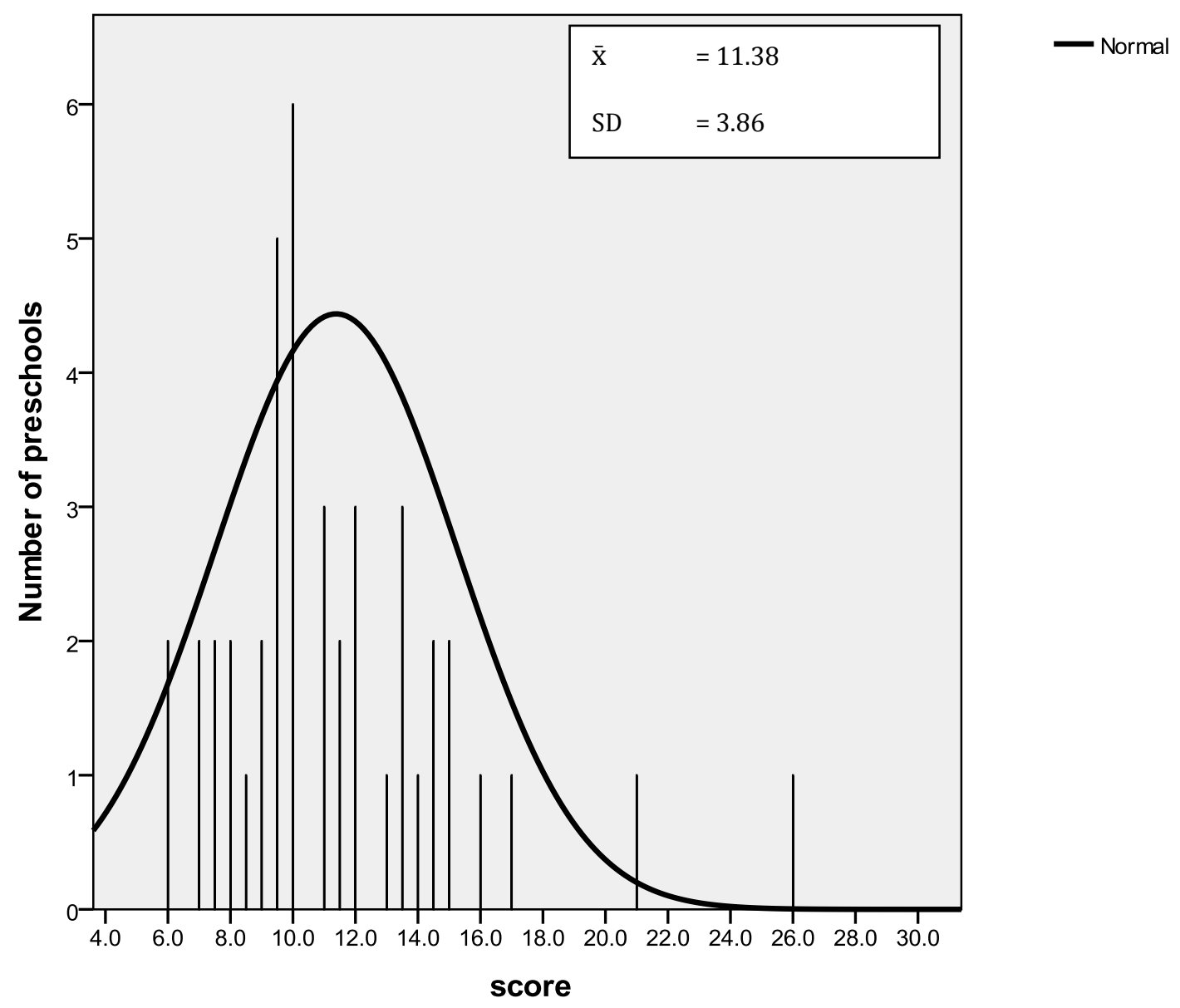

Figure 8: Evidence supporting inclusion: Score distribution among preschools

According to figure 8, the score for the 43 preschools that participated in the survey ranged between 6 (i.e., lowest score) to 26 (i.e., highest score), with a mean score of 11.38. The distribution of scores across the 43 preschools tended to group towards the lower end of the scale, suggesting that in most cases, respondents did not observe much evidence that practices facilitating or promoting inclusion were in operation in their preschools. 
Following analysis of this data, a comparison of scores across preschools was used to select case study sites for the qualitative phase of my research. Since the main aim for the qualitative part of this study was to illuminate and explore further the questionnaire findings, one preschool, which had scored the highest, one which had scored the lowest, and one which had scored in between these two poles were chosen as case study sites. I decided that by selecting three centres which offer differing levels of evidence of facilitating inclusion, maximum information and indepth understanding of different circumstances and events that were affecting the state of inclusion and perceptions of it at those sites could be obtained, which could then offer understanding of the state of inclusion in Malaysian integrated preschools generally.

Since there were more options to chose from among schools with the lowest score (i.e., two schools) and schools with the median score, 10 (six schools), convenience sampling was used to pick the second and third sites. The description of each site will be discussed in the next chapter.

\section{Summary of findings}

In addressing the first research question, teachers' responses indicated that children with SEN in Malaysian integrated preschool programmes seem to be having few opportunities for interaction with their typically developing peers during lessons (academic integration), and few opportunities for interaction during activities initiated intentionally by teachers. These findings suggest that there may not be much inclusion being initiated in Malaysian integrated preschools. In most cases findings appeared to show that children with and without SEN interacted in out-of-classroom activities (social integration) that took place mostly by chance, and for a limited amount of time within the school day. Teacher responses in section two of the questionnaire appeared to confirm this situation.

In responding to item 1, which asked about opportunities to include children with SEN into regular classrooms, the mean score obtained indicated that the majority of teachers had chosen scores 0 or 1 . That means, in most cases, these teachers were 
suggesting that there was either no evidence at all of inclusive practices being in operation in their integrated preschool programmes, or that there was minimal evidence. Comparisons of total scores using the APQI score methods showed that the majority of the integrated preschool programmes surveyed appeared to have scored at the lower end of the range of scores. This suggests that there was little evidence of events and processes facilitating or promoting practices of inclusion in the majority across integrated preschool programmes involved in this study.

\section{Research Question:}

- How do the preschool teachers perceive the idea of inclusion and to what extent are they supportive of its implementation in Malaysian integrated preschool programmes?

Whilst establishing the prevalence of inclusion in Malaysian integrated preschool programmes, the questionnaire was also able to gauge an initial overview of integrated preschool teachers' views about the education of children with SEN in regular educational settings. Two items in section I of the questionnaire addressed this idea. These items required teachers to select between three choices: 'yes', 'no', and 'not sure' in responding to two statements:

- Children with SEN should be educated alongside their typically developing peers in a regular school (integration); and

- Children with SEN should be educated alongside their typically developing peers in a regular classroom (inclusion).

The findings suggested a noticeable degree of acceptance for integration among the teachers surveyed. The majority of respondents, 90.1\% (73 out of 81 ), indicated 'yes' or agreed that preschoolers with SEN should be educated alongside their typically developing peers in a regular school (see Table 7). A total of 40 (95.2\%) special classroom teachers and 33 (84.6\%) regular classroom teachers responded 'yes' to this item. The findings indicate that regular and special classroom teachers were fairly evenly divided in their opinion about the practice of educating 
preschoolers with SEN in a regular school. A chi-squared test was performed on the data in Table 7, which revealed no significant difference in acceptance between the both groups of teachers $\left(X^{2}=3.231, p=0.199\right)$.

Table 7: $\quad$ Teachers views on education of preschoolers with SEN in regular schools

\begin{tabular}{lrrrrr}
\hline & \multicolumn{3}{c}{ Integration } & \multirow{2}{*}{ Total } \\
\cline { 3 - 4 } & & Yes & No & Not sure & \\
\hline Profession & & & & \\
& Special education teacher & 40 & 2 & 0 & 42 \\
& Regular education teacher & 33 & 4 & 2 & 39 \\
& Total & 73 & 6 & 2 & 81 \\
\hline
\end{tabular}

However, as shown in Table 8, teachers are less supportive of inclusion. The majority of respondents, $67.9 \%$ (55 out of 81), reported that preschoolers with SEN should not be educated alongside their typically developing peers in the same classroom.

Findings in Table 8 indicate that although special classroom teachers $(n=15$, $35.7 \%$ ) were generally more willing to accept the idea of including preschoolers with SEN into regular classrooms when compared to regular classroom teachers $(n=4,10.3 \%)$. It was interesting to note, however, that the 55 teachers who responded 'no' to this practice were evenly divided between being regular and special classroom teachers. Therefore, despite being more supportive than the regular classroom teachers towards inclusion generally, this was not universal, and a significant number of special classroom teachers were not in agreement with the idea of educating preschoolers with SEN in a regular classroom. 
Table 8: Teachers views on the education of preschoolers with SEN in regular classrooms

\begin{tabular}{lccccc}
\hline & & \multicolumn{3}{c}{ Inclusion } & \\
\cline { 3 - 5 } Profession & & Yes & No & Not sure & Total \\
\hline & Special education teachers & 15 & 27 & 0 & 42 \\
& Regular education teachers & 4 & 28 & 7 & 39 \\
Total & 19 & 55 & 7 & 81 \\
\hline
\end{tabular}

A comparison was made between the two groups, regular and special education teachers, using the data shown in Table 8. A chi-square test comparing observed proportions to expected proportions showed a significant relationship between the two variables, 'profession' and 'inclusion' $\left(X^{2}=13.294, \mathrm{p}=0.001\right)$, indicating that there was a difference between regular and special educators views about inclusion. However, a visual comparison of findings shows that the seven teachers who responded 'not sure' to the placement of preschoolers with SEN into regular classrooms were all regular teachers, which therefore may have contributed to the significant relationship between the variables. An analysis of the adjusted residuals indicate a significant difference between regular and special educators responses for the two categories 'yes' $(d=2.7, \mathrm{p}=0.007)$ and 'not sure' $(d=2.9, \mathrm{p}=0.004)$.

\section{Summary of findings}

The analyses of findings in this section suggest that whilst the majority of teachers in Malaysian integrated preschool programmes were supportive of the idea of educating preschoolers with SEN in a regular school (integration), they appeared to respond negatively towards the idea of educating these children in a regular classroom (inclusion). Both groups of teachers, from regular and special classrooms, held the same opinion in this regard. Although in general, special education teachers seemed to perceive the idea of inclusion more positively than regular teachers, it was important to note that there was a significant percentage (64.3\%) of special education teachers who disagreed with this practice. 


\section{Research Question:}

- What are the factors that may be influencing the implementation of inclusion in Malaysian integrated preschool programmes?

Whilst addressing the research question above, the analyses of findings in this section made a comparison of regular and special classroom teachers' views about factors influencing inclusion practices in Malaysian integrated preschool programme settings. Teachers' responses to an open-ended item in the questionnaire, which requested them to state factors that influenced teachers practices of inclusion in an integrated preschool programme were analysed.

Of the 81 respondents, 64 (79\%) answered the open-ended item in the questionnaire. Out of this 29 (45.3\%) respondents were regular teachers and 35 $(54.7 \%)$ were special education teachers. The answers for this item were concise and to the point. Only one line was provided for written responses, which did not encourage elaborate responses. In order to analyse the findings of this item, the written or qualitative data in the questionnaire were converted to quantitative data. This step involved the coding of responses for content themes.

Each written response was first analysed based on the codes associated with it. It must be noted that each respondent's responses may have contributed to more than one code. Then, these various codes were collapsed into five broad themes, either derived from the literature, or that emerged from the responses themselves. Coded responses that did not fit any themes were classified as 'others' (see Appendix D for code sheet details). Inter-coder reliability checks by an independent coder were carried out to ensure that coding decisions were made explicit and consistent. Percent agreement for coding consistency was obtained by calculating the percentage of all coding decisions that both coders had agreed upon. This was done by adding up the number of codes that received the same rating by both coders, and dividing that number by the total number of cases rated by the two coders. Agreement on the occurrences of codes for the themes ranged from 85 to $100 \%$ with a mean of $91.7 \%$. In order for the percent agreement to be considered 
reliable, the generally accepted standard is $90 \%$ or higher (Lombard, Snyder-Duch, \& Bracken, 2002). Hence, the percentage that was achieved indicated fairly good levels of agreement between the two coders, meaning the coding decisions were reliable. Table 9 presents the broad themes, and the total number of segments of data matching them based on teachers' responses.

Table 9: $\quad$ Factors influencing inclusion

\begin{tabular}{lccc}
\hline Themes & \multicolumn{2}{c}{ No. of responses } & \multirow{2}{*}{$\begin{array}{c}\text { Total } \\
\text { (\%) }\end{array}$} \\
\cline { 2 - 3 } & $\begin{array}{c}\text { Regular classroom } \\
\text { teachers }\end{array}$ & $\begin{array}{c}\text { Special classroom } \\
\text { teachers }\end{array}$ & \\
\hline School culture & & & $42(24.3)$ \\
Skills and competency & 13 & 29 & $34(19.6)$ \\
Guidance and information & 21 & 13 & $31(17.9)$ \\
Workload & 17 & 14 & $27(15.6)$ \\
Students' disability & 15 & 12 & $25(14.5)$ \\
Other & 14 & 11 & $14(8.1)$ \\
Total & 7 & 7 & $173(100)$ \\
\hline
\end{tabular}

Findings in Table 9 indicate that the impact of the school culture towards inclusion had the highest reported frequency (24.3\%) among the responses related to factors influencing inclusion in Malaysian integrated preschool programmes. Responses received under this theme suggested that school personnel's and parents' attitudes, beliefs, support, and cooperation in relation to inclusion, the special education teacher's initiative, and the principal's role as administrator in promoting inclusion were pivotal for the successful implementation of this practice. The second most common theme mentioned was educators' own feeling that they lacked skills and competencies in relation to inclusion and special education (19.6\%). Among others, issues associated with teacher skills and competency were those concerning the school principals' and regular classroom teachers' knowledge about inclusion, special education and disability.

There were also issues concerning special classroom teachers' experience and practical knowledge about inclusion, and both regular and special classroom teachers' ability to make curriculum adaptations and adopt classroom instructions 
to suit inclusive lessons. Table 9 also indicates that issues relevant to the first two themes (school culture and educators' skills and competency) appeared to have the highest difference in response between regular and special education teachers. In addition, findings in Table 9 also appear to suggest that whilst special educators seem to find issues associated with school culture as mostly influencing inclusion, regular educators appear to believe that issues associated with educators' skills and competency are the chief influence upon inclusion having been (or having not been) put into practice in Malaysian integrated preschool programmes.

Respondents also stated that educators' and parents' lack of access to relevant information on inclusion, lack of step-by-step guidance for teachers and school principals, and lack of staff development programmes on inclusion were issues they saw as influencing the implementation of inclusion. A total of $17.9 \%$ respondents stated issues relevant to these issues, which were categorised under the theme, guidance and information

Teachers' workload (15.6\%) and the condition of children's disabilities (14.5\%) were approximately similar in their reported frequency of responses. Responses on teachers' workload included issues of student-teacher ratio in regular classrooms, insufficient time for individual attention for preschoolers with SEN, added responsibility for regular education teachers, and the difficulty in meeting parental and curriculum demands. The 25 responses in relation to children with SEN's disability conditions were mostly associated with the disruptive behaviours that children with learning disabilities may have, and the difficulty in engaging these children in academically integrated activities with their typically developing peers. Other factors noted by respondents as influencing inclusion included bullying, and the non- compulsory inclusion policy, which gave teachers a choice whether or not to implement inclusion. There were also issues concerning the distant location of regular and special classrooms in the school compound, which in some cases presented difficulty in making transitions from one class to another for inclusion. 


\section{Summary of findings}

Teachers' responses to the open ended item in the questionnaire appear to show that both regular and special education teachers generally saw similar factors as influencing teacher decisions to carry out practices of inclusion in their preschools. However, there were factors which special education teacher or regular teachers reported more frequently than the other. The findings suggest that educators' and parents' attitudes toward inclusion, particularly their support for the practice, teachers' skills and competencies, the availability of guidance and information, issues of workload and preparation for teachers, and the nature of the preschoolers' disability were all factors that influenced practices of inclusion in the preschools surveyed.

\section{Chapter summary}

The questionnaire was used to gauge the extent to which inclusion is prevalent in Malaysian integrated preschools, teachers' general perceptions of inclusive practices, and factors that might be influencing inclusive practices in the preschools surveyed. Findings from the questionnaire show that practices of inclusion varied across Malaysian integrated preschools. However, generally there was little evidence that indicated practices of inclusion were taking place in these preschools. There were not many opportunities for interaction among preschoolers with SEN and their typically developing peers. Furthermore, the majority of integrated preschools only provided opportunities for preschoolers with SEN to be involved together with their typically developing peers in non- academic activities such as assemblies, meal times, or on the playground, indicating that opportunities for interaction between preschoolers with and without SEN in integrated preschool programmes mostly took place by chance without much planning on the teachers' part.

Furthermore, although special education teachers were more accepting than regular teachers about including preschoolers with SEN into regular classrooms, in general, both groups of teachers perceived the practice negatively. Both groups of 
teachers felt more favourably toward the idea of placing preschoolers with SEN into separate classrooms in regular school compounds.

Findings from the open ended item in the questionnaire showed that teachers perceived a range of issues, operating both within and beyond the preschool setting, as influencing inclusion in Malaysian integrated preschool programmes. These included issues relevant to educators' and parents' beliefs, teacher skills and competencies, teachers' workloads, the amount of guidance and on-going support and information teachers received, and students' behavioural difficulties.

Following analyses of the findings from the questionnaire, I conducted further investigations using multiple site case studies. Interviews, document examination, and observations were used to investigate plausible explanations as to why teachers responded to their questionnaires in the way they did, as well as to probe more deeply into possible reasons for perceptions and practices of inclusion being as they were in the preschools surveyed. The analyses of these findings are presented in the next chapter. 


\section{CHAPTER 7}

\section{-Qualitative Data: Case Study Findings-}

\section{Introduction}

This chapter presents findings from three case study sites. The sites selected as case study preschools were determined based on findings obtained from a survey by questionnaire (see Chapter 6). It was decided early in the study that three preschools with differing levels of inclusive practices would be able to provide maximum information and in-depth understanding of perceptions and practices of inclusion representative of Malaysian integrated preschool programmes in general. Hence, the first case study chosen was one that had the highest score, showing strong evidence of events and processes that facilitated or promoted practices of inclusion in the preschool. The second site had the lowest score and the third site was a preschool that obtained a medium score among the 43 preschools involved in the survey.

In this chapter, the findings from each case study site are presented, beginning with a general description and followed by a detailed presentation of the findings for each site, using descriptive data and commentary interpretations. The detailed presentation includes an account of processes, situations, and patterns of activities relevant to inclusion and non-inclusion circumstances, as well as findings that reveal educators' and parents' perceptions of inclusion at each site. Throughout the discussion, data obtained from different sources (i.e., interviews, documents and observations) are incorporated to convey a comprehensive account of the findings. Selections of documented quotes are presented in the analyses to offer detailed information on individual understandings, perceptions and descriptions of practices in the preschools. Pseudonyms are used for the schools, participants and other people involved in the quotes and notes. The quotes were also edited to improve readability. This was done by eliminating the 'ums', 'ahs' and 'errs' in the speech. At the end of each case study analyses, a summary of the findings, covering the nature and extent of inclusion practices, and factors impacting the implementation of inclusion in each site is provided. 


\section{General description of case study sites and procedures}

The preschools selected for the qualitative phase of this study covered three states in Peninsular Malaysia, therefore representing different demographic settings in this country. However, as education in Malaysia is centrally controlled, all three preschools had commonalities in terms of their administrative structure and general features. The case study sites were all fully funded government integrated preschool programmes, administered in a primary school compound. All three preschools were under the jurisdiction of the Ministry of Education, and the principal was the head of the school. The selected preschools were co-educational and the medium of instruction Malay.

Collections of data at the sites were carried out separately, using similar steps and procedures in each. Practices of inclusion in each site were investigated by exploring the extent to which daily activities offered opportunities for interaction among children with and without SEN. Data gathered was based on examinations of documents, observations, and semi-structured interviews. Examinations of documents in the preschool included the National Preschool Curriculum and The National Special Education Preschool Curriculum, teachers' lesson notes, and documents and reports that contained information about activities in the preschool. Non-participatory observations were carried out in the classrooms and general preschool environment, and field notes were made describing regular and special education teachers' planning of activities, and the routines and schedules in the preschool.

The examination of documents, and observations presented a means of accessing information about relevant processes and interactions that demonstrated practices of inclusion or exclusion in the preschools assessed. These procedures also provided evidence to validate information that was collected during the interviews.

A total of seventeen participants were involved in the interview stage. The participants across the three sites were the three school principals, five regular classroom teachers, three special classroom teachers, three parents of typically 
developing preschoolers, and three parents of preschoolers with SEN. During the interviews, all participants were asked (i) to describe their understanding of inclusive education or inclusion, (ii) to state how they felt about inclusion, and (iii) how they felt about the current practices in the preschool. The teachers and principals were also asked about, (iv) their experiences in relation to inclusion, and (iv) factors that influenced the practices of inclusion in the preschool. Case-by-case analyses of all the information obtained in the preschools are presented in the following section. Patterns of findings that emerged in each site are also presented as a summary at the end of each case, so findings across the three case study sites can be compared and contrasted before integrating them with quantitative findings (see Chapter 8).

\section{Case Study 1}

\section{Description of setting and events}

The first site, hereafter School 1, was situated about twenty minutes drive from the federal territory. The surrounding area of the school was busy and noisy as this site was located nearby to a commercial centre. The school, however, seemed quiet and bound by strict in-house rules. On the first visit, the guard only allowed me to enter the school premises after the school's morning assembly was over. There were strict orders from the principal about allowing visitors into the school. Forms had to be filled out at the guardhouse and a pass collected from the office, before it was possible to proceed with other formalities for the research.

The principal of the school had been working at School 1 for the past five years. He had been a principal at several other schools, and had been an educator for 19 years before becoming a principal. The principal was primarily in charge of a team of around 60 teachers and paraprofessionals who served around 1,000 students from preschool level (four to six year olds) to primary six (12 years old). The number of teachers included eight special education teachers who were responsible for the education of students with SEN at the primary level, and one special education teacher who was responsible for six students with SEN at the preschool level. 
The integrated preschool programme was made up of two classrooms; one regular and one special education. Both classrooms were located in different blocks of buildings, opposite one another. The classrooms were facing one another on the ground floor of a three-storey building with a small roofed yard between the buildings. Preschoolers from both classrooms often used this yard for outdoor activities. There was also a common playground located behind the regular preschool classroom where all the preschoolers would often play at break time or in the mornings before school begun. The start time for preschool was 8.00 a.m. and the preschool day ended at 11.45 a.m. The early comers were allowed to be either at the playground or in their respective classrooms where they often did some colouring, or played with building blocks, manipulatives or did other activities.

The regular preschool classroom consisted of 25 children (14 girls and 11 boys) and the special education preschool classroom consisted of six children (4 girls and 2 boys) with a variety of SEN. Information gathered from the special education teacher's classroom registration indicated that one child had autism, two of the children had Down's syndrome, and another two had learning and speech difficulties. Preschoolers from both regular and special education classrooms wore uniforms of the same design.

The regular classroom teacher held a bachelors degree in Communication and a Teaching Diploma in Preschool Education. She had been a preschool teacher for six years. The special education classroom teacher held a diploma in education and had attended long and short-term special education courses throughout her five years of experience as a preschool teacher. However, she had 20 years of teaching experience as a remedial teacher in a primary school and had been a trainer for remedial education courses that were carried out at the state level before becoming a special education preschool teacher. Both preschool teachers had been teaching at School 1's preschool for around five years. 
Besides the teachers, each of the preschool classrooms had a teacher-assistant who was in charge of cleaning, preparing meals for the children, preparing teaching materials, helping preschool teachers with administrative work, and, supervising the preschoolers both during lessons and outside the classroom. These teacher assistants had completed their secondary school education and on-the-job training. The training included courses relevant to their work descriptions conducted by the Ministry of Education from time to time.

\section{Nature and extent of inclusion}

School 1 practiced partial inclusion. Preschoolers with SEN were placed into the regular preschool classroom from the beginning of the school day until break time. This practice, however, was not carried out on a daily basis. Information obtained from the preschool teachers and their teaching notes confirmed that inclusion was only carried out about twice a week. On the days and times inclusive lessons were not taking place, preschoolers from both classrooms remained in their own classrooms, engaged in specific learning activities with their respective teachers.

During the interview, the special classroom teacher mentioned that all the preschoolers with SEN were involved in academic integration, regardless of their disability. According to this teacher, since both she and the regular classroom teacher agreed on team-teaching during inclusive lessons, it was not feasible for her to include selective students only. She would normally guide all preschoolers with SEN to the regular classroom for their shared lessons on every Tuesday and Thursday morning. However, if any of the preschoolers with SEN demonstrated problem behaviour, or was difficult to handle on the day, then that child would be left under the care of the teacher assistant in the special education classroom until the child was calm enough to be coaxed to join the inclusive lesson.

The regular and special classroom teachers shared responsibility for all the preschoolers during inclusive lessons. Information obtained from the special education teacher, and the observations carried out during inclusive lessons, indicated that team teaching was evident and predominantly used during such 
lessons. Both teachers were involved in instruction within the classroom, and worked cooperatively in assisting all the preschoolers, regardless of whether they were preschoolers with or without SEN. Teachers encouraged peer coaching during activities, pairing up or deliberately placing children with SEN in groups with their peers from the regular classrooms. All the children, with and without SEN, had equal opportunity to participate in the activities. Children with and without SEN seemed comfortable with each other's company and addressed each other by name, appearing to know one another well.

The teachers made curriculum adaptations for inclusive lessons by selecting and adapting common skills across both regular and special education preschool curriculum documents. Observational data and examination of relevant documents showed that inclusive lessons in this preschool seemed to generally cater for preschoolers with SEN, involving less academic oriented skills and activities. Inclusive lessons mostly involved activities such as music and movement, craft, finger painting, cutting, pasting, grooming and those activities that were fun and exciting for all the children.

Based on teachers' planning of activities, schedules and routines in the preschool, it was apparent that activities that fostered social integration between children with and without SEN were definitely occurring at School 1. Preschoolers with SEN and their peers from the regular classroom had many opportunities for interaction within the school environment, on a daily basis. They had their morning assembly together, held every day in the courtyard in front of their classroom. During morning assembly, preschoolers from both classrooms recited their morning prayer together, followed by the national anthem and a greeting song, after which they adjourned to their respective classrooms. These children were also often seen playing together in the regular or special education classrooms, while waiting for after school transport, as the duty teacher assistant took care of them. They also shared the same break time and were together in the playground after their meal. The following anecdote describes an incident in the playground, which 
demonstrates the interaction between preschoolers from the regular and special education classroom as they engaged in one of their daily routines:

(At the playground, before the morning bell)

....Aina, who had Down's syndrome was on the swing. Yogi, who is from the regular preschool classroom was helping to push the swing while Aina sat on it. They were talking to each other and laughing loudly. I could hear them addressing each other by their names. After some time, Yogi began shaking the swing and asking Aina to get off. Yogi then told Aina that it was time to switch places. Aina was getting off the swing when the bell rang. All the children who were at the playground were screaming and running off to their respective classrooms. Yogi was sighing [maybe because she did not get her turn to sit on the swing]. Then I heard Yogi shouting out at Aina "It's your turn to push me later during recess, okay?". Aina did not reply; she continued running back to her class.

Both regular and special classroom teachers in School 1 mentioned that they tried to ensure that children with and without SEN had maximum opportunities to interact and participate in shared activities. Other than partial inclusion and those routine out-of-classroom activities already mentioned, both teachers described a variety of events that provided opportunities for children with and without SEN to interact. According to the teachers, most of these other events involved parental participation. For example, they mentioned that field trips, birthday and festive celebrations, sports day, and the end of the year concert for preschoolers from both classrooms were all held together. Reports on some of these events that had already taken place contained information and photographs which demonstrated the involvement of regular and special classrooms teachers, students, teacher assistants and parent assistants. These events were also stated in the teachers' yearly activity plan and documented in the school's annual planner.

\section{Perceptions of inclusion}

Interviews were carried out with five participants in this site. They were: the school principal, the special and regular classroom preschool teachers, the mother of a typically developing preschooler, and the mother of a preschooler with SEN. The following discussions relate to how inclusion was perceived by educators and parents in School 1, what affected their perceptions and how it affected the implementation of inclusion in the preschool. 


\section{School principal}

The principal was able to clearly articulate his understanding of inclusive education. He believed that, theoretically, the aim of inclusion is to provide an environment that is inclusive and equally accessible to all children, with and without SEN, and at all times. However, he believed that in practice and within the Malaysian integrated school system, a form of inclusion was already taking place because the schools' environment provided opportunities for children with and without SEN to spend time together. In his opinion, it did not matter whether children with or without SEN spent time together in or outside the classroom, instead the most important thing was for these children to have opportunities to interact and spend time together.

The principal strongly supported inclusion and believed that it was important, given that both children with and without SEN benefited from it. However, he felt that it was not feasible to include children with SEN into regular classrooms for the whole day or on a full time basis, because children with SEN have specific individual needs and thus, require the expertise of special education teachers in a special education setting. Hence, he believed that practices of both inclusion and exclusion are important:

... inclusion is a great practice. I agree that inclusion creates the opportunity for these children to meet, be together, mingle, and learn from each other. But there has to be a balance... there must also be a time for both groups of children to be receiving the kind of attention that they should be receiving from the experts who are better at handling them

... separate placements allows the special education teacher to pay attention to the individual needs of special children and for the regular teacher to direct the needed attention to the children in the regular classroom. So, both teachers can worry less about whether or not the lesson would be appropriate for both groups of children

In terms of inclusion at the preschool level, this principal felt that preschool inclusion was far less challenging compared to the implementation of inclusion at the primary or secondary education level. As indicated in the following quote, he also believed that the preschool education system, which was more inclined to flexibility, made preschool inclusion practicable:

I believe inclusion is more practicable at the preschool level than it is at a higher level... you see, primary and secondary education is formal, exam oriented. It's a crazy race to complete syllabi, produce high achievers, competitions, academic 
merits and all the rest of that. But preschool education is more relaxed, learning through play, no exams, individual evaluations... yeah, there is more room for flexibility there. I believe it's because the focus is not the same at the preschool level... teachers can accommodate to inclusion...

When asked about the role that the Ministry had played in terms of supporting integrated school programmes to implement inclusion, this principal was hesitant about pointing fingers at the Ministry of Education when referring to the state of inclusion in an integrated school. This principal argued that the government had already done their part by creating the avenue for inclusion, building schools that could cater for the needs of children with and without disabilities. Therefore, the execution of inclusive practices relied very much on the responsibility of the school:

By having integrated schools, trained teachers, extra funding and all, it shows that the Ministry has taken the major step. The next step is up to the schools...

Although he valued the government's effort in creating inclusive opportunities, he acknowledged the fact that there were barely any courses that were conducted, either at the ministerial level or at department level, guiding teachers on practices of inclusion in integrated school settings. However, he identified these as limitations, and was concerned that such limitations were often used as excuses to deter practices of inclusion in such schools:

... these could be limitations, maybe due to lack of funds or resources,...but then what is the use of having trained teachers? Majority of our teachers are exposed to courses on special educational needs in their training days. This is the time to put the knowledge to good use. Instead, all we hear are excuses... I don't have the skill, I don't know how to handle these children, it is not my job, how am I to finish my syllabus? Why include? What is the benefit?

The principal indicated that he was immensely grateful to the regular and special education preschool teachers, as he felt that the main reason for preschool inclusion to have taken place at an encouraging level in his school was that the teachers put in personal effort, commitment and willingness to implement it. He stated that even though inclusion was generally easier to be implemented at the preschool level, it was not compulsory for the preschool teachers to carry out this practice. Yet both preschool teachers had shown the interest and commitment to do it. He believed that his teachers' positive attitudes towards inclusion, their ability to work well together, and their willingness to cooperate for the benefit of 
their students were key factors in determining the planning and implementation of inclusive practices in his school:

... all the credit should go to my preschool teachers. It is basically their initiative that inclusion is taking place in our preschool...

This principal once again stated that he strongly believed that teachers' positive attitudes toward inclusion were pivotal for successful inclusion, especially because inclusion is a non-compulsory practice in Malaysia:

...inclusion is not compulsory, the willingness to carry out inclusive practices on the teachers part is the key to successful inclusion in Malaysian integrated schools. If teachers have negative attitudes towards inclusive education and are not committed to it, then it is simply not going to work

\section{Special education preschool teacher}

The special classroom teacher felt that she had a clear understanding of inclusion, which she had mostly acquired during her training and a short-term course overseas on special and inclusive education. To her, inclusion was the placement of children with SEN into regular classrooms for either a whole school day or when possible. This teacher, who was generally very optimistic about practices of inclusion, associated her enthusiasm for inclusion with her experience of witnessing inclusive practices in another country. She believed that she was motivated to carry out inclusion when it became apparent to her that other countries had been successful with it despite the challenges they faced. Furthermore, she believed that inclusion was generally a practice that had positive outcomes:

The course instructors in [name of country] stated that despite the challenges that they too face, the developmental achievement among the children in inclusive settings have proven to be better compared to being in segregated settings. So I told myself, why shouldn't I try out inclusion in my school? I mean that's what our job is all about... to ensure our children achieve optimum development, right? We have got nothing to lose by practicing inclusion. I decided to think positively and give it a go. It's been four years now. I learn from the weaknesses, hitches and improvise each time

This teacher believed that there was a lot more to be done in terms of inclusion in the local education system, especially concerning teachers' training and support services within the regular classroom. She felt that Malaysian preschools were not 
ready yet for full inclusion. However, she believed that partial inclusion was a considerably good first step:

We are not as advanced as some other countries in terms of inclusive education. Inclusive education is still new to our education system. I think partial inclusion is a good start in our preschools

She voiced dissatisfaction about the enrolments in regular classrooms, which were generally high in Malaysian preschools. This was because the accepted enrolment number fixed by the Ministry of Education for every regular preschool classroom was up to 25 students. She felt that the size of the regular classroom was a major factor that was deterring practices of full inclusion from taking place in most of the preschools, including hers. She believed that it would be too stressful and impossible to address the individual needs of preschoolers with SEN if they were placed full time in the same classroom with 25 other typically developing preschoolers. She particularly felt that the task of planning full time inclusive lessons that catered for a large classroom of preschoolers with vast differences in developmental characteristics would be very challenging for preschool teachers. So in her opinion, children with SEN should alternatively have as much opportunity as possible to interact with their typically developing peers during non-academic activities.

This teacher credited her success in carrying out practices of inclusion to having the right kind of people to work with. She indicated that the cooperation of the regular classroom teacher, the parents and the principal were the key factors in making inclusive practices possible in her school. Their ability to work together and share ideas made the job of planning and carrying out the inclusive lesson interesting and less stressful. She also appreciated the regular classroom teacher for going the extra mile with her efforts in trying to ensure that preschoolers with SEN felt comfortable and had a sense of belonging in the regular classroom. Observational data also showed that such efforts from the regular classroom teacher were evident. Artefacts on the regular preschool classroom's wall included a beautifully decorated bulletin board, pasted with the photographs and names of both regular and special classroom teachers, the teacher assistants and the preschoolers with and without SEN. There were also samples of work that children 
with and without SEN had produced during shared lessons, hung around the classroom.

Whilst this teacher acknowledged some challenges in terms of curriculum adaptations, she explained that there were considerable team efforts between her and the regular classroom teacher in initiating inclusion:

...the fact that we have two separate curriculums makes it difficult for us to carry out full inclusion... we each have our own skills to concentrate on. But we can still work towards having some shared lessons... You see, the good thing is that both of the curriculums cover similar and different skills. The similar skills are generally suitable for both groups of children. So Liza [regular classroom teacher] and I normally compare and pick skills that are similar. We then sit together and plan the inclusive lessons based on those skills. Sometimes, we also need to do some modifications and try our best to ensure that the lesson is beneficial and meaningful to all our children

Probing questions signalled other challenges in relation to curriculum adaptations. According to this teacher, there was no information in either the regular or special education preschool curriculums to guide or direct integrated preschool teachers in how to plan their teaching and learning activities together, which made both her and the regular classroom teacher wonder if they were doing things the right way when shared lessons were carried out:

I appreciate the readily available simplified skills in the curriculum. These are helpful. But then it can still be challenging sometimes, because at times we do wonder if we are doing it correctly... there is not much information in the curriculum to guide us on how to carry out shared learning activities. But if only there was some form of guidance, it would be of great use to those of us who want to do it. In fact, I think it could also be a way of encouraging more teachers to carry out shared lessons.

The special education teacher considered continued parental support critical for the successful implementation of preschool inclusion. She believed that the preschool teachers gained parents' support for inclusion in the preschool each year by providing them with sufficient information about inclusive education. According to her, such information guided parents to make informed judgments about practices in the preschool, and to overcome initial concerns they might have about preschool inclusion. She stated:

I normally have an inclusive education introduction session on orientation day. I talk about the benefits of inclusion, I also let the parents know how we [the regular and special classroom teachers] do things here, what the rules are, and how we hope to receive the parents support and cooperation. We felt that it was important to have this session because some parents may have the usual concerns like, would 
my child get bullied? What if my child hurts another in the regular classroom? Is this possible?...

In addition, this teacher mentioned that she often tries to keep parents informed of ongoing activities in the preschool through the children's memo books. Parents are also encouraged to participate and get involved with the preschool's activities whenever possible. She stated that she often exchanged ideas with parents on intervention strategies that worked with their children in school/at home and how they could be applied. These exchanges were not only done during the formal meetings held once each term, but also during informal chats after and before school hours. According to this teacher, parents' suggestions on their children's strengths, weaknesses and preferences for activities always have been good sources of ideas when she plans intervention strategies for preschoolers with SEN in her classroom.

She also acknowledged that parents in her centre have always been a great help in terms of donating toys, teaching aids, and other materials (e.g., recycled egg cartons, cardboard boxes), which not only helped parents feel involved, but also helped make classroom activities more interesting. Parents had also been supportive during special events, offering themselves as volunteers during field trips, sports activities, and sometimes in classroom teaching and learning activities.

This teacher also stated that the principal's knowledge of inclusion and the positive attitude that he had toward it made the planning and implementation of inclusion in the preschool uncomplicated. She stated that the principal also often voiced positive remarks about the preschool teachers' inclusive efforts, which made them (the teachers) feel motivated and appreciated. She also believed that the support the principal showed towards inclusive practices played an important role in gaining the parents' support in and for the preschool:

The support that the principal has towards practices of inclusion can really make our job easier. We need not worry if other staff members or the parents are unhappy with what we are doing, especially when we have the principal's backing... When Mr Deen talks about opportunities for children with and without SEN to be involved in shared activities to the parents on the preschool orientation day, parents become aware that the principal is supportive of inclusion... then they too become more confident about it. 


\section{Regular preschool teacher}

The regular preschool teacher admitted that she only began to clearly understand the concept of inclusive education through the experiences she had gained in this school. She stated that the exposure she had received about inclusive education during her training had only provided a vague understanding of this concept. She gave credit to the special classroom teacher who motivated her in carrying out inclusion, and raising her awareness of inclusion by pointing out the benefits of inclusion, as well as showing her that inclusion was not impossible. This was evident from the following quotes:

When I first agreed to her suggestion of inclusion, honestly, I had no opinion about inclusive practices, it was new to me. Zilah [the special classroom teacher] showed me that inclusion is definitely possible if we work on it together.

... I have learnt a lot from her. She is very patient and tolerant. I simply admire the way she handles these children.

She acknowledged that her experiences in carrying out inclusive practices had proven that inclusion prepared children with and without SEN to live with each other in the real world. She strongly felt that opportunities for children with and without SEN to spend time together were very important, and had personally seen how it helps typically developing students develop acceptance towards their peers with SEN.

I feel that inclusive practices are necessary in every integrated preschool. I have clearly seen the changes in these children. At the beginning my students call some of these special children names, but Zilah and I always step in and make sure that this kind of behaviour does not continue. As time passes, my students become caring. During class activities, there is a natural mentoring process going on in the classroom. My students often volunteer to help their special friends with their work and often look out for these special ones.... They actually become best of friends.

Although she had no doubt that inclusion would maximise the learning potential of children with and without SEN, she strongly doubted the practicability of placing children with SEN on a full time basis into regular preschool classrooms. She perceived the idea of partial inclusion as a more suited and attainable practice in Malaysian preschools compared to full inclusion. Similarly to the special classroom teacher, this teacher felt that full inclusion would not work mainly because the regular preschool classrooms' enrolment was generally large, with an average of 20 to 25 preschoolers per classroom. She felt that managing a large classroom was 
already challenging even without inclusion, because regular teachers had their own set of teaching goals to achieve. Furthermore, children with SEN would not be able to cope with the academic standards in regular classrooms on a full time basis, because regular classroom learning was designed for preparing preschoolers for future formal and purely academically oriented education in the following year (primary one):

I sincerely don't think placing children with SEN into regular classrooms all the time is a good idea. Most of the skills in the syllabus will not suit the special kids. What we are practising now, partial inclusion is more appropriate. We can pick and choose the skills we want for inclusive lessons. If it is full inclusion, there's no way a regular teacher will be able to cope. Even during non-inclusive lessons, managing 25 fellows in my class is already a huge task. I have my own syllabus to cover and my students will be in year one next year.... Education is formal and purely academic in year one. There are stuffs that I have to make sure that they know before they begin their primary school.... Reading, writing, maths, spelling, and all that. The special kids won't be able to cope with these stuffs.

She believed that practices of partial inclusion were manageable, especially if the preschool teachers took advantage of the available support surrounding the integrated preschool system. She related this to teacher assistant support in the class, indicating that the presence of a teacher assistant for each preschool classroom was an advantage, as these teacher assistants were a great helping hand during inclusive lessons. According to this teacher, it was often quite challenging to maintain discipline during inclusive lessons, due to the high level of anxiety in a large classroom, and the excitement of children at the presence of peers from another classroom. Therefore, the supervision and assistance received from teacher-assistants during inclusive lessons reduced the student-teacher ratio, and thus made inclusive lessons less stressful for the teachers.

She acknowledged that there was not much direct guidance or support from the Ministry with regard to information on inclusion. However, she believed that the knowledge that special education teachers had about inclusion was mostly available through their special education training by the Ministry. Therefore, the special education teacher's role within the school, which included advocating for inclusive practices through a focus on professional development, and the sharing of expertise, offered a form of guidance to the school and an alternative to the lack of direct support from the Ministry. This was evident in the following quote: 
... we don't receive that kind of direct information or guidance from the Ministry. I have never attended any courses on inclusive education outside the school. But Zilah has carried out relevant [to inclusion] courses in the school. I guess that's how it works. The special education teachers are trained by the Ministry and they have been provided with the knowledge and understanding about inclusive education. Maybe the Ministry then expects that special education teachers to convey this information to the schools. I mean, look at Zilah, that's what she is doing. She initiated the inclusion. She shared her expertise with me... and who trained her? The Ministry right? It's the same in the primary education classrooms. The special education teachers are the ones who initiate inclusion and guide the regular teachers about their students and so on.

The initiative of the special education teacher was seen as an important factor in ensuring the implementation of inclusive practices. She believed that the special education teacher's willingness to share her expertise and to raise awareness about inclusive practices among staff and parents across the school was the main reason for that preschool inclusion was taking place in the school:

....but Zilah, she goes all out for the special needs students. She carries out in-house courses on inclusive practices in the school for all the teachers. Many of us actually learnt a lot from these courses, that inclusion is not something impossible. She initiates gatherings with the parents and educates them on inclusive education. ... Frankly, she is our motivator. If it was not for her, I don't think there would be any inclusion in our preschool.

This teacher also felt that the willingness of a regular teacher to pursue inclusion was an important factor to ensure its successful implementation. She expressed concern and disappointment that regular teachers often used unrealistic excuses, for example their lack of expertise in the field of special education, as a reason to totally put off inclusive practices, including social integration:

Let's look at it this way, how much skill and competency do we need to handle little children? We are teachers, I mean... come on....you don't need training to let preschoolers with disabilities play in the same playground with our preschoolers? There's no pressure in having them to sing together or play together right? ... I have never had any training to teach children with disabilities, nor did I have the experience. All I had was the will to try, the attitude to cooperate with Zilah. That's all, and everything went on well. Both of us are enjoying what we do.

This teacher explained that she was not sure as to whether or not the parents of typically developing preschoolers were supportive of inclusion. However, she believed that parents had no objection to the preschool's efforts in carrying out shared academic and social activities among children with and without SEN. She believed that the best way to get parental support was to get parents involved in the preschool's inclusive efforts, and to keep parents informed of what was going 
on in the preschool. According to her, parents had been informed of the preschool's practices, and parents had not voiced dismay about them. Further, parents also seemed to be cooperative and willing to participate when a need for volunteers in activities involving both groups of children arose.

This teacher indicated that the role of the principal was also another contributing factor influencing inclusive practices in the preschool. She was glad that the principal was supportive of inclusive education and believed that the principals' support created a positive inclusive culture in the school:

He has no objection and is supportive of what we do. I guess he recognises our efforts... He promotes inclusive practices to our preschool parents, which is good because it sort of reflects on the schools' support for this practice and eventually the parents start showing their support.

\section{Parent of typically developing preschooler}

This parent associated her knowledge and understanding of inclusive education with her experience of being a secondary school teacher for the past 13 years. She did not have any personal experience teaching in inclusive situations. She conveyed her understanding by explaining it as the practice of placing students with SEN into regular classroom settings to receive social and learning opportunities. She further elaborated on inclusive education, stating that it required modifications of teaching approaches and a variety of teaching strategies, which required considerable effort on the part of regular education teachers, in order to cater for the needs of students with SEN.

She believed that inclusion was excellent as theory. However, in reality, she considered it would not work unless the right people were assigned to carry it out, indicating that the teachers involved in inclusive practices had to be highly motivated and committed. She felt that this was true especially because inclusion was not a compulsory practice in Malaysian schools and thus, required personal initiative by the teachers who were involved: 
Well, I suppose inclusion as a theory is excellent. ... But in reality, I wish I could say it would work that easily...

...In my opinion, the teachers involved have to be well trained, flexible, and wish to see progress in the special needs students. If the regular teachers are adapting their teaching methods and are happy to cater for the needs of the special needs students in their class, then all is well and fine. But, what if a teacher is not willing to make adaptations?... I mean inclusion is not compulsory here. So, some may think that it is just extra work and unnecessary stress. What good is inclusion if the special student is in a regular classroom for the sake of being included? A statistic, so to say, but no effort made to cater for his needs...

She regarded inclusion as essential in preschool settings because it supported young children in all developmental domains, especially their social and emotional development. She believed that inclusion effectively taught young children to gain a sense of acceptance of individual differences, and was pleased to share the positive changes she had observed in her daughter's behaviour in this regard:

My daughter used to have many questions at first when Zilah's students used to come over to her class - why is she like that? Why isn't she like me? ... but eventually she seemed to have forgotten the differences and just treated them as friends. The curious questions eventually faded and there were only talks about daily events in the school with her friends.

Despite expressing strong support for preschool inclusion, she was satisfied that practices of inclusion in School 1 were limited to partial inclusion rather than full inclusion. She particularly supported the current practices in the preschool because it favoured two conditions, which were of utmost importance to her:

I am in favour of the current practices [partial inclusion] in this preschool mainly for two reasons; First, the academic values for regular preschool children are not affected by inclusive practices. Second, the safety and well being of the preschoolers are well taken care of by the teachers

She further indicated that partial inclusion would be sufficient to address all of the preschoolers' social and emotional needs, without interrupting the regular classroom children's academic needs. Instead, if full inclusion were implemented, regular education preschoolers would lose a great deal of the teachers' attention in the classroom, resulting in negative influence on their academic achievement:

I think that permanently placing SEN children into regular classroom is a not good idea... If the school decides on full inclusion the lessons would then have to cater for all. It is not going to be easy for the regular teacher. How is she going to cope paying attention to everyone?...

....teachers can make adaptations to the lessons and all. But, the regular classroom children may find the lessons too watered down. It will affect their academic achievement. They may not be getting what they actually deserve. It will not be fair 
to them. What the preschool is practicing now [partial inclusion] is more than sufficient and is definitely a better way to ensure that all of them [children with and without SEN] would benefit academically and socially...

Her concern over the safety of the preschoolers with regard to preschool inclusion was primarily related to the impulsive behaviours of preschoolers, especially those with SEN. She stated:

I know preschoolers with SEN can be very unpredictable sometimes. Although I am okay with inclusion; but as a parent, I would not be happy if my daughter got hit by her peer with SEN just because that child decided to act up and all. And of course, it could happen the other way around as well... our kids may bully the other kids, calling them names or something ... It is a relief that the teachers here share the same concern and I know that they are doing their best to ensure the safety and well being of all the children.

She felt that the idea of informing the parents of the preschool's views about inclusion and the practices in the preschool was a great way of gaining support from the parents. She believed this helped parents of typically developing children understand inclusion better and view it in a more positive way. This parent felt that practices of inclusion in the preschool were successful because the preschool teachers were committed to achieving their goals and had positive work attitudes towards inclusion.

\section{Parent of preschooler with SEN}

This parent shared some background about her son's preschool experiences before discussing her understanding of inclusive education. Her son, Nori, had autism. This was the third preschool for Nori. He was rejected by two other private regular preschools before coming here.

Nori's mother acknowledged that she was not highly educated (she had only completed primary school education) and thus, was not aware that her son was autistic until the principal of the second preschool had approached her about it. She assumed that he was a 'naughty and playful' four year old. Furthermore, since her older son had also had a delay in speech development, she assumed Nori was similar. However, Nori's mother expressed disappointment and distress when she spoke of the teachers in the first preschool, who had constantly complained about 
her son's behaviour. She was upset that despite being educators, and having professional knowledge in child development, the teachers in the first preschool were not aware of her son's problem and kept telling her that her son was stubborn and difficult to manage. The constant complaints eventually brought about her decision to enroll Nori in his second regular preschool:

Physically, he is fine, I had no idea he had autism. The sad thing is that the first preschool teacher, an educator, mind you, she kept telling me that Nori was stubborn and that he would ignore her when she tried talking to him. This really upset me, so I used to try and reprimand him at home, not knowing that he is a special child [sobs]. She complained and complained about him. And then one fine day, I decided to pull him out of that place and send him to another preschool which was little further off from my house.

The second preschool rejected Nori's enrolment two weeks after he had begun there, and refunded the registration fee. However, Nori's mother was very grateful to the teachers and principal in the second preschool because they did not complain about Nori's behavioural difficulties and send him away because of them. Instead, they identified Nori's problem and offered to help in other ways. The principal of the second preschool guided Nori's mother in getting the proper help for Nori from sources outside the school, such as a speech therapist and other specialists. Furthermore, it was that principal who guided Nori's mother with the application for School 1.

Despite her effort in educating herself on autism and special educational needs since finding out about her sons' disability, this parent had no idea what the term inclusion or inclusive education meant when she was initially asked about it. She could, however, relate to practices of inclusion in the preschool when I provided some basic information:

$\begin{array}{ll}\begin{array}{l}\text { Nori's mother : } \\ \text { Researcher }\end{array} & \begin{array}{l}\text { No, I don't think I know what it means } \\ \text { In this preschool, children with SEN have } \\ \text { the opportunity to spend time with regular children during } \\ \text { [before completing the statement] }\end{array} \\ \text { Nori's mother : } & \begin{array}{l}\text { Oh that! Yes, Zilah has told us about it on the first day of } \\ \text { school. Yes, I know, inclusion. That's when they include } \\ \text { children like Nori into the other classroom right? }\end{array}\end{array}$

This mother conveyed her understanding of inclusion by plainly stating that it was the placement of students with SEN into regular education classrooms. She 
believed that it was a good practice, because it helped children with SEN learn by imitating their able peers, however, she didn't believe that inclusion was beneficial to typically developing children in any way. She admitted that it was not very important to her whether the preschool practiced inclusion or not. Although she was happy for Nori to pick up some positive social skills through inclusion, her main concern was that Nori had a place to call 'school', and that he was taught by individuals who knew about SEN, especially people who cared for the well being of children with SEN. She believed that the special education classroom teacher possessed these qualities and did not want anything further. She stated that after being rejected by two regular preschools previously, she often felt as if practices of inclusion were similar to placing Nori in a classroom that might not accept him for who he was. On the other hand, in a special classroom, Nori would be able to learn at his own pace, in an environment that was less stressful, and receive constant attention from the special education teacher:

\begin{abstract}
After all he was rejected before. Inclusion is like sending him back to a place where people had rejected him for not being smart enough. In a special education classroom, he is with other children like him, no pressure. The teacher understands him well. She is dedicated. Zilah has seen him screaming, throwing things, but has never come complaining to me. She knows what to do. She is a wonderful teacher. The other teacher, I do not know, she may not know how to handle this type of behaviour.
\end{abstract}

This parent also stated that she was happy with School 1 because the special classroom teacher always kept parents informed of what was taking place in the preschool. Furthermore, she appreciated the teacher's ways in treating parents as important members of the preschool and the children's learning processes:

Zilah always makes us feel important. She is always willing to accept parents' ideas, open to suggestions about our children. This really makes parents like me feel like important people ... like our opinions are important and appreciated and that our child's well being is of importance to the preschool.

She then confirmed that she supported inclusive practices in the preschool, mainly because she was aware that the special education teacher was mostly present throughout the inclusive lessons and routines:

I am happy with inclusion as long as his class teacher is around. She or the special education teacher assistant is involved in most of the inclusive activities, so I have nothing to worry about. They will look out for Nori. 
She stated, though, that even if teachers were not carrying out inclusion in the preschool, it wouldn't have mattered to her, adding that it was already good enough that her child was at least attending a regular school. She stated that because they were able to attend a school attended mostly by 'normal' children, children like Nori were not being segregated; there were sufficient opportunities for children with and without SEN to spend time together, outside the classroom, even if not in the same classroom. She also saw nothing wrong with segregating children with and without SEN into separate classrooms within a regular school compound. Instead, she felt that it was an effort to ensure that both groups of children were getting the kind of attention and education that had been designed to suit their learning needs. This was evident in the following quote:

It is not like he is segregated and placed in a special school. Nori is [emphasis] in a regular school. He would automatically get opportunities to be included whenever possible. It's just that he is in a separate classroom. That's fair. I can accept that. He is in a classroom that will be catering for his needs, and the other children without SEN are in a classroom that suits their needs. They can go further, learn more, and children like Nori, they would get special attention. I don't see anything wrong with that.

\section{Summary of findings in School 1}

School 1 practiced partial inclusion. Practices of inclusion seemed to be initiated by the special classroom teacher, and carried out as a shared decision by educators and parents in the preschool. All the children with SEN in this site had opportunities for inclusion, twice a week, for half of the school day. The placement of children with SEN into the regular classroom was supported with their engagement and participation in meaningful activities with their typically developing peers. The regular and special classroom teachers engaged in team teaching during inclusive lessons. The teachers were selective of the types of activities conducted during academic integration, making sure that activities were suitable and engaging for both groups of children.

Children with SEN's interaction and opportunities to engage in shared activities with their typically developing peers in School 1 were not, however, limited to inclusive lessons only. Social integration between children with and without SEN 
was commonly taking place outside the classrooms during routine activities, on a daily basis, which according to the teachers was also part of the preschool's move towards inculcating inclusive practices.

The findings that emerged from School 1 showed that members of the school community related to inclusion in similar ways, ascribing equivalent meanings to it. Participants in School 1 described inclusion as opportunities for students with and without SEN to learn together in the same educational setting, and inside or outside the classrooms. Generally, the school had a positive culture towards inclusion. All the participants in School 1 believed that inclusion was a positive experience for preschoolers with and without SEN. However, they strongly maintained that full inclusion was not the best way to meet all the preschoolers' needs.

Parents were mentioned by school staff as supportive of the current practices in the preschool. However, parent voices did indicate some concerns they had about inclusion. The parent of the regular preschooler was concerned about issues related to safety, indicating that children with SEN can be very impulsive and could inflict harm upon others if left unattended in an overloaded classroom. Another concern of this parent was the effect on the academic education of preschoolers in the regular classroom if lessons were adapted to be too simple, in order to cater for the needs of preschoolers with SEN.

The parent of the preschooler with SEN, on the other hand, was concerned that the differing needs of preschoolers with SEN, which required exceptional attention from the special education teacher, might slacken in an overloaded regular classroom. She was also concerned that the regular preschool teacher might not have expertise appropriate to managing the behavioural problems sometimes shown by children with SEN. 
In sum, the findings for School 1 showed that there were a range of factors influencing the state of inclusion at this site. These were:

- principal's role and support for preschool inclusion

- collaboration between regular and special classroom teachers

- special educator's knowledge and experience concerning inclusion

- partnership between parents and the preschool

- perceived importance of special education services

- importance placed on academic values for typically developing children

- parental concerns (beliefs about children with SEN's disability conditions)

- large enrolment in regular preschool classrooms

- difficulty in making instructional adaptations during inclusive lessons

\section{Case Study 2}

\section{Description of setting and events}

The second case study site, School 2, was in the outskirts of a town located in the Southern State of Peninsular Malaysia. The school was in a residential area and the surroundings were peaceful and quiet. Most of the students and staff came from nearby villages and newly developed housing estates around the school.

School 2 revealed a relaxed atmosphere. On the first visit to this site the security guard escorted me to the office while having a quick chat about the weather. I was also able to meet the principal immediately, without many formalities. Whilst showing me around the school, the principal personally introduced me to the preschool teachers. The school and preschool teachers' willingness to participate in the study was confirmed by the end of the school day.

The principal had been at this school for 6 years. She had a diploma in Malay Language Education, and 21 years of experience as a primary school teacher and a senior assistant in a few other schools before becoming a principal at School 2. About 50 teachers and staff served the school. There were around 700 students in 
this school, from preschool to primary six. This school did not offer special education services at the primary education level, and instead it was only available for preschoolers. At School 2, there were two regular preschool classrooms and one special education preschool classroom. The regular classrooms' day began at 7.30 am and ended at $11.30 \mathrm{am}$. Meanwhile, the special education classroom's day began at $7.45 \mathrm{am}$ and ended at $11.30 \mathrm{am}$.

Both regular classrooms were attached to one another and had a door in between that connected these classrooms. The regular classrooms were located on the ground floor of a double storey building. There were 17 typically developing preschoolers (ten girls and seven boys) in one of the classrooms, and 18 (eleven girls and seven boys) in another. All the regular classroom preschoolers shared a playground, which was located along the side yard of their classrooms.

Both regular classroom teachers had degrees. One of them had a degree in Islamic Studies and the other was a Social Science graduate. Both had acquired a postdegree teaching diploma in preschool education, and had been teaching preschools for the past three years. According to these teachers, their training had not offered any courses on special or inclusive education. Both regular preschool classrooms also had a teacher assistant each. These teacher assistants were in charge of helping their respective preschool classroom teachers with administrative work. However, in addition, they often shared their responsibilities in cleaning, preparing meals and teaching aids, and in supervising the regular classroom preschoolers during lessons.

The special education preschool classroom was a small building by itself, and was located two blocks away from the two regular classrooms. Not many staff or students used the corridor outside this classroom. Thus, this part of the school seemed very quiet and secluded. There was a playground outside the special education classroom, and a small (class) room near the playground. The special education teacher had converted this small room into a mini therapy centre for the 
use of the preschoolers with SEN. Preschoolers with SEN came to this room twice a week for sensory development and other related activities.

There were nine 5-6 year old preschoolers in the special education preschool classroom, with a variety of SEN. Three of them had Autism Spectrum Disorder with Attention Deficit Hyperactivity Disorder (ADHD), three with Down's syndrome, two with mild mental retardation and ADHD, and one who had Global Developmental Delay.

Although there were nine children enrolled in this classroom, not all of them were present every day. Three of these preschoolers attended preschool only twice a week. This was an arrangement made by the special education teacher and the three preschoolers' parents/guardians due to the preschoolers' disruptive behaviour in the classroom. The disruptive behaviours were evident during classroom observations. These children were very restless and active, requiring constant attention from the teacher or teacher assistant. There was a time when the teacher had to hold on to one of the boys' hands all the time, because he displayed physical and verbal aggression towards the other children in the class. He kept pulling the other children's hair and clothes, and shouting abusive words at them, which created a very stressful atmosphere in the classroom.

The special education teacher had been a primary school teacher for ten years prior to obtaining a degree in early childhood education. After her degree, she had been teaching in a regular preschool for five years. She applied to teach preschoolers with SEN when there was a vacancy for this post in School 2, and had been teaching there for four years. According to this teacher, she attended two semesters of special education courses during her degree programme, and a number of special education courses since becoming a special educator. The special education preschool also had a teacher assistant with a similar job description to the teacher assistants in the regular preschool classroom. However, she was only in charge of activities and preschoolers in the special education classroom, and did not share any of her responsibilities with the regular classrooms' teacher assistants. 


\section{Nature and extent of inclusion}

Throughout the duration of data collection at this site, I barely witnessed any interactions between preschoolers with and without SEN. Findings from observations, interviews, and document examinations in School 2 confirmed that neither inclusion nor social integration took place between preschoolers with and without SEN at this site.

In most instances, preschoolers with and without SEN spent their preschool day segregated from each other. Preschoolers in regular and special classrooms used separate playgrounds, had their learning activities carried out in separate classrooms, and had different start and end times for recess/mealtime, and conducted other routine activities in their own designated spaces. Thus, there was barely any evidence to support the school's effectiveness in providing inclusive, meaningful opportunities for preschoolers with and without SEN to participate in activities together, or to interact with each other in the school environment. The only feature that the regular and special education preschool classrooms seemed to share was their physical location, which was within the same school compound.

There were no intentional planning and teamwork evident between the regular and special education teachers to support shared activities among children with and without SEN. Both the regular classroom teachers indicated that they only carried out teamwork and team planning with each other, but not with the special education teacher. The special education teacher, on the other hand, indicated that she was working on all her classroom activities by herself with support and help from the teacher assistant, and on some occasions with the parents of the preschoolers in her classroom. The preschool teachers also confirmed that there were not many opportunities for children with and without SEN to interact throughout the preschool day.

Observations that were carried out in regular classrooms revealed that team teaching was evident among regular classrooms teachers. Further examination of their teaching records showed that both the regular classroom teachers shared the 
same yearly and semester themes. Their yearly planner indicated shared agendas such as field trips, sports activities, concert planning, parent open day and birthday celebrations. There were also many similarities in their daily lesson plans in terms of their classrooms' timetables, their choice of teaching and learning activities, teaching aids, lesson procedures/steps, and circle time songs and activities. Information that was gathered during my interviews with the regular preschool teachers confirmed that they often shared ideas and discussed their lessons.

The teachers further indicated that by having the same timetable for both the classrooms it was easier for them to plan team teaching or carry out routines together. Besides planning their lessons together, the regular preschool teachers also showed a great sense of collaboration in planning the physical space, management, and organisation of both the regular preschool classrooms. For instance, these teachers converted the corridor that faced the playground into a dining area. According to the teachers, the conversion provided enough space for preschoolers from both regular classrooms to have their morning snack and lunch break together. This way, the teachers and teacher assistants from both classrooms could take turns to be on duty during mealtime, and at the same time keep an eye on the preschoolers when they were at the playground.

A comparison of the classrooms' timetable confirmed that there were no purposefully planned interactions between preschoolers with and without SEN. The timetables also indicated that there were no considerations for creating random opportunities for preschoolers with and without SEN to participate in activities together or interact during routine activities (mealtime, break time, playground, circle time). According to the special education teacher, it was not easy to have mealtime or playground time together, especially since the special education preschool classroom was isolated, two blocks away from the two regular preschool classrooms. She further added that both regular and special classrooms had different start times, and children with SEN often turned up late to class, which made planning morning routine activities with the regular classrooms problematic. 
A comparison of the special and regular classroom teachers' teaching records confirmed the incongruity between their plans of work. The regular and special education teachers had planned their teaching on different themes. The special education teacher's yearly, semester, weekly and daily lesson planning were completely different from that of the regular preschool teachers. The yearly preschool planner also showed a different agenda for preschoolers with SEN. Their field trips were scheduled on different dates and to different destinations than those for the regular classroom preschoolers. The preschoolers with SEN also had sports day activities, planned according to events organised for students with SEN by the State's Special Education Department. According to the special education teacher, she had never discussed any of her planning for the special education classroom with the regular classroom teacher, nor had the regular classroom teachers discussed their plans with her. However, unlike the regular classroom activities, most of the special classroom teacher's planning of agendas involved parent volunteers.

\section{Perceptions of inclusion}

Interviews were carried out with six participants in this site; the school principal, the special education preschool teacher, two regular preschool teachers, the father of a typically developing preschooler, and the mother of a preschooler with SEN. The following discussions relate to how inclusion was perceived by educators and parents in School 2, what affected their perceptions, and how it affected the implementation of inclusion in the preschool.

\section{School principal}

The principal admitted that she had a vague understanding of inclusive education. She explained inclusion as the placement of children with SEN into regular classrooms to be educated with 'normal' children. She further elaborated by stating that the general principles of inclusive education promoted opportunities for children with and without SEN to learn and play together. However, she felt that only children with SEN who were capable of following lessons in the regular classroom would benefit from this practice, and not all children with SEN. 
The principal of School 2 had an unbiased opinion about the implementation of inclusion in the regular education system. She was neither supportive, nor did she have any opinion against practices of inclusion. To her, whether or not practices of inclusion needed to be carried out, was very much a decision that the special education teacher had to make:

It's up to the special education teacher. She knows her students best. If she thinks her children can cope, then, I leave it to her...it's up to her if she wants to include them in the other classroom

When asked about the regular classroom teachers' involvement in this regard, the principal's opinion was:

...That too, I leave it up to my teachers to make the decision. They have to come to an agreement that all of them are comfortable with, and what is best for their students.

The principal confirmed that inclusion was not carried out in her school. She believed that inclusion was not taking place in the preschool primarily because the preschoolers that were enrolled into the special education preschool were mostly in the category of moderate to severe disabilities, and thus felt that they would not be able to cope with academic integration. However, she made it very clear that she would support inclusive practices in her school if the teachers implemented it:

... most of our special needs children have moderate to severe disabilities. I was told that there is one child who comes to school with her diapers on. So, maybe it's just not feasible to carry out inclusion. That's why the teachers are not doing it ... Anyway, if they want to go ahead and carry out lessons together, I have no problems with that. I would definitely ask them to go ahead with it.

The severity of children with SEN's disability was presumed to be a reason as to why there were little opportunities for preschoolers with SEN to engage in shared activities with their typically developing peers in the school. She referred to the situation at the playground as an example, stating that issues concerning the safety of preschoolers with SEN and the regular classroom's enrolment were taken into consideration when a separate playground was built for them. This was because the playground outside the regular preschool classroom had to cater for preschoolers in two classrooms, which could be as many as 50 children at one time if the enrolment in each regular classroom was at its maximum. An overcrowded playground made it difficult for the teachers to keep a close eye on all the children, especially those with SEN. 
The principal of this school believed that it was not accurate to say that children with SEN were excluded, segregated or denied their rights just because they were placed in a separate classroom in a regular school. She believed that by having special classrooms in regular schools for children with SEN, the transformation had already taken place in the national education system to respond to the needs of children with SEN. These children's rights were already addressed. Furthermore, she felt that the placement of children with SEN into a separate classroom was similar to streaming, and streaming was common in many schools, so children would be able to learn and receive teaching at their own pace:

... it's not right to say that they have been denied their rights, just because they are stationed in another classroom. We have always practiced streaming. This is just like that. Just assume that the special education class is a weaker class. That's all. They are segregated into another classroom for a good reason. To cater for their learning needs. The teachers will be able to concentrate on them and teach them at a pace that they are able to cope with.

Despite believing that the Ministry of Education had transformed the education system to cater for the needs of children with SEN, the principal felt that the lack of practices of inclusion in the preschool education system was also dependent on factors at the ministerial level. She supported her stance by stating that the objectives of an integrated preschool system were not clearly delineated by the Ministry of Education. Further, she felt that there was generally not much involvement on the Ministry's part in promoting inclusion either, stating that there were no clear and specific guidelines for the principal or teachers to refer to in the implementation of inclusive practices in integrated preschools.

As a principal, I haven't received any guidelines or information on inclusion. How am I to direct my teachers to implement inclusion without receiving directives to do so? ... My teachers don't attend any courses on inclusion. So, how can I force my regular teachers?

The principal also voiced that, since the integrated preschool approach was new to the education system, there should be more efforts from the Ministry of Education in providing guidance training to the regular teachers and informing them of inclusion:

Integrated preschool programmes are new to us. We are talking about young children with SEN here. It's not like primary or secondary school ... the regular preschool teachers are also new to integrated preschool programmes. Maybe if the Ministry encourages inclusion through short courses or training, we can see more inclusion. 
The principal also felt that it was reasonable for the special education teacher to avoid inclusion on the basis that it would be challenging for her to work with regular teachers who lacked knowledge and skills on special education, or were not keen to cooperate on inclusive practices. Therefore, it would also be unfair to blame the special education teacher if inclusive practices were not initiated or implemented in the preschool.

\section{Special education preschool teacher}

The special education teacher explained inclusion as an approach to educating children with SEN with typically developing children in a regular classroom. She further stated that within the Malaysian context, practices of inclusion were not limited to teaching and learning activities in the classroom only. Instead, inclusion could take place anywhere or anytime within the school. However, she believed that, since preschool education is an introduction to school, practices of inclusion at this level would largely depend on the ability of preschoolers with SEN to acclimatise themselves to a school environment:

Preschool is like the beginning of school life for most of these children, so we need to see how well they adapt to their surroundings and the school environment first before moving into inclusion. This would allow the teachers to check how well they've adapted to their own class routine and classmates before moving into the routines in the regular classrooms ... Some of my kids come to school with their diapers and pyjamas, need to be fed, changed and coaxed into doing some activities. They require flexible schedules and are not ready for regular classroom learning yet. It's too complex for them. They may be ready one day soon, or may never be ready for it. I don't know.

This teacher believed that inclusion was difficult to implement in School 2, and referred to a range of reasons in stating this belief. The physical location of the special education classroom was one of these factors; she found the special education classroom to be isolated from the regular preschool classrooms, which she believed not only created a form of discrimination between children with and without SEN, but also prevented natural opportunities for these children to meet and participate in unplanned activities 
She also stated that support from the school community was lacking, not only in terms of inclusion, but also in showing general interest in SEN. She often felt discouraged and demotivated to initiate inclusion, due to other staff's lack of awareness about children with SEN. She related her frustrations through an incident that had taken place in the school, as stated below:

We were having a school-level celebration for Malaysia Day, and I had told the teacher in charge that my kids would be taking part. I got them traditional Malaysian costumes - you know, Indian, Chinese, Malay ... I wanted them to march in time to music. We practised in class, and it was wonderful seeing my kids all dressed up and working together. But when the day came, and the MC was announcing the programme line-up, there was no mention of my event. I asked her, "What happened to my event?", and she said, "No one told me your kids are performing - they told me to go according to the programme booklet and there's nothing there!"

I was so very sad, I felt so bad for my children ... but I mean, come on - I told them I'd do it. So I told the MC to announce my event regardless of what was in the booklet, and you know what, my assistant and I were struggling with the kids, trying to set things up, and nobody helped us ... and there was a child with polio who used crutches that year as well ... After the performance many teachers walked up to me and said that they were touched ... moved to tears watching my kids perform. It was difficult to believe what they were saying ... if you were touched by their plight, you would stand up and help us ... but they just sat there, watching, when we were struggling to get the kids up stage. I mean, if you were touched, wouldn't you be kind enough to stand up and lend a helping hand?

She agreed that there was lack of teamwork and collaboration between her and the regular classroom teachers. According to the special education teacher, despite expressing her interest in planning out some informal activities for preschoolers with SEN to join in with their regular classroom peers several times to the regular classroom teachers, the regular classroom teachers had always excluded her from their discussions and annual planning of events for the preschoolers. This made her feel uncomfortable working with them. She sometimes felt that they were ignoring her request. She believed that the regular preschool teachers' prejudices against children with SEN could be another reason for the non-cooperativeness among them. The special children's limited cognitive, social, and behavioural capabilities were often used as a reason by the regular teachers for declining shared activities among preschoolers with and without SEN. 
However, she agreed that the nature and severity of her preschoolers' disabilities could be very challenging for the regular classroom teachers to handle. She further stated that even being a special educator, she herself sometimes found it exceptionally difficult to manage young children with SEN. Therefore, it was not unusual for regular teachers to see inclusion as stressful, particularly since the regular teachers worked towards maintaining a semblance of order in the classrooms through behavioural management and class control, so that the preschoolers were better prepared for formal schooling at the primary school level.

This teacher maintained that she shared a good relationship with parents of preschoolers with SEN. Parents had been invited to be involved as volunteers during field trips, out-door activities, and at the therapy centre from time to time. She said that parents/guardians were also welcome to her classroom during the school day. Some of the parents sat in during classroom activities (note: this was evident during classroom observation). Sometimes parents come in to assist with intervention, and at other times to observe and gain a better understanding of how the teacher carried out activities with their children so that similar approaches and routines could be carried out at home. According to this teacher, she communicated with parents whenever there was a need, by phone, or when they stopped by to fetch or drop-off the children. However, formal meetings were also held three times a year, which were primarily related to matters concerning children with SEN's individual educational plans (IEP).

According to this teacher, at the beginning of the school year, parents usually enquired about whether or not their children would be joining the preschoolers in the regular classrooms. She felt that there were mixed feeling from parents about inclusion. Some of the parents expressed relief when they learned that there was no inclusion, and some of them expressed disappointment. However, none of the parents had brought up the topic of including their children into regular classrooms to the principal or during parent-teacher meetings. 
This teacher believed that the principal's unbiased stance on inclusion was a disadvantage to efforts of inclusion, because without the principal's express support, the school lacked the most powerful advocate for inclusion. At the same time, she felt that it was awkward to get the principal involved in lobbying for inclusion, or to bring up the issue during the staff meetings, since the regular classroom teachers had already indicated their reluctance to participate in inclusive practices.

This teacher believed that the level of input and support from the Ministry of Education in terms of inclusion was sorely lacking. According to this teacher, the Ministry needed to play a significant role in terms of guiding school principals and teachers on the importance of inclusion. Furthermore, there was no training provided on inclusion for all concerned in integrated schools, including those like her (special educators). She believed such training and information was important, so that principals and teachers value the importance of inclusive education. This teacher appeared to strongly believe that preschool teachers would never comply with inclusion, unless there were directives from the Ministry of Education that made inclusion compulsory in preschools.

\section{Regular preschool teachers}

Between the two regular preschool teachers, only one of them acknowledged that she was familiar with the term inclusion. This teacher acknowledged that inclusion might be beneficial to regular and special education children, however, she believed that inclusion should begin in primary education instead of at the preschool level. She believed that preschool was an introduction to school, and that young children with SEN needed more time to get used to a change in routine (between home and school). Therefore, she felt that the special education preschool classroom was like a preparatory stage, where in a segregated environment, children with SEN could get ready for proper schooling by acquiring the routines and habits before being included into regular classrooms at the primary education level. 
The other regular teacher stated that she had only a vague understanding of inclusion. She then related inclusion by stating that it was the concept of educating children with diverse cultural backgrounds and needs in one environment. This teacher felt that there might be possibilities for inclusion to benefit preschoolers with and without SEN. However, she associated her opinion about inclusion with her own lack of experience and knowledge about it. She believed that it would be irresponsible to allow just any teacher to handle young children with SEN for the sake of implementing inclusion. She further added that inclusion could bring more harm than good to young children's social and emotional competence if it was not carried out properly. In particular, she believed that any form of education involving children with SEN must be carried out by educators who knew about SEN, or had some background training for dealing with children with SEN.

Both teachers agreed that the special education teacher had approached them to plan inclusive activities for preschoolers in all three classrooms. Both teachers also explained the apprehension they had towards inclusion as related to their lack of knowledge and training in the field of special education. One of them mentioned (once again) that her reluctance to proceed with inclusion was because of her fear of making the wrong decisions concerning the teaching and learning of children with SEN:

I wish that I could be of more help and accept Shona's [special classroom teacher] suggestions. But I do not know anything about special education. I have no knowledge or skills to deal with SEN children. I mean, what if I had set them back developmentally, because of something I did without thinking during lessons?

The other regular classroom teacher mentioned feeling challenged to implement inclusion, not only because she believed she lacked the required knowledge to make instructional adaptations, but she also felt that such efforts were too demanding on the regular teachers:

I honestly find it very taxing to adopt the teaching approaches to suit the needs of the preschoolers in that classroom. ... it's just not going to be as easy as it sounds. It will interrupt my lessons and the learning objectives that I have planned for my students.

...I know the special education teacher would help and all. But, it won't be fair to sit around and let her do everything... So I think the best is for the special teacher to handle the kids over there [referring to special classroom] and we regular teachers to look into the needs of our kids. 
Information that emerged from the findings showed that the idea of having two separate curriculums for children in regular and special classrooms in the integrated preschool programme may be affecting the way education of children with SEN is perceived, and the subsequent emphasis that is placed on inclusion practices in this school. One of the teachers stated:

The idea of having two separate curriculums for the education of children with and without SEN means that two separate types of educational endeavours are also expected right? So, I don't see anything wrong with having two separate classrooms for children with and without SEN. It is less complicated.

What challenged the teachers further was that, they believed, practices of inclusion in the preschool would not necessarily be accompanied by a reduction in the number of students in their classroom. They felt that practices of preschool inclusion must be supported by reasonable enrolment in the regular classroom so that teachers could effectively manage behavioural problems, and provide full support for the participation of preschoolers with SEN inside and outside classroom activities.

(Teacher 1)

I am already having a tough time coping with my normal workload and responsibilities towards a class load of preschoolers. How are we going to add children with SEN into the classroom? We have to be realistic here - How are we going to manage?

(Teacher 2)

Maybe if there is flexibility in the system that allows us to enroll fewer regular preschoolers, then we can consider inclusion. At least we can plan indoor or outdoor activities that are more manageable and maximise the participation of all the children [referring to children with SEN and without SEN].

Complications in terms of behaviour management and reinforcement were also seen as a factor for both teachers' reluctance to practice inclusion. They indicated that the difference in the way children with and without SEN were treated in an inclusive classroom might have repercussion on both groups of children. This is evident from the following quotes:

(Teacher 1)

...They are six year olds with some form of disability, and most of them display emotional and behavioural difficulties that need to be attended to in a very thoughtful and delicate way. I think they would be treated with more empathy, sympathy and affection in a special education classroom compared to a regular classroom... In our classrooms there is quite a bit of discipline enforced, quite a few rules which have to be obeyed. It just wouldn't be conducive for the special kids ... They might be confused or get upset with all the rules in the regular classroom. 


\section{(Teacher 2)}

If the preschoolers with SEN are given special treatment in the regular classroom, the kids in our classroom would then start wondering - why is this child able to get away with lots of things? Why can't I do the same? etcetera and etcetera. Many of the children with SEN look just like the preschoolers in our classroom. Our kids won't understand why those kids are getting special treatment ... so at the end of the day, it would be difficult for us, the regular teachers to establish control over the regular preschoolers.

Both teachers stated that they would comply with directives from the Ministry of Education if inclusion were made compulsory in preschools. However, one of them was frank about indicating that her effort and commitment towards inclusion would depend on the type of support she received to cater for instructional approaches in an inclusive classroom. These included support in terms of training, resources and guidance drawn out for regular classroom teachers in terms of inclusion. This teacher felt that without a combination of such supports, the directives from the Ministry would only bring about the placement option for preschoolers with SEN in regular classrooms, and not educators encouraging and supporting the children's full participation in the classroom.

In terms of parents' stance on current practices in the preschool (i.e., non-inclusive and segregated), the teachers commented that most of the parents were barely involved in anything school-based, and were only seen on enrolment day, open day, or when they rushed off after drop-off and pick up time. However, both the teachers acknowledged that they never got the parents involved in the preschool's goings on either, thus could not confirm how they felt about current practices in the preschool. One of them also commented that the regular preschool teachers had enough support and help from each other and the two teacher-assistants to organise and implement teaching and learning activities, so they did not require much parental involvement. However, if extra help was required for special events, such as sports day or field trips, they did send out invitations to parents and select a few parents as volunteers. 


\section{Parent of typically developing preschooler}

This parent had no understanding of inclusion and admitted that he had never heard of the term. Hence, a general description of inclusive education was provided in order to carry on further discussions with him. When informed about the practice of inclusion, he was pleased to know that there was such an approach to educating children with SEN.

Given that he had no knowledge of this practice, he stated that he was happy with the way the regular classroom teachers were carrying out daily teaching and learning activities. This parent admitted having very little involvement in the preschool's activities, and said he had never paid attention or given a thought to the non-inclusive or segregated practices involving children with and without SEN in the preschool.

However, this parent felt that inclusive practices in the preschool would be a good way to instill positive values among children, and shape the type of caring society to which the nation aspired.

I suppose nothing that gets people closer to one another can be bad. It would be good for all involved, I'm sure. Like for regular children, it would be an education in affective behaviour, maybe like, looking out for others in need, caring for each other, tolerance and all that; especially since our country has always placed emphasis on a caring society ... It would be good to start the caring culture from young.

Further explanation of inclusion from the researcher was able to draw out relevant views about inclusion from this parent. For example, although this parent had stated positive ideas about educating children with and without SEN together, he appeared to indicate conditional support for inclusion. This parent believed that the regular preschool teachers must be committed to inclusion and confident about their capabilities to cope with the combination of teaching and learning strategies drawn from regular and special education classroom practices. Otherwise, he believed that there would be profound effects on the children's learning and motivation, and apprehension from the parents. This was evident from the following quotes:

I may not know much about this practice, but I am quite sure that the presence of the special kids in the regular classroom would mean that the teachers must modify the way they teach, manage the children's behaviour and other things to suit both 
groups of children. If the teachers are confident about managing the educational needs of both groups of children at one time, then as a parent, I certainly don't have anything against this practice.

.... As a parent, I won't be happy if the lessons were too simplified to cater for the children in the other classroom. I have high expectations for my child. I am sure the parents of children in the other classroom won't be happy about their children being forced to fit into the learning styles and expectations in this classroom either. It would affect all the children's motivation and learning outcomes. All parents want the best for their children.

However, when asked about social integration, this parent indicated that he would be fully supportive of it:

If the teachers decided on having more shared opportunities for all of them (referring to children with and without SEN) to play at the playground, have lunch together, I am absolutely fine by that. In fact, maybe during physical education, music, and art activities, these too, should be okay.

When asked if he would be happy to talk about his suggestions on inclusion (mentioned above) to the regular preschool teachers, he stated that he normally preferred not to get involved in preschool affairs, and would rather leave it to the teachers to make such decisions. He believed that the preschool teachers may have had other reasons for not doing inclusion; challenges he was not aware of. He added that since he lacked knowledge about inclusion, he may not be a good advocate for it. However, this parent clarified that if the topic of inclusion did come up by chance, or if there was a proposal to carry out shared activities among children with and without SEN in the preschool, and parents' views were required, then he wouldn't mind giving his opinion to the teachers, but would still leave it to the teachers to make the final decision.

\section{Parent of preschooler with SEN}

This parent had a Down's syndrome child, Regina, enrolled in School 2. Prior to enrolling, Regina attended the toddler programme at the Kiwanis Down's Syndrome Foundation (KDSF) when she was two, and the special education programme there until she turned six. (Note: KDSF is a non-profit organization in Malaysia, which is committed to the welfare of young children with Down's syndrome). 
Regina's mother appeared to have a clear understanding of inclusive education, which she said she had mostly gained from the parent support group at the KDSF. This parent felt that inclusion was important for building on the learning potential of every child, with and without SEN:

To me inclusion is an excellent practice. Every child will learn something positive from it. The disabled child can pick up skills from their non-disabled peers. The other children [non-disabled/typically developing children] will grow up learning to be tolerant and more understanding of disabled people's needs...

According to this parent, initially she was pleased that there were provisions in Malaysian preschools for children with SEN to be placed in the same educational environment with their typically developing peers. However, she stated that she became disappointed to discover that there were barely any opportunities for children with SEN and without SEN to participate in activities together in her daughter's preschool:

I was really happy when I found out that the Ministry of Education had come up with the implementation of integrated preschools. I was happy that Regina would be able to attend a regular school after all ... but sadly, when I asked Shona [special classroom teacher] about inclusive practices in the preschool, she said they were not doing it.

Despite feeling disappointed with the current segregated practices in School 2, she stated that she had never approached the school principal to suggest that more opportunities were made available for children with and without SEN to engage in shared activities. Instead, she indicated that she was glad that the special classroom teacher was not forceful about inclusion. She supported her statement by associating it with her knowledge about inclusive education and teachers' attitudes towards it:

...the teachers must support the participation of children with SEN in the regular classroom, or at least be supportive of social integration. But if the teachers in the regular classroom are not interested in inclusion, why should we force them, and plead with them? I wouldn't want my daughter to be in a classroom that she is not welcomed to ... I am happy that Shona did not force the regular classroom teachers into it [inclusion] ... Inclusion doesn't work like that. It will only work if every child feels welcomed and valued ... The teachers must receive them happily ... If these children are placed in regular classroom for the name sake of inclusion, isolated in one corner of the classroom, it's not going to work. Then, they may as well be here [special classroom]. 
This parent was also disappointed that the location of the special education preschool classroom was 'out-of-the-way' from the regular preschool classroom in School 2:

\begin{abstract}
...I also don't see a reason why the special education classroom has to be so isolated from the other two classrooms. These children don't even share the same space for their meal, or the same space to play. It's like they are purposely being segregated. But why? If they did share such space, at least they bound to have some opportunities to mingle with one another during playtime or mealtime. I mean, at least some kind of integration can take place, right?
\end{abstract}

This parent said that she was mostly disappointed because the regular teachers seem so reluctant to support or initiate any form of activity that enabled the integration of children with and without SEN in the preschool. She further related her views to the use of the playground in the school:

\begin{abstract}
Why not just make adjustments so children in this classroom [special classroom] can play there? At least these kids can make friends with the other kids over there. I mean ... what's wrong with that? It's not fair to alienate these children. This is what really gets me frustrated sometimes with those teachers [referring to regular classroom teachers in School 2]
\end{abstract}

She also displayed frustration over the school's ignorance about the concept of 'integration', which she believed was limiting the opportunities for integrated opportunities between children with and without SEN, as indicated below:

....separate teachers, separate classrooms, separate playgrounds, separate curriculum. Then where is the integration? It's a shame that the school doesn't understand the concept of integration, or maybe they just don't care. I don't know.

She also stated that she tolerated the current practices in the preschool due to the distance of the other integrated preschool programmes from her home, and thus she did not want to make an issue. Furthermore, she believed that once Regina began primary school next year, there would be more schooling options for her daughter, where teachers were more experienced with inclusive education (referring to primary schools).

As for her participation in the preschool activities, she stated that she often volunteered to help out whenever possible. She was also positive about the special education preschool teacher's initiatives in getting parents to understand the importance of getting involved in their children's learning activities. However, she expressed disappointment that parental participation was limited to events that 
evolved around the special education preschool classroom, and did not take place in regular classroom events. She stated that she sometimes felt that parents of children with SEN were not treated as part of the wider school community. She further substantiated her views by stating that the only time she felt that the school acknowledged her as part of the school community was when she received the invitation to attend the Parent-Teacher Association's annual general meeting organised by the school. She also stated that she frequented the special education preschool classroom, but never saw the principal paying a visit or initiating speaking to parents, which she felt was extremely important to make parents feel welcome, and their children accepted as part of the school community.

\section{Summary of findings in School 2}

Information gathered through various data sources from different locations, situations and circumstances across the school indicated that segregation was the prevailing philosophy in this school. Daily activities in School 2 did not offer any opportunities for interaction between preschoolers with and without SEN, in planned or random activities at any time during the school day. The physicality of the special education classroom, which was isolated from the two regular classrooms in this school, seemed unsupportive to promote inclusion, and also limited the opportunities for children with and without SEN to engage in spontaneous or unplanned interactions.

The school's philosophy towards inclusion was clearly reflected in the school community's (lack of) support for inclusion, and the way they perceived inclusion. The findings that emerged from School 2 showed that only the special education teacher and the parent of the preschooler with SEN could clearly articulate the meaning of inclusion, and recognised its importance. The rest of the participants acknowledged having little understandings of this concept. The regular classroom teachers viewed inclusion as difficult and not feasible. The parent of regular preschooler had conditional acceptance towards inclusion, indicating that regular classroom teachers must be able to ensure that the educational values for preschoolers in the regular classroom were not affected if inclusion was carried out. 
The principal on the other hand, was neither supportive of nor against inclusive practices in the preschool, leaving the decision-making to the preschool teachers. Practices of segregation were clearly reflected in the way the preschool teachers worked, and the way preschoolers with and without SEN were taught in the school. The two regular classroom teachers worked collaboratively, and carried out many shared lessons and activities with the two regular preschool classrooms. The special education preschool teacher worked on her own, with support from children with SEN's parents. In short, the regular and special preschool classrooms in School 2 appeared more like two separate preschools than an integrated preschool programme.

Parental involvement in the preschool was only apparent in the special education preschool classroom. Yet the parent of the preschooler with SEN who was interviewed still felt like an outsider in terms of the wider school community, stating that parents of preschoolers with SEN's role in the school was restricted and limited to what took place in the special education preschool classroom only. On the other hand, the parent of the typically developing preschooler preferred not to get involved in preschool matters as he felt that it was better to leave it to the teachers to make teaching and learning related decisions. Regular classroom teachers also reported preferring parents of typically developing children not to be involved in the preschool's state of affairs.

In sum, the information that emerged from the findings showed that a range of factors were affecting the state of inclusion (or segregation) in School 2, and educators' and parents' support for it. These factors were mostly relevant to:

- environmental accommodations and adaptations unsupportive of inclusion

- principal's non-committal support for inclusion

- regular educators' negative attitudes towards inclusion

- regular educators' lack of knowledge about inclusion

- lack of collaborative efforts between regular and special classroom teachers

- limited parental involvement

- the use of two separate curriculums 
- large enrolment in regular classrooms

- lack of support and guidance from the Ministry of Education

\section{Case Study 3}

\section{Description of setting and events}

The third case study site, School 3, was located in a suburban town in the west of Peninsular Malaysia. The school was located in a lower middle class residential area. Most students and staff from this site came from the surrounding residential neighbourhood.

School 3 was well known for their academic achievement. The artifacts around the school reflected the school's philosophy towards promoting an academically oriented culture. There were posters concerning the importance of education for self-development and nation building pinned up on the walls, pillars, and bulletin boards along the corridors. There were also many colourful boards with idioms, short poems, children's work, and short stories hung around the school's environment, encouraging children to read when and where possible.

The principal had a total of 17 years of experience being a school principal, and had been administering this school for 4 years. She had a degree in Malay Language and had been teaching for 12 years in a few other primary schools prior to becoming a principal. There were around 1500 students in School 3, and about 100 staff served the school. Special education services were offered at the preschool level and primary education level.

The integrated preschool programme in School 3 was made up of two regular classrooms and one special education classroom. All three classrooms were at the far end of the school. The two regular preschool classrooms were situated on the ground floor of a two-storey building, and the special education classroom was located on the ground floor of another building opposite the regular preschool classrooms. The regular and special education classrooms had a well equipped 
outdoor playground between them. All the preschoolers, with and without SEN, shared this playground.

Both the regular preschool classrooms in School 3 were attached to one another and had a connecting door between. There were 22 regular preschool children in one classroom (10 boys and 12 girls) and 21 in the other (11 boys and 10 girls). One of the regular classroom teachers had a degree in early childhood education and was currently pursuing a Masters in Education. She had been a preschool teacher for the past three years. According to this teacher, she had had two semesters of courses related to the basics of special education during her degree programme. The other regular preschool teacher had a teaching Diploma in Preschool Education. She had been teaching in School 3 for three years and had been a preschool teacher for 11 years prior to that. She believed that the little knowledge she had about special education was mostly gained through her experience as an educator.

The special education preschool teacher had a diploma in Religious Studies and was a primary education teacher in School 3 for 8 years prior to becoming the preschool special education teacher. She volunteered to teach the special education preschool when there was a vacancy, two years ago. She had since been attending several special education courses organised by the State Education Department and Ministry of Education. According to this teacher, there were seven 5-6 year old children ( 5 boys and 2 girls) with a variety of SENs in the special education preschool classroom. Three of these preschoolers had Down's syndrome, another two had autism, one had ADHD, and another had cerebral palsy.

Each of the three preschool classrooms in School 3 was assisted by a teacher assistant. The three teacher assistants were assigned to one classroom each. They helped the respective classroom teachers with administrative work and classroom activities. However, they often shared their responsibilities supervising the preschoolers during outdoor activities (in the playground), and preparing meals and teaching aids for all the classrooms. 


\section{Nature and extent of inclusion}

Interaction and participation of children with and without SEN in School 3 were evident only in socially integrated activities outside their classrooms. Children with SEN had no opportunities to be included into regular classrooms at this site. Preschoolers with SEN remained in the special education classroom during academic or classroom learning hours.

However, both groups of preschoolers, with and without SEN, were engaged in social interaction on a daily basis. Every day, before and after the school bell rang, early comers from the regular and special education classrooms were seen at the playground engaged in random activities. This type of engagement also took place during break time and after school. Observations that were carried out at the playground showed that preschoolers in regular and special education classrooms knew each other by their names and were communicating freely with one another. Two adults (teacher assistant or teacher) were always on playground-duty when the preschoolers were there, whose responsibilities were to ensure the safety of the preschoolers in the playground. However, observations showed that the casual conversations that the adults had with the preschoolers sometimes encouraged the typically developing preschoolers to initiate further conversations with their peers with SEN. Therefore, these adults also played the role of initiating and enhancing successful interaction among preschoolers with and without SEN.

According to the special education teacher, she and the regular classroom teachers met once a term, and planned necessary changes or improvements for the preschool. For instance, this year, in order to avoid overcrowding in the playground and to accommodate opportunities for social integration, the special education classroom shared the same break time with one of the regular preschool classrooms every Monday and Wednesday, from 9.50am to $10.10 \mathrm{am}$. On every Tuesday, Thursday and Friday, the special education preschool classroom shared the same break time with the other regular preschool classroom, from 9.20am to $9.50 \mathrm{am}$. 
Although break time was for 30 minutes, social integration in the playground took place only for about 20 minutes daily. This was because all the preschoolers remained in their respective classrooms for the first 10 minutes, for their meal. It was also clear that not all the preschoolers had the same duration of opportunities to engage in socially integrated activities. Early comers and those who went home late had more time to be in the preschool environment and make use of the opportunities for such interactions. There were also preschoolers in regular classrooms who sometimes preferred to remain in their classrooms and play indoors. Therefore, the majority of the preschoolers with and without SEN had an average of about 20 minutes or less a day for engaging in socially integrated activities in School 3. Additionally, there was one preschooler with autism, who also displayed emotional disorder, and often remained in the classroom with the teacher assistant or special education teacher during break time, thus barely getting involved with other preschoolers.

The preschool teachers acknowledged that opportunities for children with and without SEN to engage in shared activities during daily routines took place by chance only. There were no planned or structured activities organised by teachers to ensure such integration took place, and thus nothing was stated in their daily lesson planning. However, an examination of the IEPs in the special education classroom showed that the special classroom teacher took into account the social and emotional development of preschoolers with SEN, concerning their ability to relate to situations and circumstances during socially integrated activities with peers in both regular and special classrooms.

Both the regular preschool teachers mentioned that they often carried out team teaching in the regular preschool classrooms but did not involve the special education preschool teacher in the planning of their scheme of work. An examination of the regular and special education classroom teachers' lesson notes and record books showed that the regular preschools had similar teaching plans, which were entirely different from that of the special education preschool teacher's. In addition, all the preschool teachers agreed that collaborative work among the 
three of them involved only the planning of non-academically oriented activities, such as field trips, the end of the year concert and sports day activities.

\section{Perceptions of inclusion}

Interviews were carried out with five participants in School 3. They were; the school principal, the special education preschool teacher, the two regular preschool teachers, the mother of a typically developing preschooler, and the father of a preschooler with SEN. The following discussions relate to how inclusion was perceived by educators and parents in School 3, what affected their perceptions and how it affected the implementation of inclusion in the preschool.

\section{School Principal}

The principal of School 3 had a child with SEN herself. She was very familiar with the term inclusive education. She was also well versed with the procedures and processes involved in including students with SEN into regular classrooms in the Malaysian school system, which she believed she had mostly learnt through her own initiative as a mother and as a principal.

She stated that in theory, inclusive education recommended the placement of students with and without SEN into regular classrooms environment, so that students with SEN spent all, or most, of their time in academically and socially integrated activities with regular classroom students. However, in reality she felt there were no universally agreed practices for inclusion because every country, every state, every school (and at all levels - preschool, primary, and secondary) had a way of justifying the way inclusion was carried out in context.

This principal strongly supported practices of inclusion. In her opinion, she felt that inclusive education was an excellent concept because the fundamental right of all children to receive education in the regular education environment was acknowledged by it. She felt strongly that providing children with and without SEN opportunities to interact in the school environment on a regular basis was 
indispensable. However, she stated that inclusion would depend very much on the capability of students with SEN to cope with academic integration:

\begin{abstract}
....academic integration might not benefit all the special needs students. I think those who can cope with our regular classroom learning, they'll do fine. Not every special child can cope with our regular classroom syllabus. Those who can't are better off in the special education classroom under total supervision of special education teachers. Our special education teachers are well trained and they know what is best for the child.
\end{abstract}

...Anyway, I don't see any reason why social integration shouldn't take place. Social integration is indispensable in every integrated school. I mean, that's why we have integrated schools in the first place, so some kind of integration must take place...

This principal however, believed that preschool inclusion may be a bit more challenging than primary or secondary schooling. According to her, in most cases, young children were automatically placed into regular preschool classrooms when they begin school life, and if they had learning difficulties, these would only be detected later in their schooling. However, if a child was already in a special education preschool classroom from the day they began preschool, chances are that, that child had been without doubt, identified as a child that required specialised instruction and might not be able to cope with regular classroom learning. Thus, academic integration would be too challenging for preschoolers with SEN.

In her opinion, the expertise of the special education teachers were required at the preschool level for getting preschoolers with SEN used to school life first:

...I feel when young children with SEN start preschool, they are out of their comfort zone, trying to adapt into a new environment. That takes time. We must allow some time for them to get used to the school environment, and the special educators are the best to do this [helping children with SEN adapt to change].

This principal felt that the main barrier to inclusive practices in Malaysian schools was the lack of understanding among schools' principals with regards to inclusive education.

As a principal, I understand and support inclusive practices. But sincerely, this is because of my own interest due to me having a child with SEN. I know the importance of inclusion and the benefits of this practice for children with and without SEN. But then again, how many principals are there who actually know the importance of inclusive education or promote this idea in their schools? 
She believed that the Ministry of Education was not playing their role in ensuring that principals were equipped with the information and support they needed to promote inclusion in schools:

...All schools must be given proper directives about inclusion, the how, where and why it must be encouraged. All these information must be stated clearly in a circular and sent out to every single integrated school in the country ... This is also where the Special Education Department in the Ministry of Education should play their part ... they have to go all out and educate principal, teachers and parents about inclusive education.

According to this principal, throughout her service as a principal, she had never attended any meetings at the ministerial or State Education Department informing school principals of inclusion:

I have been a principal for 17 years. But until now, I have never attended any meetings that discuss inclusion ... It's like, once the special education programme is in our school, we are left to handle the programme on our own with the help of the special education coordinator and teachers.

This principal felt that the Ministry depended totally on schools to carry out inclusion whenever possible, without proper guidance for the principals, or training for the regular teachers. She believed that the lack of such exposure and support from the Ministry was an additional pressure to principals, because regular teachers, who felt that they lacked the skills and knowledge to carry out inclusion, would show their frustrations and disappointments towards the principal, students with SEN, or the special education teacher. She further related her views on teacher's frustrations to an incident that took place at the preschool of School 3. The principal stated:

Last year a mother insisted that the preschool teacher place her Autistic child in the regular preschool. Amir had mild autism. His mother came to me and I spoke to the regular preschool teacher and encouraged her to give it a try. Amir was said by his mother to be a very quiet child, and will not disrupt the class much. Lina, obliging, reluctantly accepted Amir in her class. Amir could not follow most of the teachers' instructions and kept to himself most of the time ... showed temper tantrums. Lina tried to discipline him one day, and Amir got fits in the classroom. Lina panicked and asked the teacher assistant to get the special education preschool teacher to come over. Then there were many other incidents and finally just as I expected, Lina walked into my office one day and told me that she had had enough. She said that she does not have the expertise to handle Amir and is wasting a lot of the other children's precious time on Amir. She insisted that he would be better off in the special education classroom, so why bother her. I could see the stress she was going through when I saw the tears in her eyes. She insisted that Amir is sent back to the special education preschool classroom and let her enjoy her job. 
Her experiences as a principal showed that there was no use in forcing the teachers to carry out practices of inclusion, especially inclusive lessons in the regular classroom. This was because ultimately the teachers would comply, but their commitment towards inclusive practices would be reflected through, what she perceived to be a lackadaisical attitude towards inclusive lessons:

...it's a tricky situation. Some regular teachers don't really complain, but it's easy to know that they are not really supporters of inclusion either... You just know from their very lackadaisical attitude. They are just not interested. They treat the special child like as if he is one of them in the regular classroom. No special attention, no special coaching; either he copes or just remain there for the sake of being included [Sigh]. So, some regular teachers have no opinion at all, no complains at all, but this doesn't mean all is going well either.

Nonetheless, she also felt that it was also not fair to pressure the regular teachers if they refused academic integration, because they already had a heavy workload in terms of meeting curriculum needs, and classroom management with a classroom of up to twenty-five preschoolers. Furthermore, inclusion was not a compulsory practice in the Malaysian education system, and thus the regular teachers had a basis to disagree to it.

She believed that the principal's role was to encourage, and to support practices of inclusion in the school, and she had done this by carrying out in-house courses on inclusive education. She had also set some ground rules in the school, and thus made sure that social integration took place at the preschool and primary education level.

\section{Special education preschool teacher}

The special education preschool teacher mentioned that she had acquired a clear understanding of inclusive education when she had taught students with SEN during her experience as a primary education teacher in School 3. In addition, the courses that she had attended as a special education teacher had enhanced her knowledge on this concept. 
She believed that practices of inclusion brought about many positive changes among preschoolers with and without SEN, and mentioned that she had personally seen the improvements in her students' social skills as a result of social inclusion. She appreciated the regular classroom teachers' efforts and cooperation in making time table adjustments so preschoolers with SEN in School 3 had opportunities to engage in socially integrated activities with their typically developing peers.

However, she felt that the severity of the preschoolers' disability was an important consideration when making decisions about creating opportunities for children with and without SEN to engage in shared activities at the preschool level:

The severity of the disability is an important factor when planning on activities, regardless of whether it is carried out during lessons or at the playground or anywhere for that matter. I have one boy who has autism in my class. He is so unpredictable. We have no choice but to keep him with us in the special education classroom most of the time, even during recess. He can get really aggressive sometimes. He has kicked me once, he has pinched the other children, and I have had parents coming to school complaining, thinking that I had pinched their kids. This boy, I wouldn't dare include him in any shared activities with the preschoolers in the other classrooms, unless he has one to one supervision at all times. He might hurt them [typically developing children], and they might retaliate.

When asked to elaborate on inclusive practices and her views about them in the preschool, this teacher stated that she personally found preparing for academic integration as laborious, and requiring meticulous efforts. However, when asked about coordinating with regular classroom teachers to plan inclusive lessons instead of trying to plan it out on her own, she admitted that the regular classroom teachers and she preferred to work separately, and believed they were each responsible for their own students as far as lessons were concerned.

Actually, we don't really work that way. They have their own plan with their kids. And, I do what I have planned for mine. My lesson focus is different from theirs. We prefer not to join up during lessons. It's difficult to decide who is going to do what ... whether we should cater for my kids or theirs ... I don't mind teaching those kids, but they prefer to teach their own kids. I don't want to be an intruder [chuckles].

When asked to elaborate on the principal's support for inclusion, this teacher mentioned that the principal was generally supportive about inclusive practices in the school. She also stated that the principal often encouraged teachers to ensure that children with and without SEN had opportunities to engage in shared activities, especially social integration. However, she believed that the principal's support alone was insufficient to attain a desired level of inclusive practices in the 
preschool. She felt that there had to be commitment, teamwork, and enthusiasm about inclusive practices among the teachers. Upon further elaboration, other details from this teacher also revealed that there was a lack of cooperation among regular and special classroom teachers in School 2 in planning for inclusion:

\begin{abstract}
I feel reluctant to suggest inclusion to them [regular classroom teachers]... They have always assumed that the special education teacher's workload is less stressful because children in special education classrooms are allowed to learn at their own pace, and it doesn't matter whether these special children even learn or not ... But, they [regular classroom teachers] have always portrayed that the regular classroom teachers are rushing for time to catch up with syllabus, and have to ensure that their kids were ready for year one learning standards, especially with the Ministry's emphasis on LINUS ${ }^{3}$ now. The regular classroom teachers feel so pressured because they don't want to be blamed by the year one teachers if most of the preschoolers end up being placed under LINUS programme in year one ... So, I feel like I am suggesting an additional load of work for them if I were to propose inclusion.
\end{abstract}

This teacher clarified that parents had never brought up the issue of inclusion. She believed that this was because most of the parents were either satisfied with the current practices in the preschool, or they were not well informed of inclusive education. However, this teacher also admitted that she had never spoken of, or shared information with parents, on inclusion. However, she stated that parents were always welcome to her classroom, or to meet up with her to share ideas or information about their child. Parents had also been invited to get involved in the preschool's activities, such as classroom decoration and spring cleaning, as volunteers on field trips and annual sports activities, and other events from time to time. Further, formal communications with parents were held three times a year, which is also when IEP reviews were carried out.

\title{
Regular preschool teachers
}

Both regular preschool teachers in School 3 described themselves as having reasonable understanding of inclusive education, which they had gained through their experiences as educators. Both teachers also seemed positive about the Ministry of Education's move to initiate integrated preschools that made it possible

\footnotetext{
3 LINUS is a Literacy and Numeracy programme developed by the Malaysian Ministry of Education. This programme caters for non-disabled children who are identified as those who do not meet the required reading, writing and counting standards after screening tests are carried out with them.
} 
for children with and without SEN to have opportunities to learn within the same setting:

(Teacher1)

I think integrated schooling is a good practice... a morally justifiable practice. At least children with SEN are not totally segregated from our regular education environments.

\section{(Teacher 2)}

I think placing children with and without SEN in the same educational setting is one of the best steps that the Ministry of Education has taken in terms of children with SEN's education. At least we know now that the education system has started placing more importance on the education of children with SEN.

Although the teachers held positive beliefs about the education of children with and without SEN under the same roof, their acceptance toward the placement of children with SEN into regular classrooms appeared to be rather restrictive:

\section{(Teacher 1)}

In my opinion, I don't think it is necessary to place them [preschoolers with SEN] in the same classroom with the other kids [typically developing children]. What is important is that we must maximise their [children with and without SEN] opportunities for interaction. So, for me, I think social integration is also a form of inclusion.

\section{(Teacher 2)}

I agree that inclusion has its benefits. But it is not practicable ... I also don't believe that special children must be in the same classroom with regular kids to be able to feel included. We can make them feel included in other ways ... they can be together during recess, or at the playground. Pick up some social skills... I think that sort of inclusion will do at this stage.

The regular teachers in School 3 clearly stated that they were happy with the current practice in their preschool (social integration), and had no intention to include children with SEN into the regular classrooms. These teachers appeared to display unsupportive attitudes towards academic integration, when they spoke of their lack of support for including children with SEN into regular classrooms:

(Teacher 1)

They have different abilities. Having them in the same classroom with my kids during lessons will be a tough start for special needs children.

\section{(Teacher 2)}

In my opinion we [referring to the preschool programme] are not segregating them [children with SEN] ... we also don't think it is right to totally segregate kids with special needs and the kids here because of their differences in academic achievements. But it is so difficult to have them in the same class during lessons. 
One of these teachers believed that children with SEN were best educated in separate classrooms, under the supervision of special education teachers because, special education classroom enrolment was low and thus the special educator could afford to devote all the time and attention that these children deserved. This teacher then related to her personal experiences with children with SEN and lack of knowledge in teaching these children when she spoke of her reluctance towards inclusion:

I really won't be able to manage special needs children in my classroom because I don't have the patience to handle them. I have tried it once when the principal convinced me to do it, I couldn't. It was simply too stressful. I lost hope in my own teaching. I spent the whole day getting him [child with SEN] to learn something really simple, like holding a pencil and scribbling, simple motor skills ... and I couldn't. He tears the paper and throws it away. He used to drive me up the wall. I used to control my tears. And worst of all, my other 22 kids' time were wasted on this one boy. No, I can't do it. I don't know about other teachers, but I can't do it.

The other teacher related to her lack of necessary skills and knowledge to teach young children with SEN in regular classrooms:

I have been trained to teach regular preschool children... I don't know how to teach them [preschoolers with SEN]. They need people who have knowledge about special education ... Better to just leave the teaching part to special education teachers.

One of the teachers' negative attitudes and lack of interest in relation to teaching children with SEN was clearly reflected in her response about this situation:

I have no interest in special education or teaching children with SEN. I believe, as teachers, we have to have some interest in this field if we want to teach them. For this reason, I have not attended any courses on special educational needs, or inclusive education, and I really don't want to. Simply because I am not interested in special education. I'd rather give away that opportunity to another teacher who would be interested to attend the course and put good use to the knowledge gained.

This teacher however, mentioned that she would conform to the Ministry's directives if inclusion were made compulsory in preschools. However, she also admitted that as a teacher she had no choice but to work in accordance to the rules and regulations of the Ministry of Education, so she would carry out inclusion only because it was obligatory. Nevertheless, this teacher indicated that she would be pleased to carry out out-of-classroom integration (social integration):

Then we regular teachers are left with no choice but to carry out inclusion. We are obliged to abide directives if it is coming from our big bosses. I mean, if I have to do it, then I will, but until and unless there is such a directive I don't need to [chuckles] ... Given a choice, I'd rather stick to out-of-classroom integration. Social integration is less stressful for the teachers and frankly, I believe, it is also less stressful for our students, all our students. 
Findings showed that the regular teachers were also troubled with the thought of having to cope with extra workload in their class if preschoolers with SEN were placed into regular classrooms. Both teachers took a similar stance in this regard. According to one of them:

I already have to deal with the needs of my existing preschoolers in my classroom, who have different abilities and interests. I can't afford to think of inclusion. Academic integration would demand painstaking teaching preparation to ensure that lessons were carried out not only to suit the needs of my preschoolers, who have various abilities, but also to suit preschoolers with SEN's disabilities ... These factors must be taken into considerations when we think of inclusion.

When asked about parental stances on current practices in the preschool, the teachers stated that they just assumed that the parents approved of it, because none of the parents had come forward and made any suggestions about inclusion, and nor did they mention anything about social integration. However, the teachers admitted that the parents were never consulted with on such matters. Both regular preschool teachers stated that parents' involvement were restricted to their own children's matters only. According to one teacher, matters often got too complicated when there was too much parental involvement, as she believed that each parent had their own stance, and that it was difficult to satisfy everyone. She believed that the best way was for teachers to make decisions where general issues were concerned, because teachers are better informed of all the students' needs and priorities:

\begin{abstract}
Sometimes it is better if we as teachers are left to make the decisions. Things get too complicated if we involve parents in every matter. Each and every one of them will have their own opinion and priorities. And often the priorities would concern their child's needs and benefits. Finally, it is we, the teachers, who get all stressed up, trying to satisfy everyone. So the best is when matters are concerning one particular child, we get that child's parent to make a decision, but if it's something general, and it involves all the children, I think the teachers can make better decisions. Our judgments will be fair to all concerned.
\end{abstract}

Findings also showed that the principal's support for social integration (rather than inclusion) at the preschool level appeared to influence the preschool teachers' practices in School 2:

She [school principal] is very supportive of any kind of activities that offer opportunities for children with and without SEN to spend time together. But somehow, she seems to be involved in initiating it [inclusion] mostly at the primary education level. In our case [preschool], she doesn't seem forceful about inclusion, and is happy for us [preschool] to carry out social inclusion. 


\section{Parent of typically developing preschooler}

This parent stated that she had some idea of inclusive education. She mentioned that she had come across this term and experienced seeing children with SEN being part of the regular classroom enrolment during job related school-visits to other primary and secondary schools. She was a nurse and her job sometimes required her to go around schools within the district to carry out short seminars, and to give talks to schoolchildren on hygiene, dental care, and other health issues. Conversations with regular and special education teachers about classroom enrolment, and students' health related issues had brought about her understanding of some basic information about inclusive education, and the placement of students with SEN into regular classrooms.

This parent was supportive of the current practices in the preschool. She was aware and happy that the preschool was carrying out social integration. She believed that providing children with and without SEN opportunities to learn in the same educational environment was a good practice, and felt that it gave children increased opportunities for meaningful friendships, as well as encouraging children to appreciate individual differences. She was pleased to share her daughter's experience with a peer from the special education classroom, which she felt helped her daughter recognise and respect other people's capabilities:

My daughter often talks about her friend, Aishah, the girl with Down's Syndrome from the special education classroom. They meet at the playground every day. I saw my daughter braiding her own hair the other day. I asked how she had learnt to do it. She told me that Aishah had taught her, then she said, "you know ma, Aishah is a very clever girl. I wish we were in the same class." I think that it was really amazing that she was not only appreciating the friendship, but also Aishah's ability to do something that she [her daughter] couldn't.

When asked about her stance on including children with SEN into regular classroom, she believed that it was not impossible to carry out inclusion at the preschool level. She further supported her belief by making a comparison of inclusive practices between the secondary, primary, and preschool education system:

My personal opinion is [pause], it is not impossible to include children with SEN into regular classroom at the preschool level. I mean, preschool education ... preschool is not so complicated like secondary school learning and all. Lots of singing and playing and colouring ... maybe it would be okay. 
She acknowledged that difficulties for teachers could arise from the different abilities of preschoolers with and without SEN, but believed that if the preschool teachers were able to carry out inclusive lessons, while adequately addressing the needs of all the children in the classroom, there should be no reason for not supporting inclusion:

...but then sometimes, children with SEN can have very different needs, they need individual attention. That's why maybe it's better for them to be in separate classrooms during lessons, like math time and all. Their learning needs are different. But if teachers can manage that, I guess it should be okay, I don't see why parents should not support this move.

Ultimately, however, this parent felt that it was up to the teachers to decide if preschool inclusion was feasible, believing that teachers knew best about their teaching, and would make better decisions about such matters as inclusion. Subsequently her response also indicated her reluctance in getting involved in the decisions that the preschool made on such matters as inclusion:

Anyway, mine is just a parent's point of view. The teachers may have other reasons for not doing it [inclusion]. I don't know. So better just let them decide what works best for the children.

This parent, however, felt that children's reactions in inclusive classrooms could be a concern. She further substantiated her point by stating that regular classroom preschoolers were still too young and naive to understand the consequences of their doings towards others' feelings and emotions, believing that some of these children might tease their peers with SEN because of their (children with SEN's) inability to follow instructions, or to carry out certain tasks due to their disabling conditions. She believed such situations could lead to unnecessary stress between parents of children with and without SEN, the teachers, and the preschoolers themselves.

\section{Parent of preschooler with SEN}

This parent had three children. His youngest daughter, Sarah who had autism was enrolled in the special education preschool in School 3. According to Sarah's father, Sarah had attended a private regular preschool when she was 4 years old (prior to her enrolment into School 3). Sarah had trouble communicating with others. She 
did not know how to talk, play, or relate to others. She also had trouble adapting to changes in routine, and displayed temperamental behaviour when there was a change in her regular schedule. Due to these characteristics, Sarah was often left to work on her own at the corner of her classroom. She was also ignored by peers, and was a loner in the first preschool. Sarah's father felt that the teachers in the first preschool did not make an effort to facilitate or promote any form of effective learning for his daughter. He finally decided to pull Sarah out from there and send her to a centre that specifically dealt with young children with autism. However, the autistic centre was about 45 minutes drive from home. Although he was pleased with the development he saw in his daughter, the distance of the centre from home caused inconvenience, and so Sarah was there for only six months. He then got Sarah enrolled into School 3.

Sarah's father stated that he had a fair understanding of inclusive education. He had mostly gained this through his own initiative while sourcing information on autism on the internet, and in books, journals, and other forms of media since discovering that Sarah was autistic. He then made a comparison of inclusion between the western and Malaysian context based on the vast variety of local and international information he had gained about it:

...there is a huge difference in the way inclusion is perceived and practiced in the western culture compared to how we look at it here [Malaysia]. There, their practices are governed by law. Teachers must do it, like it or not. But here, it is basically the teacher' choice whether or not they want to do it.

He however, was very pleased with the Ministry of Education's initiative to locate regular and special education preschool classrooms within the same educational setting. He was especially happy that the first essential step in creating possibilities for inclusion had begun in the country.

When asked about his view on the current practices in his daughter's preschool, this parent appeared pleased and satisfied, as stated:

I am happy that she is at least able to be in a regular school just like any other kids her age... The teachers in this school are nice. They don't just leave the special children in their classrooms. They are willing to ensure that children in the special classroom are having some form of interaction with the other children. 
When asked about the non-inclusion of children with SEN into regular classroom in the preschool, this parent stated that he would welcome the move if the teachers were willing to do it. He believed that teachers should explore other ways to further enhance opportunities for interaction between preschoolers with and without SEN. Nevertheless, it did not matter to him whether or not inclusion was carried out:

It would be good if the teachers were willing to try out some ways to include our kids [referring to children with SEN] there [regular classroom] ... maybe to have a singing lesson or an art lesson together ... I am sure the teachers can afford to do that ... but it doesn't matter if they don't. I am okay with that.

This parent admitted that he had never shared his views with the teachers or the principal about providing inclusion opportunities for children with SEN. He clarified that he was sceptical as to whether or not the regular education teachers would be willing to accept children with SEN into regular classroom learning. He related this statement to the prior experiences that his daughter had had in her earlier preschool, which he felt did more harm than good to her. He then briefly stated that it was the special education teacher's job to assess the children's ability, and to decide if they were capable of following regular classroom learning activities. He felt uncomfortable being the one to tell her what her job was:

She [special classroom teacher] should know. I don't need to tell her. Anyway, I don't want to be in an awkward situation after telling her either.

Despite being supportive of inclusive practices in the preschool, and believing that teachers should try and initiate inclusion, this parent felt that full inclusion was not an ideal practice. He believed that preschoolers with and without SEN needed their own time and space to be in their individual classrooms, equally, as much as they were given opportunities for inclusive experiences.

I am supportive of inclusive practices. There's no doubt about that. Then again, there is also no need in overdoing it by having a pure inclusive school. That wouldn't necessarily work either. I think the best would be to have a combination of both. Preschoolers must have opportunities to be in their own classrooms with the special teachers, and have their own share of inclusive experiences.

He further supported his opinion by stating that the special education preschool teachers were trained to recognise and respond sensitively to the specific needs of preschoolers with SEN. He felt that preschoolers with SEN would miss such attention if full inclusion was carried out in the preschool. Furthermore, he believed that specific and individualised attention by the special education teacher 
towards children with SEN would be impossible in an overcrowded regular preschool classroom during inclusive lessons, once again relating this situation to his daughter's experience at the previous preschool:

\begin{abstract}
Special education teachers are specifically trained to cater for our special child's needs. Why should we miss that privilege? In my opinion, the individualised attention from the special education teacher in a segregated special educational setting is equally as important as inclusive practices in the regular classroom setting ... When Sarah was in her first preschool, she was like, just another difficult student for the regular teacher, and an invisible peer to the rest of the class. She was totally neglected. Maybe the teacher did not know what to do with her, and there was not enough time to pay full attention to her in a large classroom. But in the autistic centre, and here, in this preschool, the special education teachers know what to do, and how to cater for her needs. She receives individualised attention. It is a great relief to know that the special education teacher is there for her.
\end{abstract}

\title{
Summary of findings in School 3
}

Practices of inclusion in School 3 operated on the premise that social integration rather than academic integration was more suited at the preschool level. The findings showed that opportunities for interaction and engagement in shared activities between children with and without SEN in School 3 were evident through social integration only. Preschoolers with SEN had no opportunities for inclusion, and remained in their classroom during classroom learning hours. Children with and without SEN were engaged in shared activities on a daily basis during their playtime in the playground, before and after school hours. They also had opportunities for such interactions during other intermittent activities, such as during field trips, sports activities, concerts or other school celebrations.

Although the school community viewed inclusive education positively, and believed that practices of inclusion would bring about positive effects in the education of preschoolers with and without SEN, their acceptance towards practices of inclusion in the preschool appeared to be rather restrictive and uncertain. The principal, although supportive of inclusion, believed that academic integration was not suitable at the preschool level, due to the vast difference in developmental level between preschoolers with and without SEN. The regular and special classroom teachers appeared to have a similar stance about not including children with SEN into regular classrooms, and instead preferred to maintain children's opportunities 
for interaction through socially integrated activities outside the classrooms. The regular and special classroom teachers in School 3 did not seem to be interested in making efforts to work collaboratively for initiating or implementing inclusion. Regular classroom teachers' lack of support for inclusion was also associated with their lack of knowledge and interest in special education, and prior difficult experience in teaching children with SEN. These teachers also held negative attitudes toward teaching children with SEN.

Parents of preschoolers both with and without SEN, on the other hand, were supportive of preschool inclusion. However, they seemed to indicate that nonacademic oriented subjects would be more suited for inclusive lessons. The parent of the preschooler with SEN also indicted special education services as still relevant and important for children with SEN. Parents' views about inclusion appeared to be closely associated with their experiences and knowledge about the education of children with SEN.

The information that emerged from the findings showed that factors affecting the way inclusion was carried out in School 3 were mostly related to:

- teachers' negative attitudes towards inclusion and SEN

- lack of collaboration between regular and special education teachers

- lack of support for academic integration

- perceived importance of special education

- principals' beliefs in relation to preschool inclusion

- lack of parental involvement

\section{Chapter summary}

This chapter presented the state of inclusion, and educators and parent's perceptions of it, in three integrated preschool settings in Malaysia. Findings revealed that the ethos and culture surrounding preschool inclusion at each site were reflected through the individual school's shared vision or philosophy towards inclusive education. In particular, the respective principals' administrative style 
and perspectives on inclusion, the shared perspectives of the regular and special education preschool teachers, parents' support for and involvement in inclusive practices, and the preschool environment had given each of the preschools an individual identity, reflected in the ways inclusion was perceived and practised in these preschools. The triangulation of multiple sources of data in each case study site corroborate the findings of my original questionnaire; that these three case study sites were indeed preschools that represented integrated preschool settings with differing levels of events and processes to facilitate and promote inclusion. In the next chapter, findings that emerged across the three cases will be combined with my survey findings, and discussed in relevance to existing literature. 


\section{CHAPTER 8 \\ -Discussion-}

\section{Introduction}

The aim of this study was to explore how much inclusion was occurring in Malaysian integrated preschool programmes; educators' and parents' perceptions of inclusion and their support for it; and factors that could be influencing the state of inclusion in the preschools. This chapter discusses the findings of the study. Key findings from the quantitative survey, and across the three case study sites presented in the previous chapters (Chapters 6 and 7) highlighted a range of circumstances that together provide an in-depth understanding of inclusion in Malaysian integrated preschool programmes. These circumstances, which were interrelated in nature, were organised into themes, as stated below, and will be discussed with reference to existing literature in subsequent sections of this chapter:

- Segregation within integration

- General lack of support for inclusion

- Unsupportive teaching and learning environment

- Lack of collaborative efforts and commitment in relation to inclusion

- Lack of information and support from the Ministry of Education

- Cultural beliefs and values in relation to inclusion and SEN

The specific processes, persons, contexts and time factors that may be affecting decisions and outcomes pertaining to preschool inclusion, as guided by the bioecological perspective (Bronfenbrenner, 1999, 2005; Bronfenbrenner \& Ceci, 1994; Bronfenbrenner \& Morris, 1998) are also incorporated into the discussion. 


\section{Segregation within integration}

Educators' and parents' responses, as well as observation and document examinations undertaken at all three studied sites revealed that the placement of preschoolers with SEN in Malaysian integrated preschools, in most instances, was not supported with their involvement in shared activities with typically developing preschoolers. Instead, the placement of preschoolers with SEN into regular educational settings was mostly limited to their presence in special education classrooms and activities only.

As noted in the literature review, the true notion of inclusion must be supported with significant processes through which regular schools develop responses to value diversity (Von der Embse, Brown, \& Fortain, 2011) and maximise the quality of children with SEN's participation in regular school environments (Booth, 1999, UNESCO, 2005). However, findings from the research undertaken for this thesis showed very little evidence of such responses and processes in Malaysian integrated preschools. More specifically, the teachers who were supposed to stand as the key decision makers of inclusive practices in Malaysian integrated preschools (see chapter 2), were barely initiating this practice in the first place. Survey findings provided significant information in this regard.

For example, when teachers were asked to indicate who initiated inclusion in their preschools, a total of $24.7 \%$ indicated that special classroom teachers were initiating inclusion in the preschool. Conversely, the majority (67.9\%) responded that this process was not even applicable in their preschool. Another $4.9 \%$ indicated that parents had initiated this practice in their preschools. These findings suggest that in most instances, decisions to include children with SEN into regular classrooms were not being made. Further confirmation of this situation was obtained when subsequent findings showed a mean score of 0.7 for opportunities to include children with SEN into regular classrooms, indicating that the majority of teachers who participated in the survey had reported that currently, in their preschools, evidence supporting inclusion ranged from minimal evidence to no evidence at all. 
Qualitative findings in the study corroborated the questionnaire findings. Exhaustive analysis of details obtained from across each of the three case study sites confirmed that full time placement of preschoolers with SEN into regular classrooms was not evident in any of the settings. However, one of them (School 1) carried out partial inclusion. All six children at School 1, with a variety of SEN, were included into regular classrooms twice a week, for about two hours on each of the days. Children with and without SEN were observed to be actively involved together in a range of engaging activities throughout their inclusive lessons.

Although it was apparent that opportunities for children with SEN to be included into regular classrooms were scarce, the variety of data in questionnaire and case study findings revealed that there were some opportunities for children with and without SEN to engage in socially integrated activities outside their classrooms. Survey findings showed $59.3 \%$ of the teachers reported that opportunities for interaction between children with and without SEN in informal or outdoor activities were clearly evident in their preschools. However, such activities occurred mostly for between one to two hours a week only (e.g., during assembly, recess, or at the playground) or on other intermittent occasions (e.g., during school trips, sports day).

The state of inclusion in Malaysian integrated preschools as identified by this study above seems distinct from the results reported in a recent Malaysian study by Muhammad and Wan Mahmud (2010). Muhammad and colleague (2010) used a case study approach to examine the inclusion of eight children with autism in an integrated primary school. The selected school was part of a pilot project to fully include children with autism who had initially received support and educational services from the National Autism Society of Malaysia (NASOM). Each included child was also accompanied with a resource teacher from NASOM. Results showed that full inclusion was taking place well. Further, all eight children with autism who were included into regular classrooms coped well, academically and socially. Nonetheless, it may be inequitable to compare the findings in Muhammad and 
colleague's study with the current study since they were looking at inclusion in one school only. Furthermore, every child who was included in Muhammad and colleague's study had individualised support from resource teachers, which may have contributed towards the positive outcome of their study.

What was interesting, if not puzzling, however, is that despite the integrated school system's aim to maximise the participation of children with SEN in the educational and social life of typically developing children, survey findings in the current study showed evidence of total segregation of children with SEN from their typically developing peers in two preschools. That is, children with SEN were neither placed into regular classrooms for inclusion purposes, nor were they involved in socially integrated activities with typically developing peers outside the classroom. Case study findings in School 2 confirmed this situation. Children with and without SEN remained in their respective classrooms during lessons, had separate outdoor play areas, were confined to their respective mealtime locations, and barely socialised with members of the regular classroom/s. Further, there were no responses from 70 preschools (out of the 113 involved in the survey), which suggests that there may be more of these preschools in Malaysia that could be exercising total segregation. On a more positive note, however, the non-response could also mean that there were other preschools exercising inclusion and social integration but who did not participate in the survey.

The state of segregation in Malaysian integrated preschools, as identified in this study, seems consistent with results reported in a recent Malaysian study by Ayob, See and Selamat (2008). Ayob and colleagues reported that other than locational integration, or the mere placement of students with SEN into regular educational settings, there was little evidence supporting academic integration in the majority (91.8\%) of the 49 integrated primary and secondary schools involved in their survey. Only four (8.2\%) schools carried out inclusion. Although quantitative data reported social integration was taking place in these schools on an occasional basis, further observations and interview data in 49 selected schools showed no such evidence. 
The literature review revealed three different ways that inclusion has been conceptualised: provision, process and organisational culture. Subsequently, this framework is useful in exploring whether the current situation of educating children with SEN in Malaysian integrated preschool programmes is limited to just placements of children with SEN in regular educational settings, or if it has progressed further towards inclusion, supported by relevant processes that shape quality learning environments, and a school culture that reflects inclusion. Findings in the current study suggest that in general, the education of children with SEN in Malaysian integrated preschool programmes were mostly limited to provisions only; fulfilling the LRE criteria, or as Pijl (2007) puts it, the prerequisite of "just being there" (p.2). Whilst some variations exist in the current state of children's inclusive opportunities in Malaysian integrated preschools, the overall service delivery options in responding to inclusive schooling in these settings seem to range from partial inclusion to total segregation. Whilst opportunities for children with SEN to be included into regular classrooms were evident, they were relatively scarce. The few opportunities that children with and without SEN had for interaction were primarily supported through socially integrated activities outside the classrooms. These opportunities, however, mostly took place by chance, with very little meaningful planning or initiative on the teachers' part.

\section{General lack of support for full inclusion}

Results from this study support conclusions of previous studies in suggesting that educators' perspectives and personal characteristics can directly influence and impinge on a school's decision to implement inclusion (e.g., Abbott, 2006; Chhabra, Srivastava, \& Srivastava, 2010; Garrick-Duhaney \& Salend, 2000; Narumanchi \& Bhargava, 2011). This idea is also clearly explained in Bronfenbrenner's bioecological theory, which guides my study and analysis. According to Bronfenbrenner, the 'person' characteristics of a school situation can reduce or enhance the power and directions of developmental processes (Bronfenbrenner \& Morris, 1998). These are characteristics that have to do with one's own beliefs, perceptions, motivation, responsiveness, interest, feelings or attitudes; as well as their own resources, such as capabilities, disability conditions, knowledge, skills, 
prior experiences or birth defects. Findings in this study demonstrated that the ways in which educators' perceived inclusion, and their knowledge and understanding of matters concerning inclusion varied between case study sites, and consequently, affected their commitment and support for inclusion.

Principals, teachers, and parents who participated in this study generally held positive attitudes toward the philosophical propositions of inclusive education. However, they all had strong reservations about the practical implementation of inclusion. In other words, there was evidence in every site showing that educators and parents perceived inclusion (in theory) as morally, ethically and/or socially right, stating that inclusion created increased opportunities for meaningful friendships and positive learning experiences for children with and without SEN. However, none of these participants supported full inclusion as feasible, or as an ideal service delivery model. Findings showed that in case study sites that did practice inclusion, the prevailing support was only for partial inclusion. The widespread preference among educators and parents in the current study was to just provide opportunities for preschoolers with and without SEN to participate in shared out-of-classrooms activities (i.e., social integration).

Similar findings were also reported in the literature, particularly around educators' and parents' perspectives on the philosophical versus practical implementation of inclusion. In Conrad and Brown's (2011) study for example, 18 primary school principals' perspectives on inclusion were examined. Data from self-administered questionnaires and focus-group interviews revealed that the principals displayed philosophical willingness to embrace inclusion, and generally agreed that no student should be discriminated against or deprived of education. However they held non-committal attitudes toward the implementation of inclusion. Similarly, Leyser and Kirk (2004) found that the majority of parents of children with mild, moderate or severe disabilities in their study supported the concept of inclusion from a philosophical and legal stance, but many of them expressed concern over a range of issues related to the implementation of this practice. 
Whilst total segregation of students with and without SEN was not stated as a preferred practice by most of the educators and parents, and was also criticised by some interviewees, segregation was still present in the participating schools. For example, in School 2, both regular classroom teachers reported outright rejection of any form of inclusion in the preschool. These teachers not only held negative attitudes towards including preschoolers with SEN into their classrooms, but were also not supportive of these children's participation in shared out-of-classroom activities with typically developing preschoolers. One of the regular classroom teachers believed that the behavioural and emotional difficulties of young children with SEN would make integrated activities too challenging and complicated for regular classroom teachers, and the preschoolers under their care. She believed that providing special treatment for children with SEN in regular classrooms was not practical, and would be problematic for teachers, as typically developing preschoolers may then perceive themselves as being treated differently. The other teacher believed that younger children with SEN needed specialised attention, and thus would be better off segregated under the supervision of their special education teachers.

The literature indicates contradictory findings in relation to regular education teachers' perceptions of including young children with SEN into regular classrooms. For example, Smith and Smith (2000) examined regular early childhood education teachers' perceptions of inclusion. Findings showed that teachers held positive attitudes and beliefs about inclusion. Although this belief was "shadowed by substantial questions, concerns, and reservations" (p. 177), none of the teachers voiced a need to do away with inclusion. Similarly, findings from another study by Leatherman (2007) showed that early childhood teachers found inclusive classrooms as the best place for educating children with SEN, and for the teachers themselves to learn and grow together.

An important consideration in Malaysian integrated schooling at the time of the current study was that both regular and special education teachers played a crucial part in the school's inclusion decision-making processes. However, the research 
undertaken for this thesis uncovered that both regular and special education teachers held fairly similar stances about (not) including children with SEN into regular classroom. For example, survey findings revealed that only $35.7 \%$ of special classroom teachers and $10.3 \%$ of regular classroom teachers were supportive of this practice (see Table 8: Chapter 6). Most importantly, the 55 teachers who responded with 'no' to including children with SEN into regular classrooms were fairly divided between both regular and special education teachers (28 and 27 teachers respectively). This finding was indicative of the fact that, despite being more generally supportive of inclusion than regular education teachers, a significant number of special education teachers may not be in agreement with the practice. It would appear therefore, that if both regular and special education teachers in Malaysian integrated preschools are not supportive of the practice, then preschoolers' opportunities for inclusion are most likely to be limited or worse, non-existent.

The literature however, has repeatedly shown evidence that special educators are generally more supportive than regular educators toward including learners with SEN into regular classrooms. Lifshitz, Glaubman and Issawi (2004), for example, surveyed the attitudes toward inclusion of Israeli and Palestinian primary school teachers who worked in integrated classrooms. One hundred and twenty five regular classroom teachers and another 103 teachers with background knowledge in special education took part in the survey. One of the aims of the survey was to discover the willingness of teachers to include students with different severities of disability in a regular classroom, and to garner a sense of teachers' feelings of efficacy in teaching children with SEN. Findings showed significant differences between regular and special education teachers' attitudes towards inclusion in relation to all degrees of disability, with special education teachers demonstrating more willingness to include children with SEN into regular classrooms. Similarly, Buell, Hallam, Gamel Mc-Cormick and Scheer (1999) compared the views of regular and special education teachers working in inclusive school settings in one state's Department of Education in the United States. A total of 289 teachers took part in a survey. Overall findings indicated that special education teachers were more 
confident and prepared to include students with SEN in regular classroom settings than regular education teachers.

In this study, however, special and regular preschool educators are more similar in their views. Particularly, they commonly have a similar, negative stance about inclusion. Arguably, this is because in Malaysia, inclusion happens to be as new an idea to special educators as it is to the regular educators, at least at the preschool level. Even integrated schooling is a relatively new phenomenon at the preschool level in Malaysia (see chapter 2). Therefore, although special classroom preschool teachers may have much of the knowledge and competency required to teach a mixed class of preschoolers, with and without SEN, they may still be lacking the confidence to put their knowledge and skills into practice during inclusive lessons. This is one possible explanation for the gathered evidence, in which special classroom preschool teachers are sometimes just as negative towards inclusion as regular classroom teachers.

Generally, educators, and as will be discussed, parents, in the research conducted for this thesis signalled two circumstances that explained their lack of support for full or partial inclusion. These were: (i) their views that segregated practices were still significant, as far as the education of children with SEN were concerned; (ii) the negative attitudes that they held towards academic integration. These ideas are elaborated further in the following section.

\section{Perceived importance of segregated practices}

The view that full inclusion would make it impossible for children with and without SEN to receive ability-relevant instruction appeared to be a major influence on the extent of educators' and parents' support for inclusion (in some cases support for full inclusion, in others, partial inclusion). For example, the principal and teachers in School 1, despite unanimously supporting and promoting practices of inclusion in the preschool, were convinced that the best way to adequately address the needs of children with and without SEN was when these children were in their individual 
classrooms. Hence, these educators opted for the implementation of partial instead of full inclusion in their preschool.

Similar findings were reported by Heiman (2004), who examined 140 British and 116 Israeli middle school teachers' perceptions of preferred inclusive placements and instructional practices. Findings showed that the majority of teachers in both countries showed preference towards an in-and-out model (partial inclusion), and believed that this was the most appropriate approach in carrying out inclusion, as learners with SEN benefitted from both worlds (regular and special education).

That there is a demand for segregated, specialised services was especially evident from the views of parents of children with SEN across case study sites. Whilst these parents acknowledged the benefits of inclusion, they believed specialised educational services were pivotal for their children. For example, one of the parents of a preschooler with SEN reported that preschoolers who had a disability needed special attention, which was better addressed in special education classrooms, and not regular classrooms. Hence, she saw segregating children with SEN into separate placements for expert attention as more valuable than inclusion for those like her child. Another parent, who hoped for teachers at his child's preschool to carry out some form of inclusion, also stated that it would be ignorant to do away with special education services. He used the term "overdoing" to describe practices of full inclusion, and instead opined that children with SEN needed the time and space to be with special educators who have been trained to effectively address the needs of children with SEN.

The importance that parents of children with SEN placed on segregated specialised services for their children is not unusual, given that substantial precedent exists in the literature in this regard (e.g., Garrick-Duhaney \& Salend, 2000; Nind, Flewitt, \& Johnston, 2005). For example, Nind and colleagues (2005) investigated the expectations that parents of children with SEN had of combined placements (i.e., special education and mainstream services) in early years settings in England. Findings showed that parents did not perceive inclusive education as offering the 
best form of education to their children. Although parents welcomed the social and normal learning environment in inclusive placements, there was lack of faith among them that the "special" input needed by their children could be provided in inclusive placements.

To return to Malaysia, as my research has found, educators, on the other hand, held negative attitudes towards inclusion and believed that segregated placements were more feasible when a child's severity of disability conditions did not permit him or her to be involved in shared activities with their peers. For example, special education teachers in School 2 and 3, despite having somewhat positive views about inclusion generally, identified (selected) children with SEN in their classroom who displayed emotional and behavioural conditions requiring that they remained under close supervision most of the time, due to their (child with SEN's) disruptive, sometimes aggressive behaviour. This made it difficult for these children to interact with peers in both regular and special education classrooms, both because of the child's behaviour itself, and because of the need to monitor the behaviour, requiring staff attention. Comparable views were offered by Avissar's (2000) on principals' attitudes toward inclusion in Israel. Although the majority of principals involved in Avissar's study generally held positive attitudes toward inclusion, they believed that the severity of a child's disability should be taken into consideration when deciding on inclusion.

Nevertheless, whilst segregated practices received their share of support from educators and parents in my research, it appeared that too much segregation was not welcome either. For example, in School 2, where total segregation was the prevailing practice (i.e., no inclusion or social integration was evident), the regular teachers were criticised by members of the special classroom for being ignorant, uncooperative, and negative about inclusion. The parent of a child with SEN was disappointed that there were no opportunities for inclusion in the preschool, and that her child learned full time in the special education classroom. Most of all, this parent's greatest frustration was that no initiative had been taken in facilitating 
children with and without SEN in at least socialising with one another. This, she felt, was unfair and unreasonable.

On a more positive note, one of the regular classroom teachers stated that if a preschool was not initiating any form of integrated activities, at the least, outside the classroom, on the basis that it was difficult to handle children with SEN, then, the teachers were merely giving nothing but excuses. Similar views were stated by principal and parent participants. These findings suggest that the prevalence of total segregation of preschoolers with SEN in Malaysian integrated preschools, which is to say confining them only to activities in special classrooms, was less likely, due to a lack of educator and parent support for such practices. Given these feelings, the occurrences of total segregation could be due to the lack of inclusion initiatives and negative attitudes on an individual teachers' part, especially since teachers make the main decisions about inclusion in integrated preschool settings.

\section{Negative attitudes in relation to academic integration}

Findings in this study indicate that educators and parents are generally not supportive of academic integration, and that this view is affecting decisions to include children with SEN into regular classrooms. In particular, interviews revealed that all five of the six parents across my case study sites who held somewhat positive attitudes toward partial inclusion had a condition attached to their support for it. Their condition, in most instances, was that teachers must be able to meet the needs of children with and without SEN during inclusive lessons. For example, one of the parents of a regular classroom preschooler was concerned that teachers would simplify lessons to suit children with SEN, affecting her child's learning needs. So, this parent preferred teachers to only carry out social inclusion outside the classroom if they (teachers) were not confident of effectively catering for diverse needs. A parent from the special classroom on the other hand, was concerned that regular classroom teachers would not be able to handle her child's behavioural disorder during inclusive lessons, causing distress to the teacher and other children in the classroom. 
Previous studies have offered comparable views to the findings of my research. Narumanchi and Bhargava (2011) found that parents of typically developing children agreed that an inclusive setup would benefit children with SEN over special schools, as they would learn from typically developing peers, and have opportunity to experience acceptance and tolerance. However, their positive views were apparent only with non-academic activities like art, music, singing and sports. When academics were involved, the majority of these parents suggested separate classes for both groups of children with and without SEN.

In addition to parents' views above, my research also revealed that teachers' negative attitudes about academic integration was likely to be causing children with SEN to have fewer opportunities for inclusion in Malaysian integrated preschools. In particular, findings across case study sites showed that of the eight interviewed teachers, six teachers were not willing to include children with SEN into regular classrooms because they were not keen on academic integration, finding it too challenging to plan lessons that met diverse learning needs. Whilst one of the teachers reported academic integration as stressful, another perceived it as laborious and needing meticulous collaborative efforts of both regular and special education classroom teachers. The two teachers who were willing to carry out inclusive lessons, however, were selective about the types of activities that they carried out during the lessons, carefully deciding on those that were less academically oriented, and structuring the lessons to cater mostly for children with SEN. Teachers who rejected academic integration had no objection to activities that provided preschoolers with and without SEN opportunities to engage in shared out-of-classroom/socially inclined activities, and five of them were already implementing such activities in their preschools (i.e., teachers in School 1 and 3). However, academics were perceived differently, and my findings appeared to suggest that teachers' negative attitudes towards academic integration were affecting their inclusive decisions in the preschools.

In sum, my research findings, as discussed in this section, suggest that although educators and parents in Malaysian integrated preschools agree that inclusive 
education can optimise children's learning potential, their support for the implementation of inclusion is not as strong. Additionally, the level of support held by parents and educators concerning inclusion may be reflective of the state of inclusion in Malaysian integrated preschools, as discussed earlier in this chapter, ranging from partial inclusion to total segregation

\section{Unsupportive teaching and learning environment}

Guided by the bioecological theory, this thesis recognises that particular elements in context can be especially supportive or unsupportive to the development and learning of young children with SEN. A significant finding in this study was the impact of the physical and instructional learning environments on the way the preschools functioned. Questionnaire responses gathered during research provided encouraging responses in this regard. Findings showed that the mean scores for environmental accommodation and adaptations $(\overline{\mathrm{x}}=2.2$ and 2.3 for regular and special education teacher responses respectively), as well as instruction and support to maximise children with and without SEN's interaction $(\overline{\mathrm{x}}=2.8$ and 2.6 for regular and special education teacher responses respectively) were among the highest rated of the factors surveyed. This means that the majority of teachers had reported that there was some, or clear, evidence of these accommodations in their preschools.

However, interview and observational data obtained during the qualitative phase of my study were less positive. In particular, findings across case study sites showed that the physical location of regular and special classrooms, regular classroom size, and the instructional material (i.e., curriculum) in integrated preschools were not always entirely supportive of inclusion. These situations are discussed separately in the following sections:

\section{The physical environment}

The shared participation and involvement of learners with and without SEN in ongoing activities within a regular school environment is the basis of inclusive schooling (Renzaglia, Karvonen, Drasgow, \& Stoxen, 2003). Clearly, the school 
environment must be designed to maximise learning and social experiences between learners with and without SEN if successful inclusion is to take place (Pivik, McComas, \& Laflamme, 2002). Yet, my research showed that the physical environment of Malaysian integrated preschool programmes tended not to respond to this idea effectively.

Case study data showed that the specific location of the regular and special education classrooms in integrated preschool programme settings arguably influenced planned and spontaneous interactions between children with and without SEN. The impact of location was apparent in the concerns articulated by educators and parents. For example, in school 2, the special education teacher and one of the parents of a preschooler with SEN believed that the isolated location of the special education classroom within the school created a form of discrimination between children with and without SEN, and prevented natural opportunities for these children to meet and participate in shared activities. Furthermore, questionnaire analyses illustrated a possibility of similar situations taking place in other preschools, as survey findings revealed that there were a significant number of preschools (34.9\%) throughout the country where special education classrooms were located more than 100 meters from the regular education classrooms.

In contrast to findings from School 2, findings in the other two case study sites, School 1 and School 3, showed that when regular and special education classrooms are within close proximity, there were notably more opportunities for children with and without SEN to engage in planned, and spontaneous, shared activities. In both these sites, the regular and special education classrooms were located opposite one another, and shared common facilities in the school compound (e.g., playground, open-yard activity space, before and after school waiting area). These findings are not surprising given that substantial empirical evidence exists that physical structures in regular schools can often pose as barriers or facilitators of inclusion (Pivik et al., 2002; Renzaglia et al., 2003). Nonetheless, with regard to the Malaysian context, the findings in this study suggest that purpose built 
environments are imperative in integrated settings as they can contribute towards optimising children's inclusive opportunities.

\section{Regular classroom enrolment}

Findings in the current study also revealed that large numbers of students in regular preschool classrooms posed a formidable barrier to teachers' inclusion initiatives in Malaysian integrated preschools. Educators and parents across case study sites reported a number of concerns, believing it to be impossible to address the individual needs of preschoolers with SEN, and the various interests of the typically developing preschoolers, if children with SEN were to be included into large regular classrooms.

Regular classroom teachers were particularly concerned about the increase in their workload in terms of making preparations to cater for children with SEN, while also concentrating on regular classroom learning. The requirement for regular classroom learning to meet specific goals so preschoolers would be ready to cope with formal, academically oriented education when they entered primary school education the following year exacerbated regular classroom teachers' concerns. Two of the five interviewed regular classroom teachers also referred to the large enrolment in their regular classrooms to defend their stance against practices of social integration between preschoolers with and without SEN in the playground. The principal supported these teachers' views, stating that it was already too challenging to monitor the safety and activities of nearly 50 preschoolers from two regular classrooms when these children were at the playground. Hence, she felt that including preschoolers with SEN into the already overcrowded playground was too risky, and an additional stress to the teachers. Similar findings were reported by Haniz Ibrahim (1998), who examined teachers' attitudes toward inclusion in Malaysian primary schools. Ibrahim found that regular classroom teachers held negative attitudes towards inclusion because they believed that the placement of children with SEN into regular classrooms without the reduction of class size would only add to teachers' burdens in terms of lesson preparation and implementation. 
There were also concerns among educators and parents that the implementation of inclusive practices in overcrowded regular classrooms would increase the possibilities for social and behavioural issues, such as bullying and teasing, stating that, it was highly probable for such issues to slip away unnoticed by teachers in classrooms with large number of students. Similar findings were reported in the literature by Nind and colleagues (2005), who investigated expectations that parents of children with SEN had of combined placements in early years settings in England. The researchers reported large class sizes, and the "comparatively poor ratio of staff to children" (p. 19) in such settings as a potential disadvantage to their children.

\section{Curriculum adaptations and implementation}

Another critical means for creating inclusive learning environments is the practice of making curriculum adaptations. UNESCO (2005) emphasised that an accessible and flexible curriculum is the key to creating inclusive schools that cater for all its learners. This idea is also clearly stated in the Salamanca Statement and Framework for Action (UNESCO, 1994), which Malaysia endorses. The Salamanca World Conference on Special Needs Education in 1994 stated that schools should make curricula adaptations to cater for children's needs, and not vice-versa.

Findings from my research revealed that one of the key factors influencing the lack of efforts taken by teachers in carrying out inclusion in Malaysian integrated preschools is likely to be the existence of two separate curriculums for regular and special education classroom learning. However, it is worth mentioning that an examination of both documents revealed that the special education preschool curriculum for children with learning disabilities, although documented separately, was for the most part an adapted version of the National Standard Preschool Curriculum used for regular classroom teaching and learning activities. The main strands and components are identical. The skills and learning objectives were simplified in some cases, and in other cases, different. Nonetheless, the use of two separate curriculums appears to be affecting the ways in which some of the 
preschool teachers are utilising and thinking about information concerning the curriculum (in relation to inclusion), subsequently affecting their decisions to include children with SEN into regular classrooms.

For example, both regular preschool teachers in School 2 used the existence of two separate curriculums to justify their stance in not cooperating with the special education teacher in carrying out inclusive lessons. One of the teachers at this site felt that the idea of having two separate curriculums implied that two separate educational endeavours are expected for meeting the educational needs of preschoolers with SEN and typically developing preschoolers. The teachers in this school openly stated that it was therefore less complicated to simply let both groups of preschoolers remain segregated in separate classrooms during lessons. Similarly, one of the regular teachers in School 3 also commented that adapting lessons to suit the needs of children with and without SEN involved a great deal of effort, which she was not prepared to do. These teachers were, however, happy to promote social integration outside the classroom through random, unplanned activities during recess or assembly, which they knew did not involve teaching preparations or curriculum adaptations, and was thus less stressful for teachers.

Nevertheless, as Udvari-Solner (1996) points out, the extent to which classroom activities cater for the needs of diverse learners depends also on whether or not the teacher adopts a model of curriculum adaptation in the processes of instructional planning. Similarly, Berry (2010) reported that teachers must be willing to accommodate relevant instructional adaptations to cater for learners with SEN in order for inclusion to work. This situation appeared to be true in my research. For example, the teachers in School 1, instead of being stopped by difficulties, believed that it was the responsibility of integrated preschool teachers to make curriculum adaptations, and thus took up the task positively. These teachers initiated inclusion by making their own improvements and modifications so instructions and learning materials could cater for inclusion. 
However, despite feeling satisfied that they were able to use common skills and contents in the curriculum documents to implement inclusive practices, the teachers in School 1 reported feeling unsure if they were doing things the right way when shared lessons, and other forms of inclusive activities, were carried out. This issue highlighted another curriculum-related factor that may be causing teachers to underutilise the provision for teaching common skills and content present in the similarities between the two curriculums as a tool for assisting them in carrying out inclusive lessons. Further examination of both curriculum documents revealed that there were no instructions or guidelines informing teachers of inclusive lessons. Improvements could therefore include suggestions in Malaysian integrated preschools' curriculum documents, guiding the teachers on how to plan their teaching and learning activities together, particularly in how to cater for academically integrated activities. As Carroll-Lind, Bevan-Brown, and Kearney (2007) conclude, it is essential that curriculum documents clearly show teachers that adaptations are possible to provide for learners with diverse needs. These researchers were primarily supporting the idea of a single curriculum design to meet the needs of all learners in New Zealand, but their argument on the importance of having the how to aspect in curriculum documents to support and guide teachers' inclusive efforts are nonetheless relevant to promoting inclusive supportive learning environments in Malaysian integrated preschools.

\section{Lack of collaborative efforts and commitment in relation to inclusion}

It could be argued that many of the issues affecting the state of inclusion in Malaysian integrated preschools identified by my research are indicative of a lack of collaborative efforts and commitment within the members of the school community. Even with the little inclusion that is taking place within Malaysian integrated preschools, it was clearly evident from findings across case study sites that there was a distinct culture of collaboration in a school that implemented inclusion, as compared to a school that did not. Findings relevant to this theme are discussed below, in relation to three specific issues; regular and special classroom 
teachers' collaborative efforts, the principals' role and commitment, and parental involvement in relation to inclusion.

\section{Regular and special classroom teachers' collaborative efforts}

The literature indicates that the collaborative efforts between regular and special educators have become increasingly critical as more learners with SEN receive instructions in regular educational settings, (Ali, Mustapha, \& Jelas, 2006; Ajuwon, 2008). However, my research findings suggested that the prevalence of such efforts was minimal in Malaysian integrated preschool programmes. For example, regular and special education teachers' responses in my questionnaire showed the lowest mean score of all items rated $(\overline{\mathrm{x}}=0.3)$ for team teaching, indicating that the majority of teachers had reported that there was minimal to no evidence of this practice in their preschool.

The critical need for regular and special classroom teachers to work cooperatively in implementing inclusion within the Malaysian context is well documented (e.g., Ali et al., 2006; Haniz Ibrahim, 2007; Jelas, 2000). However, my research findings showed that such efforts appeared to be causing a lot of stress for some of the teachers in Malaysian integrated preschools, subsequently affecting their decisions to include preschoolers with SEN into regular classrooms. Special classroom teachers identified some specific situations in this respect that warrant separate reporting.

When interviewed, two of the three special educators reported receiving the message that regular classroom teachers were not interested in teaming up with them to carry out inclusion. One of the special classroom teachers interviewed reported that her colleagues in the regular classrooms ignored her suggestions for inclusion, and never included her in their discussions about their planning of events in the preschool. Another said that regular classroom teachers indicated that they only wanted to teach their students, and not those with SEN, so it was difficult to carry out inclusion. Similarly, Ali et al. (2006), despite reporting on teachers' positive attitudes towards inclusion in the Malaysian context, found that regular 
and special classroom teachers in primary and secondary schools in Malaysia maintained distinct responsibilities, and formed perceptions of inclusion based on confusion over issues such as whether it was the regular or special educator who had to take charge of inclusive lessons, or who should be responsible for learners with SEN. This finding is consistent with mine; teachers who were successful with inclusion (School 1) reported that inclusion was only workable at their school because regular and special education teachers were willing to take up shared responsibilities for all the students in the preschool.

Questionnaire findings also indicated that there was a substantial level of reluctance among regular and special teachers in accepting responsibilities over both groups of children (i.e., children with and without SEN). For example, findings revealed that only $10.1 \%$ of regular teachers and $31 \%$ of special classroom teachers indicated that they were willing to teach both groups of children, with and without SEN. The rest of the special and regular classroom teachers preferred to teach preschoolers in their respective classrooms. It would appear, therefore, that if both regular and special education teachers in Malaysian integrated preschools do not assume their role as teachers in "integrated" preschools, and continue to treat themselves as teachers of different groups of children, then they will remain unsupportive of inclusion.

However, it may not be fair to place blame solely on teachers for their lack of interest in working collaboratively, particularly since regular and special classroom teachers in Malaysia attend separate teacher education programmes that "do not equip them with an integrated knowledge of the expected roles, functions and responsibilities to meet the diversity of learning needs" in inclusive classrooms (Jelas, 2010, p. 201). Case study and questionnaire findings in my research further substantiated Jelas' suppositions, particularly around regular and special classroom teachers' skills and competencies concerning inclusion. For example, when teachers were asked in my questionnaire to state factors influencing teachers' inclusive decisions in Malaysian integrated preschools, $19.6 \%$ of respondents identified issues relevant to teacher skills and competency. Among other factors, 
this issue was associated with regular classroom teacher's knowledge and understanding about inclusion, as well as regular and special classroom teachers training and experience with inclusion. Further, four of the five regular classroom teachers who were interviewed, reported their reluctance to work collaboratively on inclusion with their counterpart in the other classroom because they lacked the knowledge and skill in this regard.

Bronfenbrenner's (1995) view of a chronosystem seems to be useful for clearly interpreting the situation in the findings revealed above. According to Bronfenbrenner, the different roles held by people over time can affect the different ways in which they support or oppose something. Whilst the idea of integrated schooling and inclusion has brought about a critical need for teachers in Malaysian integrated preschools to think and act collaboratively, their training and traditional roles as teachers in segregated settings could be acting as a barrier to their ability to do so. Immediate improvements for change in this regard could therefore include mentoring support from educators in Malaysian primary and secondary integrated schools, who have a longer history and success in working collaboratively in support of inclusion (e.g., Muhammad \& Wan Mahmud, 2010).

\section{Principal's role and commitment}

Like prior studies (e.g., Praisner, 2003; Villa, Thousand, Meyers, \& Nevin, 1996), the current study also found that the principal's positive attitudes and commitment could be an important factor in encouraging successful inclusion. Findings across case study sites revealed that when the principals made it their responsibility to get involved, teachers and parents felt supported and encouraged to carry out inclusion. Conversely, principals' lacklustre attitudes toward inclusion appeared to impact teachers' and parents' attitudes towards initiating inclusive efforts in the school, even when the principal's attitude was not expressly negative.

For example, the regular and special classroom teachers in School 1 believed that their principal's support and involvement concerning inclusion made inclusive efforts in the preschool more meaningful and less stressful. Both teachers also 
reported parents as feeling confident and willing to cooperate with inclusion when they (parents) were aware that the principal was supportive of this practice. On the other hand, the special class teacher in School 2 reported feeling discouraged by the lack of support for inclusion in the school. This teacher believed that the principal's unbiased stance (i.e., neither supportive, nor against) for inclusion made inclusive efforts in the school ineffective, because the school lacked the most powerful advocate for inclusion. These findings further support Salisbury and McGregor's (2005) view that, because principals are the school's instructional head, the ways in which they perceive inclusion can significantly influence much needed administrative efforts to support inclusive practices among student, staff and parents.

Whilst the teachers and parents I interviewed perceived the commitment and involvement of the school principal as critical for the effective implementation of inclusion, the principals themselves saw their role as limited and restricted in terms of inclusion. Instead, all the principals in the current study perceived the teachers as holding the key to the state of inclusion in the preschools. Findings revealed that the policy and practice of inclusive education within the Malaysian context may also be a significant factor that was impacting on the principals' views in this regard. For example, one of the principals reported that principals do not have the right to employ force or exert their perspectives about inclusion upon the teachers, because inclusive education is a non-compulsory practice. Similarly, another principal repeatedly stated that she preferred to leave it to the teachers to make decisions about inclusion or integration, and felt that it was inappropriate to force teachers to carry out inclusion.

These findings are comparative to the perspective stated by Graham and Spandagou (2011), that "principals do not form their perceptions in a vacuum. The process is reciprocal: contexts influences perceptions, perceptions influences attitudes and, in return, attitudes influence the context" (p. 226). In other words, principals in Malaysian integrated preschools may be seeing the non-compulsory inclusive policy as sending out the message to them that the efforts they put in (or 
not) to foster inclusion would exert little influence on the nature and extent of inclusive practices in the preschool if the teachers were not willing to implement inclusion. This view may be causing the principals to not take up the leading role in implementing inclusion in a significant way in the preschools.

\section{Limited parental involvement}

A host of prior research has pointed out that the home-school relationship is a critical mesosystem influence that can impact on children's participation in inclusive settings (e.g., Bennett, Deluca, \& Bruns, 1997; Odom et al., 2004). Expounding on Bronfenbrenner's perspective of parental involvement, GarrickDuhaney and Salend (2000) reported that parental involvement concerning inclusion demonstrates their participation and interest in school decisions, and is closely related to teacher actions in terms of making further improvement to children's learning outcomes. Yet my findings revealed that parents were hesitant to get involved or participate in preschool matters to improve inclusive opportunities for children with and without SEN. Despite believing their children's preschools could offer more inclusive opportunities than what was presently available at the time of the study, parents of both groups of preschoolers, with and without SEN, in School 2 and 3 were neither advocating for more inclusion, nor interfering with teachers' non-inclusion decisions. These findings were reflective of what was initially discovered in questionnaire analyses.

Questionnaire findings showed that out of the 81 responses, only $4.9 \%$ of teachers reported that parents had initiated the idea of including children with SEN into regular classrooms. Further, only $6.9 \%$ of respondents indicated that the final decision on including children with SEN into the regular classrooms in their preschools involved the shared decision between integrated preschool teachers and the parents. Given that the majority of survey respondents had also reported that initiating and decision-making concerning inclusion were practices that were not applicable in their preschools (67.9\% and $61.7 \%$ respectively), a logical assumption for the lack of parental involvement might be the plain fact that there was not much inclusion taking place in Malaysian integrated preschools in the first 
instance. However, further investigations across case study sites in the current study provided greater understanding of other factors that might also be affecting parental involvement.

My findings revealed that parents reported that gaining different levels of recognition and acceptance impacted upon their involvement and support concerning the preschools' decisions and actions on inclusion matters. For example, parents of preschoolers with and without SEN in School 1 reported feeling welcomed, appreciated, and that their views and ideas were valued by teachers and the school principal. Subsequently, they also reported willingness to get involved in inclusion efforts at the preschool. On the other hand, case study findings in School 2 revealed that whilst feeling very much as a valued member of the special education classroom community, the parent of a preschooler with SEN felt like an outcast within the wider school community. In particular, there were issues of feeling excluded from school events, and rejection of children with SEN's participation in regular classroom activities, which made the parent feel like children with SEN and their parents were unimportant and unwelcome members of the school community.

The findings discussed above thus confirm previously stated conclusions that a school culture that values and works aggressively to build respectful and reciprocal relationships with families is pivotal for parental participation in their children's learning (e.g., Mapp, 2003). Similar views were stated in a study by Bennett et al. (1997), which explored the perspectives of parents of children with SEN and teachers, concerning parental involvement and factors contributing to successful inclusion. Findings showed that parents who felt that they were an important member of the school team who worked with their children were actively involved in and supportive of the school's inclusive efforts.

As well as issues associated with recognition and acceptance, teachers' views also revealed other situations that may be discouraging or depriving parents of opportunities for involvement in preschool's state of affairs. Findings indicated that some teachers tended to view parental involvement as troublesome. For example in 
School 3, regular classroom teachers reported that parental involvement was strictly restricted to their own child's matters only. The teachers felt that too much parental involvement would only result in decision-making becoming too complicated, as they believed that every parent's decisions often favoured their own child's circumstances. The teachers also reported that parental involvement interfered with teachers' preferences and resolutions, which the teachers felt were more considerate of choices that would suit the majority of preschoolers, and not any particular group or child. These findings appear to suggest that teachers perceived themselves as holding an important role in making decisions pertaining to inclusive decisions. Hence, even if parents wanted to advocate for inclusion or to get involved in the school's inclusion decisions, their involvement and ideas may not be welcomed if it is not considered in the best interest of those teachers.

My findings further revealed that lack of understanding about inclusion may also be a cause for parents' reluctance in getting involved in their children's preschools' decisions on inclusion. Case study findings revealed that parents were hesitant to make suggestions to teachers or the school principal about the state of inclusion in the preschool, admitting that they (parents) themselves were ignorant of inclusive education. This included parents not being aware of or lacking knowledge of such a term or practice (inclusion), and believing that teachers-know-best, meaning that parents were better off as followers or silent teammates. A similar finding is reported by Hanson et al. (2001), who investigated decision-making regarding children's participation in inclusive programmes. Findings showed that family members' access to information, and their own personal comfort and ability with advocating for their child affected their ability to be heard. These researchers reported that parents who were unfamiliar with the cultural values in schools, and those who had difficulties understanding the laws that govern the technical aspects of education were likely to be left behind in the processes of decision-making. 


\section{Lack of information and support from the Ministry of Education}

The scarcity and poor circulation of information on inclusive education emerged as one of the prevailing factors influencing inclusive practices and support for them in Malaysian integrated preschools. My findings revealed that educators and parents were pleased that the government had taken a good first step by building integrated preschools to promote opportunities for young children with SEN to engage in shared activities with their typically developing peers. However, their views also signalled that the Ministry of Education had failed to provide sufficient information to guide school personnel on the implementation of inclusion in integrated settings. For example, there were cases where parents indicated that the information they had gained on inclusion and SEN came mostly from their own initiative, or from sources outside the school. Principals also complained that there was lack of effort from the Ministry in educating principals, teachers and parents about integrated schooling and inclusion, making it difficult for educators and parents to understand the importance of inclusive education for children with SEN.

Educators also questioned the Ministry's commitment to inclusive education, indicating there was a lack of information from the Ministry concerning the goals and expectations with regard to inclusion in integrated preschools. The principals complained that there was no written information or guidance for principals to refer to about the aims of integrated schooling and inclusive practices, making it difficult for the heads of schools to direct teachers on inclusion. Furthermore, most regular teachers also appeared unclear on their roles as integrated preschool teachers and their responsibilities in supporting inclusion generally. Despite being teachers in integrated preschools, these teachers seemed to work detached from special classrooms, and did not see children with SEN as part of their responsibility in any way.

My findings corroborate findings from studies previously conducted within the Malaysian context. Abdullah (2000), for example, found that 93.3\% of secondary school teachers who were involved in her survey of teachers' attitudes towards inclusion believed that inclusion was a noble effort by the Ministry of Education to 
integrate children with SEN into the regular education system. However, $66.7 \%$ of these teachers reported that their reluctance to carry out inclusive practices was primarily due to the lack of clear guidance and guidelines by the Ministry of Education on the implementation of inclusion, relevant special education courses for regular teachers, and an available specialist in areas of disabilities for teachers to be able to refer to for advice. Similarly, Bosi (2004), in her review of Malaysian teachers' attitudes toward inclusion, emphasised that most teachers tend to hold negative attitudes toward inclusion; they do not want to include children with SEN in their classrooms because of problems that arise from their lack of understanding of the inclusive education policy in the country. Hence, my findings, and those reported in the literature suggest that if educators themselves do not have a clear idea of what is expected from them in terms of inclusion and the complexities associated with it, the initiation of inclusion in Malaysian integrated preschools would seem doubtful.

Expounding on Bronfenberenner's (1979; 1995; 2005) idea of an exosystem, Odom and colleagues (2004) explained how regulations or education policies set up by policy makers who do not personally get involved in teaching and learning activities in the preschool can increasingly exert influences on the actions made by members of the preschool. This was apparent from the way educators explained feeling 'unsupported' by the Ministry's initiative on integrated schooling and inclusion. For example, one of the principals complained that school administrators were never invited by the Ministry to discuss inclusion. Teachers and school principals also reported that other than creating placement options for children with SEN in regular preschools, the Ministry did not appear to assist teachers to implement inclusive practices through professional development courses on inclusion. One of the regular teachers, for example, boldly stated that unless there is follow up support from the Ministry in terms of training, resources, and guidance drawn out for regular teachers she would not bother to implement inclusion. It would therefore appear that the Ministry's lack of involvement in providing the right kind of support and information on inclusion in integrated preschool 
programmes has resulted in making educators feel neither obligated nor responsible to implement inclusion in Malaysian integrated preschools.

\section{Cultural beliefs and values in relation to inclusion and SEN}

Education of individuals with special needs in Malaysia is documented as having developed from a historically conservative society that neglected and deprived individuals with disabilities of education, towards provisions for segregated learning, and later progressing on to integrated schooling and inclusion (Bosi, 2004; Haq, 2000). The move towards adapting international mandates and policies on inclusive education in recent years indicates that there is already formal recognition in Malaysia of the need to respond to the education of individuals with special needs. However, "if the culture and climate are not inclusion-friendly then the outcome, irrespective of policies or indeed practices, may not be successful" (Reid, 2005, p.100). As indicated in the literature (e.g., Ashman \& Elkins, 2005; Carrington, 1999), addressing change within the education system requires reexamining the beliefs and values that lie within the social and cultural context of a community. In this study, educators and parents in Malaysian integrated preschools represented the local community. My findings revealed that many of their beliefs and values about education for individuals with special needs have changed over time, yet much has also remained the same.

In particular, my findings indicated that whilst members of the school community valued the humane and ethical qualities that came with provisions of inclusive service delivery models, their belief took on a different dimension when it came to classroom practices. In particular, negative attitudes were absent when educators and parents applauded the Malaysian government's move towards integrated schooling and inclusion, but seemed to be strongly rooted when they needed to make a decision on including children with SEN into regular classrooms. For example, issues such as children with SEN's behavioural difficulties, (in)ability to cope with regular classroom learning, and need for specific instructional adaptations caused teachers to categorise children with SEN as causing difficulty and incapable of fitting into the 'normal' environment. Such negative responses 
signalled that there was still a belief among educators that inclusion was challenging because of the problems that rose from the child's disability conditions. Similarly, Paliokosta and Blandford (2010), in their study found that teachers (in responding to inclusion) generally attributed their difficulties to problems that existed within the child with SEN. Such views were concluded as automatically categorising the children and removing teachers' sense of ownership and responsibility toward the child. This way of labelling and categorising children with SEN was also identified by Rioux (2007) as often being the cause of an unjust and unjustifiable exclusion of children from school.

My findings also revealed that there was still a belief within the school community that the education of children with SEN was charity-based rather than rights-based, hence making the participants feel that non-inclusion practices were acceptable. For example, one of the interviewed parents of a child with SEN, whose child had been rejected by a previous regular preschool, reported acceptance towards his child's placement in a separate special classroom in the integrated school, feeling contented that his child was "at least" able to attend a school that was predominantly attended by typically developing learners. He mentioned that it did not matter to him whether or not teachers carried out inclusion, but would be pleased if teachers were "willing" to carry out inclusion. Similarly, another parent stated that instead of her child being rejected totally, which was what had happened to her child in a previous centre, she was "satisfied" that her child had opportunities to learn in a regular school, even if not in a regular classroom. It appears therefore, that these participants were not treating attendance in a regular school or classroom as the child's right ${ }^{4}$. Instead, these parents' views were suggesting that children with SEN were fortunate already if they could attend a regular school, and inclusion might be asking too much. Further, they appeared to believe that if inclusion was indeed taking place, it was simply an added advantage for children with SEN, and not part of the school or teachers' responsibility towards these children.

\footnotetext{
${ }^{4}$ As stated in the Persons with Disabilities Act (Laws of Malaysia, 2008): "Persons with disabilities shall not be excluded from the general education system on the basis of disabilities, and children with disabilities shall not be excluded from pre-school, primary, secondary and higher education, on equal basis with persons or children without disabilities..." (p. 23).
} 
Therefore, the findings above suggest that the negative attitudes and beliefs that educators and parents hold about children with SEN could have a key role in the force behind non-inclusion practices in Malaysian integrated preschools. Nevertheless, the policy and practice in the Malaysian education system, which permits teacher discretion in the decision-making process about the inclusion of individual children with SEN could also be a leading cause for the manifestation of negative attitudes and prejudice against disability in preschools. The literature has offered similar views in this regard. Rioux (2007), for example, found that the practice of segregating children based on their perceived capabilities to learn lead to vast numbers of children being denied ordinary learning experiences and the potential to live ordinary lives. However, some participants in my study, as well as other findings in the literature (e.g., Adnan \& Hafiz, 2001; Haniz Ibrahim, 1998) argued that such decisions by teachers were still relevant because some learners with SEN require more support and assistance than others, and thus need more time before they can be gradually assimilated into regular learning environments.

\section{Chapter Summary}

This chapter discussed the main findings of my research, with reference to reviewed literature. It was noted that whilst the concept of inclusive education seemed popular in theory, findings indicate that this is not the reality in practice. Findings from both quantitative and qualitative data revealed that in many ways, integrated preschool programmes in Malaysia were neither practicing nor promoting inclusion. Whilst there was some evidence of partial inclusion, educators' and parents' responses, as well as observations and document examinations revealed that in most instances, the education of children with SEN in integrated programme settings were confined essentially to special classrooms. The little shared participation that preschoolers with and without SEN engaged in took place mostly by chance, outside the classroom, with little or no effort on the teachers' part. School principals, as well as regular and special classroom teachers, were generally not keen on inclusive education. Parents were barely getting involved in decisions about the nature of their children's opportunities for inclusion in the preschool. Educators' and parents' views, as well as findings across 
case study sites, identified a range of issues that impacted upon support for inclusion, and the subsequent state of this practice in the preschools. These issues included factors relevant to the importance placed on the continuing need for special education services; unsupportive teaching and learning environments; lack of collaborative efforts among educators and between educators and parents; lack of relevant information and support from the Ministry, and existing cultural beliefs and values in relation to inclusion and SEN. The next chapter concludes this thesis by stating the limitations of this study, and exploring the implications of the research conducted for this thesis for practice, policy and future research. 


\section{CHAPTER 9}

\section{-Conclusion-}

\section{Introduction}

The previous chapter discussed significant findings in relation to inclusion in Malaysian integrated preschools, specifically directed toward answering the following research questions:

1. To what extent is inclusion practiced in Malaysian integrated preschool programmes?

2. How do the principals, preschool teachers and parents perceive the idea of inclusion and to what extent are they supportive of its implementation in Malaysian integrated preschool programmes?

3. What are the factors that may be influencing the implementation of inclusion in Malaysian integrated preschool programmes?

In this chapter an overview of the key findings is first stated. Then, the limitations of this study, directions for future research, and the implications of this study for inclusive education practice and policy are considered, before the chapter concludes with a summary of the contributions of this research.

\section{Overview of key findings}

Inclusion in Malaysian integrated preschool programmes has been analysed and discussed exhaustively in this thesis. The analyses of proximal processes or the typical everyday activities in preschool settings, as well as educators' and parents' views in relation to inclusion, provided evidence in different ways for the following conclusion:

- The practice of including children with SEN into regular classrooms to be educated alongside their typically developing peers was barely evident. In most instances, children with and without SEN were confined to activities in 
their own classrooms. However, there were some opportunities for social integration during routine activities outside their classrooms.

- Educators and parents were idealistic about inclusive education. However, they were hesitant in practice. The school principals held non-committal attitudes towards inclusion, leaving inclusion decision-making to the teachers. Regular classroom teachers' perceived lack of knowledge about inclusive education and SEN affected their support for inclusion and the subsequent interest they showed towards working collaboratively with special educators to implement this practice. Parents, on the other hand, were sceptical as to whether the needs of their children could be adequately met in inclusive classrooms.

- Whilst a number of factors were identified as influencing the extent and manner of practicing inclusion in Malaysian integrated preschool programmes, it appeared that many of the issues were encapsulated by overarching barriers that operating beyond the school or micro-level environment, chief among them being the absence of a clearly delineated policy governing inclusive education in the country. This, makes effective participation between "actors" at all levels in the ecological system - the Ministry, school, educators and parents - impossible. In particular, the implementation of inclusion, as guided by the Ministry of Education currently, is contradictory and ambivalent to educators and parents. At present the practice of including children with learning disabilities is based on the school's judgement of the learners' (in)ability to cope with regular classroom learning. However, there are no guidelines to indicate how the school/teachers should make those judgements. As for those learners with SEN who are not included, there are no organised monitoring systems or guidelines in place to ensure that these children have other opportunities to be involved in shared activities with their typically developing peers. Hence, every school seemed to implement (or not implement) inclusion according to their own set of rules and justifications. The role of parents in relation to 
their school's decisions on inclusion is also not clear, reflecting the lack of importance placed on home-school partnership in this regard, and the subsequent lack of parental voice and involvement in schools' decisions on inclusion.

- The Ministry of Education was also viewed as offering limited training and support, which exerted considerable influence on the implementation of inclusive education. There were calls to step up training and professional development for teachers, as participants believed that teachers' adequate knowledge and expertise on inclusion and SEN were critical for teacher empowerment and the subsequent development of positive attitudes towards inclusive education. The use of two separate curriculums was also seen as exacerbating teachers' lack of interest in the implementation of inclusion. Regular classroom teachers viewed the task of making instructional adaptations based on two curriculum documents as an added stress to their already excessive workload, which centred on meeting the various educational needs of typically developing preschoolers in large regular classrooms. Accordingly, the Ministry's support through the reduction of regular classroom size is also crucial if inclusion is to be enhanced and segregated practices reduced.

- Another significant barrier to inclusion is the beliefs and practices, or as Bronfonbrenner (1977, p. 515) calls it, the "societal blueprints", of the surrounding school culture. These play a significant part in influencing support for inclusion and practices of it in Malaysian integrated preschools. Most participants' (especially teachers') beliefs and attitudes were centred on how children's disabilities made it difficult for practices and conditions in the preschool to cater for inclusion, rather than how to overcome disabling practices and learning conditions in the preschool so inclusion was achievable. Hence, inclusive education was seen like it was not worth an effort because children with SEN would find it difficult to fit into normal environments anyway. Such beliefs and attitudes are problematic because whilst the move towards legislating against discrimination can improve 
practices and learning environments, it is not possible to legislate against people's negative beliefs and attitudes.

\section{Limitations of the current study}

The study undertaken for this thesis presents significant information pertaining to inclusion at the preschool level in Malaysia. Integrated preschool programmes are still new in the country, so the use of a mixed method study design was found to be the most suitable for my research. Nevertheless, there are limitations, particularly those which restrict the findings being generalised to the overall state of preschool inclusion and perceptions of it in Malaysia.

The limitations of this thesis come primarily from the selection of preschool and participant samples. First, only integrated preschools operated by the Ministry of Education were targeted by my research. It would also have been useful to include typical special preschools (i.e., only attended by children with SEN), or regular preschools (i.e., predominantly attended by typically developing children) to find out if educators and parents in such settings held the same perceptions about including children with SEN into regular classrooms. Another type of preschool that would have provided valuable information about the state of inclusion and educators' and parents' perceptions of it, are preschools operated by other government entities and private sectors in Malaysia.

Secondly, since special classrooms in Malaysian integrated preschools enrolled only children diagnosed with learning disabilities, the findings in this study may not represent the practices and views of educators and parents of children with different types of SEN. At the time of conducting research for this study, preschool aged children diagnosed as visually or hearing impaired were primarily placed in special education preschools. Hence the findings of this study may be reflective of situations and perceptions associated with children with learning disabilities only. Thirdly, the case study sites discussed here represent a very small sample size of preschools, so findings may not necessarily reflect the views of all educators and parents involved in Malaysian integrated preschools. 
It is also relevant to note that there can be multiple realities to any single phenomenon. This study used educators' and parents' perceptions as a basis for understanding the state of inclusion in Malaysian integrated preschools. Findings thus showed that there was an emphasis on the shortcomings of factors operating at the level of the Ministry of Education impacting inclusive practices at the preschool or microlevel. If the study had taken the perceptions of education officers or policy makers as its basis, the findings would likely to have been completely different. Nevertheless, the use of the bioecological systems perspective (Bronfenbrenner, 1999, 2005; Bronfenbrenner \& Ceci, 1994; Bronfenbrenner \& Morris, 1998) as the guiding framework of the study provided a basis for considering the impact of varying events and processes at different levels in the context when interpreting the findings.

\section{Future research}

This study provides significant insights into the state of inclusion, perceptions of it, and factors that may be influencing inclusion in Malaysian integrated preschool programmes. Nevertheless, future studies are critical to obtain a better understanding of the complexities of issues involved. In light of the findings and the limitations of this study stated in the previous section, some of the following areas are ripe for further research.

- $\quad$ Since integrated schooling at the preschool level is a fairly new venture, it will be interesting to evaluate the outcomes of varying levels of inclusive practices of preschoolers in integrated preschools. A particular focus could be the impact of inclusive opportunities on preschoolers with SEN's social skills, or peer acceptance of children with SEN by their typically developing peers.

- An important area of research could also include in-depth research about inservice and pre-service teachers' attitudes towards preschool inclusion. The variables that may be impacting teachers' overall attitudes in this regard can be pivotal for making informed decisions, especially in terms of improving 
and restructuring existing course modules for initial teacher education, and on-going professional development courses, as well as developing new courses.

- Another area warranting further examination is the roles that principals play as school administrators in initiating inclusive practices, and influencing teachers' attitudes towards this practice.

- Additionally, research could also include the perceptions of educators and parents in private preschools. Their views could be able to shed more light on other significant factors influencing the state of inclusion at the preschool level in Malaysia.

- It is also important to examine the perspectives of parents of children with different categories of SEN regarding inclusion. In addition, there is also a need for researchers to continuously examine parents' views and ideas as part of making improvements for SEN services. For example, there is a need to find out parents' views on schools' (non)inclusive decisions, and the extent to which parents have a say in such decisions.

- $\quad$ There is also a need to examine policies on the education of children with SEN in Malaysia, and the possible changes in polices for the effective implementation of inclusive practices.

- It would also be informative to conduct a large-scale study about the beliefs and values that the wider community holds about disability and inclusive practices. This would provide information on how people deal with the dissonance between ideas about inclusive practices, and negative and pessimistic attitudes about disability in Malaysia generally. 


\section{Implications of the current study}

Whilst the findings of the research conducted for this thesis need to be interpreted within the context of the research limitations, the outcomes of this study have significant implications for practice and policy. This study provides information that will be useful to the Ministry of Education, teacher training institutions, and schools for evaluating their current practices, with a focus on ways to support and improve inclusive practices. The implications of this study are discussed in the following, along with some recommendations made to the government and relevant government agencies in Malaysia:

1. Findings showed that teachers' lack of knowledge and skills about inclusive education impacted on their attitudes towards inclusion and the decisions they made about it. Expecting teachers to support inclusion without much knowledge or understanding about disability or inclusion is unrealistic.

Recommendations:

- There is a need for the Ministry of Education to ensure that all teachers, regardless of whether or not they are specialising in special education, are equipped with relevant knowledge and information on inclusion and SEN. The existing initial and in-service teacher education programmes and modules (particularly for regular classroom teachers) need to be re-examined to ensure that they encompass theoretical and practical knowledge about inclusion and managing SEN.

- The Ministry's, teacher training institution's, and school level training and development programmes need to consider incorporating organised opportunities for trainee teachers and teachers to experience the teaching of children with SEN in regular classrooms. This idea is supported by Garner (1996) who says that being able to observe the teaching of learners with SEN in inclusive situations is pivotal for building positive attitudes and overcoming barriers to inclusion. Hence, the integration of such experiences into course modules in the form of observational or practical exposure should boost teachers' confidence 
in relation to inclusion, subsequently encouraging them to think and act more inclusively.

- Particularly important is that when every teacher has some knowledge of SEN and inclusion, collaborative efforts between regular and special classroom teachers, which are essential in integrated schools, becomes less complicated. There must also be consideration given to include inclusive teaching strategies and cooperative pedagogies, focusing specifically on regular and special classroom teaching and learning. Such a consideration encourages a sense of professional partnership between regular and special educators, and mutual responsibility towards all children, rather than separate groups of children.

2. The findings from this study also have implications for the practice of ensuring school principals take an active part in promoting inclusion. Principals are the figure of authority in a school, and play a significant role in supporting inclusion by offering the right kind of knowledge and information to their teachers (Barnett \& Monda-Amaya, 1998; Salisbury \& McGregor, 2005). The availability of such support can directly influence teachers, as well as parent's opinions and attitudes about inclusion (Salisbury \& McGregor, 2005).

\section{Recommendations:}

- There must be ongoing support systems or strategies in place for ensuring principals receive effective professional learning to enable them to hold a facilitative role in developing positive school climates for inclusion. Short and long term planning can also include the implementation of mentorship programmes, in which education officers from the Ministry or State Special Education Departments are assigned to particular schools, offering on-going support and information on inclusion to school principals. Such support systems for principals are particularly important in a setting like Malaysian integrated preschools where inclusion is still a new phenomenon. 
3. This study has also identified that there is a lack of awareness among educators and parents about inclusion and SEN. It is crucial that the government create awareness among parents and the wider school community about what inclusion means to learners with SEN and how parents/ community can do their part to support inclusion.

Recommendations:

- Possible considerations for effective dissemination of information can include the use of mass media to educate the public on children with SEN's rights to education in regular schools.

4. The findings presented in this study also imply that learners with disabilities are denied full participation and inclusive experiences if the learning environment does not support optimal learning and social experiences.

Recommendations:

- The Ministry of Education and school personnel need to work collaboratively in ensuring that the location of regular and special classrooms and other facilities (e.g., playground, meal and circle time area) in integrated preschools are built or located with consideration for inclusion. The school principal and preschool teachers especially need to play an active role, taking responsibility to ensure that the physical environment in their preschool is not affecting children with and without SEN's opportunity to engage in shared activities.

5. There is a dire need to reconsider the present guidelines for including children with SEN into regular classrooms in Malaysian integrated preschools, which is based on children with SEN's ability to cope with regular classroom learning. 
Recommendations:

- Inclusion must be made compulsory for all learners with SEN, regardless of their disability, and especially at the preschool level. This is not to imply that there is a need to revamp the current integrated school system to adopt an ideal concept of inclusion, or as Idol (1997) states, one where children with SEN are enrolled in an age-appropriate classroom for $100 \%$ of the school day. The Ministry of Education acknowledges that there are constraints and limitations to cater for such ideal inclusion scenarios in the Malaysian context (Haniz Ibrahim, 1998; Ministry of Education Malaysia, 2004). Nevertheless, this should not stop the Ministry from developing effective policies for inclusion, and refining the current inclusive education guidelines in integrated school settings so that there won't be situations of total segregation in integrated preschools. Opportunities for children with and without SEN to engage in structured and unstructured socially integrated activities must be made a compulsory practice at the preschool level.

- Further, there need to be guidelines about minimum opportunities for inclusion at the preschool level, so that regular and special classroom teachers will initiate inclusion, not based on teacher discretion of learners' ability, but instead as part of teachers' responsibilities towards learners with disability.

6. Without legislation and policy to provide clear guidelines on inclusive education, successful inclusion is impossible (Agbenyega, 2007; Asia Community Service, 2007).

Recommendations:

- There is a need to develop mandates on inclusive education so that there will be clear policies to address issues specific to integrated schools in the Malaysian context. The issues identified in this study, such as classroom enrolment, teacher competency, inclusion guidelines, 
curriculum and environment adaptations are particularly important to be addressed through policy guidelines, because such issues have profound impacts on teachers' inclusive decisions, especially when inclusion is not a mandatory practice. Only with legislation and clear policy guidelines will there be a whole-school approach towards inclusive education, where every member of the school community will recognise that they have a responsibility in ensuring that inclusion takes place effectively.

- The use of policy to command practice is, however, a continuously problematic aspect of inclusive education. For policy to work at macrolevel, it has to also work at micro-level. Literature has indicated that even with legislations in place, many countries are still struggling with the implementation of inclusion due to the lack of support and satisfaction among educators and parents (e.g., Pivik et al., 2003; Maher, 2007). Because educators' and parents' views are representative of micro-level requirements that need to be met to overcome shortcomings in successful inclusion, there must be involvement on their part at all phases of inclusive education policy development and decision-making. It would be helpful to have a systematic tool for making informed decisions on inclusion based on educators' and parents' feed-back and critique, applicable specifically to the Malaysian context, similar to the British Index for Inclusion (Booth et al., 2000) or other kinds of PQI (e.g., Cushing et al., 2009; NYSED, 2001) that have been used in other countries. 


\section{Contributions to knowledge and theory}

This study contributes to knowledge about inclusive education in general, and to knowledge about inclusive education in Malaysian integrated preschool programmes in particular. It has provided evidence about the extent to which children with SEN have opportunities for inclusion in integrated preschool settings, and the nature of integrated activities that support outcomes of inclusion in this context (social and/or academic). This study has also collected information about how educators and parents of children with and without SEN in Malaysia perceive inclusion, and the extent to which they are supportive of its implementation, particularly at the preschool level. This research has also shown the complexity of issues involved in regular and special classroom teachers' efforts to work collaboratively to include children with SEN into regular classrooms in integrated settings.

Through the application of the bioecological systems perspective (Bronfenbrenner, 1999, 2005; Bronfenbrenner \& Ceci, 1994; Bronfenbrenner \& Morris, 1998) to examine inclusion in Malaysian integrated preschools, this study has not only enabled the examination of bioecological theory in a new context, but has also demonstrated the importance of taking into consideration specific pathways and interrelated components in the studied context when exploring development. Through the use of this theory, this study illustrates that the person factor, processes in the immediate and wider school context, and the changes of events and expectations over time were significantly influencing the state of inclusion and the support for it in Malaysian integrated preschools.

\section{Conclusion}

The move to place children with SEN in a regular educational environment marked the "important first step" (Pijl, 2007, p.2) for removing the stigma of segregation in Malaysian educational settings. However, this significant step was not supported with adequate preparations for inclusion on the part of policy makers, and this has subsequently impacted upon the ways in which school personnel and their surrounding community have responded. What has emerged from this study is a 
snapshot of segregated practices in integrated schooling environments, with educators and parents who are willing to embrace the moral principles and ideologies of inclusion, yet who are hesitant to initiate or implement it in practice.

However, the findings of research conducted in this study revealed that the notion of inclusive education was not completely lost either. Whilst the impact of collective beliefs and attitudes was evident, the impact of individual thinking and expectations were also visible, as were examples of on-going change and improvement in policy and practice that have developed over time in support of the rights of persons with disabilities in Malaysia. Participants' positive views about inclusion and the efforts initiated through suitable processes in their preschools to promote inclusion were reflective of this situation. The implementation of change, however, takes time (Tufue-Dolgoy, 2010). This study took place a mere 5 years after the inception of integrated preschools in Malaysia. It is hoped that the modest contribution of knowledge and information from this study, and from future ongoing studies, will be able to bring about improvements, and favourable outcomes for inclusion in Malaysian integrated preschools. 


\section{REFERENCES}

Abdullah, N. (2000). Attitudes of secondary school teachers towards inclusive education. Unpublished master's project paper, University of Malaya, Malaysia.

Abbott, L. (2006). Northern Ireland head teachers' perceptions of inclusions. International Journal of Inclusive Education, 10(6), 627-643.

Adnan, A. H., \& Hafiz, I. A. (2010). A disabling education: The case of disabled learners in Malaysia. Disability and Society, 16(5), 655- 669.

Agbenyega, J. (2007). Examining teachers' concerns and attitudes to inclusive education in Ghana. International Journal of Wholeschooling, 3(1), 41-56.

Ainscow, M. (2005). Developing inclusive education systems: What are the levers for change? Journal of Educational Change, 6, 109-124.

Ainscow, M. (2007). Taking an inclusive turn. Journal of research in Special Educational Needs, 7(1), 3-7.

Ajuwon, M. (2008). Inclusive education for students with disabilities in Nigeria: benefits, challenges and policy implications. International Journal of Special Education, 23(3), 11-16.

Ali, M. M., Mustapha, R., \& Jelas, Z. M. (2006). An empirical study on teachers' perceptions towards inclusive education in Malaysia. International Journal of Special Education, 21(3), 36-44.

Ang, H. B. (1999). Konsep dan kaedah pengajaran dengan penekanan pendidikan inklusif. Kuala Lumpur: Penerbitan Utusan.

Angelides,P. (2005). The missing piece of the puzzle called 'provision of equal participation in teaching and learning'(?). International Journal of Special Education, 20(2), 32-35.

Ashman, A., \& Elkins, J. (2005). Educating children with diverse abilities (2 ${ }^{\text {nd }}$ ed.). Australia: Pearson Prentice Hall.

Asia Community Service. (2007). Inclusive preschool education in Malaysia: A comparative study of present situation \& future direction. Malaysia: Glory Printing.

Avissar, G. (2000). The School Principal and Inclusion: A Cross Cultural Research Investigation. Paper Presented at the International Special Education Congress (ISEC) Including the Excluded. University of Manchester, Manchester UK.

Avramidis, E., Bayliss, P., \& Burden, R. (2000). A survey into mainstream teachers' attitudes towards the inclusion of children with special educational needs in 
the ordinary school in one local education authority. Educational Psychology, 20(2), 191-211.

Avramidis, E., \& Norwich, B. (2002). Teachers' attitudes towards integration/inclusion: a review of the literature. European Journal of Special Needs Education, 17(2), 129-147.

Ayob, A., See, C. M., \& Selamat, S. (2008). Kajian keberkesanan program pendidikan khas integrasi-inklusif di Malaysia. Jabatan Pendidikan Khas, Kementerian Pelajaran Malaysia: Putrajaya.

Bahagian Pendidikan Khas (BPK). (2008). Maklumat pendidikan khas. Jabatan Pendidikan Khas, Kementerian Pelajaran Malaysia: Putrajaya.

Baldock, P., Fitzgerald, D., \& Kay, J. (2009). Understanding early years policy (2 ${ }^{\text {nd }}$ ed.). London: Sage.

Barnett, C., \& Monda-Amaya, L. E. (1998). Principals' knowledge of and attitudes toward inclusion. Remedial and Special Education, 19(3), 181-192.

Bennett, T., Deluca, D., \& Bruns, D. (1997). Putting inclusion into practice: Perspectives of teachers and parents. Exceptional Children, 64(1), 115-131.

Bergen D. (2003). 'Perspectives on inclusion in Early Childhood Education'. In J.P. Isenberg \& M.R. Jalongo (Eds.), Major Trends and Issues in Early Childhood Education, New York and London: Teachers College Press.

Berry, R. A. W. (2006). Inclusion, power, and community: Teachers and students interpret the language of community in an inclusion classroom. American Educational Research Journal, 43(3), 489-529.

Berry, R. A. W. (2010). Preservice and early career teachers' attitudes toward inclusion, instructional accommodations, and fairness: Three profiles. The Teacher Educator, 45(2), 75-95.

Berry, R. A. W. (2011). Voices of experience: general education teachers on teaching students with disabilities. International Journal of Inclusive Education, 15 (6), 627- 648.

Bogdan, R. C., Biklen, S. K. (2003). Qualitative research for education. an introduction to theories and methods ( $4^{\text {th }}$ ed.). Boston: Allyn \& Bacon.

Bonner, A., \& Tolhurst, G. (2002). Insider-outsider perspectives of participant observation. Nurse Researcher, 9(4), 7-19.

Booth, T. (1999). Viewing inclusion from a distance: gaining perspective from comparative study. Support for Learning, 14(4), 164-168.

Booth, T., \& Ainscow, M. (2002). Index for inclusion: Developing learning and participation in schools (Rev. ed.). Retrieved August 20, 2011, from http://www.eenet.org.uk/resources/docs/Index\%20English.pdf 
Booth, T., Ainscow, M., Black-Hawkins, K., Vaughan, M., \& Shaw, L. (2000). Index for inclusion: Developing learning and participation in schools. Retrieved August 20, 2011, from http://www.eenet.org.uk/resources/docs/Index\%20English. pdf

Booth, T., Ainscow, M., \& Kingston, D. (2006). Index for inclusion: Developing play, learning and participation in early years and childcare. Retrieved August 20, 2011, from http://www.eenet.org.uk/resources/docs/ Index\% 20EY \%20English.pdf

Bosi, W. (2004). The pilot implementation of inclusive education in Malaysia: A review. Doctoral dissertation, Massey University, New Zealand.

Braun, V., \& Clarke, V. (2006). Using thematic analysis in psychology. Qualitative Research in Psychology, 3(2), 77-101.

Bronfenbrenner, U. (1977). Toward an experimental ecology of human development. American Psychologist, 32, 513- 531.

Bronfenbrenner, U. (1979). The ecology of human development: Experiments by nature and design. Cambridge, MA: Harvard University Press.

Bronfenbrenner, U. (1995). Developmental ecology through space and time: A future perspective. In P. Moen, G. H. J. Elder, \& K. Lusher (Eds.), Examining lives in context: Perspectives on the ecology of human development (pp. 619647). Washington, DC: American Psychological Association.

Bronfenbrenner, U. (1999). Environments in developmental perspective: Theoretical and operational models. In S. L. Friedman \& T.D. Wachs (Eds.), Measuring environment across the life span: Emerging methods and concepts (pp. 3-28). Washington, DC: American Psychological Association.

Bronfenbrenner, U. (2005). Ecological systems theory. In U. Bronfenbrenner (Ed.), Making human beings human: Bioecological perspectives on human development (pp. 106-173). Thousand Oaks, CA: Sage

Bronfenbrenner, U., \& Ceci, S. J. (1994). Nature-nurture reconceptualised in developmental perspective: A bioecological model. Psychological review, 101(4), 568-586.

Bronfenbrenner, U., \& Morris, P. A. (1998). The ecology of developmental processes. In W. Damon \& R.M. Lerner (Eds.), Handbook of Child Psychology: Volume 1: Theoretical Models of Human Development (pp. 993-1028). New York: Wiley.

Bryant, D. P., Smith, D. D., \& Bryant, B. R. (2008). Teaching Students with Special Needs in Inclusive Classrooms. Boston, MA: Pearson Education, Inc.

Buell, M. J., Hallam, R., Gamel-McCormick, M., \& Scheer, S. (1999). A survey of general and special education teachers' perceptions and inservice needs 
concerning inclusion. International Journal of Disability, Development and Education, 46(2), 143-156.

Burton, D., \& Bartlett, S. (2009). Key issues for education researchers. Thousand Oaks, CA: Sage.

Carrington, S. (1999). Inclusion needs a different school culture. International Journal of Inclusive Education, 3(3), 257-268.

Carrington, S. (2006). Developing an inclusive school culture. In M. Keeffe \& S. Carrington (Eds.), Schools and Diversity, (pp. 18-32). Australia: Pearson.

Carrington, S., \& Robinson, R. (2004). A case study of inclusive school development: a journey of learning. International Journal of Inclusive Education, 8(2), 141153.

Carrington, S., \& Holm, K. (2005). Students direct inclusive school development in an Australian secondary school: an example of student empowerment. Australasian Journal of Special Education, 29(20), 155-171.

Carroll-Lind, J., Bevan-Brown, J., \& Kearney, A. (2007). Critique of the New Zealand draft curriculum. An inclusive/special education perspective. Report to the Ministry of Education. Palmerston North, New Zealand: Massey University.

Cavallaro, C. C., \& Haney, M. (1999). Preschool inclusion. Baltimore, Maryland: Paul H Brookes.

Chhabra, S., Srivastava, R., \& Srivastava, I. (2010). Inclusive education in Botswana: the perceptions of school teachers. Journal of Disability Policy Studies, 20(4), 19-28.

Chitiyo, M., \& Wheeler, J. (2004). The development of special education services in Zimbabwe. International Journal of Special Education, 19(2), 46-52.

Clark, J. (1997). Educational research: Philosophy, politics and ethics. Palmerston North, New Zealand: ERDC Press.

Cohen, L., Manion, L., \& Morrison, K. (2000). Research methods in education ( $5^{\text {th }}$ ed.). London: Routledge Falmer.

Conrad, D. A., \& Brown, L. I. (2011). Fostering inclusive education: principal's perspectives in Trinidad and Tobago. International Journal of Inclusive Education, 5(9), 1017-1029.

Cook, B. G. (2001). A comparison of teachers' attitudes toward their included students with mild and severe disabilities, The Journal of Special Education, 34(4), 203-213.

Cook, R., Klein, M. D., \& Tessier, A. (2008). Adapting early childhood curricula for children in inclusive settings (7th ed.). Upper Saddle River: Pearson Prentice Hall. 
Country Report Malaysia. (2000). Strengthening and encouraging school development. The nineteenth APEID Seminar on Special Education, 6-11 November, 2000, Yokosuka, Kanagawa, Japan: Author.

Country Report Malaysia. (2009). Towards an inclusive society: Strengthening the collaboration between social welfare, health and medical systems for children with disabilities. The $7^{\text {th }}$ ASEAN and Japan High Level Official Meeting on Caring Societies, $31^{\text {st }}$ August- $3^{\text {rd }}$ September, 2009, Tokyo, Japan: Author.

Country Report Malaysia. (2010). Reaching the unreached. 11 ${ }^{\text {th }}$ Regional Meeting of National EFA Coordinators, 18- 20 November, 2010, Bangkok, Thailand: Author.

Creswell, J. (2002). Educational research: Planning, conducting and evaluating qualitative and quantitative research. Upper Saddle River, N,J: Merrill Prentice Hall.

Creswell, J. (2003). Research design (2 ${ }^{\text {nd }}$ ed.). Thousand Oaks, CA: Sage.

Creswell, J., \& Plano Clark, V. L. (2007). Designing and conducting mixed methods research. Thousand Oaks, CA: Sage.

Crotty, M. (1998). The foundations of social research: Meaning and perspective in research process. Crows Nest, NSW: Allen \& Unwin.

Curriculum Development Centre Malaysia. (2007). Early childhood care and education policy implementation review. Malaysia: Ministry of Education.

Cushing, l. S., Carter, E. W., Clark, N., Wallis, T., \& Kennedy, C. H. (2009). Evaluating inclusive educational practices for students with severe disabilities using the program quality measurement tool. The Journal of Special Education, 42(4), 195-208.

de Boer, A., Pijl, S. J., \& Minnaert, A. (2010). Attitudes of parents towards inclusive education: A review of the literature. European Journal of Special Needs Education, 25 (2), 165-181.

Denzin, N., \& Lincoln, Y. (2005). Introduction: The discipline and practice of qualitative research. In N. Denzin \& Y. Lincoln (Eds.), The sage handbook of qualitative research ( $3^{\text {rd }}$ ed., pp. 1-32). Thousand Oaks, CA: Sage.

Deppeler, J., \& Harvey, D. (2004). Validating the British index for inclusion for the Australian context: stage one. International Journal of Inclusive Education, $8(2), 155-184$.

Education Review Office. (2010). Including students with high needs. Retrieved September 20, 2011, from http://www.ero.govt.nz/NationalReports/Including-Students-with-High-Needs-June-2010.

Eichinger, J., Meyer, L., \& D'Aquanni, M. (1996). Evolving best practices for learners with severe disabilities. Special Education Leadership Review, 3 (1), 1-13. 
Eisner, E. W. (1991). The enlightened eye: qualitative enquiry and the enhancement of educational practice. New York, NY: Macmillan Publishing Company.

Elhoweris, H., \& Alsheikh, N. (2006). Teachers' attitudes toward inclusion. International Journal of Special Education, 21(1), 115-118.

Elkins, J., Kraayenoord, C. E., \& Jobling, A. (2003). Parents' attitudes to inclusion of their children with special needs. Journal of Research in Special Educational Needs, 3(2), 122-129.

El-Zein, H. L. (2009). Attitudes toward inclusion of children with special needs in regular schools (a case study from parents' perspective). Educational Research and Review, 4(4), 164-172.

Foreman, P. (Ed.). (2005). Inclusion in action. Victoria: Harcourt Australia Pyt Ltd.

Frankel, E. B. (2004). Supporting inclusive care and education for young children with special needs and their families: An international perspective. Childhood Education, 80(6), 310-316.

Friend, M. (2005). Special education: Contemporary perspectives for school professionals ( $2^{\text {nd }}$ ed.). Boston: Allyn and Bacon.

Friend, M. (2011). Special Education: Contemporary Perspectives for School Professionals. ( $3^{\text {rd }}$ ed.) Upper Saddle River, NJ: Pearson.

Garner, P. (1996). A Special education? The experience of newly qualified teachers during initial teacher training. British Journal of Special Education, 23(4): 176-179.

Garrick-Duhaney, L. M., \& Salend, J. S. (2000). Parental perceptions of inclusive educational placements. Remedial and Special Education, 21(2), 121-128.

Garuba, A. (2003). Inclusive education in the 21 st century: challenges and opportunities for Nigeria. Asia Pacific Disability Rehabilitation Journal, 14(2), 191-200.

Gilles, R. M., \& Carrington, S. (2004). Inclusion: culture, policy and practice: a Queensland perspective. Asia Pacific Journal of Education, 24(2), 117-128.

Gillham, B. (2000). Case study research methods. London: Continuum.

Glazzard, J. (2011). Perceptions of the barriers to effective inclusion in one primary school: voices of teachers and teaching assistants. Support for Learning, 26(2), 56-63.

Gomez, C. (2004). Dyslexia in Malaysia. In I. Smythe, J. Everatt \& R. Salter (Eds.), Intern8ational book of Dyslexia: A guide to practice and resources (pp. 158163). New York: John Wiley. 
Graham, J. L., \& Spandagou, I. (2011). From vision to reality: views of primary school principals on inclusive education in New South Wales, Australia. Disability and Society, 26(2), 223-237.

Greene, J., \& Caracelli, V. (Eds.). (1997). Defining and describing the paradigm issue in mixed-method evaluation. New Directions for Evaluation, 74, 5-16.

Grisham-Brown, J. L., Hemmeter, M. L., \& Pretti-Frontczak, K. L. (2005). Blended practices for teaching young children in inclusive settings. Baltimore: Paul Brookes Publishing Company.

Guba, E.G., \& Lincoln, Y. S. (1981). Effective evaluation. San Francisco: Jossey-Bass.

Guba, E.G., \& Lincoln, Y. S. (Eds.). (2004). Competing paradigms in qualitative research: Theories and issues. New York: Oxford University Press.

Guralnick, M. J. (1999). That nature and meaning of social integration for young children with mild developmental delays in inclusive settings. Journal of Early Interventions, 22(1), 70-86.

Guralnick, M. J. (2001). Early childhood inclusion: focus on change. Baltimore: Paul H Brookes Publishing.

Hallahan, D. P., \& Kauffman, J.M. (2006). Exceptional learners: Introduction to special education (10 th ed.). Boston : Allyn and Bacon.

Haniz Ibrahim. (1998). Inclusive education in Malaysia: Teachers' attitudes to change. Unpublished doctoral dissertation, University of Exeter, United Kingdom.

Haniz Ibrahim. (2007). Special education, inclusive practices and the teaching of science and mathematics to children with special needs. Retrieved 05 May, 2011, from http://www.recsam.edu.my/cosmed/cosmed07/Abstracts FullPapers 2007/keynotes\%20\&\%20plenary\%5CPL001F.pdf

Hanson, M. J., Horn, E., Sandall, S., Beckman, P., Morgan, M., Marquart, J., Barnwell, D., \& Hsin-Ying, C. (2001). After preschool inclusion: Children's educational pathways over the early school years. Exceptional Children, 68(1), 65-83.

Haq, F. S. (2000). From divided responsibility to shared responsibility: Inclusion in Malaysia. Paper Presented at the International Special Education Congress (ISEC) Including the Excluded. University of Manchester, Manchester UK.

Heiman, T. (2004). Teachers coping with changes: including students with disabilities in mainstream classes: an international view. International Journal of Special Education, 19(2), 91-103.

Hick, P. (2005). Supporting the development of more inclusive practices using the index for inclusion. Educational Psychology in Practice, 21(2), 117-122.

Hinkson, M., \& Kieth, L. (2000). The attitudes and perceptions of high school administrators toward agricultural science teachers in Texas. Journal of Southern Agricultural Education Research, 50(1), 180-186. 
Horne, P. E. \& Timmons, V. (2009). Making it work: teachers' perspectives on inclusion." International Journal of Inclusive Education 13, no. 3: 273-286.

House of Commons Education and Skills Committee. (2006). Special educational needs, vol. 1. London: The Stationery Office.

Human Rights Commission of Malaysia. (2006). SUHAKAM's report on the human rights approach to the millennium development goals: Goal 2- Achieve universal primary education. Perkasa Nilam: Selangor, Malaysia.

Idol, L. (1997). Creating collaborative and inclusive schools. Austin, Texas: Pro-Ed.

Idol, L. (2006). Toward inclusion of special education students in general education: a program evaluation of eight schools. Remedial and Special Education, 27(2), 77-94.

Inos, R., \& Quigley, M. (1995). Research review for inclusive practices. Hawaii: Pacific Region Education Laboratory.

Israel, M., Hay, I. (2006). Research ethics for social scientists. London: Sage.

Jelas, Z. M. (2000). Perceptions of inclusive practices: the Malaysian perspective. Educational Review, 52(2), 187-196.

Jelas, Z. M. (2010). Learner diversity and inclusive education: A new paradigm for teacher education in Malaysia. Procedia Social and Behavioral Sciences, 7, 201-204.

Jelas, Z. M., Salleh, N. M., \& Ali, M. M. (2010). Developing the foundations of inclusive education through university-school partnership. The International Journal of Learning, 17(6), 145-156.

Johnson, B., \& Christensen, L. (2008). Educational research: Quantitative, qualitative and mixed approaches ( $3^{\text {rd }}$ ed.). Thousand Oaks, CA: Sage.

Johnson, B., \& Onwuegbuzie, J. (2004). Mixed methods research: A research paradigm whose time has come. Educational Researcher, 33(7), 14-26.

Kalyva, E., Gojkovic, D., \& Tsakiris, V. (2007). Serbian teachers' attitudes towards inclusion. International Journal of Special Education, 22(3), 30-35.

Kandlbinder, P. (2003). Critical reconstruction as a methodology for higher education research. Paper presented at the higher education research and development society of Australia (Herdsa) Conference 2003. Retrieved August 12, 2010, from http://surveys.canterbury. ac.nz/herdsa03/pdfsnon/N1220.pdf.

Kartz, J., \& Mirenda, P. (2002). Including students with developmental disabilities in general education classrooms: Social benefits. International Journal of Special Education, 17(2), 25-35. 
Kearney, A. (2009). Barriers to school inclusion: an investigation into the exclusion of disabled students from and within New Zealand schools. Unpublished doctoral dissertation, Massey University, New Zealand. Retrieved, January 31, 2012, from http://mro.massey.ac.nz/bitstream/ handle/10179/876/02whole.pdf?sequence=1

Kementerian Pelajaran Malaysia. (2007). Maklumat pendidikan khas 2007. Bahagian Pendidikan Khas: Kementerian Pelajaran Malaysia.

Khader, F. R. (2012). The Malaysian experience in developing national identity, multicultural tolerance and understanding through teaching curricula: lessons learned and possible applications in Jordanian context. International Journal of Humanities and Social Science, 2(1), 270-288.

Kugelmass, J. (2004). What is a culture of inclusion? EENET-Enabling Education. Retrieved 19 August, 2012, from http://www.eenet.org.uk/newsletters/ news8/page 14.shtml

Laws of Malaysia. (2008). Act 685: Persons with disability act 2008. Percetakan Nasional Malaysia Berhad. Appointed Printer to the Government of Malaysia.

Leatherman, J. M. (2007). "I just see all children as children": teachers' perceptions about inclusion. The Qualitative Report, 12(4), 594-691.

Leatherman, J. M., \& Niemeyer, J. A. (2005). Teachers' attitudes toward inclusion: factors influencing classroom practice. Journal of Early Childhood Teacher Education, 26(1), 23-36.

Lee, L. W., \& Low, H. M. (2012). 'Unconscious' inclusion of students with learning disabilities in Malaysian mainstream primary school: teachers' perspectives. Retrieved 20 August, 2012, from http://onlinelibrary. wiley.com/doi/10.1111/ j.1471-3802.2012.01250.x/pdf.

Lefrancois, G. R. (1997). Psychology for teaching. Belmont: Wadsworth Publishing.

Lerner, R. M. (2005). Foreword. In U. Bronfenbrenner (Ed.), Making human beings human: Bioecological perspectives on human development (pp. ix-xxvi). Thousand Oaks, CA: Sage.

Leyser, Y., \& Kirk, R. (2004). Evaluating inclusion: an examination of parent views and factors influencing their perspective. International Journal of Disability, Development and Education, 51(3), 271-285

Leyser, Y., \& Kirk, R. (2011). Parents' perspectives on inclusion and schooling of students with angelman syndrome: suggestions for educators. International Journal of Special Education, 26(2), 1-14.

Lieber, J., Hanson, M. J., Beckman, P. J., Odom, S. L., Sandall, S. R., Schwartz, S. I., ... Wolery, R. (2000). Key influences on the initiation and implementation of inclusive preschool programs. Exceptional Children, 67(1), 83-98. 
Lifshitz, H., Glaubman, R., \& Issawi, R. (2004). Attitudes towards inclusion: the case of Israeli and Palestinian regular and special education teachers. European Journal Special Needs Education, 19(2), 171-190.

Lombard, M., Snyder-Duch, J., \& Bracken, C (2002). Content analysis in mass communication: assessment and reporting of intercoder reliability. Human Communication Research, 28(4). Retrieved March 1, 2011 from http://public.univie.ac.at/fileadmin/userupload/lehrstuhl_marketing/Lehr e/Lehrinhalte/09SS/Lombard_et_al__2002_-1.pdf

Magill-Evans, J., Darrah, J., \& Adkins, R. (2003). Youths with cerebral palsy and their satisfaction with recreational services: Implications for inclusion. Journal of the Canadian Association for Leisure, 28, 71-86.

Mahat, M. (2008). The development of psychometrically-sound instrument to measure teachers' multidimensional attitudes toward inclusive education. International Journal of Special Education, 23(1), 82-92.

Maher, M. (2007). Inclusive education a decade after democratisation: The educational needs of children with disabilities in KwaZulu-Natal. Doctoral dissertation, Auckland University of Technology, New Zealand.

Mapp, K. L. (2003). Having their say: Parents describe why and how they are engaged in their children's learning. The School-Community Journal 13(1), 35-64.

Mastropieri, M.A., \& Scruggs, T. E. (2005). Feasibility and consequences of response to intervention: Examination of the issues and scientific evidence as a model for the identification of individuals with learning disabilities. Journal of Learning Disabilities, 36(6), 525-531.

Mentis, M., Quinn, S., \& Ryba, K. (2005). Linking inclusive policies with effective teaching practices. In D. Fraser, R. Moltzen, \& K. Ryba (Eds.), Learners with special needs in Aotearoa New Zealand (3 ${ }^{\text {rd }}$ ed.), (pp. 74-98). Palmerston North: Dunmore Press.

Merriam, S. (1988). Case study research in education: A qualitative approach. San Francisco: Jossey-Bass.

Merriam, S. (1998). Qualitative Research and Case Study Application in Education: Revised and Expanded from Case Study Research in Education. San Francisco: Jossey-Bass.

Merriam, S. B. (2002). Introduction to qualitative research. In S.Merriam \& Associates (Eds.), Qualitative research in practice : Examples for discussion and analysis (pp. 3-39). San Francisco: Jossey-Bass.

Mertens, D. (2005). Research and evaluation in education and psychology: Integrating diversity with quantitative, qualitative and mixed methods $\left(^{\text {nd }}\right.$ ed.). Thousand Oaks, CA: Sage. 
Mertens, D. (2010). Research and evaluation in education and psychology: Integrating diversity with quantitative, qualitative and mixed methods (3rd ed.). Thousand Oaks, CA: Sage.

Mertler, C., \& Charles, C. (2011). Introduction to Educational research (7th ed.). Boston, USA: Allyn \& Bacon.

Ministry of Education Malaysia. (2004). The development of education: National report of Malaysia. Retrieved May 5, 2009 from http://www.ibe.unesco.org/International/ICE47/English/Natreps/reports/ malaysia.pdf

Ministry of Education Malaysia. (2008a). Malaysia education for all mid-decade assessment report 2000-2007: Reaching the unreached. Putrajaya: Malaysia.

Ministry of Education Malaysia. (2008b). The development of education: National report of Malaysia. Paper Presented at the International Conference on Education, Geneva, Switzerland.

Miles, M. B. \& Huberman, A.M. (1994). Qualitative data analysis: An expanded sourcebook (2nd ed.). Thousand Oaks, CA: Sage Publications.

Mitchell, D. (Ed.). (2005). Contextualizing inclusive education: Evaluating old and new international perspectives. Routledge: Taylor \& Francis Group.

Mohd Daud, F. H. (1992). The mainstreaming of visually handicapped students in a secondary school in Kuala Lumpur. Unpublished master's dissertation, University of Malaya, Malaysia.

Muhammad, K., \& Wan Mahmud, W. A. (2010). Pelaksanaan program pendidikan inklusif murid autistic di sebuah sekolah rendah: satu kajian kes. Retrieved August 12, 2011, from http://file.upi.edu/Direktori/ PROCEEDING/UPIUPSI/2010/Book_3/PELAKSANAAN_PROGRAM_ PENDIDIKAN_INKLUSIF_MURID_AUTISTIK_DI_SEBUAH_SEKOLAH_RENDAH -SATU_KAJIAN_KES.PDF

Mutch, C. (2005). Doing educational research: A practitioner's guide to getting started. Wellington, NZ: NZCER.

Naicker, J. (2008). Educators' preparedness for inclusive education. Unpublished master's dissertation, University of Zululand. Retrieved 13 August, 2011, from

http://uzspace.uzulu.ac.za/bitstream/handle/10530/239/Educators\%20pr eparedness $\% 20$ for $\% 20$ inclusive $\% 20$ education $\% 20$ -

$\% 20 \mathrm{~J} \% 20$ Naicker.pdf?sequence=1.

Nanus, B. (1992). Visionary leadership: Creating a compelling sense of directions for your organization. San Francisco: Jossey-Bass. 
Narumanchi, A., \& Bhargava, S. (2011). Perceptions of parents of typical children towards inclusive education. Disability, CBR and Inclusive Development, 22(1), 120-129.

New York State Education Department. (2001). Autism program quality indicators: A self -review and quality improvement guide for schools and programs serving students with autism spectrum disorders. Retrieved, June 23, 2009 from http://www.p12.nysed.gov/specialed /autism/apqi.htm

Ng, S. B. (2010). Governance of education related EECCE policies in Malaysia. International Journal of Child care and Education Policy, 4(1), 45-57.

Nind, M., Flewitt, R., \& Johnston. (2005). Parents choosing to combine special and inclusive early years settings: The best of both worlds? Retrieved 15 June, 2011, from http://eprints.soton.ac.uk/19241/1/Final_Report_ 16.12.05.pdf

Obeng, C. (2007). Teacher's views on the teaching of children with disabilities in Ghanaian classrooms. International Journal of Special Education, 22(1), 96102.

Odom, S. L. (2000). Preschool inclusion: What we know and where we go from here. Topics in Early Childhood Special Education, 20(1), 20-27.

Odom, S. L., Vitztum, J., Wolery, R., Lieber, J., Sandall, S., Hanson, M. J., ... Horn, E. (2004). Preschool inclusion in the United States: a review of research from an ecological systems perspective. Journal of Research in Special Educational Needs, 4(1), 17-49.

Oliver, P. (2003). The students guide to research ethics. Maidenhead, England: Open University Press.

Oliver, P. (2008). Writing your thesis. Thousand Oaks, CA: Sage Publications.

Paliokosta, P., \& Blandford, S. (2010). Inclusion in school: a policy, ideology or lived experience? similar findings in diverse school cultures. Support for Learning, 25(4), 179-186.

Palmer, D. S., Fuller, K., Arora, T., \& Nelson, M. (2001). Taking sides: parent views on inclusion for their children with severe disabilities. Exceptional Children, $67(4), 467-484$.

Patton, M. Q. (1990). Qualitative evaluation and research methods (2 ${ }^{\text {nd }}$ ed.). Newbury Park, CA: Sage.

Patton, M. Q. (2002). Qualitative research and evaluation methods (2nd ed.). Thousand Oaks, CA: Sage.

Peters, S. (2004). Inclusive Education: an EFA Strategy for All Children. Washington, DC : World Bank. 
Petriwskyj, A. (2010). Who has rights to what? Inclusion in Australian early childhood programs. Contemporary Issues in early Childhood, 11(4), 342-352.

Pijl, S. J. (2007). Introduction: The social position of pupils with special needs in regular education. European Journal of Special Needs Education, 22(1), 1-5.

Pivik, J., McComas, J., \& Laflamme, M. (2002). Barriers and facilitators to inclusive education. Exceptional Children, 69(1), 97-107.

Praisner, C. L. (2003). Attitudes of elementary school principals toward the inclusion of students with disabilities. Exceptional Children, 69(2), 135-145.

Prime Minister's Department. (2010). Government transformation programme: The roadmap. Putrajaya, Malaysia: Author.

Pugach, D., \& Wargner, C. I. (2001). Curriculum matters. Remedial and Special Education, 22, 194-196.

Rea, P. J., McLaughlin, V. L., Walter-Thomas, C. (2002). Outcomes for students with learning disabilities in inclusive and pull out programs. Exceptional Children, 68(2). 203-222.

Refice, A. (2006). Inclusion in the classroom: finding what works for general education teachers. Law and Disorder, 1, 25-31.

Reid, G. (2005). Learning styles and inclusion. London: Sage.

Renzaglia, A., Karvonen, M., Drasgow, E., \& Stoxen, C. C. (2003). Promoting a lifetime of inclusion. Focus on Autism and Other Developmental Disabilities, 18(3), 140-149.

Riehl, C. J. (2000). The principal's role in creating inclusive schools for diverse students: a review of normative, empirical, and critical literature on the practice of educational administration. Review of Educational Research, $70(1), 55-81$.

Rioux, M. (2007). Disability rights in Education. In L. Florian (Ed.), The Sage Handbook of Special Education (107-116). London: Sage Publications.

Robbins, S. P., Millett, B., Cacioppe, R., \& Waters-Marsh, T. (1998). Organisational behaviour: Leading and managing in Australia and New Zealand, (2 ${ }^{\text {nd }}$ ed.). Australia: Prentice Hall.

Rombo, J. L. (2007). School cultural features and practices that influence inclusive education in Papua New Guinea: A consideration of schools in southern highlands province. Master's dissertation, The University of Waikato, New Zealand. Retrieved August 13, 2010, from http://researchcommons.waikato.ac.nz/bitstream/handle/10289/2387/ thesis.pdf? sequence $=2$

Rouse, M., \& Florian, L. (1997). Inclusive education in the market-place. International Journal of inclusive Education, 1(4), 323-336. 
Salisbury, C., \& McGregor, G. (2005). Principals of inclusive schools. Retrieved August 13, 2010, from http://www.urbanschools.org/pdf/principals. inclusive.LETTER.pdf

Salkind, N.J. (2009). Exploring Research (7th ed.). Upper Saddle River: Pearson Prentice Hall.

Sandlin, M. M. (2006). Perceptions of parents and teachers regarding preschool inclusion. Masters Thesis. Paper 2926. Retrieved July 6, 2011, from http://scholarworks.sjsu.edu/etd_theses/2926

Schools of Malaysia Directory. (2008). Your guide to children's schooling and upbringing. Selangor, Malaysia: Challenger Concept.

Sebestian, S. (1992). Special education: Current trends. Masalah Pendidikan University Malaya, 16, 45-62.

Sergiovanni, T. (2001). Leadership: What's in it for schools? London: Routledge Falmer.

Smith, J., \& Osborn, M (2008). Interpretative phenomenological analysis. In J.A. Smith (ed.), Qualitative Psychology: A practical guide to methods $\left(2^{\text {nd }}\right.$ ed., $p p$. 53-80). London: Sage.

Smith, M. G. (2000). Secondary teachers' perceptions toward inclusion of student with severe disabilities. NASSP Bulletin, 84(613), 54-60

Smith, M. K., \& Smith, K. E. (2000). “I believe in inclusion, but...”: regular education early childhood teachers' perceptions of successful inclusion. Journal of Research in Childhood Education, 14(2), 161-180.

Stake, R. (1995). The art of case research. Thousand Oaks, CA: Sage Publications.

Stake, R. (2005). Qualitative case studies. In N. Denzin \& Y. Lincoln (Eds.), The sage handbook of qualitative research ( $3^{\text {rd }}$ ed., pp. 443-466). Thousand Oaks, CA: Sage.

Stark, R., Gordon-Burns, D., Purdue, K., Rarere-Briggs, B., \& Turnock, K. (2011). Other parents' perceptions of disability and inclusion in early childhood education: implications for the teachers' role in creating inclusive communities. He Kupu, 2(4), 4-18. Retrieved April 14, 2012, from http://www.hekupu.ac.nz /journalfiles/issue1march2011/1.pdf.

Swain, J., \& Cook, T. (2001). In the name of inclusion: 'we all, at the end of the day, have the needs of children at heart'. Critical Social Policy, 21(2), 185-207.

Swick, K. J., \& Williams, R. D. (2006). An analysis of Bronfenbrenner's bio-ecological perspective for early childhood educators: Implications for working with families experiencing stress. Early Childhood Education Journal, 33(5), 371378. 
Tashakkori, A. \& Creswell, J. (2007). Editorial: The new era of mixed methods. Journal of Mixed Methods Research, 1(1), 3-7.

Tashakkori, A., \& Teddlie, C. (1998). Mixed methodology: Combining qualitative and qualitative approaches. Thousand Oaks, CA: Sage.

Tashakkori, A., \& Teddlie, C. (Eds.). (2003). Handbook of mixed methods in social \& behavioural research. Thousand Oaks, CA; Sage.

Taylor, S. J. (2004). Caught in the continuum: a critical analysis of the principle of the least restrictive environment. Research \& Practice Persons with Severe Disabilities, 29(4), 218-203.

Terzi, L. (2008). Justice and equality in education: A capability perspective on disability and special educational needs. New York: Continuum.

The Star Online. (2008, April 23). Educate public on rights of the disabled. Retrieved July 07, 2012, from http://thestar.com.my/news/story.asp? file $=/ 2008 / 4 / 23 /$ focus $/ 21028878 \&$ sec $=$ focus

The Star Online. (2008, April 24). Salvation at hand. Retrieved July 07, 2012, from http://thestar.com.my/news/story.asp?file=/2008/4/24/lifepare nting /20988282\&sec=lifeparenting

The Star Online. (2012, January 4). Empowering the disabled. Retrieved July 07, 2012, from http://thestar.com.my/lifestyle/story.asp?file=/2012 /1/4/lifefocus /1018 3489\&sec=lifefocus

Thomas, G., \& Webb, J. (1997). From exclusion to inclusion: promoting education for all. Essex: Barnardos.

Travers, J., Balfe, T., Butler, C., Day, T., Dupont, M., McDaid, R., O’Donnell, M., \& Prunty, A. (2010). Addressing the challenges and barriers to inclusion in Irish schools. Report to Research and Development Committee of the Department of Education and Skills. Retrieved July 06, 2011, http://www.spd.dcu.ie/main/academic/special__ education/documents/ StPatricksCollegeSENReport2010_000.pdf

Tsoi Hoshmand, L. L. S. (1989). Alternate research paradigms: a review and teaching proposal. Counselling Psychologist, 17(1), 3-79.

Tufue-Dolgoy, R. (2010). Stakeholders' perspectives of the implementation of the inclusive education policy in Samoa: A cultural fit. Unpublished doctoral dissertation, Victoria University of Wellington, New Zealand.

Tutt, R. (2007). Every child included. London: Sage.

Udvari-Solner, A. (1996). Examining teacher thinking: Constructing a process to design curricula adaptations. Remedial and Special Education, 17, 245-254

UNESCO. (1994). The Salamanca statement and framework for action on special needs education, World Conference on Special Needs Education: Access and 
Quality, 7-10 June 1994, Salamanca, Spain. Retrieved April 7, 2009, from http://www.unesco. org/ education/pdf/SALAMA_E.PDF

UNESCO. (2005). Guidelines for inclusion: ensuring access to education for all. Paris: UNESCO.

UNESCO. (2009). Malaysia: National Report on the provision of inclusive quality primary and secondary education. Sub-regional Workshop on "Building inclusive education system to respond to the diverse needs of disabled children". Jakarta, Indonesia: UNESCO International Biro of Education.

UNESCO. (2011). World data on education: $7^{\text {th }}$ edition, 2010/2011. Retrieved August 20, 2012, from http://www.ibe.unesco.org/fileadmin /user_upload/Publications/WDE /2010/pdf-versions/Malaysia.pdf

United Nations. (2011). Malaysia: The millennium development goals at 2010. Kuala Lumpur, Malaysia: United Nations Country Team.

Valeo, A. (2008). Inclusive education support systems: teacher and administrator views. International Journal of Special Education, 23(2), 8-16.

Villa, R. A., Thousand, J.S., Meyers, H., \& Nevin, A. (1996). Teacher and administrator perceptions of heterogeneous education. Exceptional Children, 63(1), 29-46

Von der Embse, N., Brown, A., \& Fortain, J. (2011). Facilitating inclusion by reducing problem behaviours for students with autism spectrum disorders. Intervention in School and Clinic, 47(1), 22-30.

Vaughn, S., Bos, C. S., \& Schumm, J. S. (2007). Teaching students who are exceptional, diverse, and at risk in the general education classroom. Boston: Pearson.

Wan Chik Bakar, W. K. (1994). Polisi sekolah mengenai persekolahan inklusif. Bahagian Sekolah, Kementerian Pelajaran Malaysia: Putrajaya

Warnock, H. M. (1978). The Warnock Report: Special educational needs. Report of the committee of Enquiry into the Education of Handicapped Children and Young People. London: HMSO.

Warnock, H. M. (2005). Special educational needs: a new look. Philosophy of Education Society of Great Britain.

Wearmouth, J., Berryman, M., \& Glynn, T. (2009). Inclusion through participation in communities of practice in schools. Wellington: Dunmore.

Whyte, B. (2005). Collaborating with diverse cultures. In D. Fraser, R. Moltzen, \& K. Ryba (Eds.), Learners with special needs in Aotearoa New Zealand (3 ${ }^{\text {rd }}$ Ed.), (pp. 117-127). Palmerston North: Dunmore.

Wiersma, W., \& Jurs, S. G. (2005). Research methods in education: An introduction ( $8^{\text {th }}$ ed.). Boston: Pearson Education. 
Wiersma, W., \& Jurs, S. G. (2009). Research methods in education: An introduction ( $9^{\text {th }}$ ed.). Boston: Pearson Education.

Wilde, A., \& Avramidis, E. (2011). Mixed feelings: towards a continuum of inclusive pedagogies. Education 3-13: International Journal of Primary, Elementary and Early Years Education, 39(1), 83-101.

Wiles, R., Crow, G. Heath, S., \& Charles, V. (2006). Anonymity and confidentiality. Paper presented at the ESRC Research Methods Festival, University of Oxford, UK. Retrieved August 20, 2012, from http://www.ccsr. ac.uk/methods/festival/programme/aac/documents/anonandconf paperRMF06.pdf

Wills, D., \& Jackson, R. (2001). Report card on inclusive education in Australia. Interaction, 14(2), 5-12.

Winter, S. M. (2007). Inclusive early childhood education: A collaborative approach. New Jersey: Pearson.

Wong, S. M., \& Cumming, T. (2010). Family day care is for normal kids: facilitators and barriers to the inclusion of children with disabilities in family day care. Australasian Journal of Early Childhood, 35(3), 3-12.

Yin, R. (1994). Case study research: Design and methods (2nd ed.). Beverly Hills, CA: Sage Publishing.

Yin, R. (2003). Case study research: Design and methods (3rd ed.). Beverly Hills, CA: Sage Publishing.

Yusof, K. M. (2008). Basic education curriculum revisited: A look at the current content and reform in Malaysia. Paper presented at the SEAMEO-RETRAC $11^{\text {th }}$ Governing Board Meeting and Conference, 27-30 August 2008. Pahang, Malaysia: Institut Aminuddin Baki.

Zigmond, N. (2003). Where should students with disabilities receive special education services?: Is one place better than another?. The Journal of Special Education, 37(3), 193-199. 


\section{APPENDICES}

\section{APPENDIX A:}

\section{Integrated Preschool Programme Questionnaire (IPPQ)}

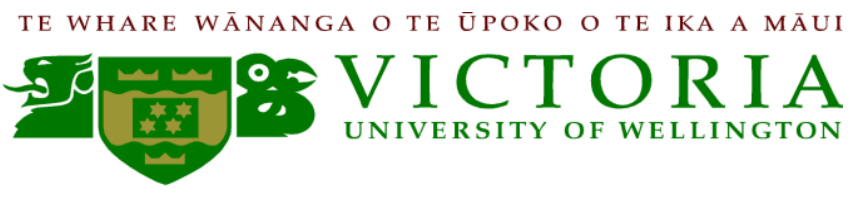

Dear Sir /Madam,

My name is Sailajah Nair Sukumaran. I am a PhD student in the School of Educational Psychology and Pedagogy, Victoria University of Wellington. As part of my research I am inviting regular and special education classroom teachers to complete a questionnaire each about inclusion in Malaysian integrated preschool programmes.

Inclusion, as defined by the Malaysian Ministry of Education (Kementerian Pelajaran Malaysia, 2007), refers to the education of children with special needs in regular classrooms alongside their typically developing peers for part of or a full school day (partial inclusion or full inclusion).

My questionnaire aims to find out the extent to which practices that support inclusion are present in your preschool.

The questionnaire is included in this pack.

If you agree to participate in this research:

- Please read the attached information sheet

- Sign and date the statement of consent (one copy is for you)

- Complete the questionnaire

- Place the completed questionnaire and a copy of the statement of consent into the big pre-addressed envelope (stamp provided)

- Post both the envelope at your soonest convenience

Thank you for taking the time to read this letter. Your participation in this research is deeply appreciated.

Sailajah Nair Sukumaran 
This Questionnaire contains two sections. Please answer every question.

Section 1: Please indicate your answer to each question by marking the response or filling

\section{A. $\quad$ Yourself}

1. Your gender: $\square$ Male $\square$ Female

2. Your profession:

$\square$ Special education classroom teacher $\quad \square$ Regular classroom teacher

3. Which field of education did you receive your professional qualification in?

4. Did your training include any course/s related to special education?

$\square$ Yes $\quad \square$ No

5. Have you had an opportunity to attend any refreshment courses / short courses/ in-service courses/ workshops / training in special education since you became a qualified teacher?

$\square$ Yes

$\square$ No

6. How long have you been working in an integrated preschool?

7. Do you know what inclusive education is?
$\square$ Yes
$\square$ No
$\square$ Not sure

8. Which of the following choices describe the group of preschool children you would like to work with / teach?

Children with SEN

typically developing children

Both 


\section{B. Your Opinion}

1. Children with special educational needs should be educated alongside their typically developing peers in a regular school
$\square$ Yes
$\square$ No
$\square$ Not sure

2. Children with special educational needs should be educated alongside their typically developing peers in a regular classroom
$\square$ Yes
$\square$ No
$\square$ Not sure

3. In your opinion what are the factors that influence teachers' practices of inclusion in an integrated preschool programme?

\section{C. $\quad$ Your school}

1. How many students with disabilities are there in the integrated preschool programme in your school?

2. Where is the special education preschool classroom located?

$\square$ It is attached to the regular education classroom

$\square$ Within $100 \mathrm{~m}$ of the regular preschool classroom

More than $100 \mathrm{~m}$ of the regular education classroom

3. How often do the special education children interact with their typically developing peers?
Up to an hour per day
$\square$ More than an hour per day
$\square$ Up to an hour per week
$\square$ 1-2 hours per week
$\square$ 3-5 hours per week
$\square$ never

4. How many of the special needs children have opportunities to interact with their typically developing peers?

$10 \%-30 \%$

$60 \%-80 \%$

None of them $\square 40 \%-60 \%$

More than $80 \%$ of them

Not applicable 
5. When do children with special needs have the opportunity to interact with their typically developing peers?

$\square$ During lessons

$\square$ Structured outdoor activities

$\square$ Assembly

$\square$ Recess/ playground

$\square$ Other: (please specify)

$\square$ Not applicable

6. Are there any shared activities carried out by both the preschool classrooms (regular and special education) stated in their daily time tables/lesson plan?

$\square$ Yes (please specify)

$\square$ No

7. Who initiates the inclusion of children with special needs into the regular preschool classroom?

$\square$ The preschool special education teacher teacher

$\square$ The regular preschool

$\square$ Parents

$\square \quad$ Not

applicable

8. Who makes the final decision to include children with special needs into the regular preschool classroom?

$\square$ The special education teacher

$\square$ The regular education teacher

$\square$ The principal

Shared decision between:

$\square$ the regular and special education teachers

$\square$ the special education teacher and the principal

$\square$ the special education teacher and the parents

$\square$ other: (please specify)

Not applicable 


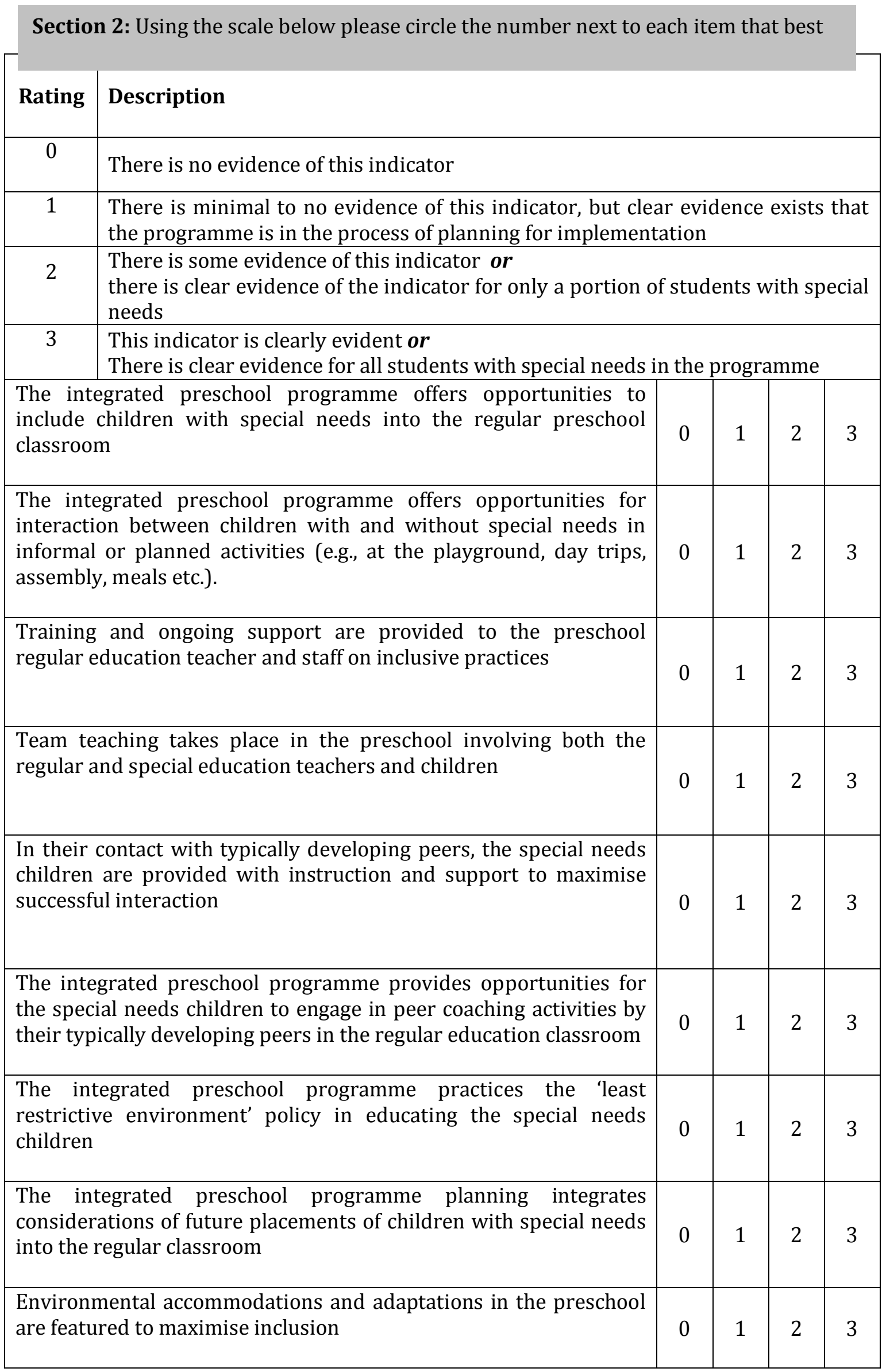




\section{APPENDIX B:}

\section{Permit to carry out research}

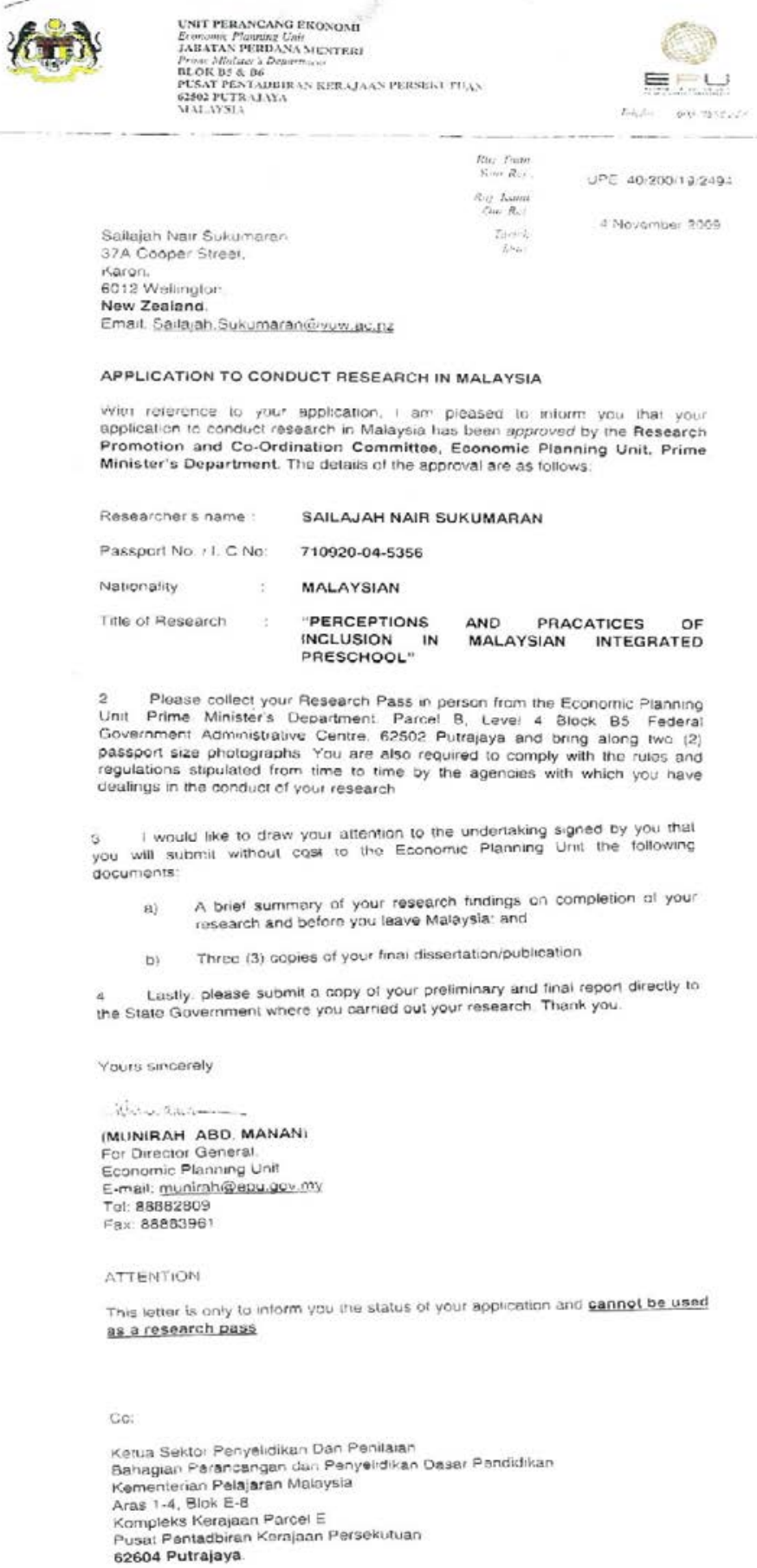




\section{APPENDIX C:}

\section{Research information sheet: survey participants}

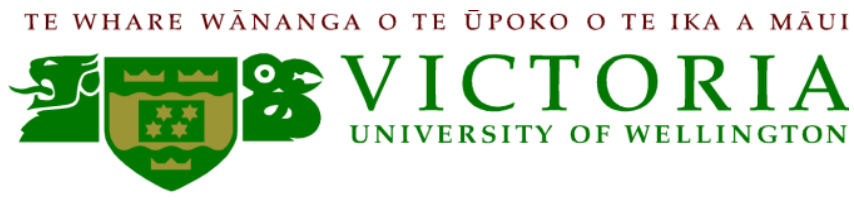

Date:

Sailajah Nair Sukumaran

c/o Postgraduate Office, Faculty of Education

Victoria University of Wellington

Karori, Wellington.

Dear Sir / Madam

\section{Research Title: Perception and Practices of Inclusion in Malaysian Integrated Preschools}

Researcher: Sailajah Nair Sukumaran, School of Education, Victoria University of Wellington

\section{Research Information Sheet: Survey Participants}

I am a trained teacher and have been teaching student teachers who are majoring in preschool and special education at the Malaysian Teachers' Institute, Raja Melewar Campus. I am currently doing my PhD in the School of Educational Psychology and Pedagogy, Victoria University of Wellington. As the requirement for my $\mathrm{PhD}$ dissertation, I am doing a research in preschool special education in Malaysia. The title of my research is "Perception and Practices of Inclusion in Malaysian Integrated Preschools". This research is supervised by Dr Judith Loveridge and Associate Professor Vanessa A Green.

The purpose of this research is to develop an understanding of what opinions teachers in Malaysian integrated preschools hold about preschool inclusion. This research also aims to provide greater understanding about factors influencing the regular and special education teachers' attitudes toward inclusion and the way they practice inclusion in integrated preschools.

Data collection for this research will involve a number of phases. This phase will involve a survey which you are being invited to complete. Your voluntary participation in this survey will provide valuable information to education planners with an interest in the implementation of inclusive education at the preschool level in Malaysia. The questionnaire involved in this survey is distributed to all integrated preschools in Malaysia. Responses from the integrated preschool teachers (regular and special education teachers) are greatly appreciated.

\section{What happens if you agree to participate?}

- $\quad$ To participate in this survey you are required to complete a short questionnaire which will provide general information about you and your preschool, practices of inclusion in your preschool and the integrated preschool teachers' opinion about inclusion.

- During the research you are free to withdraw at any point before your data has been collected 
- It should take about 10 minutes for you to complete the questionnaire.

- As a token of appreciation, you will be entitled to participate in a draw and stand a chance to win one of five RM100.00 cash vouchers.

\section{How will I ensure that your privacy and confidentiality is protected?}

- All the distributed questionnaires will be coded numerically only so I will be able to invite the selected schools and teachers to participate in case studies and a focus group interview. This coded numbers will also be used for a lucky draw.

- You will never be identified in this research. All names of schools and participants will remain confidential to me and my supervisors. Participants and the schools will not be named and will be given a pseudonym in this research project or in any other presentation or publication

- All the data obtained for this research will be stored with care in a locked cabinet to protect the confidentiality of participants.

\section{What happens to the information provided by participants?}

- Initially your coded data will be used in writing my doctoral dissertation. The PhD dissertation will be submitted to the university and deposited in the university library (student research).

- Subsequently papers will be written to be presented at conferences and articles submitted to academic journals

This research has been reviewed and approved by The Victoria University of Wellington Research and Human Ethics Committees. The University requires that ethics approval be obtained for research involving human participants. If you agree to participate in this research, please complete and return the attached consent form using the enclosed envelope. If you would like a summary of the survey findings please indicate this by circling YES on the consent form and providing relevant details.

If you require any further information or clarifications about this research please do not hesitate to contact my supervisors at Victoria University of Wellington or myself (details below)

Supervisors contact details

\begin{tabular}{|l|l|}
\hline $\begin{array}{l}\text { Associate Professor Vanessa A Green } \\
\text { VUW College of Education }\end{array}$ & $\begin{array}{l}\text { Dr Judith Loveridge } \\
\text { VUW College of Education } \\
\text { KO Bo 17-310 }\end{array}$ \\
Karori, Wellington 6147 New Zealand & Karori, Wellington 6147 New Zealand \\
\hline $\begin{array}{l}\text { My contact details } \\
\text { Sailajah Nair Sukumaran } \\
\text { 1775 Taman Bukit Kaya } \\
70200 \text { Seremban, Negeri Sembilan }\end{array}$ & \\
Malaysia & \\
Email: Sailajah.Sukumaran@vuw.ac.nz & \\
Ph: +6067634554 & \\
\hline
\end{tabular}

Thank you for taking the time to read this letter and thinking about your participation in this research. The information gained from you for this research is very important to education planners, parents, teachers and future teachers. Most of all your valuable opinion will help in developing and providing the best education services for preschool children with special needs.I look forward to your reply.

Yours Sincerely, Sailajah Nair Sukumaran 


\section{APPENDIX D:}

\section{Inter-coder reliability instruction and code sheet}

\section{Coding Instruction for open ended item (B3) - questionnaire}

Please read these instructions carefully before you begin coding.

1. I have prepared a code sheet (attached). Each sheet states the response, the themes and a number of related issues. Please examine the responses that I have stated (labelled as "response") and mark 'yes' (present) or 'no' (not present) in the attached sheet under the related issue where you think it best fits.

2. Please note that the responses may contain information that can be associated to more than one theme or related issue.

3. There may be differences in the terms or terminology used to describe the same issues. For example, some respondents would have used the term "involvement (penglibatan)" while there may be others who would have used the term "contribution (sumbangan)" or "participation" (penyertaan, turut serta) to discuss the same idea. As long as the text is concerning the same idea, then it should be accepted that the issue is present and indicated as "yes". Conversely, if the written responses used a term from the code sheet but conveyed a different idea from the related issue in the code sheet, then this issue should be treated as not present and indicated as "no".

4. If you have difficulty locating the issue, and are unsure if it relates to a particular criteria required to be accepted as present, the presumption should be that the issue is not present.

5. If you have difficulty deciding, or have a lingering question about your choice after putting it down on the sheet, feel free to mark it with a hatch (\#) beside your choice of answer.

6. If you feel the responses in the questionnaire contain any additional issues, please feel free to add them below or on the back of the sheet.

Thank you. 


\section{Code sheet}

Coder:

Response:

Questionnaire Code:

School culture towards inclusion

\begin{tabular}{|l|l|l|l|}
\hline \multirow{2}{*}{} & Related Issues & \multicolumn{2}{l|}{ Present } \\
\cline { 3 - 4 } & & Yes & No \\
\hline 1. & Educators attitudes/support /commitment /beliefs & & \\
\hline 2. & Headmaster's role/support/involvement & & \\
\hline 3. & Regular teachers' co-operation/ teacher collaboration & & \\
\hline 4. & Special education teacher's initiative /commitment & & \\
\hline 5. & Parents' attitudes/ support/ beliefs/involvement & & \\
\hline 6. & Teacher aide's attitude/ beliefs/ support & & \\
\hline
\end{tabular}

Educator's skills and competencies

\begin{tabular}{|l|l|l|l|}
\hline \multirow{2}{*}{} & Related Issues & \multicolumn{2}{l|}{ Present } \\
\cline { 3 - 4 } & & Yes & No \\
\hline 1. & regular teachers' knowledge / understanding about inclusion & & \\
\hline 2. & regular teachers' knowledge /understanding about disability & & \\
\hline 3. & regular/special education teachers' experience with inclusion & & \\
\hline 4. & teachers' skills in adapting curriculum /instruction/lesson planning & & \\
\hline 5. & Headmaster's knowledge/ understanding on inclusion & & \\
\hline
\end{tabular}

Guidance and information

\begin{tabular}{|l|l|c|c|}
\hline \multicolumn{2}{|l|}{ Related Issues } & \multicolumn{2}{c|}{ Present } \\
\cline { 3 - 4 } & & Yes & No \\
\hline 1. & staff development/ in-service training & & \\
\hline 2. & guidance/ guidelines/ information from ministry & & \\
\hline 3. & materials/ teaching aids/ funding & & \\
\hline 4. & availability of information for principal, parents and teachers & & \\
\hline
\end{tabular}

Teacher's Workload

\begin{tabular}{|l|l|c|c|}
\hline \multicolumn{2}{|l|}{} & Related Issues & \multicolumn{2}{c|}{ Present } \\
\cline { 3 - 4 } & & Yes & No \\
\hline 1. & large regular classroom enrolment & & \\
\hline 2. & time constraints/need for individual attention & & \\
\hline 3. & planning and implementation / added responsibility/teacher stress & & \\
\hline 4. & curriculum demand (regular classroom) & & \\
\hline 5. & parental expectation/ demand & & \\
\hline 6. & parents' concern & & \\
\hline
\end{tabular}


Students' disability

\begin{tabular}{|c|c|c|c|}
\hline & \multirow[t]{2}{*}{ Related Issues } & \multicolumn{2}{|c|}{ Present } \\
\hline & & Yes & No \\
\hline 1. & severity of disability/ ability to cope academic integration & & \\
\hline 2. & behavioural difficulty/ disruptive behaviour & & \\
\hline 3. & academic value for preschoolers with SEN & & \\
\hline
\end{tabular}

Others

\begin{tabular}{|c|c|c|c|}
\hline & \multirow[t]{2}{*}{ Related Issues } & \multicolumn{2}{|c|}{ Present } \\
\hline & & Yes & No \\
\hline 1. & non-compulsory inclusion policy & & \\
\hline 2. & school's physical setting and environment & & \\
\hline 3. & bullying & & \\
\hline & & & \\
\hline & & & \\
\hline
\end{tabular}




\section{APPENDIX E:}

\section{Research information sheet: case study participants}

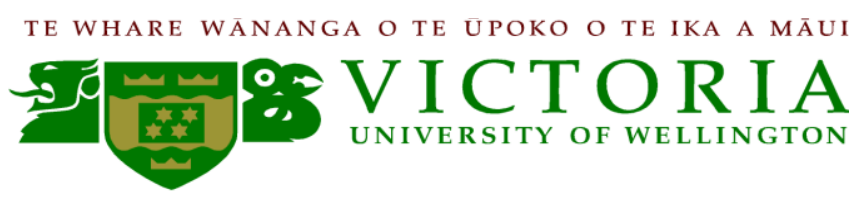

Research Information Sheet: Case Study Participants

\section{Title of Research Project: Inclusion in Malaysian Integrated Preschools}

\section{Who am I?}

My name is Sailajah Nair Sukumaran and I am a PhD student in the School of Educational Psychology and Pedagogy, Victoria University of Wellington. I am currently undertaking research in Preschool Inclusion in Malaysian Integrated Preschools as the requirement for my $\mathrm{PhD}$ dissertation. This research is supervised by $\mathrm{Dr}$ Judith Loveridge and Associate Professor Vanessa A Green.

\section{What is the purpose of this research?}

The purpose of this research is to develop an understanding of what opinions teachers in Malaysian integrated preschools hold about preschool inclusion. This research also aims to provide greater understanding about factors influencing the regular and special education teachers' attitudes toward inclusion and the way they practice inclusion in integrated preschools.

\section{How will data be collected for this research?}

Data collection for this research will involve a survey, case studies and a focus group interview. The survey has already been carried out. Based on the survey findings, three integrated preschools will be invited to be the site for case studies. Interviews with the regular and special education teachers will be carried out within the three selected case study preschools. Besides talking to the regular and special education preschool teachers, I would also like to talk to the principals of the preschools, parents and related education officers. I am interested in hearing these voices about preschool inclusion and using their opinion and experiences to inform other interested professionals.

\section{What happens if you agree to participate?}

If you agree to participate in this research, you are invited to take part in the case study as outlined in the accompanying letter. Your voluntary participation in this research will provide valuable information to education planners with an interest in the implementation of inclusive education at the preschool level in Malaysia.

\section{Rights of Participants}

All participants involved in this research have the right to:

- decline participation

- withdraw themselves (or any information provided) from the research at any time before data is analysed

- refuse to answer any particular questions

- ask questions about the study at any time throughout their participation and have the questions answered to their satisfaction 
- receive feedback or a summary of the findings when it is concluded

\section{Privacy and Confidentiality}

- All participants in this study would require informed consent

a. All names of schools and participants will remain confidential to the researcher and her supervisors. The information provided by participants will be coded numerically. Participants and the schools will not be named and will be given a pseudonym in this research project or in any other presentation or publication

b. All the data obtained for this research will be stored with care to protect the confidentiality of participants.

c. All interviews which are audio-taped will be transcribed myself using pseudonyms and stored securely to ensure anonymity and confidentiality. Transcription of data from interviews will be returned to participants for checking before using it as research data. At the completion of this research participants will have the option to retain the tapes (or copies) or destroy them.

d. All field notes taken during observation and photographs of the school physicality and other similar materials will be destroyed five years after the research is concluded.

7. What happens to the information provided by participants?

a. Initially your coded data will be used in writing my doctoral dissertation. The PhD dissertation will be submitted to the university and deposited in the university library (student research).

b. Subsequently papers will be written to be presented at conferences and articles submitted to academic journals

This research has been reviewed and approved by The Victoria University of Wellington Research and Human Ethics Committees. If you require any further information or clarifications about this research please do not hesitate to contact my supervisors or myself at Victoria University of Wellington (details below)

Supervisors contact details

\begin{tabular}{|l|l}
\hline Associate Professor Vanessa A Green & Dr Judith Loveridge
\end{tabular}

VUW College of Education $\quad$ VUW College of Education

PO Box 17-310

Karori , Wellington 6147 New Zealand

PO Box 17-310

Karori, Wellington 6147 New Zealand

My contact details

Sailajah Nair Sukumaran

1775 Taman Bukit Kaya

70200 Seremban, Negeri Sembilan

Malaysia

Email: Sailajah.Sukumaran@vuw.ac.nz

$\mathrm{Ph}:+6067634554$

Thank you for taking the time to read this information sheet. The information gained from you for this research is very important to education planners, parents, teachers and future teachers. Most of all your valuable opinion will help in developing and providing the best education services for preschool children with special needs. I look forward to your reply.

Yours Sincerely,

Sailajah Nair Sukumaran 


\section{APPENDIX F:}

\section{Letter and statement of consent: case study school principal}

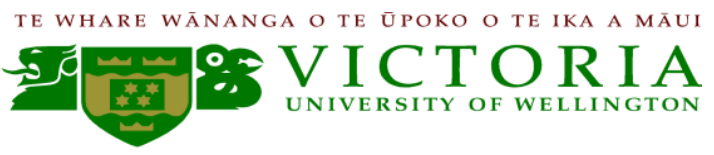

\section{Date:}

Title of research Project: Inclusion in Malaysian Integrated Preschools

Researcher: Sailajah Nair Sukumaran, School of Education, Victoria University of Wellington

\section{Dear Principal,}

I am a trained teacher and have been teaching student teachers who are majoring in preschool and special education at the Malaysian Teachers' Institute, Raja Melewar Campus. Currently I am doing my PhD in the School of Educational Psychology and Pedagogy, Victoria University of Wellington. As the requirement for my $\mathrm{PhD}$ dissertation, I am doing a research in preschool special education in Malaysia. The title of my research is "Inclusion in Malaysian Integrated Preschools".

The purpose of this research is to develop an understanding of what opinions teachers in Malaysian integrated preschools hold about preschool inclusion. This research also aims to provide greater understanding about factors influencing the regular and special education teachers' attitudes toward inclusion and the way they practice inclusion in these preschools. Besides talking to the preschool regular and special education teachers, I would also like to talk to the principals of the preschool, parents and related education officers to get a holistic picture about factors influencing practices of inclusion in Malaysian Integrated Preschools.

As part of my data collecting process I would like to invite your school to be one of the case study sites among the three integrated preschools in Malaysia to participate in this research. If you consent to the participation of your school as one of the case study sites for this research, I would like to invite you for an interview as I am very interested to hear your opinions and related stories about including preschool children with special needs into regular classrooms. I would also like to invite the regular and special education preschool teachers in your school as well as a small number of parents of the preschool children for an interview. The interview will be audio taped so I can transcribe what was said at a later stage. Besides that, photographs of the school's environment will also be taken. However, these photographs will not involve any human participants. I have attached an Information Sheet with this letter so you can understand what the research is all about and what it would mean for you and your school to take part in the research. The Information Sheet also tells you how the rights and privacy of a participant and the privacy of your school are protected.

If you would like to discuss further about the research or require further clarifications please do not hesitate to contact me at 06-7634554; e-mail Sailajah.Sukumaran@vuw.ac.nz or my supervisors (details attached) at Victoria University of Wellington.

This research has been approved by the Victoria University of Wellington College of Education Ethics Committee. The University requires that ethics approval be obtained for research involving human participants. Therefore, I need your consent to carry out this research in your school. If you agree to me conducting my research in your school, please complete and return the attached consent form using the enclosed envelope.

Thank you for taking the time to read this letter and thinking about your participation in this research. I look forward to your reply. 


\section{Statement of consent \\ (Principal)}

Title of research Project: Inclusion in Malaysian Integrated Preschools

Researcher: Sailajah Nair Sukumaran, School of Education, Victoria University of Wellington

I give consent for Sailajah Nair Sukumaran, PhD student at Victoria University of Wellington, to invite teachers and parents in (name of school) to participate in her research project.

I agree to the participation of my school in this research under the conditions set out in the information sheet

I have been given information about this project and I have understood the explanation of this research project

I have had an opportunity to ask questions and have them answered to my satisfaction

I understand that I can withdraw my consent (or any information I have provided) at any time prior to the end of the data collection period without having to give reasons and I will not be penalised for it.

I understand that any information provided will be confidential. No information will identify the school or its participants in particular.

I understand that all information will be used only for this research, publications and presentations arising from this research project

All field notes taken during observation and photographs of the school's environment and other similar materials will be destroyed five years after the research is concluded.

I understand that the tape recording of my interview will also be destroyed unless I indicate that I would like them returned to me

Name

Signature

Name of School

Date 


\section{APPENDIX G:}

\section{Letter and statement of consent: case study participants - parents}

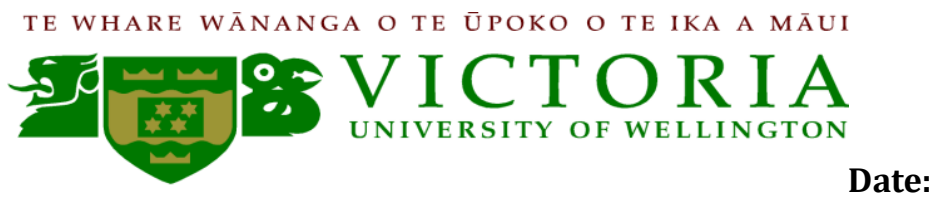

Title of research Project: Inclusion in Malaysian Integrated Preschools

Researcher: Sailajah Nair Sukumaran, School of Education, Victoria University of Wellington

Dear Sir / Madam

I am a trained teacher and have been teaching student teachers who are majoring in preschool and special education at the Malaysian Teachers' Institute, Raja Melewar Campus. I am currently doing my PhD in the School of Educational Psychology and Pedagogy, Victoria University of Wellington. As the requirement for my $\mathrm{PhD}$ dissertation, I am doing a research in preschool special education in Malaysia. The title of my research is "Inclusion in Malaysian Integrated Preschools".

The purpose of this research is to develop an understanding of what opinions teachers in Malaysian integrated preschools hold about preschool inclusion. This research also aims to provide greater understanding about factors influencing the regular and special education teachers' attitudes toward inclusion and the way they practice inclusion in these preschools. Besides talking to the preschool regular and special education teachers, I would also like to talk to the principals of the preschool, parents and related education officers to get a holistic picture about factors influencing practices of inclusion in Malaysian Integrated Preschools.

As part of my data collecting process for this research I would like to invite parents of children in integrated preschools for an interview. I am very interested to hear your opinions and related stories about including preschool children with special needs into regular classrooms. The interview will be audio taped so I can transcribe what was said at a later stage.

I have attached an Information Sheet with this letter so you can understand what the research is all about and what it would mean for you to take part in the research. The Information Sheet also tells you how your rights and privacy as a participant are protected. This research has been approved by the Victoria University of Wellington College of Education Ethics Committee. The University requires that ethics approval be obtained for research involving human participants. If you are interested to participate in this research, please complete and return the attached consent form using the enclosed envelope. I will then contact you to arrange for a meeting.

If you would like to discuss further about the research or require further clarifications please do not hesitate to call me at 06-7634554; or e-mail Sailajah.Sukumaran@vuw.ac.nz or my supervisors (details attached) at Victoria University of Wellington.

Thank you for taking the time to read this letter and thinking about your participation in this research. I look forward to your reply.

Yours Sincerely,

Sailajah Nair Sukumaran 


\section{Statement of consent \\ Case Study Participants - Parents}

Title of research Project: Inclusion in Malaysian Integrated Preschools

Researcher: Sailajah Nair Sukumaran, School of Education, Victoria University of Wellington

I agree to participate in this research under the conditions set out in the information sheet.

I have been given information about this project and I have understood the explanation of this research project

I have had an opportunity to ask questions and have them answered to my satisfaction

I understand that I can withdraw my consent (or any information I have provided) at any time prior to the end of the data collection period without having to give reasons and I will not be penalised for it

I understand that any information I provide will be confidential. No information which identifies me individually will be used and no opinions will be attributed to me in any way that will identify me.

I understand that all information will be used only for this research, publications and presentations arising from this research project

I understand that the tape recording of the interview will be destroyed unless I indicate that I would like them returned to me

Name

Signature

Date 


\section{APPENDIX H:}

\section{Letter and statement of consent: case study participants -teachers}

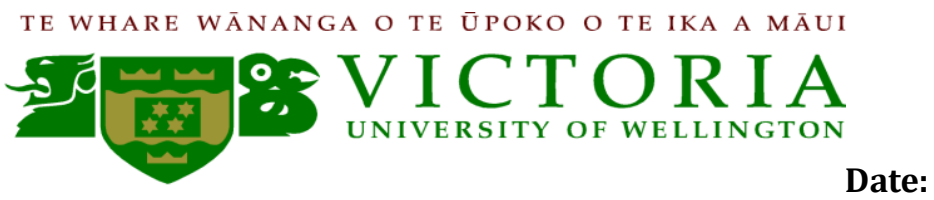

Title of research Project: Inclusion in Malaysian Integrated Preschools

Researcher: Sailajah Nair Sukumaran, School of Education, Victoria University of Wellington

Dear Sir / Madam

I am a trained teacher and have been teaching student teachers who are majoring in preschool and special education at the Malaysian Teachers' Institute, Raja Melewar Campus. I am currently doing my PhD in the School of Educational Psychology and Pedagogy, Victoria University of Wellington. As the requirement for my $\mathrm{PhD}$ dissertation, I am doing a research in preschool special education in Malaysia. The title of my research is "Inclusion in Malaysian Integrated Preschools".

The purpose of this research is to develop an understanding of what opinions teachers in Malaysian integrated preschools hold about preschool inclusion. This research also aims to provide greater understanding about factors influencing the regular and special education teachers' attitudes toward inclusion and the way they practice inclusion in these preschools. Besides talking to the preschool regular and special education teachers, I would also like to talk to the principals of the preschool, parents and related education officers to get a holistic picture about practices of inclusion in Malaysian Integrated Preschools.

As part of my data collecting process for this research I would like to invite regular and special education preschool teachers for an interview. I have approached your principal and indicated that I am keen to do my research in your preschool. I am very interested to hear your opinions, experiences and feelings about including preschool children with special needs into regular classrooms. The interview will be audio taped so I can transcribe what was said at a later stage. I will also need your kind assistance in approaching parents who might be interested in participating in this research.

I have attached an Information Sheet with this letter so you can understand what the research is all about and what it would mean for you to take part in the research. The Information Sheet also tells you how your rights and privacy as a participant are protected. This research has been approved by the Victoria University of Wellington College of Education Ethics Committee. The University requires that ethics approval be obtained for research involving human participants. If you are interested to participate in this research, please complete and return the attached consent form using the enclosed envelope. I will then contact you to arrange for a meeting.

If you would like to discuss further about the research or require further clarifications please do not hesitate to call me at 06-7634554; or e-mail Sailajah.Sukumaran@vuw.ac.nz or my supervisors (details attached) at Victoria University of Welllington.

Thank you for taking the time to read this letter and thinking about your participation in this research. I look forward to your reply.

Yours Sincerely,

Sailajah Nair Sukumaran 


\section{Statement of consent \\ Case Study Participants - Teachers}

Title of research Project: Inclusion in Malaysian Integrated Preschools

Researcher: Sailajah Nair Sukumaran, School of Education, Victoria University of Wellington

I agree to participate in this research under the conditions set out in the information sheet.

I have been given information about this project and I have understood the explanation of this research project

I have had an opportunity to ask questions and have them answered to my satisfaction

I understand that I can withdraw my consent (or any information I have provided) at any time prior to the end of the data collection period without having to give reasons and I will not be penalised for it

I understand that any information I provide will be confidential. No information which identifies me individually will be used and no opinions will be attributed to me in any way that will identify me.

I understand that all information will be used only for this research, publications and presentations arising from this research project

I understand that the tape recording of the interview will be destroyed unless I indicate that I would like them returned to me

Name

Signature

Date 


\section{APPENDIX I:}

\section{Interview guide}

\section{Semi-structured interview with educators}

1. What does the term inclusion / inclusive education mean to you?

2. Do you think inclusion is beneficial? Why?

3. Tell me, where do you think children with SEN are best educated (regular classroom/ regular schools/ separate classrooms)? Why?

4. Is your preschool currently practicing inclusion? How are you doing this/ how are children with and without SEN educated?

5. What do you think parents/ principal/ teachers think of the current practice?

6. In your opinion, what are the factors influencing the implementation of inclusive practises in Malaysian integrated preschools?

\section{Semi-structured interview with parents}

1. What does the term inclusion / inclusive education mean to you?

2. As a parent, what is your opinion about including children with special needs into regular classrooms?

3. Tell me, where do you think children with SEN are best educated (regular classroom/ regular schools/ separate classrooms)? Why?

4. What do you think of the current practice?

5. Have you voiced out your suggestion to the school? Why? / What was the response?

6. In your opinion what are the factors influencing the implementation of inclusive practises in Malaysian integrated preschools? 


\section{APPENDIX J:}

\section{Observation guide}

Observations cover:

- the setting / environment such as, the playground, physicality of the classrooms, facilities, play area, etc.

- whether or not the physical environment is adapted to encourage interaction among children with and without SEN (note isolated settings that segregate children with special educational needs from their typically developing peers)

- situations of interactions in children's daily regular activities. These will include: opportunities when and where children with and without disabilities interact, general durations of interactions, whether activities are structured/unstructured; scheduled/ random

- efforts taken by teachers/ staff to encourage or initiate inclusion, for example:

- children with special needs being supported to interact positively with other typically developing peers

- facilitating the inclusion of a special needs child into the regular classroom

- carrying out shared activities (regular and special education classroom)

- team teaching / teacher collaboration 
APPENDIX K:

Ethics approval

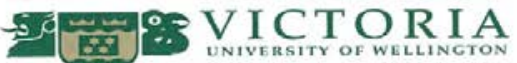

27 th October 2009

Sailajah Nair Sukumaran

PhD Student

Victoria University of Wellington Faculty of Education

$\mathrm{C} /$ - School of Educational Psychology and Pedagogy

Donald Street

Wellington

Dear Sailajah

RE: Ethics application SEPP/2009/68 RM 17021

I am pleased to advise you that your ethics application 'Perceptions and Practices of Inclusion in Malaysian Integrated Preschools' with the requested amendments, has been approved by the Victoria University of Wellington Faculty of Education Ethics Committee. Please note that the approval for your research to commence is from the date of this letter.

Good luck with your research

Yours Sincerely
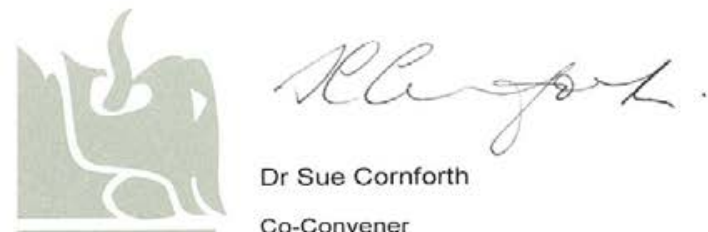

Dr Sue Cornforth

Co-Convener
Victoria University of Wellington Faculty of Education Ethics Committee

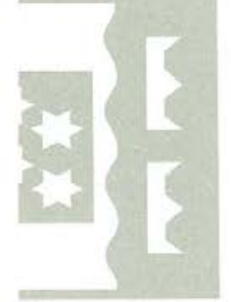

Victoria University of Wellington Faculty of Education Ethics Committee 


\section{APPENDIX L:}

\section{Translator's confidentiality agreement}

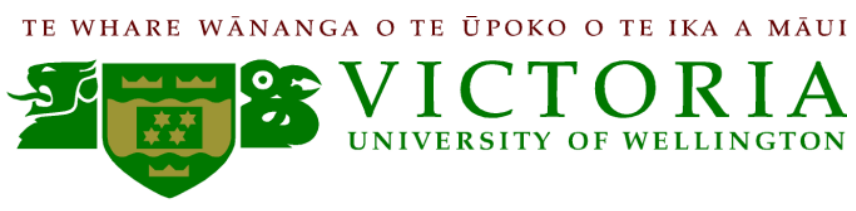

Translator's Confidentiality Agreement

Research Title: Perceptions and Practices of Inclusion in Malaysian Integrated Preschools

Researcher: Sailajah Nair Sukumaran, Faculty of Education, Victoria University of Wellington

I hereby agree to keep all information that I hear, see and document as a result of my work as a translator, confidential. I agree not to disclose or communicate any of the information or material that was used in the process of the translation to anyone. I will store all materials securely in the process of my work and not retain any information involving this research project once my work has been completed.

Signature :

Name (in full):

Date : 